\title{
Fatigue in breast cancer patients receiving adjuvant chemotherapy
}

Citation for published version (APA):

de Jong, N. (2007). Fatigue in breast cancer patients receiving adjuvant chemotherapy. [Doctoral Thesis, Maastricht University]. Maastricht University. https://doi.org/10.26481/dis.20070530nj

Document status and date:

Published: 01/01/2007

DOI:

10.26481/dis.20070530nj

Document Version:

Publisher's PDF, also known as Version of record

\section{Please check the document version of this publication:}

- A submitted manuscript is the version of the article upon submission and before peer-review. There can be important differences between the submitted version and the official published version of record.

People interested in the research are advised to contact the author for the final version of the publication, or visit the DOI to the publisher's website.

- The final author version and the galley proof are versions of the publication after peer review.

- The final published version features the final layout of the paper including the volume, issue and page numbers.

Link to publication

\footnotetext{
General rights rights.

- You may freely distribute the URL identifying the publication in the public portal. please follow below link for the End User Agreement:

www.umlib.nl/taverne-license

Take down policy

If you believe that this document breaches copyright please contact us at:

repository@maastrichtuniversity.nl

providing details and we will investigate your claim.
}

Copyright and moral rights for the publications made accessible in the public portal are retained by the authors and/or other copyright owners and it is a condition of accessing publications that users recognise and abide by the legal requirements associated with these

- Users may download and print one copy of any publication from the public portal for the purpose of private study or research.

- You may not further distribute the material or use it for any profit-making activity or commercial gain

If the publication is distributed under the terms of Article $25 \mathrm{fa}$ of the Dutch Copyright Act, indicated by the "Taverne" license above, 


\section{Fatigue in breast cancer patients receiving adjuvant chemotherapy}

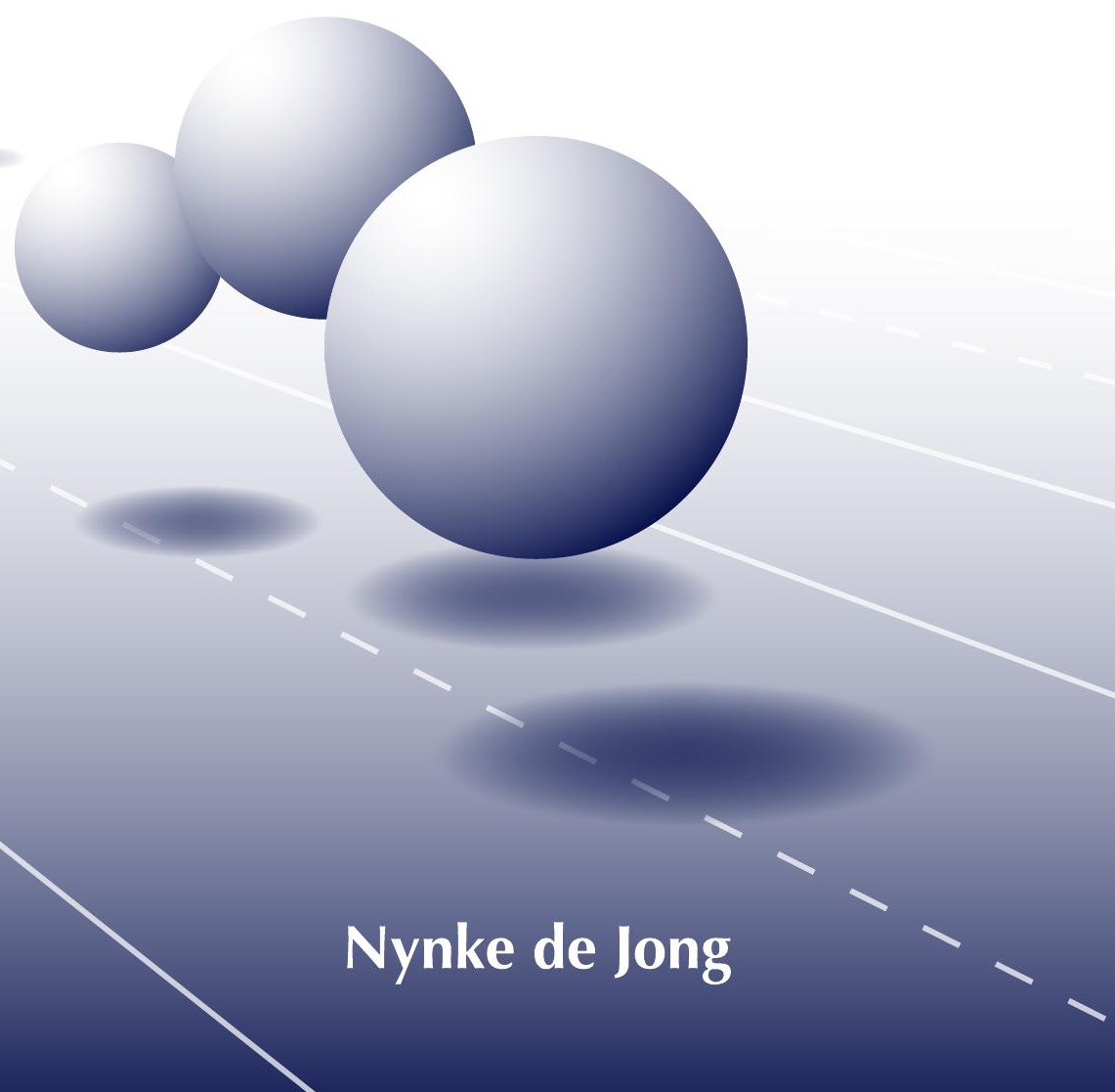


MAASTRICHT FATIGUE MODEL (MF MODEL)

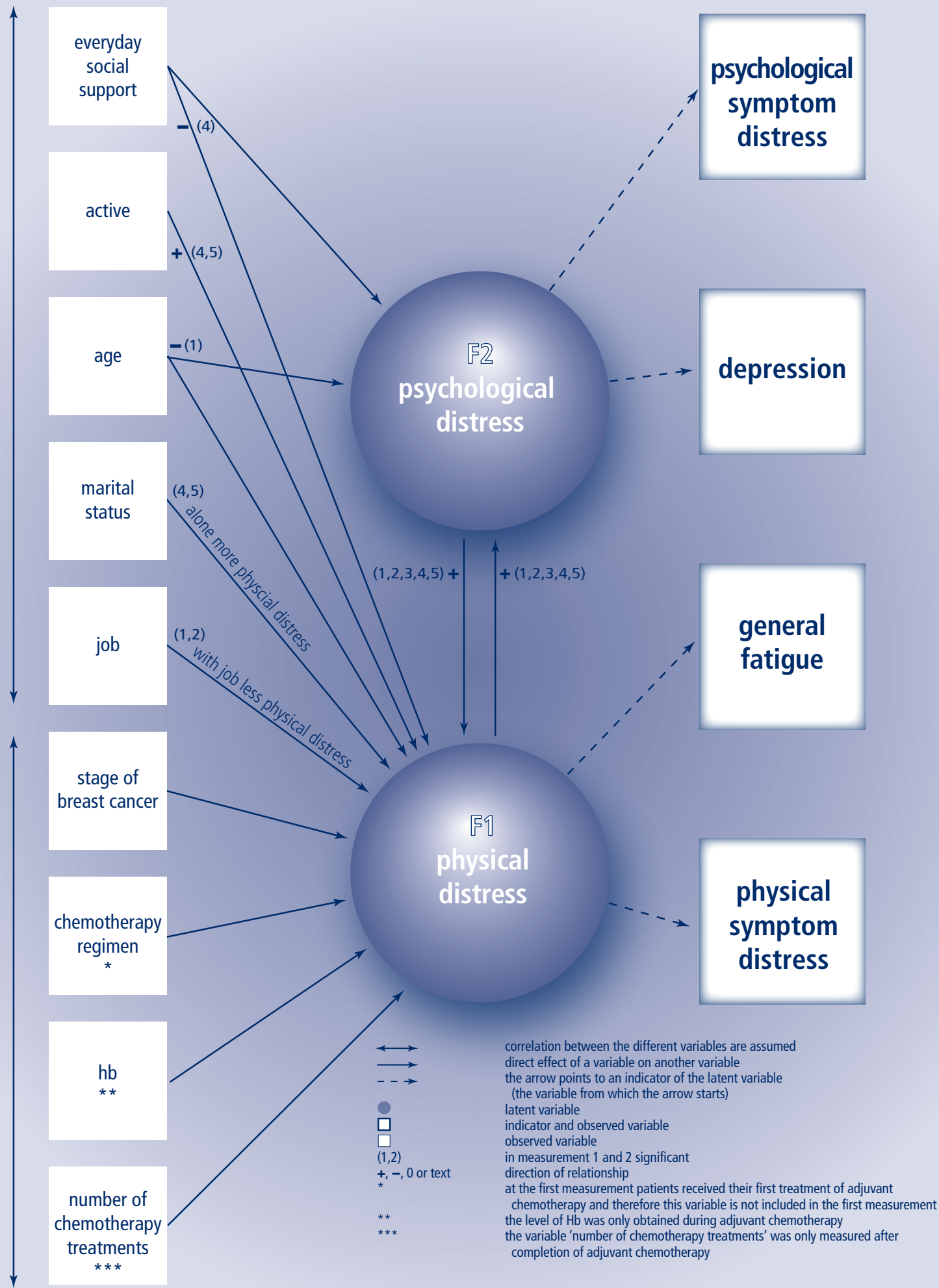

Model of fatigue and its relations based on the data of this study (significant effect with $p<0.05$ ) (Figure $3 a$, chapter 7 ) 


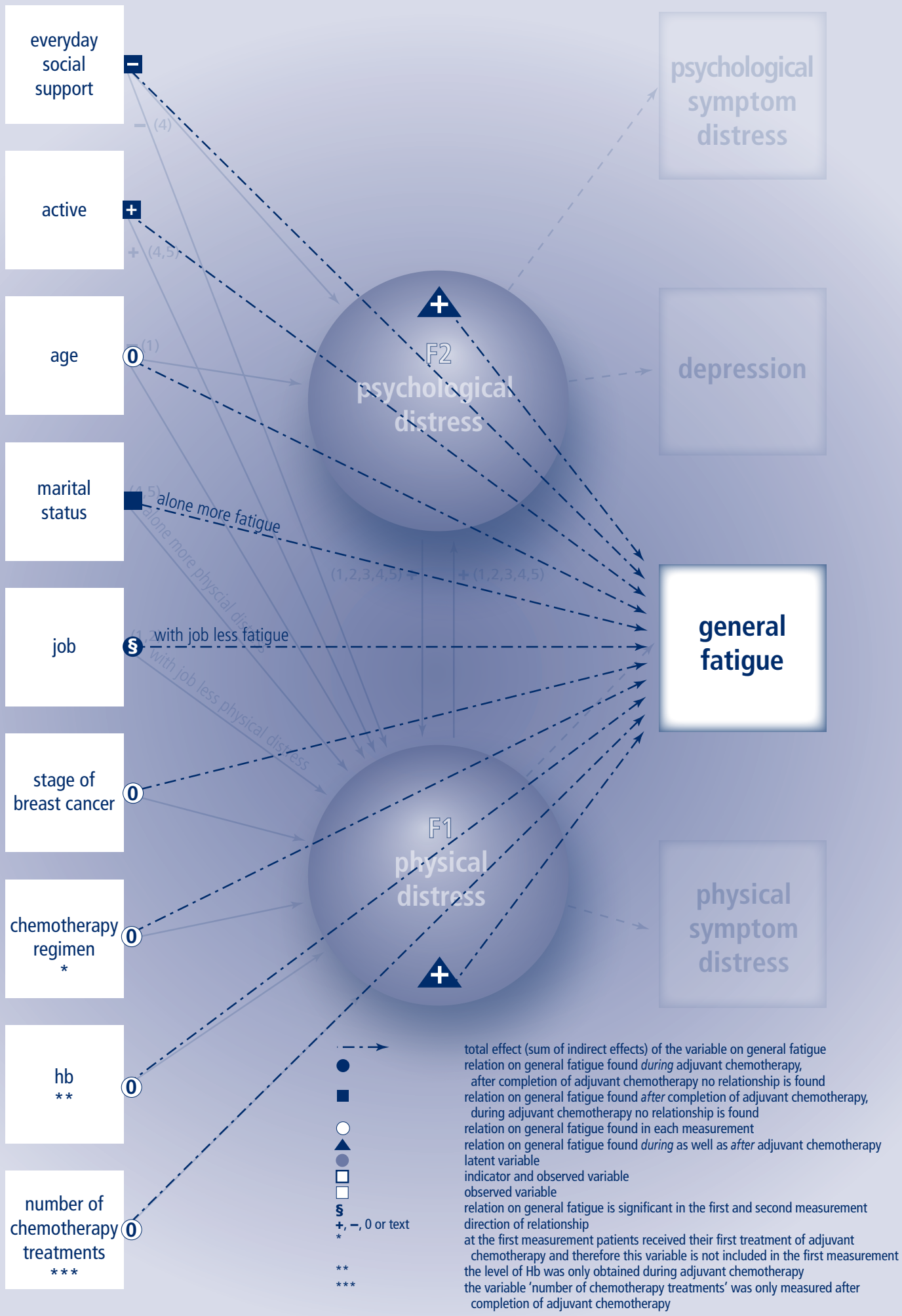

Model of fatigue and its relations based on the data of this study (significant effect with $p<0.05$ ) (Figure $3 b$, chapter 7) 
Stellingen behorende bij het proefschrift

\section{Fatigue in breast cancer patient receiving adjuvant chemotherapy}

\section{Nynke de Jong}

1. Dé eigenschap van chemotherapiegerelateerde vermoeidheid is de onvoorspelbaarheid, welke equivalent is aan de beweging van een ongecontroleerde stuiterbal (dit proefschrift).

2. Vóór en na de chemotherapiebehandeling is de vermoeidheid (in alle dimensies) gelijk (dit proefschrift).

3. Psychische klachten spelen juist na de chemotherapiebehandeling een prominente rol, wat niet betekent dat een psychische klap niet eerder uitgedeeld kan zijn (dit proefschrift).

4. Depressief zijn zonder vermoeidheid is bijna net zo onwaarschijnlijk als depressief worden omdat je geen vermoeidheid ervaart (dit proefschrift).

5. Fatsoenlijke zorg begint bij welgemanierdheid.

6. Ziek zijn buiten kantooruren is on(w)(m)enselijk.

7. Goede zorg is niet per minuut leverbaar.

8. Een verpleegkundige dient zich niet alleen verantwoordelijk te gedragen, maar dient ook verantwoordelijkheid te nemen.

9. Het spreekt voor zich dat praten niet wil zeggen dat per definitie iets zinnigs wordt gezegd.

10. Een diploma betekent niet dat je altijd je hoofd boven water houdt. 


\section{Fatigue in breast cancer patients receiving adjuvant chemotherapy}

Nynke de Jong 
ISBN 9789085900207

Copyright @ Nynke de Jong, Maastricht 2007

All rights reserved. No part of this thesis may be reproduced or transmitted in any form or by any means, electronic of mechanical, including photocopying, recording, or any information storage or retrieval system, without permission in writing from the authors, or, when appropriate, from the publishers of the publications.

Vormgeving en Uitgeverij: D\&L Graphics

Druk: Schrijen Lippertz-Huntjens 


\title{
Fatigue in breast cancer patients receiving adjuvant chemotherapy
}

\author{
PROEFSCHRIFT
}

ter verkrijging van de graad van doctor aan de Universiteit Maastricht, op gezag van de Rector Magnificus, prof. mr. G.P.M.F. Mols,

volgens het besluit van het College van Decanen,

in het openbaar te verdedigen

op woensdag 30 mei 2007 om 16.00 uur

door

Nynke de Jong 


\section{Promotores}

Prof. dr. H.C. Schouten

Prof. dr. H. Huijer Abu-Saad (American University of Beirut, Lebanon)

\section{Copromotor}

Dr. A.M Courtens

\section{Beoordelingscommissie}

Prof. dr. R. de Wit (voorzitter)

Prof. dr. G. Bleijenberg (UMC St Radboud, Nijmegen)

Prof. dr. J.C.J.M. de Haes (AMC, Universiteit van Amsterdam)

Prof. dr. M.F. von Meyenfeldt

Prof. dr. V.C.G. Tjan-Heijnen

The study was supported in part by grant no. RL97-1627 from the Dutch Cancer Society

Printing of this thesis was financially supported by the Dutch Cancer Society, Nursing Science (Universiteit Maastricht), Amgen B.V., Bristol-Myers Squibb and Roche Nederland B.V. 


\section{Contents}

\section{Chapter 1}

General introduction

\section{Chapter 2}

Fatigue in patients with breast cancer receiving adjuvant chemotherapy:

a review of the literature

\section{Chapter 3}

Prevalence and course of fatigue in breast cancer patients receiving adjuvant chemotherapy

\section{Chapter 4}

Course of mental fatigue and motivation in breast cancer patients receiving adjuvant chemotherapy

\section{Chapter 5}

Course of the fatigue dimension 'activity level' and the interference of fatigue with daily living activities for patients with breast cancer receiving adjuvant chemotherapy

\section{Chapter 6}

Course of fatigue between two cycles of adjuvant chemotherapy in breast cancer patients

\section{Chapter 7}

Influencing factors of fatigue in women with breast cancer receiving adjuvant chemotherapy: the development of a model

\section{Chapter 8}

General discussion

Summary

Samenvatting

\section{Dankwoord}

\section{Curriculum Vitae}



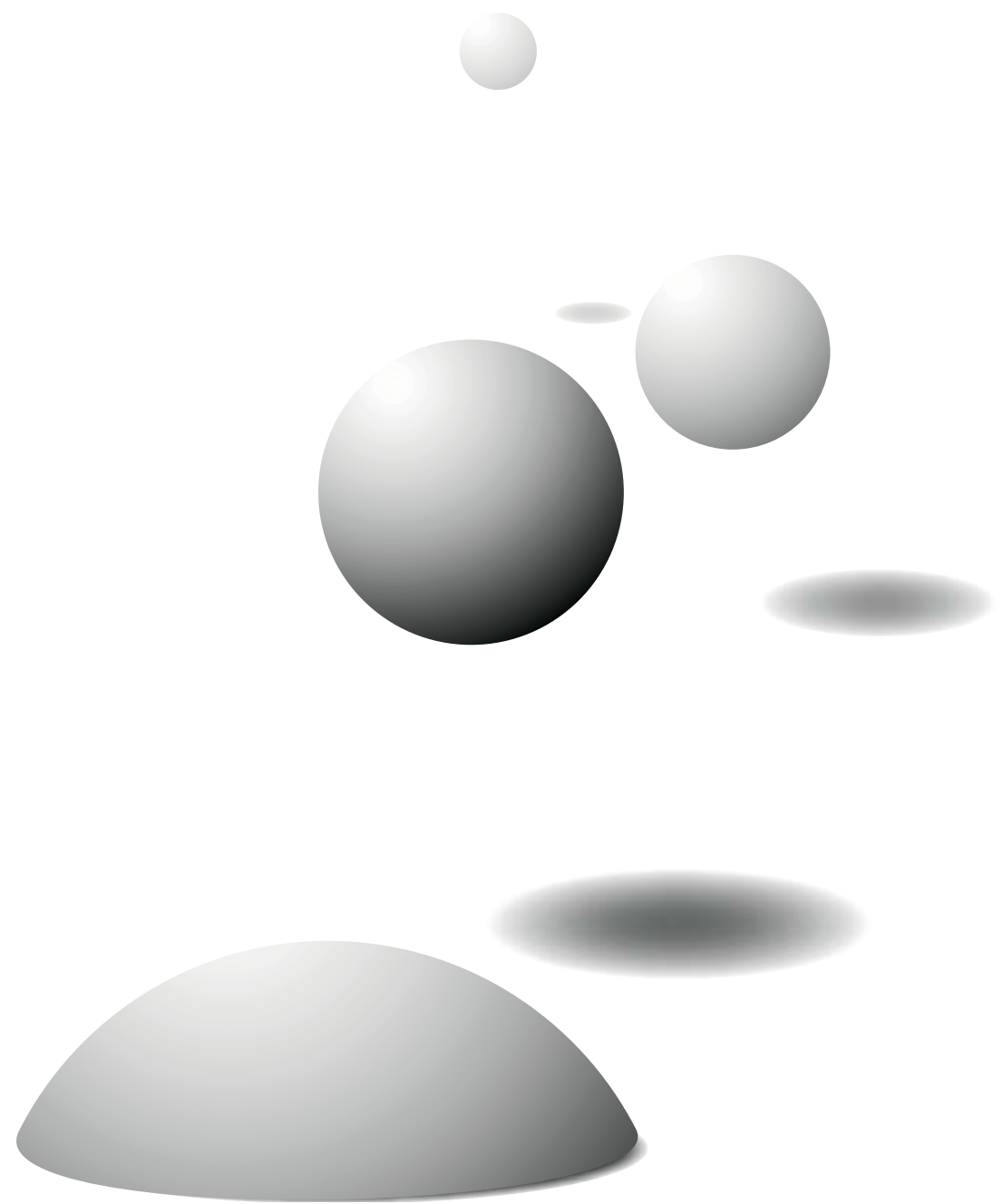
Chapter 1

General introduction

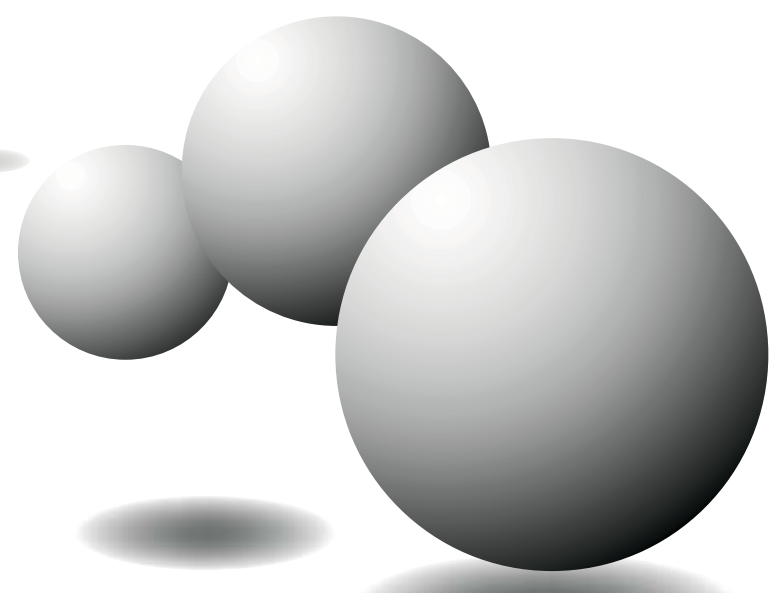




\section{INTRODUCTION}

\section{Cancer population}

In the Netherlands, $28 \%$ of the people who died in 2003 died of cancer. Cancer is the second most frequent cause of death after cardiovascular diseases [1]. Cancer occurs particularly in elderly people. At diagnosis two-thirds of all new cancer patients are older than 60 years [2].

In the future, not only the proportional increase of the ageing population will increase the demand for health care in cancer patients, but so will the better survival of cancer patients. The five-year survival in male and female cancer patients increased from $30 \%$ and $45 \%$ in the seventies to $45 \%$ and $60 \%$ respectively in 2001 [2]. Other reasons for an increase in the number of persons with the diagnosis 'cancer' are earlier diagnosis and screening as well as improved treatments for patients [2].

Since the early 1990 s breast cancer has been the most frequently occurring malignancy in women in the Netherlands. Yearly, a third of all new female cancer patients $(11,000)$ suffer from breast cancer and about 3500 women die because of it. Because of the growth of the elderly population, the incidence rate of breast cancer patients is expected to be 17,000 in 2015 [2]. Most breast cancers (90\%) are operable. Sixty percent of patients with operable breast cancer receive a type of adjuvant therapy. More than half of these patients receive adjuvant chemotherapy. Adjuvant chemotherapy is then part of the standard treatment in a large subset of breast cancer patients [2].

\section{Cancer-related fatigue}

Fatigue is a major concern in patients with cancer [3]. The National Comprehensive Cancer Network (NCCN) reported that fatigue affects $70 \%$ to $100 \%$ of patients with cancer [4]. Everyone experiences fatigue on a daily basis. Although fatigue is normally relieved by a good night's sleep, this is often not the case for patients with cancer, for whom it may become a chronic and unpleasant sensation [5]. Cancer-related fatigue is different from typical fatigue of everyday life. It is more rapid in onset, more energy draining, more intense, more severe, more unrelenting and it lasts longer [6]. Little is known about fatigue, despite the high prevalence and its profoundly negative effect on patients' quality of life [7]. Fatigue is a multicausal, multidimensional and complex concept [8-10], and it is difficult to define or describe [9, 11-13]. The definition used in this dissertation is that of the National Comprehensive Cancer Network (NCCN). The NCCN convened a panel of experts in the field of fatigue, who defined cancer-related fatigue as 'a distressing, persistent, subjective sense of tiredness or exhaustion 
related to cancer or cancer treatment that is not proportional to recent activity and interferes with usual functioning' [4] (p. MS-2). Important characteristics of cancer-related fatigue in the NCCN definition are the subjectivity of the sensation and the interference with usual functioning [7].

\section{Factors related to fatigue}

Although fatigue can be a symptom of the disease itself, it can also be expected to accompany cancer treatment [14]. Patients with cancer who are receiving chemotherapy may experience a variety of side effects such as pain, nausea, vomiting, hair loss, weight changes, fatigue, and anxiety, with fatigue being one of the most commonly reported side-effects [7]. A common perception is that more chemotherapy treatments lead to greater fatigue. Results from several studies [15-17], however, vary in this respect. Between two cycles of adjuvant chemotherapy the experience of fatigue is fluctuating [18]. After completion of chemotherapy fatigue is still experienced [19-22]. It is not known when, after completion of chemotherapy, the fatigue can be regarded as normal fatigue. There is no clear overview in the literature of the intensity of fatigue in breast cancer patients throughout chemotherapy treatment cycles, between two cycles of chemotherapy and after completion of chemotherapy.

Not only treatment factors are expected to influence fatigue. The actual mechanisms that produce fatigue are unknown $[5,23]$. The most reasonable approach is to consider multiple factors [24]. There is evidence that age, a demographic factor, influences the experience of fatigue [25]. In the literature, anemia, a disease/physical factor, has been characterized as a major contributor to fatigue [26, 27]. Physical symptom distress, such as pain, influences fatigue too $[19,22,28]$. That fatigue and depression are related is beyond doubt, but the interpretation of this relation is, however, complicated [29]. The symptoms of fatigue and depression may overlap. In addition, fatigue is one of the key symptoms of depression and may be the result of depressed mood. It is not clear whether psychological symptom distress cause fatigue or vice versa. Nowadays, the importance of social relationships and social support for an individual's wellbeing is common knowledge. Social support is expected to have buffer effects, which means that social support protects people from the deleterious effects of stress [30]. The author of an early study [31] had already reported that the uncertainties and fears experienced by a person diagnosed with cancer are likely to result in an enhanced need for social support. Komproe et al. [30] reported that many researchers have underlined the relationship between social support and physical and psychological well-being. Coping also seems an important factor. McHaffie [32] reported that how well a person copes is central in 
determining his or her well-being, no matter how ill he or she is. The daily lives of almost every individual are filled with stressful experiences which require some form of coping. The impact of each varies, because people switch between their many roles and because these roles are changing [32]. Individuals with cancer must deal with the treatment process and its side-effects, as well as the uncertainty of the disease course. They must adapt to the changes in physical functioning and other negative life changes that are inevitably imposed by the disease [33]. Distinct coping behaviours and thought can influence outcomes [34], such as fatigue.

Figure 1 presents an expected simplified model of fatigue and its related factors, the research model.

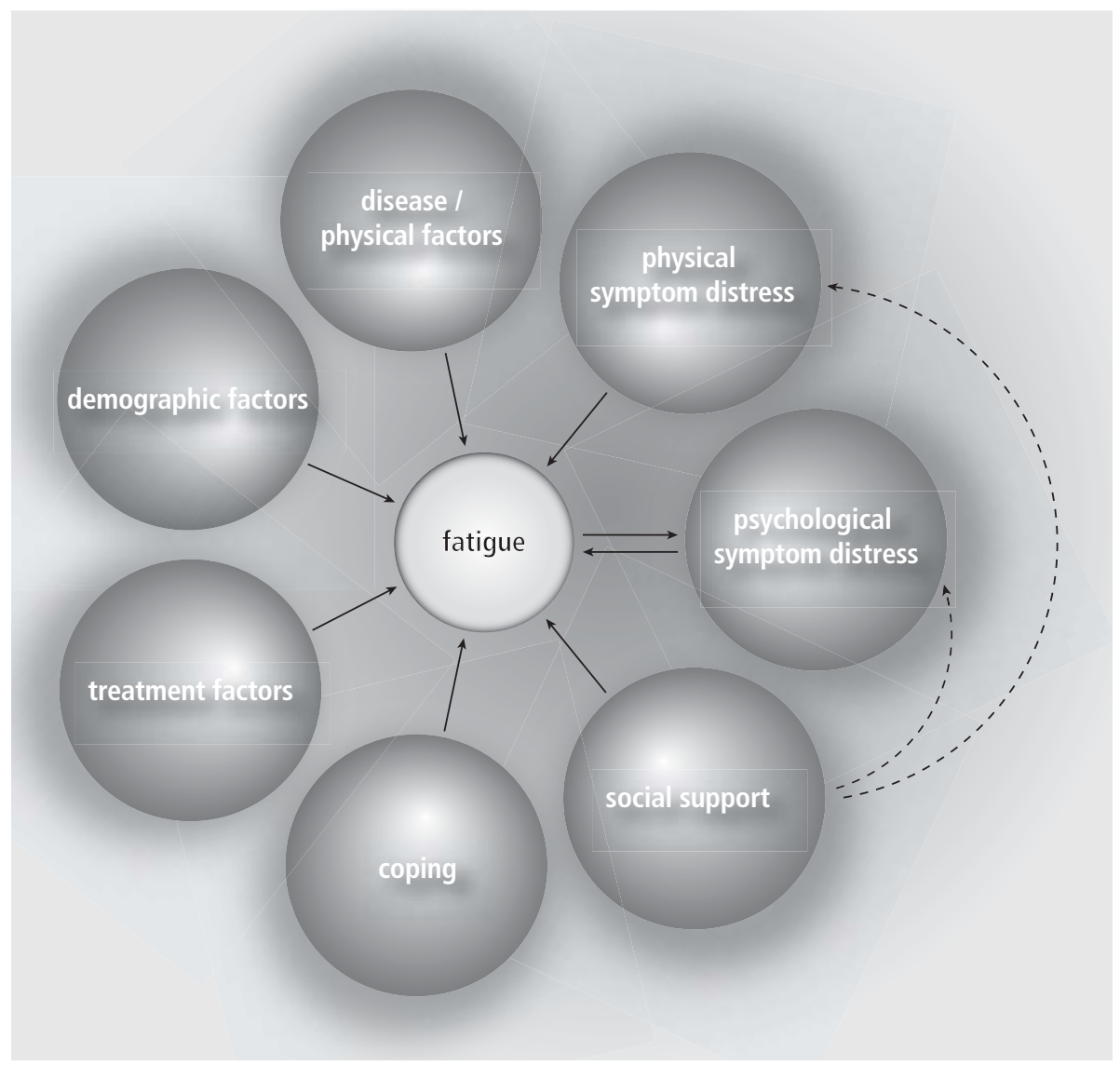

Figure 1. Model of fatigue and its relations 


\section{Chapter 1}

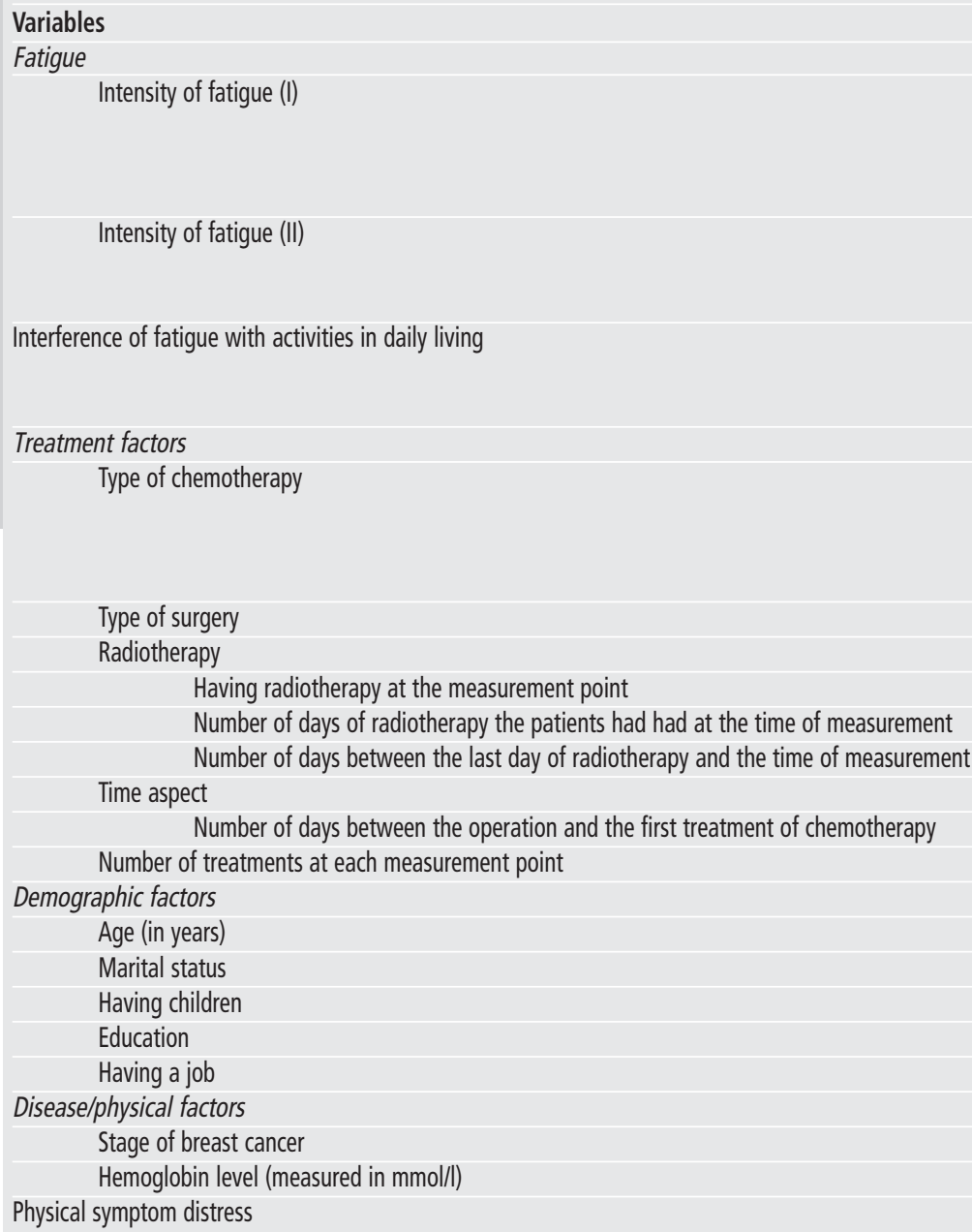




\section{Operationalisation}

The Multidimensional Fatigue Inventory (MFI-20) was used to assess the intensity of fatigue.

This 20-item self-report questionnaire, specially designed for cancer patients, consists of five scales based on different dimensions: general fatigue, physical fatigue, reduced activity, reduced motivation and mental fatigue. Each subscale consists of four items.

The Shortened Fatigue Questionnaire (SFQ) is an instrument to determine the intensity of the patient's bodily fatigue. The SFQ was used as a diary. The questionnaire consists of four questions: 'I feel tired', 'I tire easily', 'I feel fit' and 'I feel physically exhausted', each with a seven-point answer scale.

The revised Piper Fatigue Scale (revised PFS) is an instrument to measure subjective fatigue.

This 22-item questionnaire consists of four subscales. In this study one subscale was used: the behavioural/severity subscale.This subscale (6 items) reflects the degree to which fatigue interferes with activities of daily living.

Patients were treated with one of the following adjuvant treatments: CEF (cyclophosphamide, 4-epi-doxorubicin and 5-fluorouracil), CAF (cyclophosphamide, doxorubicin and 5-fluorouracil), 4-epi-doxorubicin,

4-epi-doxorubicin/taxotere, CA (cyclophosphamide and doxorubicin) and CMF (cyclophosphamide, methotrexate (oral administration from day 1 to day 14 or intravenous) and 5-fluorouracil).

Patients underwent a mastectomy or a lumpectomy with or without lymph nodes excision.

Yes or no

Married/living together, single, divorced and widow

Yes or no

Educational level 'low', 'middle' and 'high'

Yes or no

The TNM (tumour-node-metastasis) clinical classification is used to report the anatomic extent of breast cancer.

The Rotterdam Symptom Checklist (RSCL) is an instrument to determine the quality of life of cancer patients.

Patients were asked to indicate the degree to which they had been bothered by physical symptoms ( 23 items) on a four-point Likert-scale (categories: not at all, a little, quite a bit and very much).

The Rotterdam Symptom Checklist (RSCL) is an instrument to determine the quality of life of cancer patients. Patients were asked to indicate the degree to which they had been bothered by psychological symptoms (7 items) on a four-point Likert-scale (categories: not at all, a little, quite a bit and very much).

Depressive symptoms were assessed by using the Center for Epidemiological Studies Depression Scale (CES-D). Patients indicated their experience of the symptoms responding "rarely or none of the time" (0); "some or little of the time" (1); "occasionally or a moderate amount of time" (2); and "most or all of the time" (3). High scores indicate more symptoms. The range of scores is 0 to 60, with a cut-off of 16 for a depressive syndrome. Social support was assessed with the SSL12-I. The SSL12-I consists of three subscales with each four items: 'everyday social support', 'social support in problem situations' and 'esteem support'.

The Utrecht Coping List (UCL) was used to assess coping. Four coping styles can be distinguished from the short coping list: 'active coping' (5 items), 'social support seeking' (5 items), 'avoiding' (3 items), and 'palliative coping'(2 items). 


\section{Chapter 1}

This dissertation discusses the following research questions:

1 To what extent do breast cancer patients receiving adjuvant chemotherapy experience fatigue (chapter 3 )?

2 How does the experience of fatigue change over the course of time (chapter 3, 4, 5 and 6)?

3 To what extent do treatment factors, demographic factors, disease/physical factors, physical and psychological symptom distress, social support, coping influence fatigue (chapter 7)?

\section{Patients and methods}

One hundred and seventy-five breast cancer patients with an indication for adjuvant chemotherapy, treated in six hospitals, mainly in the south of the Netherlands, were included in this study if they met the following criteria: (1) had no metastasis of disease or other malignancy, (2) had not been treated with cytostatic drugs before, (3) were planned to be treated with outpatient adjuvant chemotherapy, (4) did not have a chronic disease (like hypertension, kidney disease, heart problems, Diabetes Mellitus etc.) or a poor psychological state (such as diagnosed with a depression), (5) did not use morphine or narcoleptics, (6) were not deaf, (7) had to be 18 years or older, and (8) could speak and understand Dutch.

Patients were interviewed at least four times. Patients were also asked to report their experience of fatigue in a diary on a daily basis between the third and fourth treatment with adjuvant chemotherapy.

Table 1 presents the operationalisation of the variables used in the present study. Medical data were collected from charts and were gathered after the interviews.

\section{AIMS AND OUTLINE OF THIS DISSERTATION}

This dissertation starts with a literature review, chapter 2. The aim of this literature review is to evaluate the prevalence and course of fatigue in patients with breast cancer receiving adjuvant chemotherapy and to examine factors relating to fatigue.

Chapters 3, 4 and 5 focus on the course of fatigue in breast cancer patients. These chapters constitute an entity, but can be read separately. Each chapter has been published or accepted for publication. A certain overlap is therefore inevitable. The purpose of these studies (chapters 3-5) is to investigate the course of fatigue during as well as after adjuvant chemotherapy in an attempt to circumvent the major weaknesses of previously published studies. Patients were studied directly 
before, during or after infusions at the first, third and fifth cycle of chemotherapy, and 4 and 12 weeks after the completion of chemotherapy. The Multidimensional Fatigue Inventory (MFI-20) 35 was used to assess the course of fatigue. This questionnaire consists of five subscales based on different dimensions: general fatigue, physical fatigue, reduced activity, reduced motivation and mental fatigue.

Chapter 3 covers the courses of general and physical fatigue. In addition, the prevalence of fatigue in breast cancer patients both during and after receiving adjuvant chemotherapy is determined. The purpose of chapter 4 is to determine the course of fatigue in relation to cognitive symptoms (scale 'mental fatigue') as well as the motivation to start any activity (scale 'reduced motivation') as a result of chemotherapy. In this chapter the relationship between these subscales and depressive symptoms is also studied. Chapter 5 includes a description of the course of the activity level, and discusses the extent of the interference with daily living activities.

Chapter 6 examines the course of fatigue between two cycles of adjuvant chemotherapy in breast cancer patients. The experience of fatigue of each day, from the day of administration until the day of the next infusion, is described. The hypothesis that the maximum fatigue score occurs in the first four days after treatment was tested.

The purpose of chapter 7 is to test a model of variables that influence fatigue in breast cancer patients both during and after adjuvant chemotherapy. The associations between different variables, other than fatigue, were also examined. Eventually, a 'chemotherapy-fatigue model' was developed.

This dissertation concludes with a general discussion in chapter 8 .

\section{ReferenCeS}

1. Poos, M.J.J.C., P.W. Achterberg, and E.A. Van der Wilk, Waaraan overlijden mensen in Nederland? In: Volksgezondheid Toekomst Verkenning, Nationaal Kompas Volksgezondheid. http://www.nationaalkompas.nl. 2006.

2. KWF Kankerbestrijding, Kanker in Nederland. Trends, prognoses en implicaties voor zorgvraag. 2004, Oisterwijk: Drukkerij van den Boogaard.

3. Irvine, D.M., et al., A critical appraisal of the research literature investigating fatigue in the individual with cancer. Cancer Nurs, 1991. 14(4): p. 188-99. 


\section{Chapter 1}

4. NCCN, National Comprehensive Cancer Network (NCCN) Cancer-Related Fatigue. http://www.nccn.org/professionals/physician g/s/PDF/fatigue.pdf. 2006.

5. Piper, B.F., A.M. Lindsey, and M.J. Dodd, Fatigue mechanisms in cancer patients: developing nursing theory. Oncol Nurs Forum, 1987. 14(6): p. 17-23.

6. Holley, S., Cancer-related fatigue - Suffering a different fatigue. Cancer Practice, 2000. 8(2): p. 87-95.

7. De Jong, N., et al., Fatigue in patients with breast cancer receiving adjuvant chemotherapy: a review of the literature. Cancer Nurs, 2002. 25(4): p. 283-97.

8. Piper, B.F., Pathophysiological phenomena in nursing: human responses to illness. 1993, Philadelphia: W.B. Saunders Company. 279-302.

9. Tiesinga, L.J., T.W. Dassen, and R.J. Halfens, Fatigue: a summary of the definitions, dimensions, and indicators. Nurs Diagn, 1996. 7(2): p. 51-62.

10. Magnusson, K., et al., A qualitative study to explore the experience of fatigue in cancer patients. European Journal of Cancer Care, 1999. 8(4): p. 224-232.

11. Smets, E.M., et al., Fatigue in cancer patients. Br J Cancer, 1993. 68(2): p. 220-4.

12. Gall, H., The Basis of Cancer Fatigue: Where Does It Come From? European Journal of Cancer Care, 1996. 5(Suppl. 2): p. 31-34.

13. Stone, P., M. Richards, and J. Hardy, Fatigue in patients with cancer. European Journal of Cancer, 1998. 34(11): p. 1670-1676.

14. Nail, L.M. and K.B. King, Symptom distress. Fatigue. Semin Oncol Nurs, 1987. 3(4): p. 257-62.

15. Sitzia, J. and L. Huggins, Side effects of cyclophosphamide, methotrexate, and 5fluorouracil (CMF) chemotherapy for breast cancer. Cancer Practice, 1998. 6 (1): p. 13-21.

16. Berger, A.M., Patterns of fatigue and activity and rest during adjuvant breast cancer chemotherapy. Oncol Nurs Forum, 1998. 25(1): p. 51-62.

17. Jacobsen, P.B., et al., Fatigue in women receiving adjuvant chemotherapy for breast cancer: Characteristics, course, and correlates. Journal of Pain and Symptom Management, 1999. 18(4): p. 233-242.

18. Cowley, L., et al., How women receiving adjuvant chemotherapy for breast cancer cope with their treatment: a risk management perspective. Journal of Advanced Nursing, 2000. 31(2): p. 314-321.

19. Bower, J.E., et al., Fatigue in breast cancer survivors: Occurrence, correlates, and impact on quality of life. Journal of Clinical Oncology, 2000. 18(4): p. 743-753.

20. Broeckel, J.A., et al., Characteristics and correlates of fatigue after adjuvant chemotherapy for breast cancer. J Clin Oncol, 1998. 16(5): p. 1689-96.

21. Mast, M.E., Correlates of fatigue in survivors of breast cancer. Cancer Nursing, 1998. 21(2): p. 136-142.

22. Okuyama, T., et al., Factors correlated with fatigue in disease-free breast cancer patients: application of the Cancer Fatigue Scale. Supportive Care in Cancer, 2000. 8(3): p. 215-222. 
23. Richardson, A., Fatigue in Cancer Patients: a Review of the Literature. European Journal of Cancer Care, 1995. 4: p. 20-32.

24. Nail, L.M. and M.L. Winningham, Fatigue. In Groenwald SL, Goodman M, Hansen Frogge M, Henke Yarbro C (eds): Cancer Nursing: Principles and Practice. 1993, Boston, London: Jones and Bartlett Publishers. 608-619.

25. Woo, B., et al., Differences in fatigue by treatment methods in women with breast cancer. Oncol Nurs Forum, 1998. 25(5): p. 915-20.

26. Sabbatini, P., Contribution of anemia to fatigue in the cancer patient. Oncology New York, 2000. 14(11A Suppl. 10): p. 69-71.

27. Portenoy, R.K. and L.M. Itri, Cancer-related fatigue: guidelines for evaluation and management. Oncologist, 1999. 4(1): p. 1-10.

28. Gaston Johansson, F., et al., Fatigue, pain, and depression in pre-autotransplant breast cancer patients. Cancer Practice, 1999. 7(5): p. 240-247.

29. Visser, M.R. and E.M. Smets, Fatigue, depression and quality of life in cancer patients: how are they related? Support Care Cancer, 1998. 6(2): p. 101-8.

30. Komproe, I.H., et al., Available support and received support: Different effects under stressful circumstances. Journal of Social and Personal Relationships, 1997. Vol 14(1): p. 59-77.

31. Wortman, C.B., Social support and the cancer patient. Conceptual and methodologic issues. Cancer, 1984. 53(10 Suppl): p. 2339-62.

32. McHaffie, H.E., Coping: an essential element of nursing. J Adv Nurs, 1992. 17(8): p. 933-40.

33. Manne, S.L., et al., Coping with chemotherapy for breast cancer. J Behav Med, 1994. 17(1): p. 41-55.

34. Shapiro, D.E., et al., Stage I/ breast cancer: differences between four coping patterns in side effects during adjuvant chemotherapy. J Psychosom Res, 1997. 43(2): p. 143-57.

35. Smets, E.M.A., B. Garssen, and B. Bonke, Het meten van vermoeidheid met de Multidimensionele Vermoeidheids Index (MVI-20): Een handleiding. 1995, Amsterdam: Medische Psychologie, Academisch Medisch Centrum, The Netherlands. 

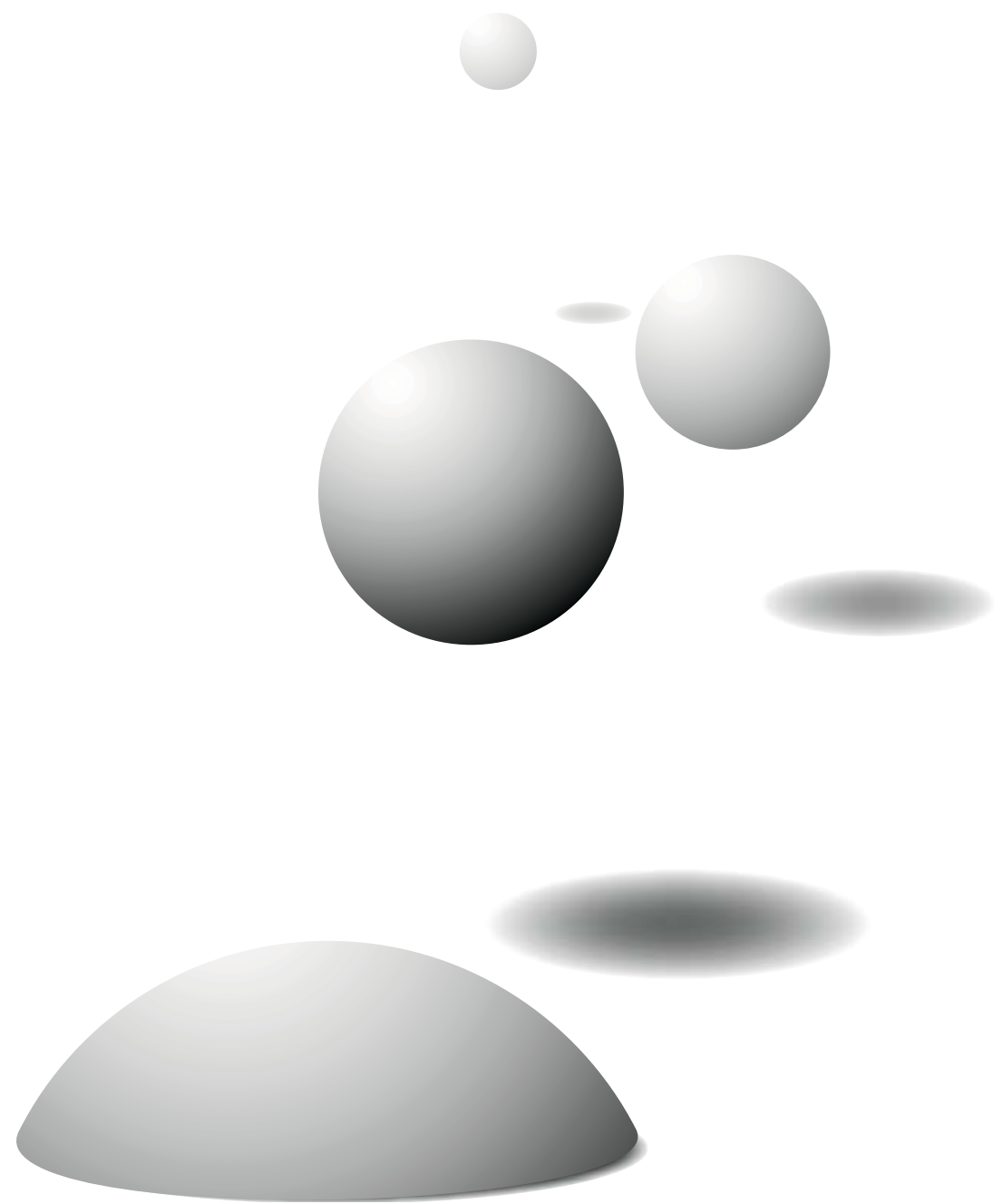


\section{Chapter 2}

\section{Fatigue in patients with breast cancer receiving adjuvant chemotherapy: a review of the literature}

Nynke de Jong, MSc, RN, Annemie M. Courtens, PhD, RN, Huda Huijer AbuSaad, FEANS, PhD, RN, \& Harry C. Schouten, MD, PhD

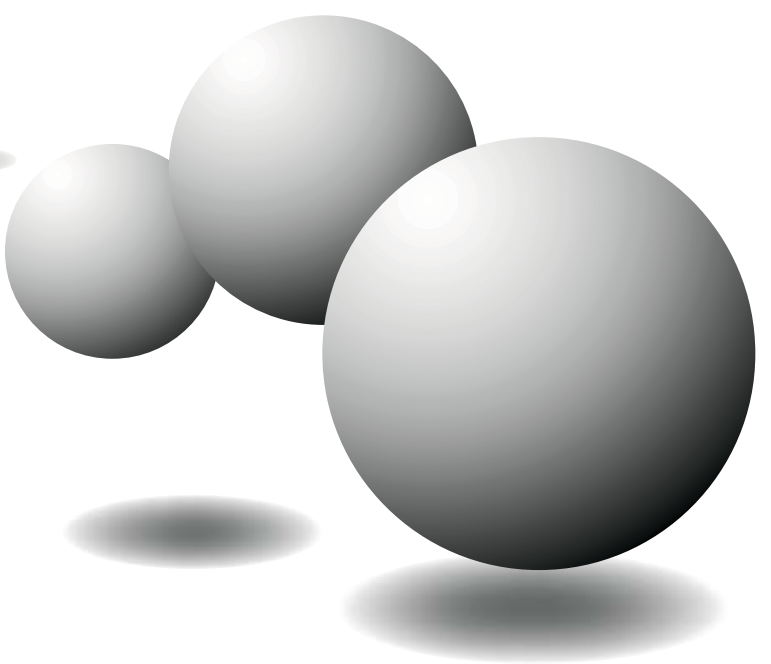

Updated version of the article published in: Cancer Nursing 2002; 25(4): 283-297. 


\section{Chapter 2}

\section{AbStRACT}

The aim of this literature review was to evaluate the prevalence and course of fatigue in patients with breast cancer undergoing adjuvant chemotherapy and to examine factors relating to fatigue. Fatigue is one of the most common side effects of chemotherapy. High and fluctuating prevalence rates of fatigue have been found not only during but also after adjuvant chemotherapy. The intensity of fatigue seems to be stable throughout the treatment cycles, despite the common perception that more chemotherapy treatments lead to greater fatigue. The first two days after a chemotherapy treatment seem to be the worst period.

The influence of factors such as pain, impaired quality of sleep, and depression are found to be highly consistent across several studies, although it is often not clear whether it is the symptoms that cause the fatigue or vice versa. The outcomes of the studies indicate that several symptoms are interrelated in a network of symptoms. Factors such as changes in weight, menopausal symptoms, coping, social support, and biochemical changes have been mentioned in the literature as potentially contributing to fatigue. Results have been conflicting and need further study.

Keywords: fatigue, breast cancer, chemotherapy 


\section{INTRODUCTION}

The most common symptom of illness, whether mental or physical, is fatigue. It is often the first indication of the presence of some abnormality and affects the totality of an individual [1]. Fatigue is a major concern in patients with cancer [2]. It is becoming increasingly realized that quality of life in patients with cancer is affected by fatigue and is becoming more visible as a result of longer cancer survival [3]. In a recent study in the Netherlands, patients with cancer (suffering from various types of cancer) stated that fatigue had a greater effect on their daily life than pain [4]. The National Comprehensive Cancer Network (NCCN) reported that fatigue affects $70 \%$ to $100 \%$ of patients with cancer [5].

Everyone experiences fatigue on a daily basis. Although fatigue is normally relieved by a good night's sleep, this is often not the case for patients with cancer, for whom it may become a chronic and unpleasant sensation [6]. Although fatigue can be a symptom of the disease itself, it can also be expected to accompany cancer treatment [7]. Ream et al. [8] reported that it is recognized that patients with cancer frequently become fatigued when undergoing treatment, notably chemotherapy. Patients with cancer who are receiving chemotherapy may experience a variety of side effects such as pain, nausea, vomiting, hair loss, weight changes, fatigue, and anxiety, with fatigue being one of the most commonly reported side effects.

In the Netherlands, breast cancer is the most prevalent form of cancer in women [9]. One third of the new cases of cancer in women concerns breast cancer. About $60 \%$ of the patients with breast cancer, who underwent an operation, received adjuvant systematic therapy. More than half of these patients received chemotherapy [9].

The purpose of this article is to critically review the literature with respect to fatigue in patients with breast cancer who are receiving adjuvant chemotherapy.

This study addressed the following questions:

- To what extent do patients with breast cancer who are receiving adjuvant chemotherapy experience fatigue?

- How does this change in the course of time?

- What are the factors relating to fatigue?

Published articles were found by means of a CD-ROM search of MEDLINE (1989 to April 2006): using the search terms fatigue, breast cancer and chemotherapy. The snowball method was used for additional literature. 


\section{THE CONCEPT OF FATIGUE}

Fatigue is a multicausal, multidimensional and complex concept [10-12], and it is difficult to define or describe [11,13-15]. Many disciplines are interested in the concept of fatigue, including medicine, psychology, physiology, nursing science and ergonomics $[11,16]$. No widely accepted definition of fatigue exists, and the concept has been associated with many other terms such as tiredness, exhaustion, weariness, malaise, weakness, and asthenia [11, 17]. In addition, differences in cultural values, meanings of words and concepts, and translation problems have influenced the meaning of fatigue [18]. The concept is used at different levels: as a symptom, a diagnosis and a syndrome [11].

Despite complexities and difficulties, Ream and Richardson proposed the following definition of fatigue for nursing purposes based on a concept analysis: "Fatigue is a subjective, unpleasant symptom which incorporates total feelings ranging from tiredness to exhaustion creating an unrelenting overall condition which interferes with individuals' ability to function to their normal capacity" [19] (p. 527). To supplement this general definition of fatigue, NCCN recently convened a panel of fatigue experts to define cancer-related fatigue. The panel defined cancer-related fatigue as "A distressing, persistent, subjective sense of tiredness or exhaustion related to cancer or cancer treatment that is not proportional to recent activity and interferes with usual functioning" [5] (p. MS-2). This definition emphasizes the unusual character of cancer fatigue, which differentiates it from the type of fatigue that healthy individuals may experience. Fatigue in patients with cancer is more severe, more distressing, and less likely to be relieved by rest. Compared with the definition proposed by Ream and Richardson [19], it seems to be the unusual character of fatigue that is specific for patients with cancer. Holley [20] also reported the unusual character of cancer-related fatigue. She reported that cancer-related fatigue had a more rapid onset and was more energy-draining, more intense, longer lasting, more severe, and more unrelenting than typical fatigue [20]. Important characteristics of cancer-related fatigue in the NCCN definition are the subjectivity of the sensation and the interference with usual functioning. These characteristics correspond with the definition proposed by Ream and Richardson [19]. 


\section{Prevalence and course of fatigue in patients With breast cancer WHO ARE RECEIVING CHEMOTHERAPY}

The literature search resulted in the identification of a number of publications reporting on patients with breast cancer who were receiving or had received adjuvant chemotherapy. This section is divided in two parts: (1) studies were fatigue was measured during, during and after, pre and after receiving chemotherapy; and (2) fatigue measured after completion of chemotherapy. Table 1 presents an overview of the methodological details of these studies, and Table 2 presents sample characteristics, main results, and limitations of the studies.

\section{Fatigue during, during and after, pre and after receiving chemotherapy}

Studies with timing of measurements adjusted to the different cycles of chemotherapy

Sitzia and Huggins [21] studied side effects in patients with breast cancer $(n=52)$ who were receiving 6 cycles of cyclophosphamide, methotrexate and 5 -fluorouracil (CMF). Data were collected after each treatment cycle using the reliable and valid Worthing Chemotherapy Questionnaire 75 (WCQ-75). This self-reporting questionnaire features a list of 61 problems. The incidence of fatigue was approximately $90 \%$, and fatigue severity remained stable throughout the treatment cycles. The strengths of this study include the use of a homogeneous group of patients with breast cancer who were receiving only chemotherapy without radiation therapy and the use of a valid and reliable tool.

Berger [22] described patterns of fatigue in 72 patients with breast cancer receiving $C M F$, doxorubicin and cyclophosphamide $(A / C)$, or cyclophosphamide, doxorubicin and fluorouracil (CAF). The Piper Fatigue Scale, a reliable and valid multidimensional subjective fatigue measure established for patients with cancer, was used to measure fatigue 48 hours after each treatment and at treatment cycle midpoints during 3 cycles. Berger's results showed that fatigue levels 48 hours after each of the first 3 chemotherapy cycles were not significantly different over time. Donovan et al. [23] reported that fatigue severity in women with early stage breast cancer increased significantly from the start of chemotherapy to the middle of chemotherapy but did not increase significantly from the middle of chemotherapy to the end of chemotherapy. The common perception that fatigue increases with time as patients receive further courses of chemotherapy is not supported by the studies of Berger [22] and Donovan et al. [23], which confirms the findings of Sitzia and Huggins [21]. Jacobsen et al. [24] found similar results 


\section{Chapter 2}

\begin{tabular}{|c|c|c|c|}
\hline Author & $\mathrm{n}$ & Design & Measuring instrument \\
\hline \multicolumn{4}{|c|}{ Studies assessing fatigue during, during and after or pre and after receiving chemotherapy } \\
\hline Blesch et al. (1991) & 77 & $\begin{array}{l}\text { Cross-sectional, descriptive, } \\
\text { correlational, comparative (2 groups) }\end{array}$ & $\begin{array}{l}\text { Visual Analogue Scale (VAS)* } \\
\text { Rhoten Fatigue Scale* } \\
\text { Rhoten Fatigue Checklist* }\end{array}$ \\
\hline Greene et al. (1994) & 86 & $\begin{array}{l}\text { Longitudinal, descriptive, } \\
\text { comparative ( } 3 \text { groups) }\end{array}$ & Self-care diary $(S C D) \dagger$ \\
\hline Longman et al. (1996) & 307 & Cross-sectional, descriptive & Side Effects Checklistt, $\ddagger$ \\
\hline Hoskins (1997) & 93 & Longitudinal, descriptive & Treatment Recovery Inventory (TRI) $t, \ddagger$ \\
\hline Longman et al. (1997) & 53 & Longitudinal, descriptive & Side Effects Checklistt, $\ddagger$ \\
\hline $\begin{array}{l}\text { Berger (1998) and } \\
\text { Berger and Farr (1999) }\end{array}$ & 72 & Longitudinal, descriptive & Piper Fatigue Scale (PFS)* \\
\hline Sitzia and Huggins (1998) & 52 & $\begin{array}{l}\text { Longitudinal, descriptive, } \\
\text { retrospective }\end{array}$ & $\begin{array}{l}\text { Worthing Chemotherapy Questionnaire } \\
75 \text { (WCQ-75) } †\end{array}$ \\
\hline Wyatt and Friedman (1998) & 46 & $\begin{array}{l}\text { Longitudinal, descriptive, } \\
\text { comparative ( } 2 \text { groups) }\end{array}$ & Symptom Measuret \\
\hline \multirow[t]{2}{*}{ Jacobsen et al. (1999) } & 108 & $\begin{array}{l}\text { Longitudinal, descriptive, } \\
\text { correlational, comparative (2 groups) }\end{array}$ & $\begin{array}{l}\text { Fatigue Scale from the Profile } \\
\text { of Mood States (POMS-F)* } \\
\text { Fatigue Symptom Inventory (FSI)* }\end{array}$ \\
\hline & 54 & $\begin{array}{l}\text { Longitudinal, descriptive, } \\
\text { correlational }\end{array}$ & $\begin{array}{l}\text { Memorial Symptom Assessment } \\
\text { Scale (MSAS) } \dagger\end{array}$ \\
\hline Jacobsen et al. (1999) & 146 & $\begin{array}{l}\text { Cross-sectional, descriptive, } \\
\text { correlational }\end{array}$ & $\begin{array}{l}\text { POMS-F* } \\
\text { FSI* }^{*} \\
\text { Multidimensional Fatigue Symptom } \\
\text { Inventory (MFSI)* }\end{array}$ \\
\hline Berger and Higginbotham (2000) & 14 & $\begin{array}{l}\text { Longitudinal, descriptive, } \\
\text { prospective, correlational }\end{array}$ & $\begin{array}{l}\text { PFS* } \\
\text { Symptom Experience Scale (SES) } †\end{array}$ \\
\hline Schwartz (2000) & 31 & $\begin{array}{l}\text { Longitudinal, descriptive, } \\
\text { comparative ( } 2 \text { groups) }\end{array}$ & VAS* \\
\hline Berger and Walker (2001) & 60 & $\begin{array}{l}\text { Longitudinal, descriptive, } \\
\text { correlational, prospective }\end{array}$ & $\mathrm{PFS}^{*}$ \\
\hline
\end{tabular}

$\begin{array}{lrll}\text { Haghighat et al. (2003) } & 112 & \text { Cross-sectional, descriptive } & \text { Cancer Fatigue Scale (CFS)* } \\ \text { Tchen et al. (2003) } & 220 & \begin{array}{l}\text { Cross-sectional, descriptive } \\ \text { correlational, comparative (2 groups) }\end{array} & \begin{array}{l}\text { Functional Assessment of Cancer } \\ \text { Therapy-Fatigue subscale (FACT-F) }\end{array} \\ \text { Bennett et al. (2004) } & 109 & \begin{array}{c}\text { Cross-sectional, descriptive } \\ \text { FACT-F* }\end{array}\end{array}$

Boehmke (2004)

120 Longitudinal, descriptive, correlational, prospective

McCorkle Symptom Distress Scale (SDS) $\ddagger$ Rhodes Adapted Symptom Distress Scale (ASDS) ¥ 
Multidimensional or unidimensional

\begin{tabular}{|c|c|c|}
\hline $\begin{array}{l}\text { Uni } \\
\text { Uni } \\
\text { Multi }\end{array}$ & $\begin{array}{l}\text { While actually receiving chemotherapy } \\
\text { and/or radiation therapy }\end{array}$ & 1 \\
\hline- & On days 2 and 5 after the first 2 cycles & 4 \\
\hline- & Unknown $¥$ & 1 \\
\hline- & 7-10 days $/ 1$ month $/ 2$ months $/ 3$ months $/ 6$ months $/ 1$ year after surgery & 6 \\
\hline- & Unknown/6-8 weeks/3 months after surgery & 3 \\
\hline Multi & 48 hours and midpoints of first 3 cycles & 6 \\
\hline- & After each treatment cycle (6 cycles) & 6 \\
\hline- & 6 weeks/3 months $/ 6$ months after surgery & 3 \\
\hline $\begin{array}{l}\text { Uni } \\
\text { Multi }\end{array}$ & $\begin{array}{l}\text { Before the start of chemotherapy/between the } \\
\text { second and third cycles/between the third } \\
\text { and fourth cycles }\end{array}$ & 3 \\
\hline- & Before the start of the first 4 cycles & 4 \\
\hline $\begin{array}{l}\text { Uni } \\
\text { Multi } \\
\text { Multi }\end{array}$ & During or after treatment & 1 \\
\hline $\begin{array}{l}\text { Multi } \\
\text { Uni }\end{array}$ & $\begin{array}{l}2 \text { days before treatment } 3 / \text { days } 1-4 \text { after treatment } \\
3 / \text { days } 5-10 \text { after treatment } 3 / \text { days } 11-21 \text { after treatment } \\
3 / 3 \text { weeks after treatment } 4 / 2 \text { months after treatment } 4\end{array}$ & 6 \\
\hline Uni & Every day over 3 cycles of chemotherapy & Diary \\
\hline Multi & $\begin{array}{l}\text { Fatigue was measured during chemotherapy at } 6 \\
\text { collection points: three encompassed } 4 \text { days at each } \\
\text { of the chemotherapy treatments } 1,2 \text { and } 3 \text { and } \\
\text { three encompassed } 3 \text { days at the midpoints of cycles } \\
1,2 \text {, and } 3\end{array}$ & 6 \\
\hline Multi & $\begin{array}{l}\text { After three cycles of chemotherapy or at least } 2 \text { weeks } \\
\text { after completion their treatment }\end{array}$ & 1 \\
\hline Uni & $\begin{array}{l}\text { While receiving adjuvant chemotherapy } \\
\text { or neoadjuvant chemotherapy }\end{array}$ & 1 \\
\hline Uni & $\begin{array}{l}\text { Most women had completed adjuvant treatment with } \\
\text { chemotherapy and or radiation, the remainder had to } \\
\text { complete adjuvant treatment } \\
\text { Timing is divers }\end{array}$ & 1 \\
\hline - & $\begin{array}{l}\text { On the day of the first dose of chemotherapy; at the nadir of the } \\
\text { chemotherapy cycle; and at the end of the first cycle of chemotherapy }\end{array}$ & 3 \\
\hline
\end{tabular}




\section{Chapter 2}

Author

n Design

Measuring instrument

Studies assessing fatigue during, during and after or pre and after receiving chemotherapy

Donovan et al. (2004)

134 Longitudinal, descriptive,

$\mathrm{FSI}{ }^{*}$

correlational, comparative (2 groups)

Jacobsen et al. (2004)

80 Longitudinal, descriptive,

FSI*

correlational, prospective,

comparative (2 groups)

Andrykowski et al. (2005)

288 Longitudinal, descriptive,

comparative (2 groups)

POMS-F*

$\mathrm{FSI}{ }^{*}$

Memorial Symptom Assessment Scale (MSAS) $\dagger$

Mar Fan et al. (2005)

206 Longitudinal, descriptive, Fatigue Catastrophizing Scale (FCS) ${ }^{*}$

Nieboer et al. (2005) prospective, comparative (2 groups)

885 Longitudinal, descriptive FACT-F* prospectivecomparative (2 groups)

SF-36+

Studies assessing fatigue after completion of chemotherapy

Berglund et al. (1991)

Beisecker et al. (1997)

Leddy (1997)

Andrykowski et al. (1998)

Broeckel et al. (1998)

Lindley et al. (1998)

Mast (1998)

Woo et al. (1998)

Gaston-Johansson et al. (1999)

Bower et al. (2000)

Okuyama et al. (2000)

Curran et al. (2004)

Bower et al. (2006)
448 Cross-sectional, descriptive, comparative (2 groups)

21 Longitudinal, descriptive

142 Cross-sectional, descriptive, comparative (2 groups)

176 Longitudinal, descriptive, correlational, retrospective, comparative (2 groups)

120 Cross-sectional, descriptive, correlational, comparative (2 groups)

86 Cross-sectional, descriptive

109 Cross-sectional, descriptive, correlationa

322 Cross-sectional, descriptive, correlationa

127 Cross-sectional, descriptive, correlational

Symptom listt, $\ddagger$

Semistructured interview $\ddagger$
Fatigue Experienced Scale

PFS*

Chalder Fatigue Scale*

Symptom Experience Report (SER)t, $\neq$

POMS-F*

$\mathrm{FSI}$

MFSI*

Symptom Distress Scale (SDS)†

Revised version of the SDSt

PFS*

PFS*

3910 Cross-sectional, descriptive, correlational, Rand 36-Item health Survey§ comparative (2 groups)

134 Cross-sectional, descriptive, correlational Cancer Fatigue Scale (CFS)*

74 Longitudinal, descriptive,

FATIGUE-D* comparative (3 groups)

RAND SF-36\$ 
Multidimensional or unidimensional

\begin{tabular}{|c|c|c|}
\hline Multi & $\begin{array}{l}C T+\text { RT\# group: first, third, and final cycles } \\
\text { of chemotherapy and at the first, fifteenth, and final } \\
\text { visits for radiotherapy } \\
\text { RT group: at the first, fifteenth, and final visits for } \\
\text { radiotherapy }\end{array}$ & $\mathrm{CT}+\mathrm{RT}$ group: 6 \\
\hline Multi & $\begin{array}{l}\text { First clinic visit for CT or RTt and last } \\
\text { visit for CT or RT }\end{array}$ & 2 \\
\hline $\begin{array}{l}\text { Uni } \\
\text { Multi } \\
- \\
\text { Multi }\end{array}$ & $\begin{array}{l}\text { Before adjuvant therapy and a post-treatment } \\
\text { assessment at the conclusion of an initial course } \\
\text { of adjuvant chemotherapy or radiotherapy }\end{array}$ & 2 \\
\hline Uni & $\begin{array}{l}\text { After at least three cycles of chemotherapy were completed, } \\
1 \text { and } 2 \text { years later }\end{array}$ & 3 \\
\hline - & Before and 1, 2 and 3 years after chemotherapy & 4 \\
\hline- & $2-10$ years after primary therapy & 1 \\
\hline- & Shortly after completion of adjuvant chemotherapy/6 months later & 2 \\
\hline Uni & $<10$ years after treatment & 1 \\
\hline $\begin{array}{l}\text { Multi } \\
\text { Multi } \\
\text { Uni }\end{array}$ & $\begin{array}{l}\text { 2-54 months after completed breast cancer treatment; } \\
\text { initial assessment for benign breast problems group } \\
\text { unknown/4-6 months later }\end{array}$ & 2 \\
\hline $\begin{array}{l}\text { Uni } \\
\text { Multi } \\
\text { Multi }\end{array}$ & Average of 471 days after treatment & 1 \\
\hline - & $2-5$ years after treatment & 1 \\
\hline Uni & 1-6 years after treatment & 1 \\
\hline Multi & Within 18 months after treatment & 1 \\
\hline $\begin{array}{l}\text { Multi } \\
\text { Uni }\end{array}$ & $\begin{array}{l}\text { Completed adjuvant chemotherapy and scheduled } \\
\text { for autologous bone marrow/peripheral blood stem cell transplant }\end{array}$ & 1 \\
\hline - & $1-5$ years after initial breast cancer diagnosis & 1 \\
\hline $\begin{array}{l}\text { Multi } \\
\text { Uni }\end{array}$ & $\begin{array}{l}786 \pm 463 \text { (SD) days after surgery } \\
\text { Off-treatment: breast cancer survivor ( } 6-26 \text { months) and } \\
\text { benign breast problems ( } 4-312 \text { months) } \\
\text { Healthy women were also measured } \\
\text { Assessments: at four specific times each day during } 5 \text { consecutive days }\end{array}$ & $\begin{array}{c}1 \\
20 \text { (diary) }\end{array}$ \\
\hline - & $1-5$ and $5-20$ years after diagnosis & 2 \\
\hline
\end{tabular}




\section{Chapter 2}

\begin{tabular}{|c|c|c|c|c|}
\hline Author & $\begin{array}{l}\text { Stage of } \\
\text { disease }\end{array}$ & Treatment / group & $\mathrm{n}$ & $\begin{array}{l}\text { Age } \\
\text { range, } y\end{array}$ \\
\hline \multicolumn{5}{|c|}{ Studies assessing fatigue during, during and after or pre and after receiving chemotherapy } \\
\hline \multirow[t]{2}{*}{ Blesch et al. (1991) } & \multirow[t]{2}{*}{ Unknown } & $\begin{array}{l}\text { Chemotherapy and/or radiation therapy } \\
\text { (patients with breast cancer) }\end{array}$ & 44 & 24-69 \\
\hline & & $\begin{array}{l}\text { Chemotherapy and/or radiation therapy } \\
\text { (lung cancer patients) }\end{array}$ & 33 & $38-74$ \\
\hline \multirow[t]{3}{*}{ Greene et al. (1994) } & \multirow[t]{3}{*}{ | or II } & $\begin{array}{l}\text { Cyclophosphamide, methotrexate, } \\
\text { and 5-fluorouracil (CMF) }\end{array}$ & 37 & $29-75$ \\
\hline & & $\begin{array}{l}\text { Cyclophosphamide, doxorubicin, } \\
\text { and 5-fluorouracil (CAF) }\end{array}$ & 29 & $31-75$ \\
\hline & & $\begin{array}{l}\text { Cyclophosphamide, mitoxantrone, } \\
\text { and 5-fluorouracil (CNF) }\end{array}$ & 20 & $41-70$ \\
\hline \multirow[t]{5}{*}{ Longman et al. (1996) } & \multirow[t]{5}{*}{ I-IV } & Chemotherapy & 169 & $25-82^{*}$ \\
\hline & & Radiation therapy & 117 & \\
\hline & & Hormone therapy & 98 & \\
\hline & & Hyperthermia & 3 & \\
\hline & & Follow-up care rather than adjuvant therapy & 14 & \\
\hline \multirow[t]{4}{*}{ Hoskins (1997) } & \multirow{4}{*}{$\begin{array}{l}\text { Diagnosed with } \\
\text { breast cancer }\end{array}$} & Chemotherapy & $?$ & $?$ \\
\hline & & Radiation therapy & $?$ & $?$ \\
\hline & & Chemotherapy and radiation therapy & $?$ & $?$ \\
\hline & & No adjuvant treatment & $?$ & $?$ \\
\hline \multirow[t]{3}{*}{ Longman et al. (1997) } & \multirow[t]{3}{*}{ I-IV } & Chemotherapy & 32 & $26-80^{*}$ \\
\hline & & Radiation therapy & 18 & \\
\hline & & Hormone therapy & 15 & \\
\hline Berger (1998) & \multirow[t]{3}{*}{ | or II } & CMF & 26 & $33-69^{*}$ \\
\hline \multirow[t]{2}{*}{ Berger and Farr (1999) } & & Doxorubicin and cyclophosphamide (AC) & 20 & \\
\hline & & CAF & 26 & \\
\hline \multirow[t]{2}{*}{ Sitzia and Huggins (1998) } & \multirow{2}{*}{$\begin{array}{l}\text { Diagnosed wit0h } \\
\text { breast cancer }\end{array}$} & CMF & 21 & \multirow[t]{2}{*}{$30-72^{*}$} \\
\hline & & CMF and hormone (replacement) therapy & 31 & \\
\hline
\end{tabular}


Fatigue

prevalence, $\%$

$99 \%$

82-68-77-73

$86-67-74-76$

58-70-80-70

83

$70-77-79^{*}$

Unknown

89 (mean

incidence $)^{\star}$

\section{Main results}

Fatigue was one of the most frequently reported side effects and did not differ in incidence among the 3 drug regimens Fatigue was significant for time; however, no distinct clinical pattern of fatigue was apparent Fatigue was the most common as well as the most problematic side effect

8-26-35-22-14-1* Fatigue and emotional distress were the most persistent issues

Fatigue was the most frequent as well as the most problematic side effect over time

Levels of fatigue 48 hours after each of the first 3 chemotherapy treatments were not significantly different over time Fatigue scores were significantly different over time, with scores higher at treatments and lower at cycle midpoints (roller-coaster pattern) The most commonly reported problem was alopecia followed by fatigue Patients judged fatigue and nausea to be the most troublesome problems Mean severity of fatigue remained stable throughout the treatment cycles

\section{Limitation of the study}

No distinction made in breast cancer

treatment

Instruments: lack of reliability and validity

data

Timing of measurements doubtful

Small sample size

Sample sizes too small to compare results Only the first days (days 2 and 5 after the first 2 cycles) studied

Instrument: lack of reliability and validity data No distinction made in breast cancer treatment

Timing of measurements doubtful

Instrument: lack of reliability and validity data No distinction made in breast cancer treatment

No distinction made between patients still receiving treatment and patients having completed treatment Instrument: lack of reliability and validity data No distinction made in breast cancer treatment

No distinction made between patients still receiving treatment and patients having completed treatment

Timing of measurements doubtful

Small sample size

Small sample size

Small sample size

Retrospective design may have biased findings 


\section{Chapter 2}

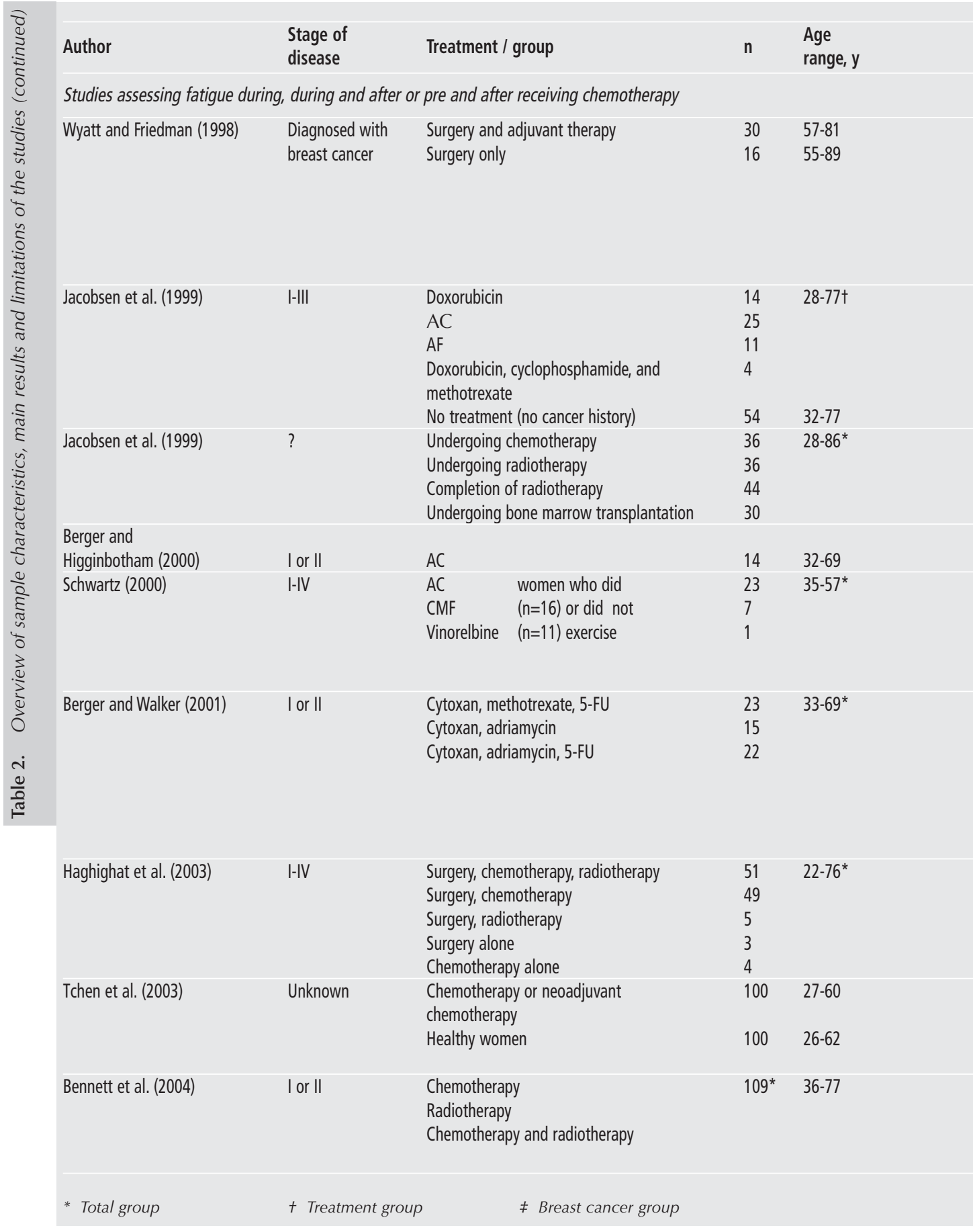


Fatigue

70-53-56

$44-32-38$

72-92-94-91†

Unknown

Unknown

49

Unknown
Unknown

Unknown

37 prevalence, $\%$

\section{Main results}

Fatigue and pain were the most

frequently reported symptoms in both groups Women reported relatively low levels of severity of fatigue; symptom did not improve over time

Patients with breast cancer experienced worse fatigue than women with no cancer history Fatigue worsened among patients after treatment started, but did not increase further over the first 3 treatment cycles

Catastrophizing was significantly related to greater fatigue intensity

Moderate fatigue identified

After chemotherapy a sharp rise in fatigue

Several women had a chaotic pattern

Women who did not exercise experienced more bad days (greater fatigue) and fewer good days (less fatigue)

Symptom distress, chemotherapy protocol and interpersonal relations behaviours influenced fatigue at treatments Symptom distress from the previous treatment, physical function and social function and interpersonal relations behaviours influenced fatigue at cycle midpoints

In comparison to treatment factors, physical and psychological symptoms have a more important role in cancer-related fatigue Fatigue should be recognized and managed even before commencing breast cancer treatment

Unknown Patients experienced significant more fatigue than the controls

Fatigue had a profound effect on the quality of life of the patients

Fatigue and psychological distress were common

Those who reported fatigue were much more likely to report psychological symptoms

\section{Limitation of the study}

No distinction made in breast cancer

treatment

Sample sizes too small to compare results Sample relatively old (age 55 or older) No distinction made between patients still receiving treatment and patients having completed treatment

Samples sizes too small to compare results Patients flooded with questionnaires Diversity of the study makes it hard to get a clear overall impression

No distinction made in breast cancer treatment

Patients were studied during or after treatment

Small sample size

Small sample size

Small sample size

No distinction made in breast

cancer treatment

Patients were studied during or after

treatment

Patients were studied on different times during the treatment of chemotherapy No distinction is made in receiving chemotherapy and neoadjuvant chemotherapy No distinction made in breast cancer treatment Patients were studied during or after treatment 


\section{Chapter 2}

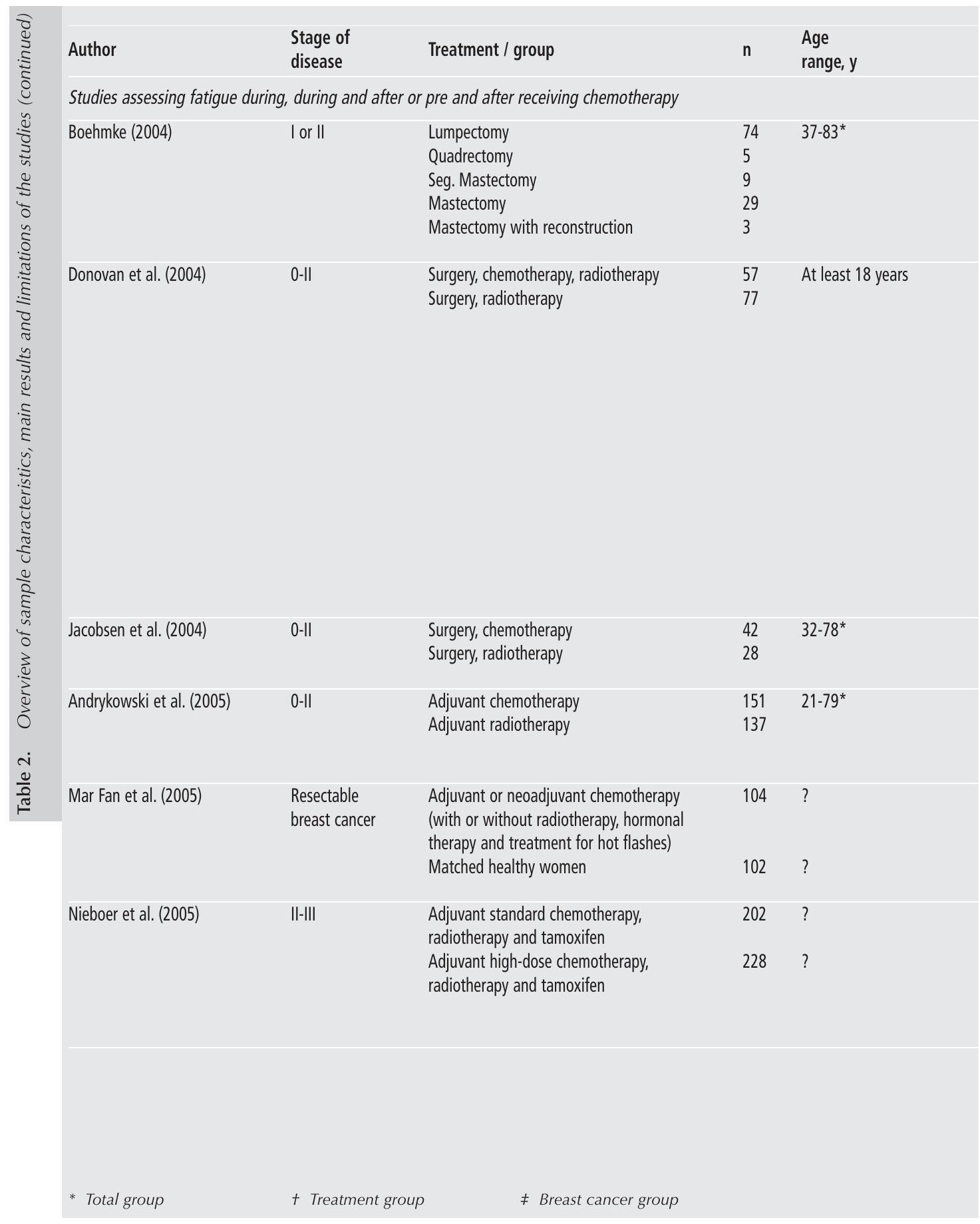




\begin{tabular}{|c|c|c|}
\hline $\begin{array}{l}\text { Fatigue } \\
\text { prevalence, } \%\end{array}$ & Main results & Limitation of the study \\
\hline Unknown & $\begin{array}{l}\text { Symptom distress scores were generally low } \\
\text { Fatigue is causing the greatest distress } \\
\text { Factors like, functioning, body image and } \\
\text { menopausal symptoms cited as contributors } \\
\text { to symptom distress level, but were not measured } \\
\text { which could account for low scores }\end{array}$ & $\begin{array}{l}\text { Measurements only during one cycle of } \\
\text { chemotherapy } \\
\text { No distinction made in breast cancer } \\
\text { treatment }\end{array}$ \\
\hline Unknown & $\begin{array}{l}\text { Women who received chemotherapy as their } \\
\text { initial type of treatment reported greater } \\
\text { fatigue than women who received radiotherapy } \\
\text { as their initial treatment } \\
\text { Women who did not have pre-treatment with } \\
\text { chemotherapy experienced increased fatigue over } \\
\text { the course of radiotherapy, whereas women } \\
\text { pre-treated with chemotherapy did not } \\
\text { The authors reported that chemotherapy is } \\
\text { associated with more severe fatigue than } \\
\text { radiotherapy } \\
\text { The authors suggest a response shift or a change } \\
\text { in internal standards, in women's perceptions of } \\
\text { fatigue as a function of prior chemotherapy } \\
\text { treatment }\end{array}$ & $\begin{array}{l}\text { Only three times during chemotherapy and } \\
\text { during radiotherapy were assessed } \\
\text { Fatigue severity during two cycles of } \\
\text { chemotherapy is not measured }\end{array}$ \\
\hline Unknown & $\begin{array}{l}\text { Catastrophizing demonstrated relationships } \\
\text { with fatigue severity and disruptiveness for RT } \\
\text { patients but not for CT patients }\end{array}$ & $\begin{array}{l}\text { Measurements are at the start and at the } \\
\text { end, not during the treatment }\end{array}$ \\
\hline $\begin{array}{l}10-26^{*} \text { met } \\
\text { criteria for Cancer- } \\
\text { Related Fatigue } \\
\text { (CRF) }\end{array}$ & $\begin{array}{l}\text { CRF is experienced before initiation of adjuvant } \\
\text { therapy and post-treatment } \\
\text { CRF has a multifactorial etiology }\end{array}$ & $\begin{array}{l}\text { Measurements are at the start and at the } \\
\text { end, not during the treatment }\end{array}$ \\
\hline$?$ & $\begin{array}{l}\text { In all assessments patients receiving } \\
\text { chemotherapy experienced significantly more } \\
\text { fatigue than the controls }\end{array}$ & Timing of measurements doubtful \\
\hline$?$ & $\begin{array}{l}\text { Chemotherapy patients experienced } \\
\text { improvements over the } 2 \text {-year period }\end{array}$ & \\
\hline $19-19-17-19$ & $\begin{array}{l}\text { Fatigue was reported in } 20 \% \text { of } 430 \\
\text { assessable patients }\end{array}$ & $\begin{array}{l}\text { Measurements are at the start and } \\
\text { at the end, not during the treatment }\end{array}$ \\
\hline $16-21-21-22$ & $\begin{array}{l}\text { Fatigue in both groups did not change } \\
\text { over time and no statistical difference were } \\
\text { found between the treatment groups } \\
\text { Mental health was the strongest fatigue predictor }\end{array}$ & $\begin{array}{l}\text { No distinction made in the different } \\
\text { treatments }\end{array}$ \\
\hline
\end{tabular}




\section{Chapter 2}

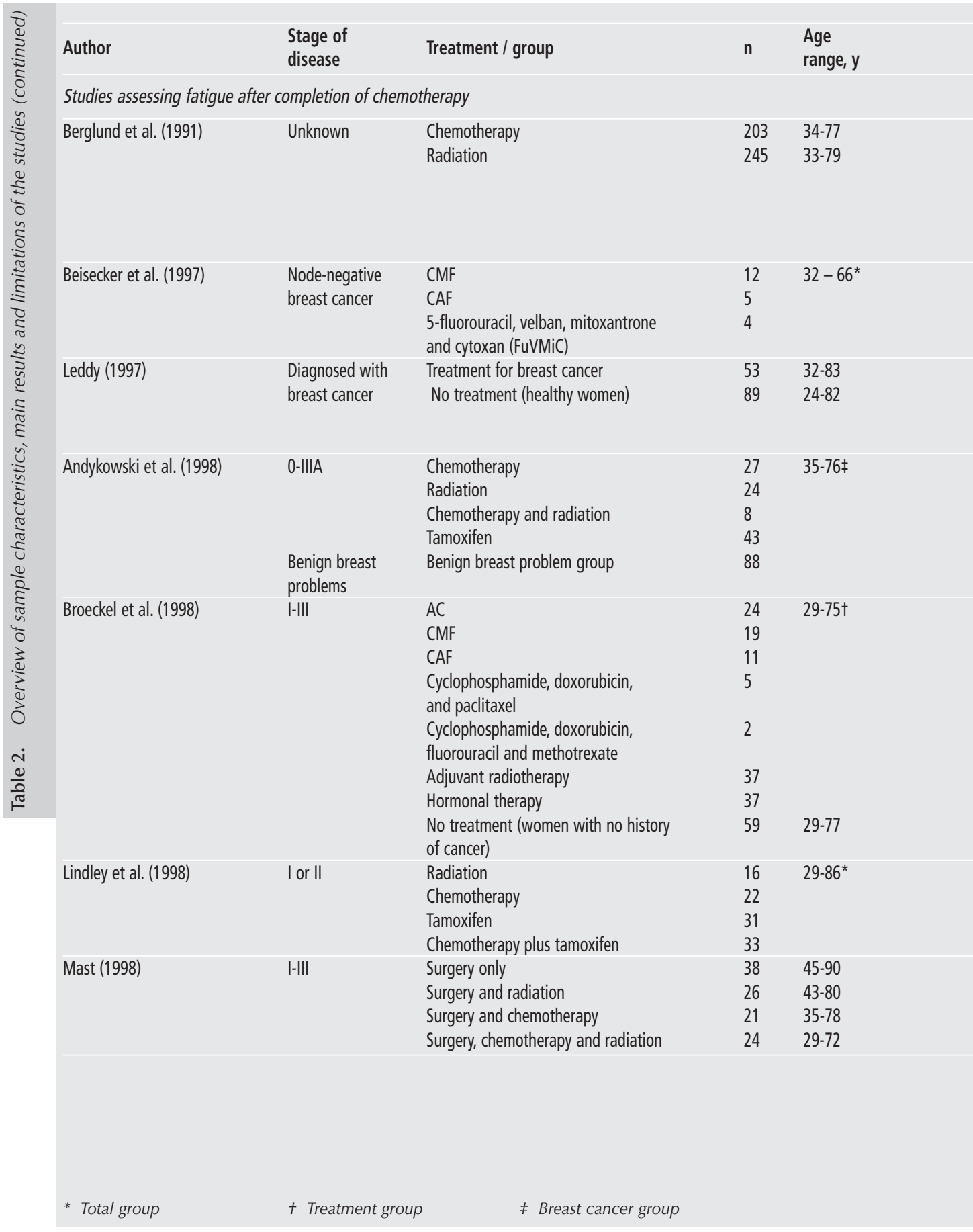




$\begin{array}{ll}\begin{array}{l}\text { Fatigue } \\ \text { prevalence, \% }\end{array} & \text { Main results } \\ 68 & \begin{array}{l}\text { No support for the hypothesis that } \\ \text { chemotherapy would lead to more severe late } \\ \text { consequences than radiotherapy } \\ \text { Fewer than } 10 \% \text { reported severe symptoms } \\ \text { No significant difference (chemo vs radio) in } \\ \text { reported fatigue }\end{array}\end{array}$

$95-83^{*}$

Unknown No significant differences between the 2 groups in health, fatigue and symptom experience

$\begin{array}{ll}\text { Unknown } & \begin{array}{l}\text { Breast cancer group reported more } \\ \text { fatigue, more weakness and less vitality } \\ \text { relative to benign breast problem group }\end{array} \\ \text { Unknown } & \begin{array}{l}\text { Women with no history of cancer reported } \\ \text { more severe fatigue }(p<0.01) \text { and worse } \\ \text { quality of life because of fatigue }(p<0.05) \\ \text { than former adjuvant chemotherapy patients }\end{array}\end{array}$

$31 \quad$ Most commonly reported moderate to (moderate severe symptom was fatigue

to severe) ${ }^{*} \quad$ Less than one third of patients reported moderate to severe symptoms

Unknown Intensity of fatigue low to moderate

\section{Limitation of the study}

Instrument: lack of reliability and validity data Range in periods after treatment too large

Instrument: lack of reliability and validity data Small sample size

No distinction made in breast cancer treatment Range in periods after treatment too wide Samples not equal in size No distinction made in breast cancer treatment

Retrospective design may have biased findings

Timing of measurements doubtful

No distinction made in breast cancer treatment
No distinction made in breast cancer treatment

Range in periods after treatment too wide

Instrument: lack of reliability and validity data No distinction made in breast cancer treatment

Range in periods after treatment too wide 


\section{Chapter 2}

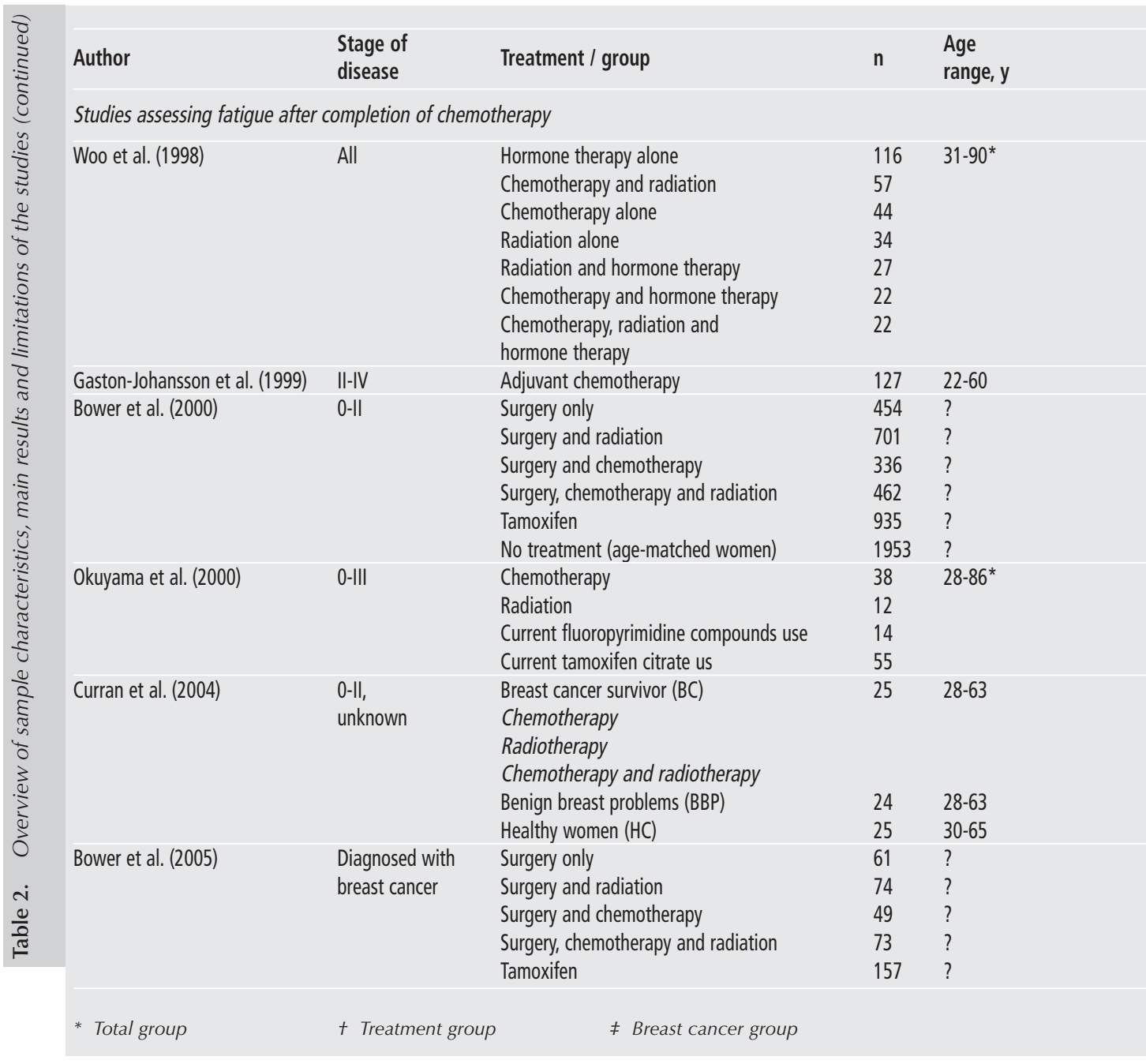

in their study of 54 patients with breast cancer who were receiving adjuvant chemotherapy. Patients had to complete the Memorial Symptom Assessment Scale (MSAS) in the clinic immediately before the start of each of the first 4 chemotherapy cycles. The MSAS assesses symptoms commonly associated with cancer and its treatment in terms of their prevalence, severity and distress. Fatigue increased after the start of chemotherapy but did not increase further during the first 3 treatment cycles. The prevalence rates of fatigue at the 4 measurement points were $72 \%, 92 \%, 94 \%$ and $91 \%$, respectively. Their study also compared patients with breast cancer with women with no cancer history using the Fatigue 


\begin{tabular}{|c|c|c|}
\hline $\begin{array}{l}\text { Fatigue } \\
\text { prevalence, \% }\end{array}$ & Main results & Limitation of the study \\
\hline Unknown & Fatigue varies with type of cancer therapy & $\begin{array}{l}\text { No distinction made in breast cancer } \\
\text { treatment } \\
\text { Factors such as depression and menopausal } \\
\text { status may have contributed to fatigue, but } \\
\text { were not analyzed }\end{array}$ \\
\hline 91 & Overall: low to moderate levels of fatigue & Timing of measurements doubtful \\
\hline Unknown & $\begin{array}{l}\text { Survivors not more fatigued than } \\
\text { an age-matched group of women }\end{array}$ & $\begin{array}{l}\text { No distinction made in breast cancer } \\
\text { treatment }\end{array}$ \\
\hline $56^{*}$ & - & $\begin{array}{l}\text { No distinction made in breast cancer } \\
\text { treatment } \\
\text { Range in periods after treatment too wide }\end{array}$ \\
\hline Unknown & $\begin{array}{l}\mathrm{BC} \text { reported greater levels of fatigue relative } \\
\text { to } \mathrm{BBP} \text { and } \mathrm{HC} \text { groups } \\
\text { No group difference in mood, activity type } \\
\text { or level, sleep duration, or diurnal pattern } \\
\text { of fatigue were evident }\end{array}$ & $\begin{array}{l}\text { The off-treatment period of the } B C \\
\text { and the BBP group is not comparable } \\
\text { No distinction is made in breast cancer } \\
\text { treatment } \\
\text { Small sample size }\end{array}$ \\
\hline $35-34^{*}$ & $\begin{array}{l}\text { Many years after cancer diagnosis } \\
\text { fatigue continues to be a problem } \\
\text { for breast carcinoma survivors } \\
\text { Approximately } 21 \% \text { reported fatigue at } \\
\text { both measurements points }\end{array}$ & $\begin{array}{l}\text { No distinction made in breast cancer } \\
\text { treatment }\end{array}$ \\
\hline
\end{tabular}

Scale from the Profile of Mood States (POMS-F) and the Fatigue Symptom Inventory (FSI). The patients completed these questionnaires at home on 3 occasions: before the start of chemotherapy, between the second and third cycles, and between the third and fourth cycles. The noncancer comparison subjects who agreed to participate were mailed the POMS-F and FSI 3 times, at 3- to 6week intervals. Women receiving adjuvant chemotherapy for breast cancer experienced significantly worse fatigue than the age-matched comparison group of women with no cancer history. Jacobsen et al. [24] used 3 measuring instruments for fatigue and assessed data at 7 measurement points. The use of a 


\section{Chapter 2}

control group in this study strengthens its validity and enhances the comparison of results. The large number of questionnaires administered to patients may, however, have led to inaccurate and incomplete information because respondents may have become tired of answering so many questionnaires, which is known to adversely influence the results.

In a more recent study of Jacobsen et al. [25], the authors revealed that the level of fatigue severity reported by the average patient with breast cancer following the start of chemotherapy can be characterized as moderate. In the study of Andrykowski et al. [26] 10\% of 288 women reported cancer related fatigue (CRF) before adjuvant therapy (chemotherapy or radiotherapy). At posttreatment the CRF prevalence was $26 \%$. Sixty patients $(21 \%)$ were incident cases of CRF, a relatively large sample. Nieboer et al. [27] reported similar results. They found that fatigue was reported in $20 \%$ of 430 assessable patients with at least a 3-year follow-up. Fatigue did not change over time or differ between the treatment arms. Fatigue was assessed before and 1, 2, and 3 years after chemotherapy (standard or high-dose).

\section{Studies with unclear timing of measurements relative to that of administration of chemotherapy}

Haghighat et al. [28] studied 112 patients with breast cancer. The assessment for patients receiving chemotherapy was scheduled after three cycles of chemotherapy, while patients off treatment were assessed at least 2 weeks after completion their treatment [28]. Overall 49\% reported fatigue to some degree (from quite a bit to very much). Bennett et al. [29] found a rate of $37 \%$. The authors included patients with breast cancer who were receiving treatment or had completed treatment, which can be seen as a limitation [29].

Longman et al. [30] studied side effects in 307 women receiving treatment for breast cancer. They found fatigue to be the most common (83\%) as well as the most problematic side effect. The Side Effects Checklist used in this study consisted of 16 common side effects of breast cancer treatment and was developed during a pilot study among 24 women who each cited specific side effects experienced after 2 to 4 weeks of adjuvant therapy and again 6 weeks later. A limitation of this checklist is the lack of reliability and validity data. The prevalence rate of fatigue was assessed without distinguishing between the types of treatment patients underwent, and a combination of treatments could have influenced the experience of fatigue and therefore biased the results. Likewise, the timing of the measurements in this cross-sectional study was doubtful, with measurements performed at a designated point in time after the start of medical treatment to allow for the appearance of treatment-related side effects. It is difficult, sometimes even 
impossible, to determine such a designated point. Longman et al. [31] subsequently extended their study with a longitudinal design in which 53 of the 307 respondents were interviewed during a 4- to 5 -months period. Data were collected at 3 points: a designated point in time after the medical treatment had started to allow for the appearance of treatment-related side effects, then 6 to 8 weeks later, and again 3 months later. They found prevalence rates of fatigue at the points of $70 \%, 77 \%$ and $79 \%$, respectively. Despite its limitations, the longitudinal design of this study reveals more details about the prevalence rate of fatigue. It appears to indicate that more patients experience fatigue with time. Hoskins [32] also studied side effects in a longitudinal design. Data were collected from 93 women diagnosed with breast cancer at 6 points in time: 7-10 days, 1 month, 2 months, 3 months, 6 months and 1 year after surgery. In this study, fatigue was one of the most prominent side effects. The investigators developed their own checklist, the Treatment Recovery Inventory, whose content validity was only verified by one clinical oncology nurse, making its value doubtful. The prevalence values of fatigue at the 6 data collection points were $8 \%, 26 \%, 35 \%, 22 \%, 14 \%$, and $1 \%$, respectively. Just as in the study by Longman [31], a limitation of this study was the lack of clarity on fatigue and the timing of the chemotherapy.

Wyatt and Friedman [33] investigated the patterns of functional and psychosocial adjustment of midlife and older women after surgery for breast cancer. They compared women who received follow-up adjuvant therapy $(\mathrm{n}=$ $30)$ with those who did not $(n=16)$. The presence and severity of the symptoms were measured at 3 time points after surgery ( 6 weeks, 3 months, 6 months). Fatigue and pain were the most frequently reported symptoms in both groups. In the group with adjuvant treatment, $70 \%$ of the patients experienced fatigue after 6 weeks, 53\% after 3 months, and 56\% after 6 months. In the surgeryonly group the corresponding percentages were $44 \%, 32 \%$, and $38 \%$, respectively. Women reported relatively low levels of severity of fatigue and this symptom did not improve over time. Differences between the two groups were not analysed because of small sample sizes. The study by Wyatt and Friedman [33] and the study by Hoskins [32] shared two of their measurement points: 3 months and 6 months after surgery. Nevertheless, their findings were very different, which may have been caused by the different measuring instruments and age ranges of the populations.

Tchen et al. [34] studied patients with breast cancer who were receiving adjuvant chemotherapy or neoadjuvant chemotherapy before scheduled surgery. A control group of healthy women was also studied. Patients with breast cancer who were receiving adjuvant chemotherapy experienced much more fatigue than healthy controls [34]. Mar Fan et al. [35] found a similar result. Also in this 


\section{Chapter 2}

study the patients receiving chemotherapy experienced significantly more fatigue than healthy controls. Chemotherapy patients experienced improvements in fatigue over the 2-year period.

\section{Studies with measurements within two cycles of chemotherapy}

Berger [22] found that reported fatigue intensities were significantly lower at the midpoint of each cycle than they were 48 hours after each of the first 3 treatments. Berger called this development of intensity the roller-coaster pattern. A recent study by Schwartz [36] among 31 patients with breast cancer had a similar result. Patients who did or did not exercise were asked to record the fatigue they experienced in a diary during 3 cycles of chemotherapy. The most common pattern was a rapid increase in the first 24 to 48 hours after chemotherapy, although several women demonstrated a chaotic pattern of fatigue, with erratic and wide swings.

In the side effects study by Greene et al. [37], 86 patients with breast cancer recorded the incidence and severity of side effects 2 and 5 days after the administration of the first and second cycles of chemotherapy [28]. The authors used a self-care diary to collect patient-reported side effects for 3 chemotherapy regimens for breast cancer (Table 2). Fatigue was the most frequently reported side effect. The percentage of patients experiencing fatigue varied from $58 \%$ to $86 \%$ (Table 2 ), and the mean severity scores for those who experienced fatigue indicated mild to moderate severity. The incidences did not differ for the 3 drug regimens. Greene et al. [37] did not find a distinct clinical pattern of fatigue, although fatigue was significant for time. A reason for not finding any pattern may have been the choice of the measurement points, which may have been too close together in time to reveal any effect. If the purpose of the study was to describe the pattern of fatigue within 2 cycles of chemotherapy, they would probably have had to cover a longer and/or different period of time. The study also had several other limitations: a relatively small sample size was evaluated and subjects were not randomized into the treatment regimens.

\section{Fatigue after completion of chemotherapy}

Gaston-Johansson et al. [38] studied 127 patients with breast cancer who had undergone mastectomy, had completed chemotherapy, and were scheduled for autologous bone marrow/peripheral blood stem cell transplant. The prevalence rate of fatigue was $91 \%$ as measured by the Fatigue Visual Analogue Scale (VAS). Participants reported low to moderate levels of fatigue. A limitation of this study was that no data were collected on the length of time between chemotherapy completion and the assessment of fatigue. 
Mast [39] studied fatigue in 109 survivors of breast cancer 1 to 6 years after treatment and found that they experienced low to moderate fatigue. The authors did not report figures on the incidence of fatigue. Fatigue was measured by a single item in the revised version of the Symptom Distress Scale (SDS): a linear analogue self-assessment scale. The reliability and validity of this item as a measure have not been assessed. Other limitations of this study are the wide range of periods after treatment and that the pattern, consistency, and intensity of fatigue over time were not evaluated.

Lindley et al. [40] used the semantic version of the SDS in 86 patients with breast cancer who had survived for 2 to 5 years after the initiation of adjuvant cytotoxic and/or hormonal therapy. Sixteen of these patients had undergone radiation therapy. The most commonly reported moderate to severe symptom was fatigue $(31.4 \%)$, followed by insomnia $(23.3 \%)$, worsening appearance $(14.0 \%)$, and altered bowel function (11.6\%). Berglund et al. [41] studied patients over an even wider range of periods after treatment for breast cancer. They reported prevalence rates in patients with breast cancer who were free of recurrence 2 to10 years after treatment. Sixty-eight percent of the patients who had received adjuvant chemotherapy perceived fatigue, compared with $76 \%$ of the postoperative radiotherapy patients. No significant differences were found between the two groups in the reported frequencies of fatigue. This self-made instrument, a symptom list with 32 items, was not tested for reliability or validity, making the results difficult to interpret.

Okuyama et al. [42] studied 134 disease-free patients with breast cancer $786 \pm 463$ (SD) days after surgery, and found a prevalence rate of fatigue of $56 \%$. Unlike Okuyama et al. [42], Leddy [43] did a comparative study, that found no significant differences in fatigue between women who had been treated for breast cancer within the past 10 years $(n=53)$ and healthy women $(\mathrm{n}=89)$. Fatigue was assessed using the Fatigue Experience Scale, which has been sufficiently tested for validity and reliability. In this study, the women treated for breast cancer were significantly older than the control group, and the two sample sizes were unequal. The influence of these differences on the fatigue data is unclear.

Broeckel et al. [44] also compared two groups, 1 of 61 women who had completed an average of 471 days of adjuvant chemotherapy and 1 of 59 women with no history of cancer. Results indicated that the former chemotherapy patients reported more severe fatigue as measured by the POMS-F than the noncancer comparison subjects. In addition, the former chemotherapy patients reported higher levels of current fatigue as measured by the Fatigue Symptom Inventory (FSI) and scored significantly higher on the general, physical and mental 


\section{Chapter 2}

subscales of the Multidimensional Fatigue Symptom Inventory (MFSI). A limitation of the study is that there was no control group of patients with other forms of breast cancer treatment besides adjuvant chemotherapy, which may have influenced the differences in fatigue.

Curran et al. [45] did also a comparative study examining the diurnal pattern of off-treatment fatigue in survivors of breast cancer, women with benign breast problems, and an age-matched group of healthy women. The participants of the study completed a daily diary at four specific times each day during 5 consecutive days. The group with survivors of breast cancer reported greater fatigue throughout the day than the two other groups. Data suggest that fatigue levels can continue to be elevated long after completion of adjuvant therapy. In the diurnal pattern of fatigue evidenced by the group with survivors of breast cancer, relative to the two other groups no difference was observed. An identical U-shaped pattern of fatigue ratings across the course of the day was found [45].

Bower et al. [46] compared 1,957 survivors of breast cancer at an average of 3 years after initial breast cancer diagnosis with age-matched women $(\mathrm{n}=$ 1,953) from a general population, using the energy/fatigue scale of the RAND Health Survey. The majority of survivors of breast cancer did not experience increased levels of fatigue relative to women in the general population. A strong methodological aspect of this study is the large sample size, although its value is limited by its cross-sectional design. In another study of Bower [47], a longitudinal study, approximately $21 \%$ of a sample of 763 breast carcinoma survivors reported fatigue at both assessment points (1-5 years and 5-10 years after diagnosis). Beisecker et al. [48] studied 21 patients with node-negative breast cancer who had undergone adjuvant chemotherapy; they also made two assessments, one shortly after the completion of adjuvant chemotherapy and one 6 months later. The prevalence rates of fatigue at these two moments were $95 \%$ and $83 \%$, respectively. Although the researchers did not study the course of the severity of fatigue, the study found that fewer patients experienced fatigue at the second assessment moment. The research team had developed the interview protocol themselves, and its reliability and validity had not been demonstrated. The small sample size was justified by the researchers by their desire to limit the sample to node-negative patients with breast cancer. 
These studies are difficult to compare because of the differences in the timing and number of measurements, instruments, populations, sample sizes and treatments. In summary, high prevalence rates were found during as well as after the administration of adjuvant chemotherapy. The intensity of fatigue seems to have been stable throughout the treatment cycles, although the first two days after a chemotherapy treatment seem to be the worst period.

\section{Factors relating to fatigue}

The actual mechanisms that produce fatigue are unknown $[6,49]$. The most reasonable approach is to consider multiple factors. Numerous factors have been found to influence fatigue, including demographic factors, disease/ physical factors, treatment factors and symptoms. Tables 1 and 2 present specific details of the studies. An overview of the factors relating to fatigue is shown in Tables $3 \mathrm{a}$ and $3 \mathrm{~b}$. Figure 1 presents a model of fatigue and its related factors based on the literature.

\section{Demographic factors}

Mast [39], Jacobsen et al. [24], Haghighat et al. [28], Donovan et al. [23], and Jacobsen et al. [25] found no significant relationship between fatigue and age. Woo et al. [51] found that younger women experienced significantly higher fatigue levels than older women. They investigated the differences in fatigue for different treatment methods in 322 survivors of breast cancer, who had received their treatment within the last 18 months. Bower et al. [46] also found a negative association between fatigue and age. The results showed that women in the group that was fatigued were slightly younger, had a lower annual income, and were less likely to be married or in a significant relationship than those in the nonfatigued group. This study did not find ethnicity, educational attainment and employment status to be associated with fatigue. In a study of Haghighat et al. [28], marital status and educational level were no significant predictors of fatigue. Jacobsen et al. [25] found also no significant correlation between fatigue and marital status, but a lower educational level was significantly associated with higher fatigue scores at the pre-treatment assessment. At the follow-up assessment, educational level also demonstrated a marginally significant negative correlation with fatigue [25]. Both, income and ethnicity were not related to fatigue [25]. 


\section{Chapter 2}

\begin{tabular}{|c|c|c|c|c|c|}
\hline Author $\rightarrow$ & $\begin{array}{l}\text { Pre and after } \\
\text { chemotherapy } \\
\text { Andrykowski } \\
\text { et al. } \\
\text { (2005) }\end{array}$ & $\begin{array}{c}\text { Pre and after } \\
\text { chemotherapy } \\
\text { Nieboer } \\
\text { et al. } \\
\text { (2005) }\end{array}$ & $\begin{array}{l}\text { Pre and during } \\
\text { chemotherapy } \\
\text { Jacobsen } \\
\text { et al. } \\
\text { (2004) }\end{array}$ & $\begin{array}{c}\text { During } \\
\text { chemotherapy } \\
\text { Blesch } \\
\text { et al. } \\
\text { (1991) }\end{array}$ & $\begin{array}{c}\text { During } \\
\text { chemotherapy } \\
\text { Berger } \\
\text { and Farr } \\
\text { (1999) }\end{array}$ \\
\hline \multicolumn{6}{|l|}{ Demographic } \\
\hline Age & & & 0 & & \\
\hline Marital status & & & 0 & & \\
\hline Income & & & 0 & & \\
\hline Ethnicity & & & 0 & & \\
\hline Educational attainment & & & $-\dagger / 0 \ddagger$ & & \\
\hline Employment status & & & & & \\
\hline \multicolumn{6}{|l|}{ Disease/physical } \\
\hline Stage of disease & & & 0 & & \\
\hline Haemoglobin level & & 0 & & & \\
\hline Duration of illness & & & & + & \\
\hline Biochemical factors & & & & 0 & \\
\hline Concurrent disease & & & & & \\
\hline Low level of activity & & & & & + \\
\hline Menopausal status & & 0 & 0 & & \\
\hline \multicolumn{6}{|l|}{ Symptoms } \\
\hline \multicolumn{6}{|l|}{ Symptom distress } \\
\hline \multicolumn{6}{|l|}{ Physical symptom distress } \\
\hline Pain & & & & + & \\
\hline Muscle and joint pain & & + & & & \\
\hline Sleeping problems & & & & & + \\
\hline \multicolumn{6}{|l|}{ Nausea } \\
\hline \multicolumn{6}{|l|}{ Mouth sores } \\
\hline \multicolumn{6}{|l|}{ Muscle weakness } \\
\hline \multicolumn{6}{|l|}{ Change in taste } \\
\hline \multicolumn{6}{|l|}{ Chills } \\
\hline \multicolumn{6}{|l|}{ Vomiting } \\
\hline \multicolumn{6}{|l|}{ Menopausal symptoms } \\
\hline \multicolumn{6}{|l|}{ Body mass } \\
\hline \multicolumn{6}{|l|}{ Dyspnea } \\
\hline \multicolumn{6}{|l|}{ Psychological symptom distress } \\
\hline \multicolumn{6}{|l|}{ Depression } \\
\hline \multirow{2}{*}{\multicolumn{6}{|c|}{$\begin{array}{l}\text { History of major depressive disorder } \\
\text { Poor mental health }\end{array}$}} \\
\hline & & + & & & \\
\hline \multicolumn{6}{|l|}{ Emotional upset } \\
\hline \multicolumn{6}{|l|}{ Anxiety } \\
\hline \multicolumn{6}{|l|}{ Adjustment or mood disorder } \\
\hline \multicolumn{6}{|l|}{ Positive mood } \\
\hline \multicolumn{6}{|l|}{ Negative mood } \\
\hline Illness uncertainty & & & & & \\
\hline
\end{tabular}




\begin{tabular}{|c|c|c|c|c|c|c|c|}
\hline $\begin{array}{c}\text { During } \\
\text { chemotherapy }\end{array}$ & $\begin{array}{c}\text { During } \\
\text { chemotherapy }\end{array}$ & $\begin{array}{c}\text { During } \\
\text { chemotherapy }\end{array}$ & $\begin{array}{c}\text { During } \\
\text { chemotherapy }\end{array}$ & $\begin{array}{c}\text { During } \\
\text { chemotherapy }\end{array}$ & $\begin{array}{c}\text { During } \\
\text { chemotherapy }\end{array}$ & $\begin{array}{l}\text { During \& after } \\
\text { chemotherapy }\end{array}$ & $\begin{array}{l}\text { During \& after } \\
\text { chemotherapy }\end{array}$ \\
\hline $\begin{array}{l}\text { Jacobsen } \\
\text { et al. JPSM } \\
\text { (1999) }\end{array}$ & $\begin{array}{l}\text { Jacobsen } \\
\text { et al. CRTC§ } \\
\text { (1999) }\end{array}$ & $\begin{array}{l}\text { Berger and } \\
\text { Higginbotham } \\
(2000)\end{array}$ & $\begin{array}{c}\text { Berger and } \\
\text { Walker } \\
\text { (2001) }\end{array}$ & $\begin{array}{l}\text { Tchen } \\
\text { et al. } \\
\text { (2003) }\end{array}$ & $\begin{array}{l}\text { Donovan } \\
\text { et al. } \\
\text { (2004) }\end{array}$ & $\begin{array}{l}\text { Haghighat } \\
\text { et al. } \\
\text { (2003) }\end{array}$ & $\begin{array}{c}\text { Mar Fan } \\
\text { et al. } \\
(2005)\end{array}$ \\
\hline
\end{tabular}

0

0

0

0

0

0

0 


\section{Chapter 2}

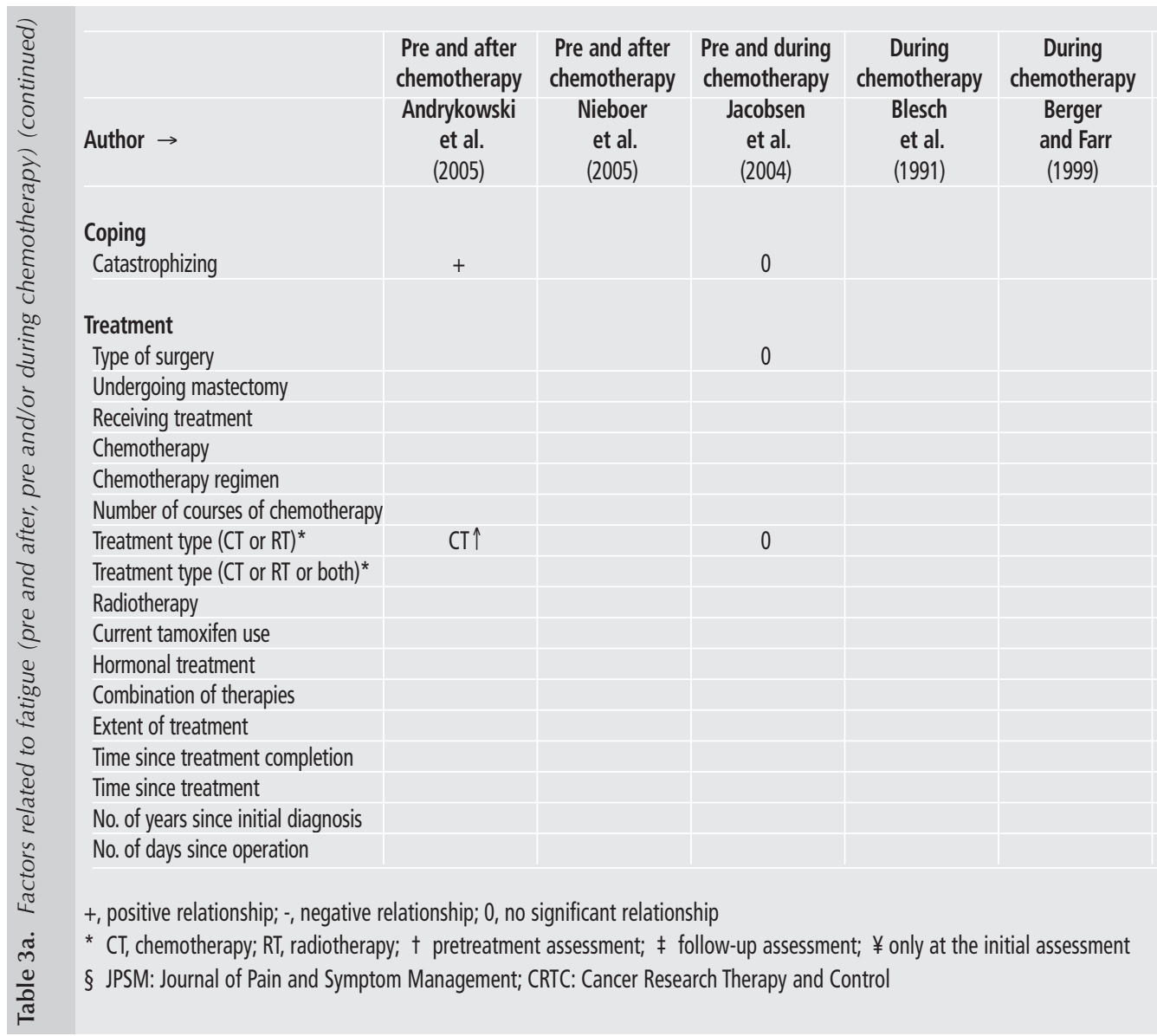

\section{Disease / physical factors}

Mast [39], Jacobsen et al. [24], Okuyama et al. [42], Haghighat et al. [28], Donovan et al. [23], and Jacobsen et al. [25] found no relationship between fatigue and stage of disease. Irrespective of the type of cancer treatment, concurrent illness was found to have a strongly positive relation with fatigue $[39,46]$. Bower et al. [46] specifically reported the correlation with chronic medical problems. The relationship between the two variables is not surprising, because the most common symptom of illness is fatigue [1]. Blesch et al. [52] reported a positive relationship between the duration of illness and fatigue in patients with breast cancer. Their results with respect to concurrent illness are corroborated by the findings by Gaston-Johansson et al. [38] and Berger and Higginbotham [53]. Gaston-Johansson et al. [38] undertook a correlational study of 127 women with breast cancer who had undergone mastectomy and 


\begin{tabular}{|c|c|c|c|c|c|c|c|}
\hline $\begin{array}{l}\text { During } \\
\text { chemotherapy }\end{array}$ & $\begin{array}{c}\text { During } \\
\text { chemotherapy }\end{array}$ & $\begin{array}{c}\text { During } \\
\text { chemotherapy }\end{array}$ & $\begin{array}{c}\text { During } \\
\text { chemotherapy }\end{array}$ & $\begin{array}{c}\text { During } \\
\text { chemotherapy }\end{array}$ & $\begin{array}{c}\text { During } \\
\text { chemotherapy }\end{array}$ & $\begin{array}{l}\text { During \& after } \\
\text { chemotherapy }\end{array}$ & $\begin{array}{l}\text { During \& after } \\
\text { chemotherapy }\end{array}$ \\
\hline $\begin{array}{l}\text { Jacobsen } \\
\text { et al. JPSM§ } \\
\text { (1999) }\end{array}$ & $\begin{array}{l}\text { Jacobsen } \\
\text { et al. CRTC§ } \\
\text { (1999) }\end{array}$ & $\begin{array}{l}\text { Berger and } \\
\text { Higginbotham } \\
(2000)\end{array}$ & $\begin{array}{l}\text { Berger and } \\
\text { Walker } \\
\text { (2001) }\end{array}$ & $\begin{array}{l}\text { Tchen } \\
\text { et al. } \\
\text { (2003) }\end{array}$ & $\begin{array}{l}\text { Donovan } \\
\text { et al. } \\
\text { (2004) }\end{array}$ & $\begin{array}{l}\text { Haghighat } \\
\text { et al. } \\
\text { (2003) }\end{array}$ & $\begin{array}{l}\text { Mar Fan } \\
\text { et al. } \\
(2005)\end{array}$ \\
\hline
\end{tabular}

0

0

0

$\mathrm{CT} \uparrow$

\begin{tabular}{l|l|l|}
+ & \\
\hline & \\
0 &
\end{tabular}

0

0

had completed chemotherapy, while Berger and Higginbotham [53] undertook a pilot study of 14 women with breast cancer to examine the relationship between health status and fatigue. Both teams found a negative association between fatigue and health status, with patients with a better health status experiencing less fatigue. Jacobsen et al. [24] found the same negative association before the start of treatment. On the other hand, they found no relationship after the start of chemotherapy.

None of the biochemical factors, such as hemoglobin or white blood count, significantly influenced fatigue in the study by Blesch et al. [52]. They mentioned that the nonsignificant findings might have been caused because biochemical factors were abstracted from the medical record and were often not collected concurrently with the person's self-assessment of fatigue [52]. Tchen et al. [34] and Mar Fan et al. [35] found that the level of hemoglobin was 


\section{Chapter 2}

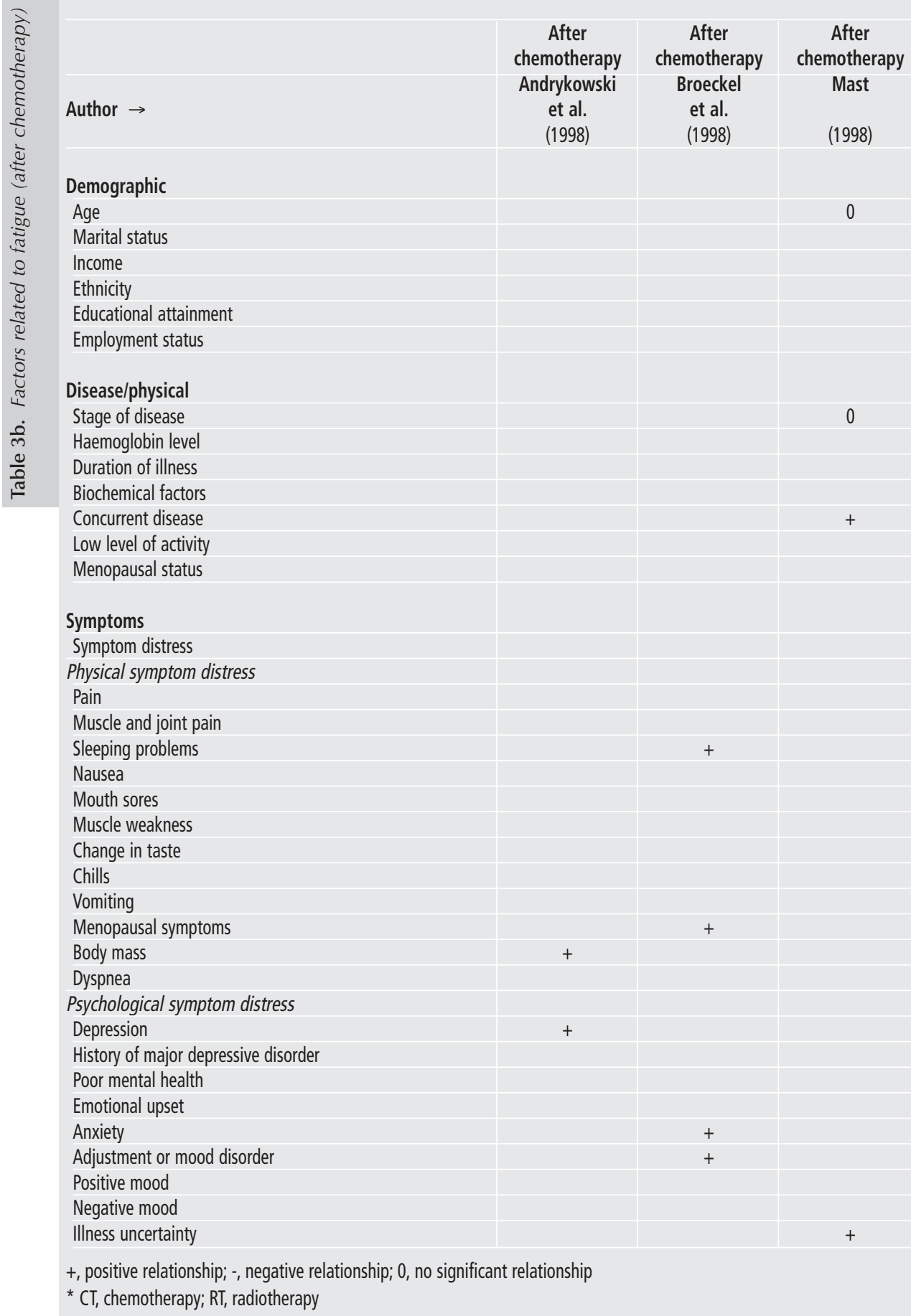




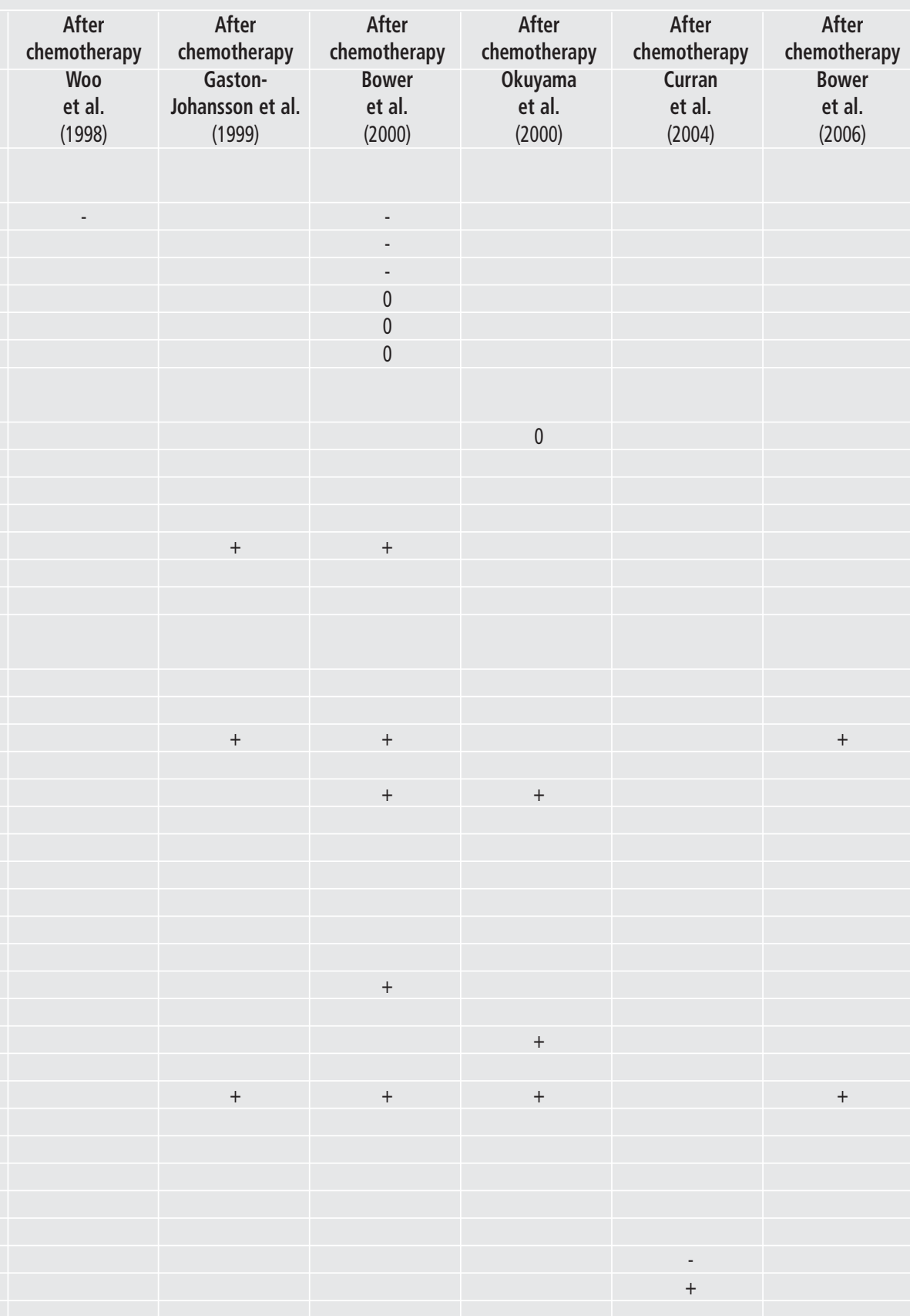




\section{Chapter 2}

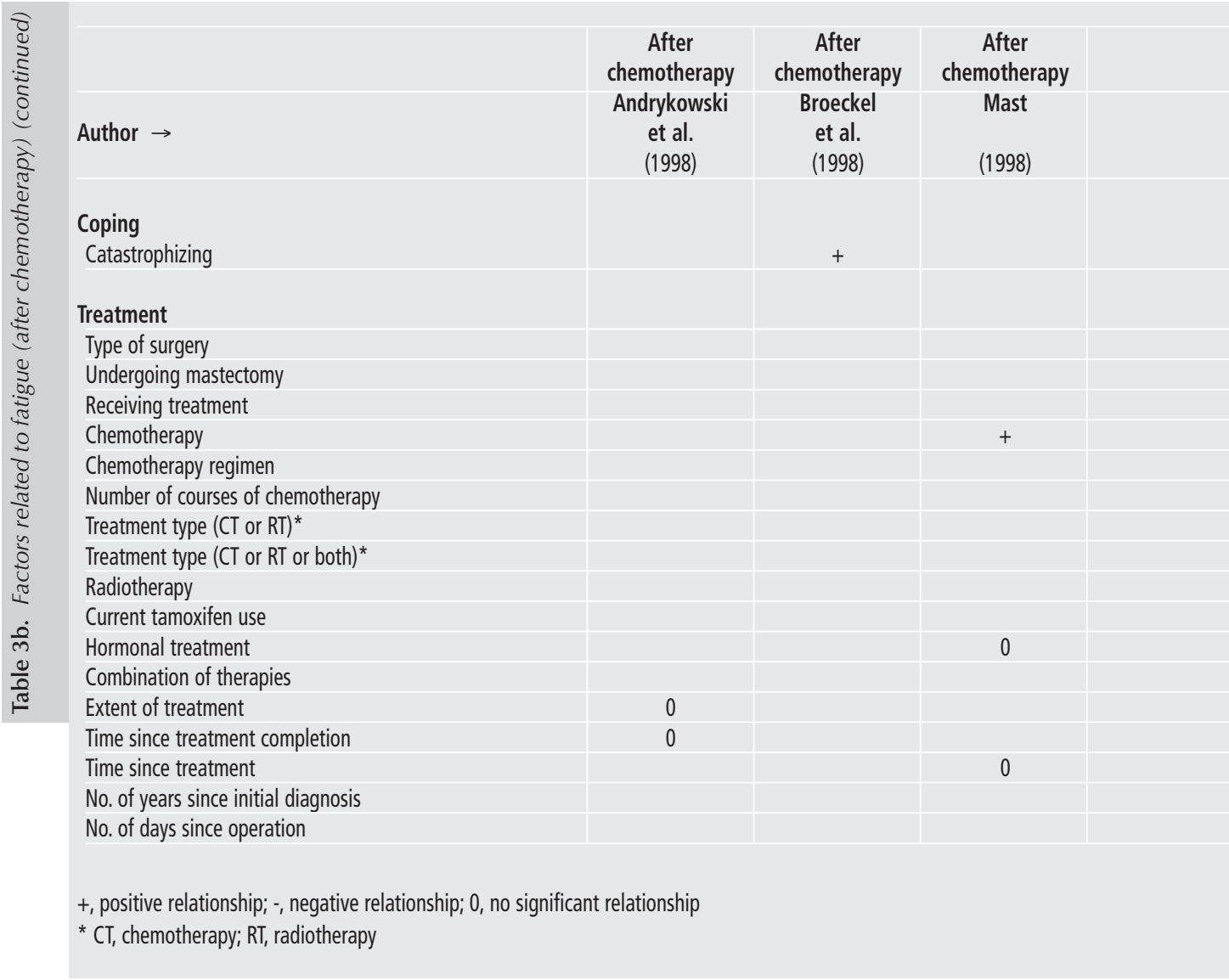

negatively associated with fatigue. On the other hand Nieboer et al. [27] did not find any relationship. No relationship was also found between menopausal status and fatigue $[23,25,27]$.

The study by Berger and Farr [54] supports the idea that daytime inactivity is associated with higher cancer-related fatigue. They studied the influence of daytime inactivity and nighttime restlessness in 72 patients with breast cancer during the first 3 chemotherapy cycles. Berger and Higginbotham [53] found similar results in their pilot study: there was a positive relation between lower activity rates and fatigue. Both studies found fatigue to be positively related to night-time restlessness.

\section{Treatment factors}

Jacobsen et al. [24], Donovan et al. [23], and Jacobsen et al. [25] concluded that fatigue was not influenced by the type of surgery (lumpectomy or mastectomy). In 


\begin{tabular}{|c|c|c|c|c|c|}
\hline $\begin{array}{c}\text { After } \\
\text { chemotherapy }\end{array}$ & $\begin{array}{c}\text { After } \\
\text { chemotherapy }\end{array}$ & $\begin{array}{c}\text { After } \\
\text { chemotherapy }\end{array}$ & $\begin{array}{c}\text { After } \\
\text { chemotherapy }\end{array}$ & $\begin{array}{c}\text { After } \\
\text { chemotherapy }\end{array}$ & $\begin{array}{c}\text { After } \\
\text { chemotherapy }\end{array}$ \\
\hline $\begin{array}{l}\text { Woo } \\
\text { et al. } \\
\text { (1998) }\end{array}$ & $\begin{array}{c}\text { Gaston- } \\
\text { Johansson et al. } \\
\text { (1999) }\end{array}$ & $\begin{array}{l}\text { Bower } \\
\text { et al. } \\
(2000)\end{array}$ & $\begin{array}{l}\text { Okuyama } \\
\text { et al. } \\
(2000)\end{array}$ & $\begin{array}{l}\text { Curran } \\
\text { et al. } \\
\text { (2004) }\end{array}$ & $\begin{array}{l}\text { Bower } \\
\text { et al. } \\
\text { (2006) }\end{array}$ \\
\hline
\end{tabular}

$+\quad 0$

both $\uparrow$

0

$0 \quad 0$

0

0

contrast, undergoing mastectomy was a significant predictor of fatigue in the study of Haghighat et al. [28]. Jacobsen et al. [24], Tchen et al. [34] and Mar Fan et al. [35] did not find any association between fatigue and chemotherapy regimens. Data provided by Mast [39] suggest that chemotherapy, with or without radiation therapy, is associated with long-term fatigue. Bower et al. [46] found similar results. They reported that women in the fatigued group were more likely to have been treated with a combination of chemotherapy and radiation therapy or with chemotherapy alone than those in the nonfatigued group. The latter group was more likely to have been treated with radiation alone or with surgery alone. This finding is corroborated by the results obtained by Okuyama et al. [42], who found no correlation between fatigue and radiation therapy. On the other hand, fatigue was not correlated with past intravenous chemotherapy in this study. Jacobsen et al. [25] and Haghighat et al. [28] have similar findings. Jacobsen et al. [25] reported no influence of type of treatment (chemotherapy or radiotherapy) on 


\section{Chapter 2}

fatigue and Haghighat et al. [28] found that variables including, receiving treatment, receiving chemotherapy and receiving radiotherapy were not significant predictors. Mar Fan et al. [35] did not find an association between fatigue and the variables 'adjuvant radiotherapy' and 'adjuvant hormonal

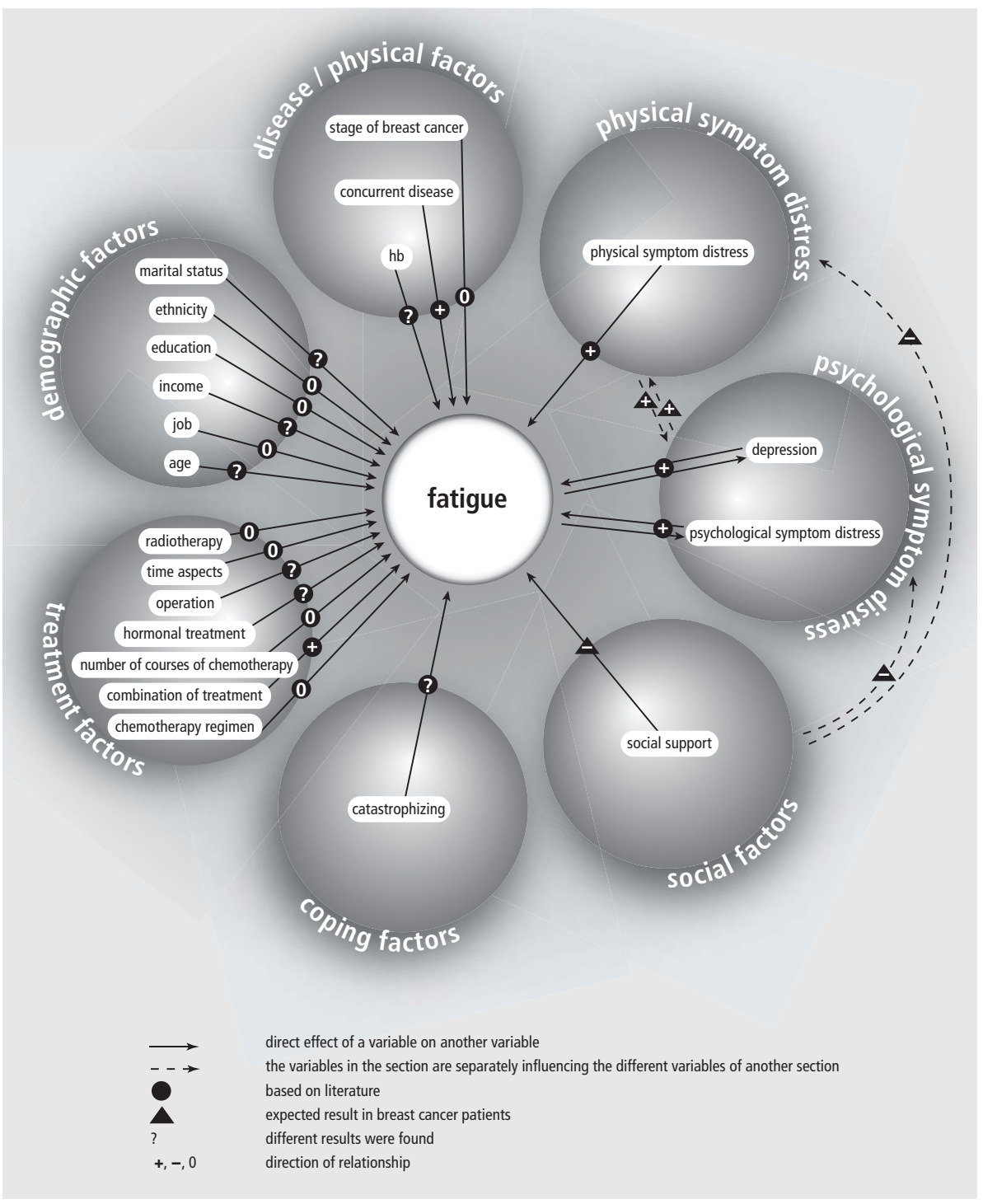

Figure 1. Model of fatigue and its relations based on literature 
therapy'. Contrary, Donovan et al. [23] found that fatigue in women with early stage breast cancer differs as a function of the type of treatment and sequencing of treatment. Women who received chemotherapy during initial treatment reported greater severity of fatigue than women receiving radiotherapy during initial treatment [23]. Andrykowski et al. [26] found similar results. Donovan et al. [23] also reported that women not pre-treated with chemotherapy experienced increased fatigue over the course of radiotherapy, whereas women pre-treated with chemotherapy did not. They believe the finding is consistent with research suggesting a response shift, or a change in internal standards [23]. Bower et al. [47] showed in their longitudinal off treatment study that women treated with either radiation or chemotherapy alone experienced a small improvement in fatigue compared with those treated with both radiation and chemotherapy. The studies by Mast [39], Bower et al. [46], and Okuyama et al. [42] and Mar Fan et al. [35] found no relationship between fatigue and hormonal treatment. On the other hand, in the study of Haghighat et al. [28] fatigue was predicted by current tamoxifen use. Recombinant human erythropoietin (rHuEPO), a red blood cell production stimulating hormone, is nowadays frequently used in cancer patients as a treatment of anemia and the thereby possible related symptom fatigue. In 2001 a meta-analysis of all randomised clinical trials (RCT) was executed in cancer patients with respect to rHuEPO efficacy [55]. The authors concluded that $\mathrm{rHuEPO}$ is able to heighten hemoglobin levels and to diminish the chance on transfusions in patients with hemoglobin levels $6.2 \mathrm{mmol} / \mathrm{l}$ and lower. Moreover, rHuEPO improved the quality of life for patients with hemoglobin levels 6.2 $\mathrm{mmol} / \mathrm{l}$ and lower. For patients with hemoglobin levels $6.0 \mathrm{mmol} / \mathrm{l}$ and higher results were not sufficiently evident [55]. Note that the studies on rHuEPO are executed in patients with different kinds of cancer.

A combination of treatments seems to increase the levels of fatigue, as was found in a study by Woo et al. [51]. They concluded that women who received combination therapy (combination of radiation, chemotherapy and hormone therapy) experienced significantly more fatigue than those who received radiation alone. Woo et al. [51] commented that this difference may have been affected by the disease stage and the treatment, because combination therapy is primarily used for women with advanced stages of breast cancer. Andrykowski et al. [56] did not find a relationship between fatigue and the type of treatment in the breast cancer group.

The influence of time on fatigue has not been thoroughly examined, although different periods of time after treatment or diagnosis have been studied. Andrykowski et al. [56] found that time since treatment completion did not appear to explain fatigue, and Mast [39] did not find a relationship between 


\section{Chapter 2}

fatigue and time since treatment either. The number of years since the initial diagnosis did not affect fatigue in the study by Bower et al. [46], and fatigue was not influenced by the number of days since operation in the study by Okuyama et al. [42]. Numbers of chemotherapy courses was not a significant factor in the studies of Tchen et al. [34] and Mar Fan et al. [35].

\section{Symptoms}

Berger and Higginbotham [53] found a correlation between greater levels of fatigue and more symptoms of distress. Fatigue and the symptoms accompany one another [57]. Most other studies have examined single associations between particular symptoms and fatigue.

\section{Physical symptom distress}

All retrieved manuscripts found a positive relationship between pain and fatigue $[24,27,28,38,45,46,52]$. Not unexpectedly, they also found a positive association between sleeping problems and fatigue [24, 42, 44, 46, 53, 54], except in the study of Haghighat et al. [28].

Okuyama et al. [42] found a positive association between fatigue and dyspnea, which they assumed might have been caused by the delayed effect of cancer treatment or by fear of recurrence, because there is evidence that dyspnea is associated with psychological status in a healthy population. On the other hand, Haghighat et al. [28] did not find a relationship between fatigue and dyspnea.

Andrykowski et al. [56] found that fatigue was positively correlated with body mass because women who were heavier experienced greater fatigue. Weight gain caused by chemotherapy-induced hyperphagia is the most popular theory. Other mechanisms that could explain weight gain are a reduction in physical activity, metabolic rate or thermogenesis [58].

Results on the influence of menopausal symptoms have not been unequivocal. Some researchers found that fatigue was significantly more severe among patients with more menopausal symptoms such as hot flushes and night sweats [34, 35, 44, 46]. Broeckel et al. [44] suggested that two mechanisms could contribute to increased fatigue in menopausal subjects. The increase in nighttime vasomotor symptoms and the menopausal symptoms could intensify depressive symptoms, including fatigue. On the other hand, Jacobsen et al. [24] found no association between fatigue and menopausal symptoms.

Jacobsen et al. [24] mentioned positive correlations between fatigue and some physical symptoms such as nausea, mouth sores, muscle weakness, change in taste, chills and vomiting. 


\section{Psychological symptom distress}

Like pain and sleeping problems, depression was found to correlate with fatigue in a number of studies [24, 28, 38, 42, 46, 47, 56]. Andrykowski et al. [26] found that patients with CRF were more likely to have a history of major depressive disorder. The relationship between the fatigue and depression is not unexpected, because one of the symptoms of depression is fatigue and chronic fatigue might be one of the causal factors of depression. Broeckel et al. [44] reported that pain and psychological distress are likely causes of sleep disturbance. This would imply that the variables pain, sleep problems and depression are interrelated.

Other positive relations between psychological symptoms and fatigue were found in the studies by Broeckel et al. [44], Haghighat et al. [28], Mast [39], Jacobsen et al. [24], Curran et al. [45] and Nieboer et al. [27]. Broeckel et al. [44] reported a relationship between fatigue and the variables anxiety and mood disorder. Haghighat et al. [28] also found a positive relationship between fatigue and anxiety. Mast [39] reported a positive relationship with illness uncertainty, and Jacobsen et al. [24] found a similar relationship with emotional upset. In the study of Curran et al. [45] positive and negative mood was significantly associated with fatigue.

The relation between two symptoms is difficult to define, because it is often not clear which symptom is the cause and which is the effect. Besides, some symptoms are inextricably linked.

\section{Social factors}

According to social support no specific literature was found about the relationship between this variable and fatigue in women with breast cancer. However many authors underline the positive influence of social support on well-being of people.

The author of an early study [59] had already reported that the uncertainties and fears experienced by a person diagnosed with cancer are likely to result in an enhanced need for social support. Nowadays, the importance of social relationships and social support for an individual's well-being has become common knowledge [60]. Van den Akker et al. [61] reported that involvement in more social networks seems to protect against morbidity. Social support is expected to have buffer effects, which means that social support protects people from the deleterious effects of stress [60]. Komproe et al. [60] reported that many researchers have underlined the relationship between social support and physical and psychological well-being. 


\section{Chapter 2}

\section{Coping factors}

McHaffie [62] reported that how well a person copes is central in determining his or her well-being, no matter how ill he or she is. The daily lives of almost every individual are filled with stressful experiences which require some form of coping [62]. The impact of each varies, because people are moving among their many roles and because these roles are changing [62]. Individuals with cancer must deal with the treatment process and its side effects, the uncertainty of the disease course and adapt to the changes in physical functioning and other negative life changes that are inevitably imposed by the disease [63]. Distinct coping behaviours and thought can influence outcomes [64], such as fatigue. Most researchers have focused on individual coping behaviours or thoughts [64]. Like Broeckel et al. [44], Jacobsen et al. [65] and Andrykowski et al. [26], they found a positive relation between fatigue and the use of catastrophizing as a coping strategy, which is characterized by negative selfstatements and negative thoughts and ideas about the future. In these studies women with breast cancer were examined. In another breast cancer study of Jacobsen et al. [25] no relationship was reported between these two variables.

A study [64] in women with stage II breast cancer receiving adjuvant chemotherapy showed that confrontive subjects reported significantly fewer side effects than avoidant-confrontive and avoidant-resigned copers. Confrontive copers reported more optimism, information seeking, and more willingness to be involved in treatment decisions.

Manne et al. [63] studied 43 women receiving adjuvant chemotherapy for breast cancer. They found that avoidant coping was associated with negative affect. In their study, escape-avoidance was described as behavioural and cognitive efforts to escape or avoid [63]. In the same study of Manne et al. [63], 'distancing' was described as cognitive strategies to create a positive outlook or detach from situation. Manne et al. [63] reported that 'distancing' was positively associated with positive affect.

\section{Discussion AND CONCLUSIONS}

Fatigue is one of the most common and problematic side effects of breast cancer treatment. High and fluctuating prevalence rates of fatigue have been found not only during but also after the administration of adjuvant chemotherapy.

In contrast with the common perception that more chemotherapy treatments lead to greater fatigue, studies reported on in the literature found the intensity of fatigue to be stable throughout the treatment cycles. Patients becoming accustomed 
to fatigue might cause this. In other words, the standard for determining the level of fatigue might be changing, a shift in the internal norm. This process of changing one's internal standard is called response shift [66].

After the treatment with adjuvant chemotherapy has ended, patients with breast cancer still experience fatigue, but because everyone experiences fatigue on a daily basis, it is unknown whether this fatigue can be regarded as normal fatigue. Further research should include this important aspect.

There is clearly a fluctuating intensity of fatigue within two cycles of chemotherapy treatment. The first two days after the administration of the chemotherapy treatment seem to be the worst. Practitioners should inform patients with cancer about this potential pattern of fatigue to help them, for example, make appropriate plans for daily activities.

The mechanisms of fatigue development are still poorly understood. The present literature study tried to identify factors relating to fatigue in patients with breast cancer, but found, for instance, that the relationship between fatigue and age does not seem to be unequivocal. Whereas some studies found no evidence of a relation between the two factors, some found a significant negative correlation, with younger women appearing to be more fatigued. Woo et al. [51] commented that this negative association might be caused by the more aggressive therapy that may have been given to younger women compared to those aged over 60 years. Another reason they suggested may be that more of the younger women had jobs and had the responsibility of caring for their families and young children, giving them fewer opportunities to save energy.

The relationships between fatigue and poorer health status and between fatigue and concurrent illness are unequivocally positive. These relationships are not unexpected, because the most common symptom of illness is fatigue [1]. By contrast, stage of disease did not appear to explain fatigue. Ongoing research involving the hormonal treatment, such as rHuEPO, must be done. The influence of rHuEPO on quality of life is not clear. EPO may be helpful in a subset of patients.

It is obvious that fatigue is associated with various physical and psychological symptoms. More specifically, research has shown that pain, sleeping problems and depression are positively related to fatigue. It is not unlikely that these variables are interrelated. For instance, Broeckel et al. [44] reported that pain and psychological distress are likely causes of sleep disturbance. Contradictory results have been found with respect to the influence of menopausal symptoms. Lower levels of activity seem to show a positive relationship with fatigue, whereas some factors, such as change in weight, biochemical factors, the effect of certain coping strategies, and social support, have not been thoroughly studied, or even studied at all, so there is a clear need for further research. 


\section{Chapter 2}

The outcomes of the studies suggest that several of the symptoms are interrelated in a network of symptoms. This could explain why the results often fail to prove clearly whether it is the physical and/or psychological symptoms that cause fatigue or vice versa.

Studies examining the unusual character of fatigue in patients with cancer have been virtually lacking, although the NCCN definition of cancer-related fatigue suggests that fatigue in patients with cancer is of a specific and unusual nature. Only the study by Schwartz [36] assessed the specific character of fatigue in patients with cancer.

Comparisons between the various studies are hampered by a number of aspects, the most obvious of which is the use of many different measuring instruments for fatigue and side effects: more than 10 different instruments were used for fatigue and as many for side effects. This raises questions about the validity of these comparisons. The differences in the answering options/ categories, the use of unidimensional or multidimensional measures of fatigue and the reliability and validity of the instruments must be considered. Three of the fatigue studies used only unidimensional instruments, which means that the value of their findings is very limited. Some studies used combinations of different instruments and assessed data at different points in time. Patients were sometimes flooded with questionnaires, which might lead to them becoming tired of filling in questionnaires and hence affect the value of their answers. Other factors that may impede comparisons between the studies include the lack of a uniform definition of fatigue, the use of insufficiently valid and reliable instruments to measure fatigue, the lack of uniformity in measurement points, and the variety of research designs used in the studies.

Some studies collected data during chemotherapy, whereas others collected data after the completion of chemotherapy. Few studies have so far addressed the effect of chemotherapy on fatigue during as well as after the administration of chemotherapy. A few studies had cross-sectional designs, whereas others had longitudinal designs. Research with a longitudinal design can address the development of fatigue over time, while studies with a cross-sectional design, which involve the collection of data only at one point in time, cannot.

It should be noted that women might already have experienced fatigue before starting any treatment. Authors often suggest that fatigue did not occur in their population before surgery. A study by Cimprich [67], however, provides evidence to the contrary. She studied 74 newly diagnosed patients with breast cancer, gathering data about 11 days before primary surgery, and found that $77 \%$ of the patients in the sample reported fatigue (ranging from mild to moderate levels). Longitudinal research that starts before surgery is needed. Fatigue as a 
sequela of surgery in patients with cancer has rarely been examined, perhaps because it is difficult to separate the consequences of surgery and anaesthesia from those of subsequent treatment [68]. Patients with cancer have often not fully recovered from surgery when adjuvant therapy is started [7].

An additional problem is the small sample size used in some of the studies, which makes it difficult to draw firm conclusions.

Because everyone experiences fatigue on a daily basis, it is difficult to distinguish between cancer-related fatigue and normal fatigue. A possible solution to this problem would be to study patients with cancer as well as healthy subjects. Most studies included in the present literature review did not use control groups. Another difficulty in measuring fatigue is its subjectivity. A person who objectively suffers a high level of fatigue may be less bothered by it than someone suffering less fatigue. Everyone copes with fatigue in a different way, and this variation in coping with fatigue has hardly been studied. Besides, most studies fail to distinguish whether the fatigue experienced affected daily functioning.

That breast cancer is a leading type of cancer among women, and that fatigue is recognised as having a great impact on the quality of life means that further research is needed. Ongoing studies are expected to tell us more about fatigue and the related factors and to provide more information about possible treatments of this complex problem.

Further research, involving larger and more homogeneous samples, must be done. The use of healthy control subjects for comparison in a study with a longitudinal design would be advisable, while the typical characteristics of cancer-related fatigue must also be taken into account.

\section{ReferenCes}

1. Hart, L.K., M.I. Freel, and F.K. Milde, Fatigue. Nurs Clin North Am, 1990. 25(4): p. 96776.

2. Irvine, D.M., et al., A critical appraisal of the research literature investigating fatigue in the individual with cancer. Cancer Nurs, 1991. 14(4): p. 188-99.

3. Pronk, P., Vermoeidheid bij kanker: achtergronden en tips. Magazine voor natuurlijke kankerbestrijding, 1999. mei: p. 22-23.

4. Foekema, H. and S. Van Gend, Vermoeidheid bij kanker: een belangrijk probleem. Vol. 5 maart 1999. 1999, Amsterdam: Rapport van het NIPO: marktonderzoekinstituut.

5. NCCN, National Comprehensive Cancer Network (NCCN) Cancer-Related Fatigue. http://www.nccn.org/professionals/physician g/s/PDF/fatigue.pdf. 2006. 


\section{Chapter 2}

6. Piper, B.F., A.M. Lindsey, and M.J. Dodd, Fatigue mechanisms in cancer patients: developing nursing theory. Oncol Nurs Forum, 1987. 14(6): p. 17-23.

7. Nail, L.M. and K.B. King, Symptom distress. Fatigue. Semin Oncol Nurs, 1987. 3(4): p. 257-62.

8. Ream, E., A. Richardson, and C. Alexander-Dann, Facilitating patients' coping with fatigue during chemotherapy-pilot outcomes. Cancer Nurs, 2002. 25(4): p. 300-8.

9. KWF Kankerbestrijding, Kanker in Nederland. Trends, prognoses en implicaties voor zorgvraag. 2004, Oisterwijk: Drukkerij van den Boogaard.

10. Piper, B.F., Pathophysiological phenomena in nursing: human responses to illness. 1993, Philadelphia: W.B. Saunders Company. 279-302.

11. Tiesinga, L.J., T.W. Dassen, and R.J. Halfens, Fatigue: a summary of the definitions, dimensions, and indicators. Nurs Diagn, 1996. 7(2): p. 51-62.

12. Magnusson, K., et al., A qualitative study to explore the experience of fatigue in cancer patients. European Journal of Cancer Care, 1999. 8(4): p. 224-232.

13. Smets, E.M., et al., Fatigue in cancer patients. Br J Cancer, 1993. 68(2): p. 220-4.

14. Gall, H., The Basis of Cancer Fatigue: Where Does It Come From? European Journal of Cancer Care, 1996. 5(Suppl. 2): p. 31-34.

15. Stone, P., M. Richards, and J. Hardy, Fatigue in patients with cancer. European Journal of Cancer, 1998. 34(11): p. 1670-1676.

16. Richardson, A., E. Ream, and J. Wilson-Barnett, Fatigue in patients receiving chemotherapy: Patterns of change. Cancer Nursing, 1998. 21: p. 17-30.

17. Winningham, M.L., et al., Fatigue and the Cancer Experience: The State of the Knowledge. Oncology Nursing Forum, 1994. 21(1): p. 23-36.

18. Glaus, A., Fatigue, an orphan topic in patients with cancer? Eur J Cancer, 1998. 34(11): p. 1649-51.

19. Ream, E. and A. Richardson, Fatigue: a concept analysis. Int J Nurs Stud, 1996. 33(5): p. $519-29$

20. Holley, S., Cancer-related fatigue - Suffering a different fatigue. Cancer Practice, 2000. 8(2): p. 87-95.

21. Sitzia, J. and L. Huggins, Side effects of cyclophosphamide, methotrexate, and 5fluorouracil (CMF) chemotherapy for breast cancer. Cancer Practice, 1998. 6 (1): p. 13-21.

22. Berger, A.M., Patterns of fatigue and activity and rest during adjuvant breast cancer chemotherapy. Oncol Nurs Forum, 1998. 25(1): p. 51-62.

23. Donovan, K.A., et al., Course of fatigue in women receiving chemotherapy and/or radiotherapy for early stage breast cancer. J Pain Symptom Manage, 2004. 28(4): p. 373-80.

24. Jacobsen, P.B., et al., Fatigue in women receiving adjuvant chemotherapy for breast cancer: Characteristics, course, and correlates. Journal of Pain and Symptom Management, 1999. 18(4): p. 233-242. 
25. Jacobsen, P.B., M.A. Andrykowski, and C.L. Thors, Relationship of catastrophizing to fatigue among women receiving treatment for breast cancer. J Consult Clin Psychol, 2004. 72(2): p. 355-61.

26. Andrykowski, M.A., et al., Use of a case definition approach to identify cancer-related fatigue in women undergoing adjuvant therapy for breast cancer. J Clin Oncol, 2005. 23(27): p. 6613-22.

27. Nieboer, P., et al., Fatigue and relating factors in high-risk breast cancer patients treated with adjuvant standard or high-dose chemotherapy: a longitudinal study. J Clin Oncol, 2005. 23(33): p. 8296-304.

28. Haghighat, S., et al., Factors predicting fatigue in breast cancer patients. Supportive Care in Cancer, 2003. 11(8): p. 533-538.

29. Bennett, B., et al., Fatigue and psychological distress-exploring the relationship in women treated for breast cancer. Eur J Cancer, 2004. 40(11): p. 1689-95.

30. Longman, A.J., C.J. Braden, and M.H. Mishel, Side effects burden in women with breast cancer. Cancer Pract, 1996. 4(5): p. 274-80.

31. Longman, A.J., C.J. Braden, and M.H. Mishel, Pattern of association over time of sideeffects burden, self-help, and self-care in women with breast cancer. Oncol Nurs Forum, 1997. 24(9): p. 1555-60.

32. Hoskins, C.N., Breast cancer treatment-related patterns in side effects, psychological distress, and perceived health status. Oncol Nurs Forum, 1997. 24(9): p. 1575-83.

33. Wyatt, G.K. and L.L. Friedman, Physical and psychosocial outcomes of midlife and older women following surgery and adjuvant therapy for breast cancer. Oncol Nurs Forum, 1998. 25(4): p. 761-8.

34. Tchen, N., et al., Cognitive function, fatigue, and menopausal symptoms in women receiving adjuvant chemotherapy for breast cancer. J Clin Oncol, 2003. 21(22): p. 4175-83.

35. Mar Fan, H.G., et al., Fatigue, menopausal symptoms, and cognitive function in women after adjuvant chemotherapy for breast cancer: 1- and 2-year follow-up of a prospective controlled study. J Clin Oncol, 2005. 23(31): p. 8025-32.

36. Schwartz, A.L., Daily fatigue patterns and effect of exercise in women with breast cancer. Cancer Practice, 2000. 8(1): p. 16-24.

37. Greene, D., et al., A comparison of patient-reported side effects among three chemotherapy regimens for breast cancer. Cancer Pract, 1994. 2(1): p. 57-62.

38. Gaston Johansson, F., et al., Fatigue, pain, and depression in pre-autotransplant breast cancer patients. Cancer Practice, 1999. 7(5): p. 240-247.

39. Mast, M.E., Correlates of fatigue in survivors of breast cancer. Cancer Nursing, 1998. 21(2): p. 136-142.

40. Lindley, C., et al., Quality of life and preferences for treatment following systemic adjuvant therapy for early-stage breast cancer. Journal of Clinical Oncology, 1998. 16

(4): p. 1380-1387. 


\section{Chapter 2}

41. Berglund, G., et al., Late effects of adjuvant chemotherapy and postoperative radiotherapy on quality of life among breast cancer patients. Eur J Cancer, 1991. 27(9): p. 1075-81.

42. Okuyama, T., et al., Factors correlated with fatigue in disease-free breast cancer patients: application of the Cancer Fatigue Scale. Supportive Care in Cancer, 2000. 8(3): p. 215-222.

43. Leddy, S.K., Healthiness, fatigue, and symptom experience in women with and without breast cancer. Holist Nurs Pract, 1997. 12(1): p. 48-53.

44. Broeckel, J.A., et al., Characteristics and correlates of fatigue after adjuvant chemotherapy for breast cancer. J Clin Oncol, 1998. 16(5): p. 1689-96.

45. Curran, S.L., A.O. Beacham, and M.A. Andrykowski, Ecological momentary assessment of fatigue following breast cancer treatment. J Behav Med, 2004. 27(5): p. 425-44.

46. Bower, J.E., et al., Fatigue in breast cancer survivors: Occurrence, correlates, and impact on quality of life. Journal of Clinical Oncology, 2000. 18(4): p. 743-753.

47. Bower, J.E., et al., Fatigue in long-term breast carcinoma survivors: a longitudinal investigation. Cancer, 2006. 106(4): p. 751-8.

48. Beisecker, A.E., et al., Side effects of adjuvant chemotherapy: Perceptions of nodenegative breast cancer patients. Psycho Oncology, 1997. 6 (2): p. 85-93.

49. Richardson, A., Fatigue in Cancer Patients: a Review of the Literature. European Journal of Cancer Care, 1995. 4: p. 20-32.

50. Nail, L.M. and M.L. Winningham, Fatigue. In Groenwald SL, Goodman M, Hansen Frogge M, Henke Yarbro C (eds): Cancer Nursing: Principles and Practice. 1993, Boston, London: Jones and Bartlett Publishers. 608-619.

51. Woo, B., et al., Differences in fatigue by treatment methods in women with breast cancer. Oncol Nurs Forum, 1998. 25(5): p. 915-20.

52. Blesch, K.S., et al., Correlates of fatigue in people with breast or lung cancer. Oncol Nurs Forum, 1991. 18(1): p. 81-7.

53. Berger, A.M. and P. Higginbotham, Correlates of fatigue during and following adjuvant breast cancer chemotherapy: a pilot study. Oncol Nurs Forum, 2000. 27(9): p. 1443-8.

54. Berger, A.M. and L. Farr, The influence of daytime inactivity and nighttime restlessness on cancer-related fatigue. Oncol Nurs Forum, 1999. 26(10): p. 1663-71.

55. Seidenfeld, J., et al., Epoetin treatment of anemia associated with cancer therapy: $A$ systematic review and meta-analysis of controlled clinical trials. Journal of the National Cancer Institute, 2001. 93(16): p. 1204-1214.

56. Andrykowski, M.A., S.L. Curran, and R. Lightner, Off-treatment fatigue in breast cancer survivors: A controlled comparison. Journal of Behavioral Medicine, 1998. 21(1)): p. 1-18.

57. Berger, A. and S.N. Walker, An explanatory model of fatigue in women receiving adjuvant breast cancer chemotherapy. Nursing Research, 2001. 50(3): p. 164-164.

58. Demark Wahnefried, W., E.P. Winer, and B.K. Rimer, Why women gain weight with adjuvant chemotherapy for breast cancer. J Clin Oncol, 1993. 11(7): p. 1418-29. 
59. Wortman, C.B., Social support and the cancer patient. Conceptual and methodologic issues. Cancer, 1984. 53(10 Suppl): p. 2339-62.

60. Komproe, I.H., et al., Available support and received support: Different effects under stressful circumstances. Journal of Social and Personal Relationships, 1997. Vol 14(1): p. 59-77.

61. van-den-Akker, et al., Marginal impact of psychosocial factors on multimorbidity: results of an explorative nested case-control study. Soc Sci Med, 2000. 50(11): p. 167993.

62. McHaffie, H.E., Coping: an essential element of nursing. J Adv Nurs, 1992. 17(8): p. 933-40.

63. Manne, S.L., et al., Coping with chemotherapy for breast cancer. J Behav Med, 1994. 17(1): p. 41-55.

64. Shapiro, D.E., et al., Stage I/ breast cancer: differences between four coping patterns in side effects during adjuvant chemotherapy. J Psychosom Res, 1997. 43(2): p. 143-57.

65. Jacobsen, P.B., L.M. Azzarello, and D.M. Hann, Relation of catastrophizing to fatigue severity in women with breast cancer. Cancer Research Therapy and Control, 1999. 8: p. 155-164.

66. Breetvelt, I.S. and F.S. Van Dam, Underreporting by cancer patients: the case of response-shift. Soc Sci Med, 1991. 32(9): p. 981-7.

67. Cimprich, B., Pretreatment symptom distress in women newly diagnosed with breast cancer. Cancer Nurs, 1999. 22(3): p. 185-94.

68. Nail, L.M. and M.L. Winningham, Fatigue and weakness in cancer patients: the symptoms experience. Semin Oncol Nurs, 1995. 11(4): p. 272-8. 

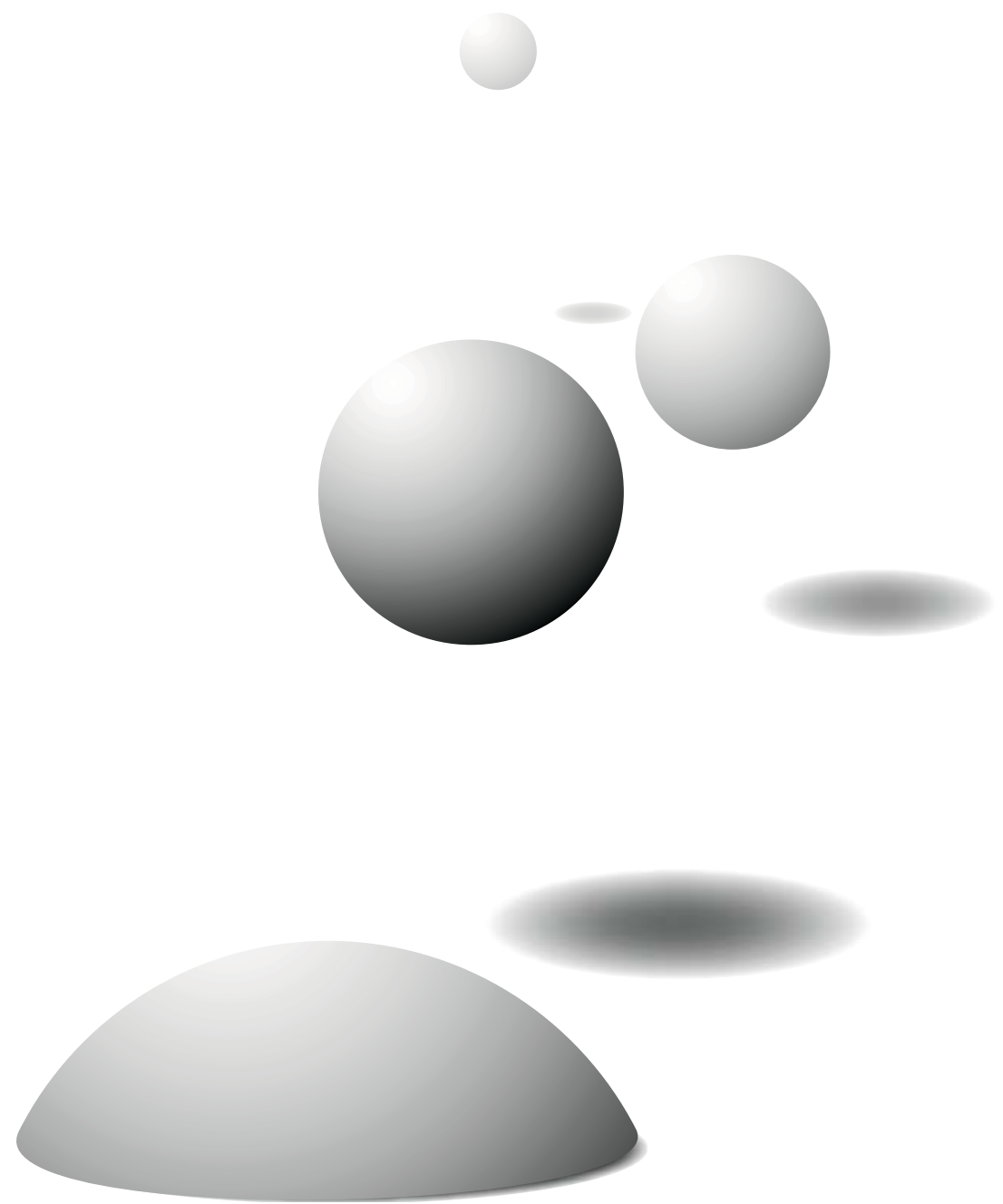


\section{Chapter 3}

\section{Prevalence and course of fatigue in breast cancer patients receiving adjuvant chemotherapy}

Nynke de Jong, MSc, RN, Math J.J.M. Candel, PhD, Harry C. Schouten, MD, PhD, Huda Huijer Abu-Saad, FEANS, PhD, RN, \& Annemie M. Courtens, PhD, RN

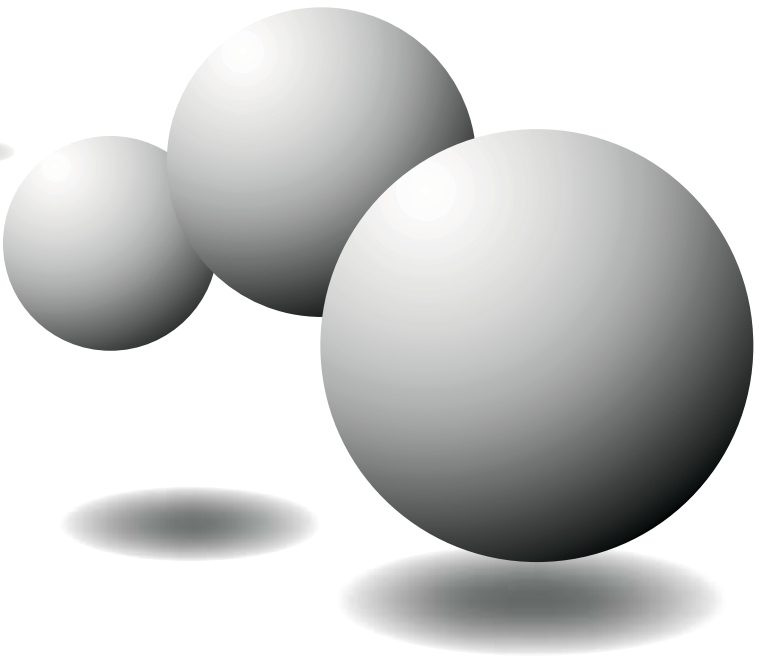

Published in: Annals of Oncology 2004; 15: 896-905.

(nominated for the Anna Reynvaan Science Prize for the best published article in Nursing Science in the Netherlands and Belgium) 


\section{Abstract}

Background: The purpose of this study was to determine the prevalence of fatigue and the course of fatigue as a function of chemotherapy in breast cancer patients undergoing adjuvant chemotherapy.

Patients and methods: In a prospective cohort study, a sample of 157 patients with breast cancer were interviewed, using the Rotterdam Symptom Checklist and the Multidimensional Fatigue Inventory, at the first, third and fifth cycle of adjuvant chemotherapy, as well as 4 and 12 weeks after the last cycle of adjuvant chemotherapy. Patients were treated with either a doxorubicin-containing schedule, or cyclophosphamide, methotrexate and 5-fluorouracil (CMF).

Results: The courses of general and physical fatigue are to a large extent similar. After the last cycle of chemotherapy, the CMF group reports a significant increase in fatigue, which was followed by a significant reduction. In the doxorubicin group a significant increase in fatigue was only seen during the first cycles of chemotherapy. The fatigue experienced at the first and the last measurements do not differ significantly.

Conclusions: The prevalence of fatigue increased significantly after the start of chemotherapy. After chemotherapy treatment the prevalence rate seemed to decline. A different impact of chemotherapy on the course of fatigue was found. In the doxorubicin group a direct increase in fatigue was found. In the CMF group a moderate direct increase occurred, followed by a delayed strong increase. An increase in fatigue was associated with a decrease in daily functioning. At all measurement occasions fatigue was affected by type of operation, such that women with a mastectomy were more fatigued than women that underwent a lumpectomy. Receiving radiotherapy also led to an increase in fatigue. With this knowledge breast cancer patients can be better informed about what they can expect. Further research should include interventions addressing how to reduce or cope with fatigue during as well as after receiving adjuvant chemotherapy.

Keywords: adjuvant chemotherapy, breast cancer, fatigue 


\section{INTRODUCTION}

Fatigue is a major concern for the patient with cancer [1]. Partly as a result of longer cancer survival, it is increasingly being realised that quality of life in cancer patients is affected by fatigue. The National Comprehensive Cancer Network (NCCN) stated that fatigue affects $70-100 \%$ of cancer patients [2].

Fatigue is a universal experience and is normally relieved by a good night's sleep. For cancer patients fatigue often becomes a chronic and unpleasant sensation [3]. Fatigue can be a symptom of the disease itself and may accompany cancer treatment [4]. Cancer patients receiving chemotherapy may experience a variety of side-effects, such as pain, nausea, vomiting, hair loss, weight changes, fatigue and anxiety; however, the most commonly reported side-effect is fatigue.

Breast cancer has been the most frequent type of cancer in women since the early 1990s, not only in the Netherlands but also elsewhere. Adjuvant chemotherapy is part of the standard treatment in a large subset of patients.

According to the literature, $58-94 \%$ of the breast cancer patients experience fatigue during treatment with adjuvant chemotherapy [5-7]. In the study of Sitzia and Huggins [6] patients with breast cancer $(n=52)$ who were receiving six cycles of cyclophosphamide, methotrexate, and 5-fluorouracil (CMF) were examined. Data were collected after each cycle. An incidence rate of approximately $90 \%$ was found. Fatigue severity remained stable throughout the treatment cycles. Results from Berger [8], who showed that in 72 patients with breast cancer fatigue levels 48 hours after each of the first three chemotherapy cycles were not significantly different over time, support this finding. Jacobsen et al. [7] also reported similar result, though the prevalence and severity of fatigue significantly increased after the start of chemotherapy, after which the prevalence of fatigue showed a stable pattern. The chemotherapy regimens in this study contain all doxorubicin. Data were collected before the start of each of the first four chemotherapy cycles [7].

Studies on fatigue in breast cancer patients after the treatment with adjuvant chemotherapy show prevalence rates between the 56\% and 95\% [9-12]. Only Beisecker et al. [10] reported prevalence rates at several time points after the treatment with adjuvant chemotherapy. They studied 21 patients with nodenegative breast cancer who had undergone adjuvant chemotherapy. Shortly after completion the prevalence rate was $95 \%$ followed by $83 \% 6$ months later.

Berger and Higginbotham [13] studied 14 breast cancer patients during as well as after doxorubicin-cyclophosphamide chemotherapy. In this pilot study, fatigue was a significant problem throughout cycle three of adjuvant breast cancer chemotherapy and continued at lower levels 2 months after the last treatment. 
The impact of different chemotherapy regimens, such as doxorubicin-containing regimens, on the course of fatigue is unclear and less studied. Greene et al. [5] reported no significant differences in intensity of fatigue related to whether doxorubicin was included. Berger and Walker [14] found recently that chemotherapy protocols which contain intravenous doxorubicin were directly associated with higher fatigue at the first treatment. They studied 60 women during the first three cycles of adjuvant breast chemotherapy [14].

There is evidence that fatigue has a strong impact on daily functioning. Berger and Higginbotham [13] reported that higher fatigue was associated with lower activity; Berger and Far [15] found similar results. The latter studied 72 breast cancer patients during the first three chemotherapy cycles after surgery for stage I/II disease [15]. The study strongly supports the position that higher fatigue is associated with daytime inactivity. Berger [8] reported in her study not only a negative correlation between fatigue and activity level, but also found that activity levels were significantly lower in women receiving doxorubicin-based protocols.

Taken together, these studies support the hypothesis that fatigue is highly prevalent during as well as after the treatment of chemotherapy. Additionally, these studies suggest that the intensity of fatigue stays stable throughout the treatment cycles and declines after completion. The impact of different chemotherapy regimens, such as doxorubicin-containing regimens, on the course of fatigue is unclear and will therefore be further examined in the present study. A last hypothesis is that fatigue will have a strong impact on daily functioning.

It should be noted that previous studies had several limitations [16], such as a small sample size, the lack of a well-validated measure of fatigue and the absence of a longitudinal design in which patients with breast cancer were studied during, as well as after, receiving adjuvant chemotherapy. The purpose of the present study was to investigate the course of fatigue during (two or three measurement points) as well as after (two measurement points) adjuvant chemotherapy in an attempt to circumvent the major weaknesses of previous studies.

\section{Patients AND methods}

\section{Population sample and procedure}

All breast cancer patients with an indication for adjuvant chemotherapy treated in six hospitals, mainly in the south of The Netherlands, were invited to participate in this study. After checking the inclusion criteria, either the oncologist or the oncology nurse introduced the study to the patient before the first cycle of adjuvant chemotherapy with written information describing the purpose and 
procedure of the investigations. After the patient had given written informed consent, either the oncologist or the oncology nurse contacted the principal investigator of this study. The principal investigator and a properly trained assistant conducted the interviews. The study was approved by all local medical ethical committees of the participating centres.

Eligible breast cancer patients met the following criteria: (i) absence of metastasis or other malignancy; (ii) no previous treatment with cytostatics; (iii) adjuvant chemotherapy treatment was as an outpatient; (iv) absence of chronic disease (such as hypertension, kidney disease, heart problems, diabetes mellitus, etc.) or poor psychological state; (v) no use of morphine or narcoleptics; (vi) no deafness; (vii) '18 years of age; and (viii) Dutch-speaking.

Patients were interviewed five times using the Multidimensional Fatigue Inventory (MFI-20) [17] and the Rotterdam Symptom Checklist (RSCL) [18], except when receiving the cyclophosphamide and doxorubicin (CA) treatment, in which case participants were interviewed four times. The first interview was at the start of chemotherapy, the second at the third cycle and the third at the fifth cycle, except for the CA regimen, where the third interview was omitted. The last two interviews were 4 weeks and 12 weeks, respectively, after the last cycle. The first three interviews took place in the hospital and were held directly before, during or after infusion. The last two interviews were done by phone. After the interviews the medical data were retrieved from charts.

\section{Operationalisation of variables}

Intensity of fatigue. The RSCL is an instrument to measure the quality of life of cancer patients [18]. In the present study, one item of the subscale physical symptom distress was used. At each measurement the patient was asked to answer the following question: have you been bothered, during the last 2 weeks, by tiredness? The answers given are 'not at all', 'a little', 'quite a bit' and 'very much'. This item was used to examine the prevalence of fatigue during the study and the scores discriminated significantly between patients scoring high and low on MFI.

MFI-20 [17] was used to assess the course of fatigue. This 20-item questionnaire, especially designed for cancer patients, is a self-report instrument consisting of five subscales based on different dimensions: general fatigue, physical fatigue, reduced activity, reduced motivation and mental fatigue. Each subscale consists of four items and the score for each subscale was calculated as the sum of the scores of the four items. High scores indicate more subjective fatigue. The MFI-20 was previously tested and validated in cancer patients receiving radiotherapy, patients with 'chronic fatigue syndrome', psychology 
students, medical students, army recruits and junior physicians. The internal consistency for the different scales and different patient groups, as measured by Cronbach's alpha averaged 0.84 (range 0.53-0.93) [19]. In the present study, we focus on the results for the two subscales general and physical fatigue. In addition, correlations between the subscale 'reduced activity' and these two subscales were calculated to give an impression of the impact of fatigue on daily functioning.

In this study, patients were asked to rate, in an interview, their fatigue as experienced during the previous 2 weeks. The items were administered in a faceto-face interview, instead of presenting the items in a self-report questionnaire, for the practical reason that the patients were already being interviewed. In addition, filling in a self-report questionnaire was expected to be too timeconsuming for the patient.

Treatment of adjuvant chemotherapy. Patients were treated with one of the following adjuvant treatments: cyclophosphamide, 4-epi-doxorubicin and 5fluorouracil (CEF), every 21 days; cyclophosphamide, doxorubicin and 5fluorouracil (CAF), every 21 days; 4-epi-doxorubicin, every 28 days (on days 1 and 8); 4-epi-doxorubicin-taxotere with the first three cycles every 28 days (on days 1 and 8) and the last three cycles every 21 days; cyclophosphamide and doxorubicin (CA), every 21 days; or CMF [cyclophosphamide, methotrexate (oral administration from days 1 to 14 or intravenous) and 5-fluorouracil] every 28 days (on days 1 and 8). Most regimens consist of six cycles, except for the CA regimen, which consists of four. The choice for either schedule was based on current practice in the participating hospitals. The involvement of different adjuvant chemotherapy regimens made it possible to create a sizeable sample in a relatively short period of time. In the analysis two groups were compared: the doxorubicin group (CEF, CAF, 4-epi-doxorubicin, 4-epi-doxorubicintaxotere and $\mathrm{CA}$ ) and the CMF group.

Stage of breast cancer. The tumor-node-metastasis TNM clinical classification is used to describe the anatomic extent of breast cancer [20].

Type of operation. Patients in the present study underwent a mastectomy or a lumpectomy with or without lymph nodes excision. Eventually, two groups were considered because of small sizes of the other groups: (i) mastectomy with lymph nodes excision; and (ii) lumpectomy with lymph nodes excision. No reconstructive surgery was done during the study period.

\section{Statistical Analyses}

First, it was statistically tested whether there were differences in patient characteristics between the CMF group and the doxorubicin group. 
The prevalence of fatigue at each measurement point was determined by choosing a cut-off for the scores on the single item of the RSCL. This allowed for creating a fatigue and a non-fatigue group. Differences in prevalence across time were analysed through a logistic multilevel model using the MLwiN program (version 1.10.0006) [21]. The data consist of repeated measurements nested within hospitals and individual subjects. The data, which have a hierarchical nature, may be characterised by dependencies between units at lower levels of the hierarchy. In this case multilevel analysis is an appropriate technique [22]. The course of fatigue, using two subscales of the MFI-20, and the dependency on the type of adjuvant chemotherapy treatment, was analysed with a linear multilevel model also using the MLwiN program.

In the prevalence analyses, as well as the analyses concerning the effect of chemotherapy regimen on the course of fatigue, dummy variables were included to represent the several measurement points. When the first measurement is taken as a reference, changes relative to the baseline measurement are analysed. The effect of chemotherapy on the course of fatigue was represented by interaction terms between these dummy variables and a binary variable chemotherapy. To correct for possibly confounding factors in this analysis, several covariates were added: 'age', 'marital status', 'having children', 'education', 'having a job', 'type of operation', 'stage of breast cancer', 'haemoglobin level (measured in mmol/l) before the first treatment of chemotherapy', 'the number of days between the operation and the first treatment of chemotherapy', 'the number of treatments at each measurement point' and 'radiotherapy'. For the covariate 'radiotherapy', three different variables were used: a variable indicating whether a patient had received radiotherapy at any point of measurement, the number of days of radiotherapy the patient had had at the time of measurement and the number of days between the last day of radiotherapy and the time of measurement. Also these covariates were included as interaction terms with the dummy variables representing the time points. In this way, possible differences in patient characteristics between the chemotherapy groups are corrected for.

Stepwise deletion took place in which non-significant covariates were removed. The effect of the variable 'treatment of adjuvant chemotherapy' was examined after the final model was determined in which only significant covariates were included. For the final model, fatigue scores, which are baseline differences and are also adjusted for differences between the chemotherapy groups, can be calculated. These will be denoted as adjusted baseline differences.

Correlations were also calculated between the subscales 'reduced activity' and 'general fatigue', as well as between 'reduced activity' and 'physical fatigue', to give an impression of their relationship. 


\section{Results}

\section{Response Rate}

A total of 175 breast cancer patients were eligible for the study. Of this sample, $18(10 \%)$ patients were excluded for different reasons: 13 (7\%) declined further participation; three (2\%) stopped adjuvant chemotherapy prematurely; and two $(1 \%)$ had a poor physical state. The remaining 157 patients were interviewed four $(n=20)$ or five $(n=137)$ times depending on their adjuvant chemotherapy schedule. The response rates are shown in Table 1. The non-response was caused by a change in the schedule of the treatment of chemotherapy except for two interviews. These two interviews were lacking because the interviewer missed one interview and one patient refused to be interviewed. The principal investigator of the study conducted $79 \%$ of the interviews. The other interviews were conducted by an assistant.

\section{Sample Characteristics}

Twenty-nine percent of the patients had received the CMF treatment, the remainder received one of the chemotherapy regimens covered by the doxorubicin group. Information about the demographic and medical characteristics of these two groups are listed in Table 2. There were two characteristics on which the groups differed. Patients in the CMF group were significantly $(t=-2.133 ; P=0.035)$ younger than patients in the doxorubicin group. The mean age was $45.0 \pm 7.9$ years in the CMF group and $48.2 \pm 9.0$ years in the doxorubicin group. Significantly $\left[\chi^{2}(1)=4.768, P=0.034\right]$ more patients in the CMF group had a job compared with the doxorubicin group. There were no significant differences with respect to the other characteristics in Table 2. Details of the total number of chemotherapy treatments for each of the

Table 1. Response rates of patients with breast cancer specified for each measurement occasion

\begin{tabular}{|c|c|c|c|}
\hline Measurement & Total $(\boldsymbol{n})$ & \multicolumn{2}{c|}{ Participants in study } \\
\hline & & $\boldsymbol{n}$ & $\%$ \\
\hline 2 & 157 & 157 & 100 \\
\hline $3^{*}$ & 157 & 157 & 100 \\
\hline 4 & 137 & 135 & 99 \\
\hline 5 & 157 & 152 & 97 \\
\hline
\end{tabular}

* Patients receiving only four chemotherapy treatments did not have this interview. 


\begin{tabular}{|c|c|c|c|c|c|c|}
\hline \multirow{4}{*}{$\begin{array}{l}\text { Age (years)* } \\
\text { Mean (SD) } \\
\text { Range }\end{array}$} & \multicolumn{2}{|c|}{$\begin{array}{l}\text { Doxorubicin group } \\
\qquad(n=111)\end{array}$} & \multicolumn{2}{|c|}{$\begin{array}{l}\text { CMF group } \\
(n=46)\end{array}$} & \multicolumn{2}{|c|}{$\begin{array}{c}\text { Total } \\
(n=157)\end{array}$} \\
\hline & \multirow{3}{*}{\multicolumn{2}{|c|}{$\begin{array}{c}48.2(9.0) \\
27-70\end{array}$}} & \multirow{3}{*}{\multicolumn{2}{|c|}{$\begin{array}{c}45.0(7.9) \\
25-62\end{array}$}} & \multirow{3}{*}{\multicolumn{2}{|c|}{$\begin{array}{c}47.3(8.8) \\
25-70\end{array}$}} \\
\hline & & & & & & \\
\hline & & & & & & \\
\hline & $n$ & $\%$ & $n$ & $\%$ & $n$ & $\%$ \\
\hline \multicolumn{7}{|l|}{ Marital status } \\
\hline Married/living together & 91 & 82 & 40 & 87 & 131 & 83 \\
\hline Single & 11 & 10 & 3 & 7 & 14 & 9 \\
\hline Divorced & 7 & 6 & 3 & 7 & 10 & 6 \\
\hline Widow & 2 & 2 & - & - & 2 & 1 \\
\hline \multicolumn{7}{|l|}{ Children } \\
\hline Yes & 87 & 78 & 37 & 80 & 124 & 79 \\
\hline No & 24 & 22 & 9 & 20 & 33 & 21 \\
\hline \multicolumn{7}{|l|}{ Educational level } \\
\hline Low & 43 & 39 & 13 & 28 & 56 & 36 \\
\hline Middle & 43 & 39 & 24 & 52 & 67 & 43 \\
\hline High & 25 & 23 & 9 & 20 & 34 & 22 \\
\hline \multicolumn{7}{|l|}{ Job* } \\
\hline Yes & 59 & 53 & 33 & 72 & 92 & 59 \\
\hline No & 52 & 47 & 13 & 28 & 65 & 41 \\
\hline \multicolumn{7}{|l|}{ Stage of breast cancert } \\
\hline I & 9 & 8 & 3 & 7 & 12 & 8 \\
\hline II & 90 & 81 & 35 & 76 & 125 & 80 \\
\hline III & 4 & 4 & 2 & 4 & 6 & 4 \\
\hline I and III (two tumours) & - & - & 1 & 2 & 1 & 1 \\
\hline Unknown (missing at the data & & & & & & \\
\hline collection point) & 8 & 7 & 5 & 11 & 13 & 8 \\
\hline \multicolumn{7}{|l|}{ Type of operation $\ddagger$} \\
\hline Mastectomy without lymph nodes excision & 3 & 3 & - & - & 3 & 2 \\
\hline Mastectomy with lymph nodes excision & 53 & 48 & 20 & 43 & 73 & 47 \\
\hline Lumpectomy without lymph nodes excision & 1 & 1 & - & - & 1 & 1 \\
\hline Lumpectomy with lymph nodes excision & 52 & 47 & 26 & 57 & 78 & 50 \\
\hline Unknown & 2 & 2 & - & - & 2 & 1 \\
\hline \multicolumn{7}{|l|}{$\begin{array}{l}\text { Treatment of adjuvant } \\
\text { chemotherapy }\end{array}$} \\
\hline CEF & 38 & 34 & - & - & 38 & 24 \\
\hline CAF & 27 & 24 & - & - & 27 & 17 \\
\hline 4 epi-doxorubicin & 21 & 19 & - & - & 21 & 13 \\
\hline 4 epi-doxorubicin / taxotere & 5 & 5 & - & - & 5 & 3 \\
\hline CA & 20 & 18 & - & - & 20 & 13 \\
\hline CMF (no oral administration) & - & - & 15 & 33 & 15 & 10 \\
\hline CMF (partially oral administration) & - & - & 31 & 67 & 31 & 20 \\
\hline \multicolumn{7}{|l|}{ Radiotherapy } \\
\hline Yes & 75 & 68 & 33 & 72 & 108 & 69 \\
\hline No & 36 & 32 & 13 & 28 & 49 & 31 \\
\hline \multicolumn{7}{|l|}{$\begin{array}{l}\text { Anaemia (haemoglobin level, } \\
\mathrm{mmol} / \mathrm{l}<7.3)^{\S}\end{array}$} \\
\hline Yes & 10 & 9 & 1 & 2 & 11 & 7 \\
\hline No & 99 & 89 & 43 & 94 & 142 & 90 \\
\hline Unknown & 2 & 2 & 2 & 4 & 4 & 3 \\
\hline
\end{tabular}




\section{Chapter 3}

Table 2. Patient characteristics (continued)

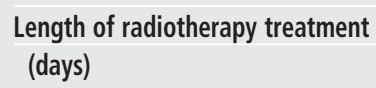

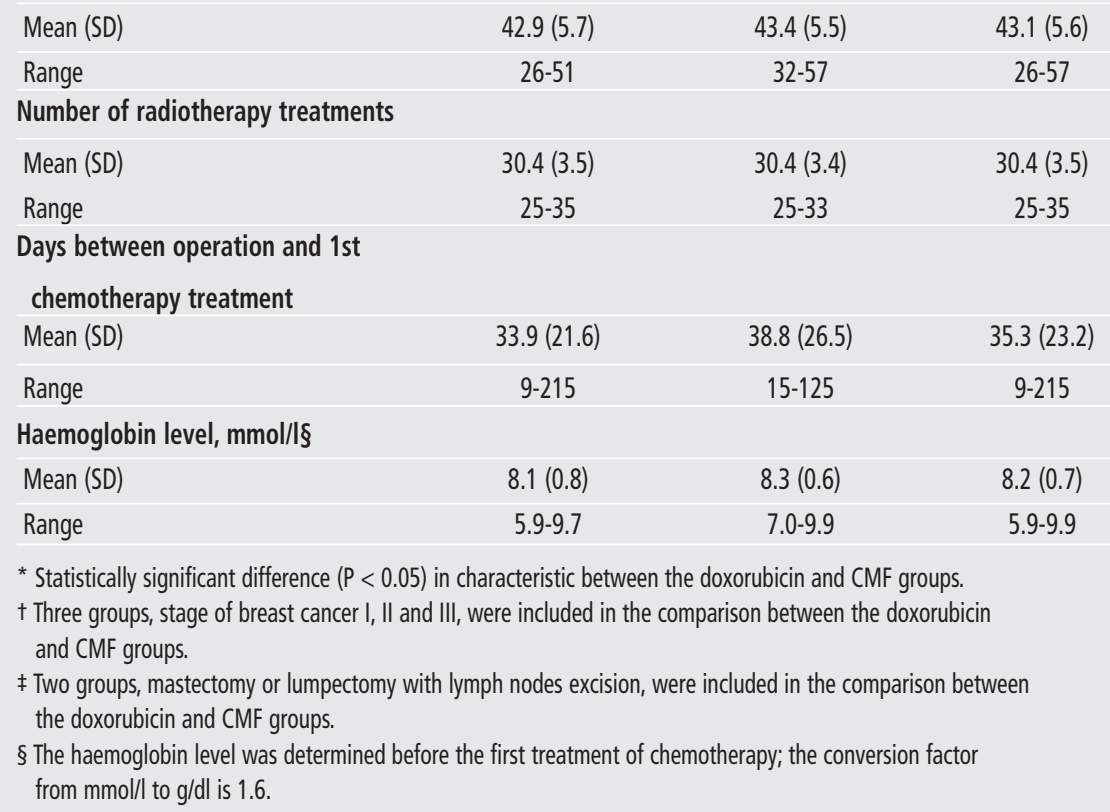

chemotherapy regimens and the number of patients receiving radiotherapy at the different measurement points are displayed in Tables 3 and 4, respectively.

\section{Prevalence of fatigue}

Table 5 contains the results for the single item of the RSCL. For three different classifications into a non-fatigue group and a fatigue group, the prevalences of fatigue were compared across time. For each fatigue classification the prevalence significantly increased at measurement point 2 . Between following consecutive time points no significant differences in the prevalence were found except for classification II. For this fatigue classification the prevalence significantly decreased at the last measurement. For the other fatigue classifications a decrease was also seen, but these did not turn out to be significant.

\section{Course of fatigue}

The course of fatigue was studied by analysing the results for the two subscales of the MFI-20: general fatigue and physical fatigue. The results for these two subscales are to a large extent similar and are therefore presented together in the next section. 


\begin{tabular}{|c|c|c|c|c|c|}
\hline \multirow[t]{2}{*}{ Total number of treatments $\rightarrow$} & 4 & 5 & 6 & 8 & \\
\hline & & & & & Total $(n)$ \\
\hline \multicolumn{6}{|l|}{$\begin{array}{l}\text { Treatment of adjuvant } \\
\text { chemotherapy }\end{array}$} \\
\hline CEF & - & 6 & 24 & 8 & 38 \\
\hline CAF & - & 3 & 24 & - & 27 \\
\hline 4 epi-doxorubicin & - & - & 21 & - & 21 \\
\hline 4 epi-doxorubicin-taxotere & 1 & 1 & 3 & - & 5 \\
\hline $\mathrm{CA}^{\prime}$ & 20 & - & - & - & 20 \\
\hline Total for doxorubicin group & 21 & 10 & 72 & 8 & 111 \\
\hline CMF & - & - & 46 & - & 46 \\
\hline
\end{tabular}

Table 4. Overview of numbers of patients with breast cancer receiving radiotherapy specified for each measurement occasion

\begin{tabular}{|ccccc|}
\hline $\begin{array}{c}\text { Measurement } \\
\text { occasion }\end{array}$ & $\begin{array}{c}\text { Receiving radiotherapy at } \\
\text { measurement }\end{array}$ & $\begin{array}{c}\text { Receiving or having finished } \\
\text { radiotherapy at measurement }\end{array}$ \\
\hline 1 & $n$ & $\%$ & $n$ & $\%$ \\
\hline 2 & 8 & 5 & 10 & 6 \\
\hline $3^{*}$ & 58 & 37 & 89 & 57 \\
\hline 4 & 3 & 2 & 94 & 60 \\
5 & 8 & 5 & 98 & 62 \\
\hline * Patients receiving only four chemotherapy treatments did not have this interview. & 103 & \\
\hline
\end{tabular}

\section{GENERAL AND PHYSICAL FATIGUE}

As far as the covariates are concerned, the following variables had significant effects on general as well as physical fatigue: 'type of operation' $\left[\Delta \chi^{2}(1)=\right.$ 147.384, $P<0.01$ and $\Delta \chi^{2}(1)=153.968, P<0.01$, respectively], 'the duration of radiotherapy' $\left[\Delta \chi^{2}(1)=19.529, P<0.01\right.$ and $\Delta \chi^{2}(1)=33.404, P<0.01$, respectively]; and 'the interval between measurement point and the last radiotherapy' $\left[\Delta \chi^{2}(1)=11.347, P<0.01\right.$ and $\Delta \chi^{2}(1)=6.831, P<0.01$, respectively]. Women with a mastectomy were more fatigued than women that underwent a lumpectomy. The effects for radiotherapy were the longer the duration of radiotherapy, the higher the fatigue, and the longer the time interval between the last radiotherapy session and the measurement point, the less the fatigue experienced at that measurement point.

The covariate 'marital status' was only significant for general fatigue $\left[\Delta \chi^{2}(3)\right.$ $=10.736, P<0.05]$. Divorced women were more fatigued than women living with a partner $\left[\Delta \chi^{2}(1)=9.515, P<0.01\right]$, and were more fatigued than single 


\section{Chapter 3}

Table 5. Prevalence of fatigue

\begin{tabular}{|c|c|c|c|c|c|c|c|c|c|c|}
\hline \multirow[t]{2}{*}{ Measurement point $\rightarrow$} & \multicolumn{2}{|c|}{$\begin{array}{l}\text { 1st cycle* } \\
n=157\end{array}$} & \multicolumn{2}{|c|}{$\begin{array}{l}\text { 3rd cycle } \\
n=157\end{array}$} & \multicolumn{2}{|c|}{$\begin{array}{l}\text { 5th cyclet } \\
\qquad n=135\end{array}$} & \multicolumn{2}{|c|}{$\begin{array}{l}4 \text { weeks after } \\
\text { the last cycle } \\
\quad n=152\end{array}$} & \multicolumn{2}{|c|}{$\begin{array}{l}12 \text { weeks after } \\
\text { the last cycle } \\
\quad n=152\end{array}$} \\
\hline & $n$ & $\%$ & $n$ & $\%$ & $n$ & $\%$ & $n$ & $\%$ & $n$ & $\%$ \\
\hline \multicolumn{11}{|l|}{ Original data RSCL: } \\
\hline Not at all (1) & 56 & 36 & 30 & 19 & 25 & 19 & 27 & 18 & 36 & 24 \\
\hline A little (2) & 61 & 39 & 59 & 38 & 50 & 37 & 62 & 41 & 69 & 45 \\
\hline Quite a bit (3) & 33 & 21 & 49 & 31 & 39 & 29 & 39 & 26 & 31 & 20 \\
\hline Very much (4) & 7 & 5 & 19 & 12 & 21 & 16 & 24 & 16 & 16 & 11 \\
\hline \multicolumn{11}{|c|}{ Classification of different answer categories into a non-fatigue group and a fatigue group: } \\
\hline \multicolumn{11}{|l|}{ Fatigue classification I: } \\
\hline Non-fatigue group (1) & 56 & 36 & 30 & 19 & 25 & 19 & 27 & 18 & 36 & 24 \\
\hline $\begin{array}{l}\text { Fatigue group } \\
(2,3 \text {, and } 4)\end{array}$ & 101 & 64 & 127 & 81 & 110 & 81 & 125 & 82 & 116 & 76 \\
\hline \multicolumn{11}{|l|}{ Fatigue classification II: } \\
\hline $\begin{array}{l}\text { Non-fatigue group } \\
\text { (1 and 2) }\end{array}$ & 117 & 75 & 89 & 57 & 75 & 56 & 89 & 59 & 105 & 69 \\
\hline $\begin{array}{l}\text { Fatigue group } \\
(3 \text {, and } 4)\end{array}$ & 40 & 25 & 68 & 43 & 60 & 44 & 63 & 41 & 47 & 31 \\
\hline \multicolumn{11}{|l|}{ Fatigue classification III: } \\
\hline $\begin{array}{l}\text { Non-fatigue group } \\
(1,2 \text { and } 3)\end{array}$ & 150 & 96 & 138 & 88 & 114 & 84 & 128 & 84 & 136 & 89 \\
\hline Fatigue group (4) & 7 & 4 & 19 & 12 & 21 & 16 & 24 & 16 & 16 & 11 \\
\hline
\end{tabular}

women $\left[\Delta \chi^{2}(1)=4.241, P<0.05\right]$. The course of physical fatigue is significantly different for the number of treatments $\left[\Delta \chi^{2}(4)=10.429, P<0.05\right]$. The effect of this covariate on the course of physical fatigue will be described later.

Figure 1 displays the adjusted baseline differences for general fatigue. The course of general fatigue is significantly different for the CMF and the doxorubicin groups $\left[\Delta \chi^{2}(4)=12.810, P<0.05\right]$. The intersection of the two lines in Figure 1 reflects this significant difference. In addition to the significant increase in general fatigue between measurements one and three in the CMF group $\left[\Delta \chi^{2}(1)\right.$ $=5.111, P<0.05]$, the only consecutive significant increase is between measurements three and four $\left[\Delta \chi^{2}(1)=4.310, P<0.05\right]$ followed by a significant decrease $\left[\Delta \chi^{2}(1)=8.555, P<0.01\right]$. The significant increase after the treatment with chemotherapy, the so-called 'late effect', is not seen in the 


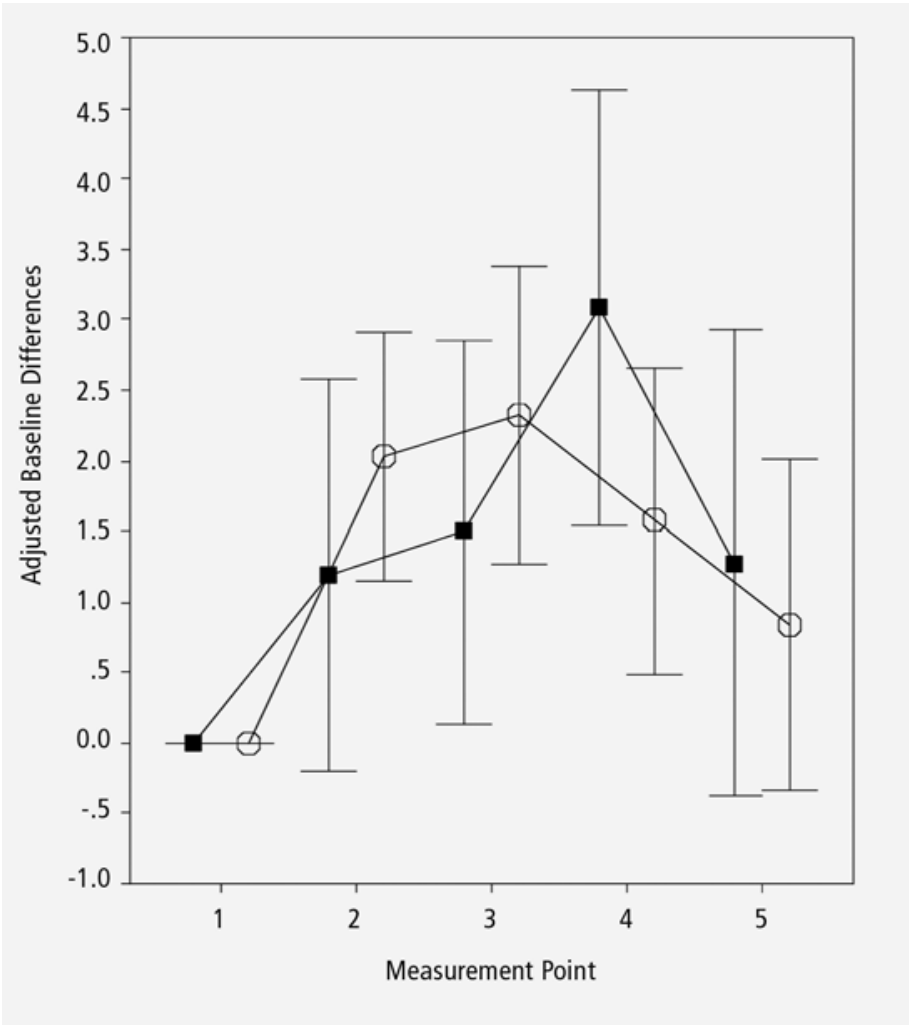

Figure 1. The course of general fatigue as a function of the type of chemotherapy. Filled square, CMF group $(n=46)$; open circles, doxorubicin group $(n=111)$; error bars, $95 \%$ confidence intervals. Patients with four treatments $(n=21)$ did not participate in the third measurement.

doxorubicin group (Figure 1). For this group, the only significant difference between consecutive measurements is found directly after the start of chemotherapy, between measurements one and two $\left[\Delta \chi^{2}(1)=13.344, P<\right.$ 0.01]. There also is an increase between measurements one and three $\left[\Delta \chi^{2}(1)\right.$ $=8.393, P<0.01]$, followed by a significant decrease between measurements three and five $\left[\Delta \chi^{2}(1)=4.455, P<0.05\right]$.

For the physical fatigue subscale, a similar pattern is seen in the effects of chemotherapy (Figures 2 and 3). In both figures the two lines intersect, implying that the course of fatigue for the two chemotherapy groups is different over time. Here the CMF group shows also a 'late effect' $\left[\Delta \chi^{2}(1)=6.438, P<0.05\right]$ and subsequently a significant decrease $\left[\Delta \chi^{2}(1)=11.195, P<0.01\right]$. Physical fatigue in doxorubicin group increases also significantly, but it does take longer. 


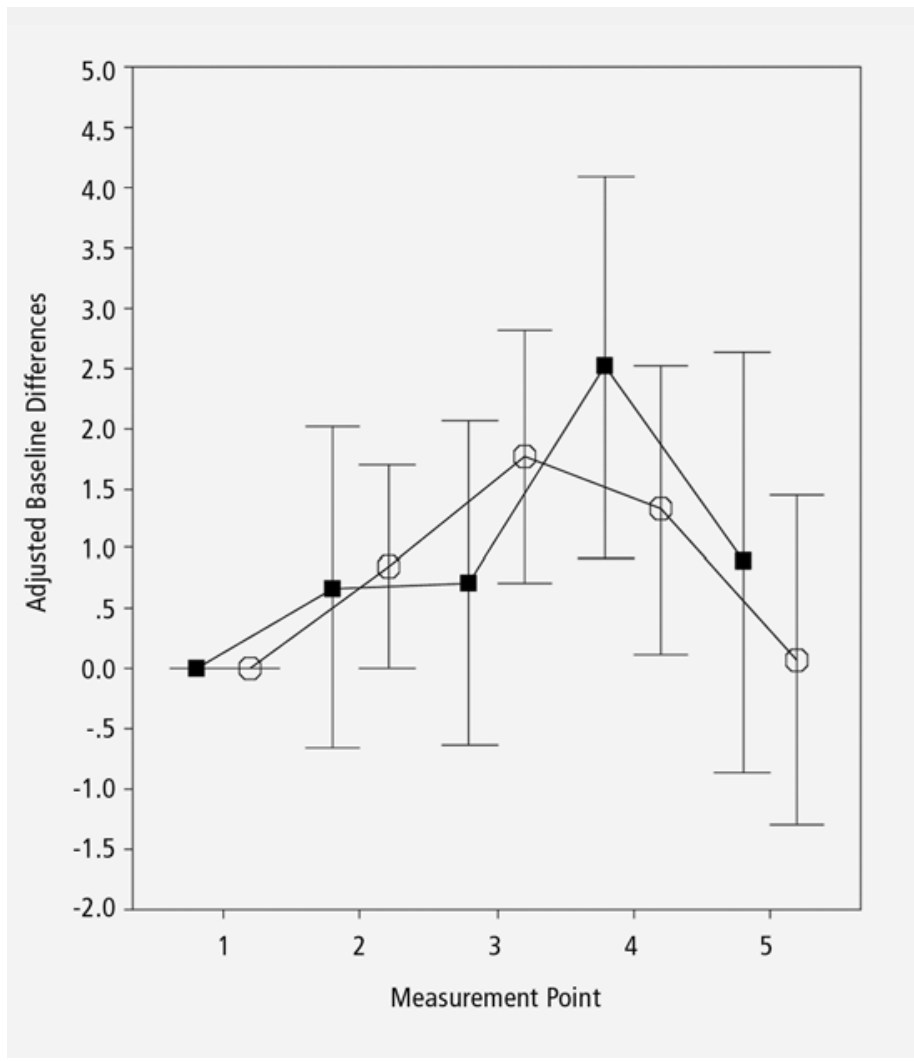

Figure 2. The course of physical fatigue as a function of type of chemotherapy: CMF group and doxorubicin group with six treatments. Filled square, CMF group $(n=46)$; open circles, doxorubicin group $(n=72)$; error bars, $95 \%$ confidence intervals.

A significant increase is seen between measurements one and three $\left[\Delta \chi^{2}(1)=\right.$ $7.018, P<0.01]$. Because the course of physical fatigue is not only significantly different for the two chemotherapy groups $\left[\Delta \chi^{2}(4)=11.105, P<0.05\right]$, but also depends on the number of chemotherapy treatments $\left[\Delta \chi^{2}(4)=10.429, P<0.05\right]$, the differences in physical fatigue after measurement three were examined for each of the chemotherapy groups stratified by the number of treatments. Stratification was only required within the doxorubicin group, because all patients in the CMF group had six treatments. Statistical testing was only possible for the doxorubicin groups with four and six treatments. The remaining groups (with five or eight treatments) were considered too small to yield reliable results. The differences in physical fatigue in the doxorubicin groups between consecutive measurement points after the last cycle of chemotherapy proved 


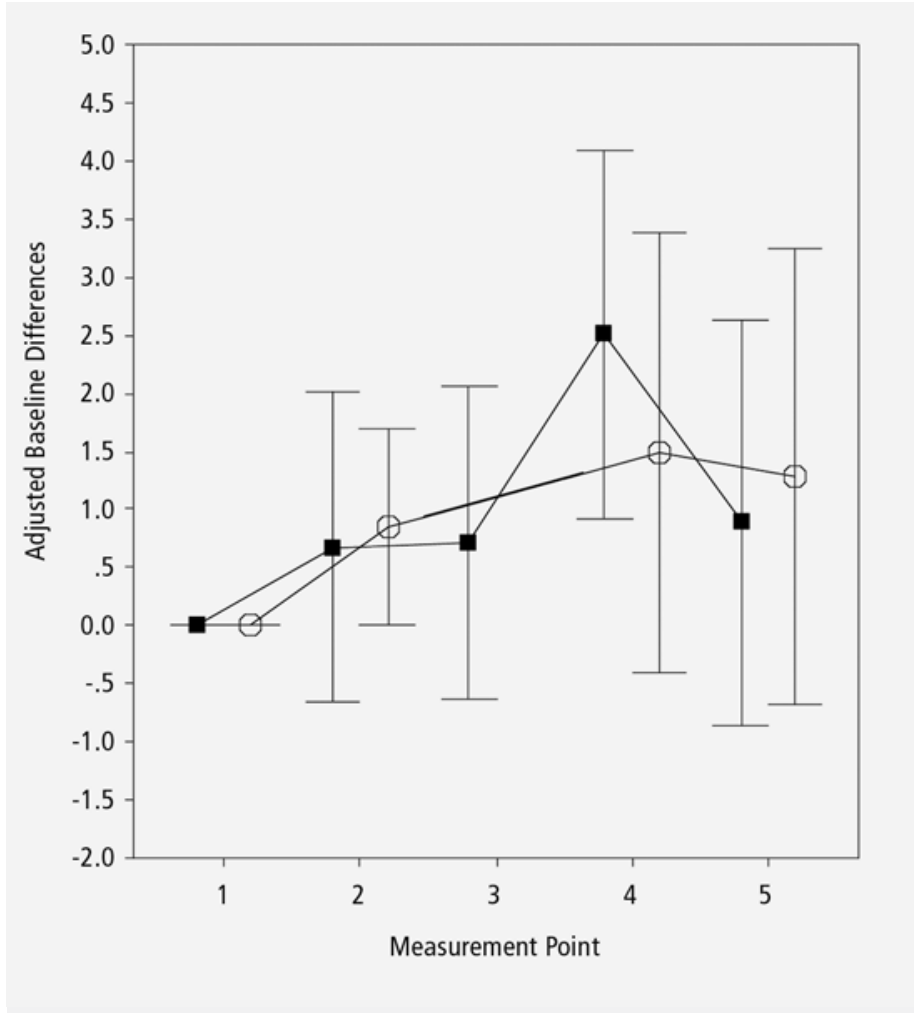

Figure 3. The course of physical fatigue as a function of type of chemotherapy: CMF group and doxorubicin group with four treatments. Filled square, CMF group $(n=46)$; open circles, doxorubicin group $(n=21)$; error bars, 95\% confidence intervals. Patients with four treatments $(n=21)$ did not participate in the third measurement.

not to be significant. Although there is a decrease in the mean fatigue scores for these groups (Figures 2 and 3), the results were not significant, possibly due to the smaller size of the groups that were examined.

Furthermore, interestingly, for each of the groups the level of fatigue at the last measurement was not significantly different from the fatigue at baseline. This was the case for general fatigue [CMF group: $\Delta \chi^{2}(1)=0.624, P=0.430$; doxorubicin group: $\Delta \chi^{2}(1)=1.02, P=0.313$ ], and for physical fatigue [CMF group: $\Delta \chi^{2}(1)=$ $0.042, P=0.838$; doxorubicin group with 4 treatments: $\Delta \chi^{2}(1)=0.361, P=0.548$; doxorubicin group with 6 treatments: $\Delta \chi^{2}(1)=0.459, P=0.498$ ].

An examination of the points at which the changes in general and physical fatigue between consecutive time points are different between the two chemotherapy groups, revealed a significant difference only for the changes 


\section{Chapter 3}

\begin{tabular}{|c|c|c|c|c|c|c|c|c|c|c|}
\hline $\begin{array}{l}\text { Table 6. Correlatio } \\
\text { 'reduced }\end{array}$ & $\begin{array}{l}\text { ons b } \\
\text { activ }\end{array}$ & $\begin{array}{l}\text { tween sub } \\
\text { ity' and 'ph }\end{array}$ & $\begin{array}{l}\text { oscal } \\
\text { hysic }\end{array}$ & $\begin{array}{l}\text { s'reduced } \\
\text { al fatigue'* }\end{array}$ & act & $t y^{\prime}$ and 'ge & ene & fatigue' ar & and $b$ & tween \\
\hline \multirow[t]{2}{*}{ Measurement point $\rightarrow$} & \multicolumn{2}{|c|}{ 1st cyclet } & \multicolumn{2}{|c|}{ 3rd cycle } & \multicolumn{2}{|c|}{ 5th cycle } & \multicolumn{2}{|c|}{$\begin{array}{l}4 \text { weeks after } \\
\text { the last cycle }\end{array}$} & \multicolumn{2}{|c|}{$\begin{array}{l}12 \text { weeks after } \\
\text { the last cycle }\end{array}$} \\
\hline & $n$ & Correlation & $n$ & Correlation & $n$ & Correlation & $n$ & Correlation & $n$ & Correlation \\
\hline \multicolumn{11}{|l|}{ General fatigue } \\
\hline Total group & 157 & 0.59 & 157 & 0.65 & 135 & 0.70 & 152 & 0.69 & 152 & 0.78 \\
\hline CMF group & 46 & 0.57 & 46 & 0.66 & 46 & 0.61 & 45 & 0.67 & 45 & 0.70 \\
\hline Doxorubicin group & 111 & 0.60 & 111 & 0.65 & 89 & 0.72 & 107 & 0.70 & 107 & 0.81 \\
\hline \multicolumn{11}{|l|}{ Physical fatigue } \\
\hline Total group & 157 & 0.67 & 157 & 0.72 & 135 & 0.80 & 152 & 0.80 & 152 & 0.83 \\
\hline CMF group & 46 & 0.61 & 46 & 0.74 & 46 & 0.79 & 45 & 0.82 & 45 & 0.75 \\
\hline Doxorubicin group & 111 & 0.70 & 111 & 0.71 & 89 & 0.80 & 107 & 0.78 & 107 & 0.86 \\
\hline
\end{tabular}

between measurements three and four $\left[\Delta \chi^{2}(1)=10.547, P<0.01\right.$ and $\Delta \chi^{2}(1)=$ 10.896, $P<0.01$, respectively]. This again underlines that the interaction between chemotherapy and the measurements is mainly due to the strong 'late effect' in the CMF group. Besides, a significant impact of the number of treatments $\left[\Delta \chi^{2}(2)=9.168, P<0.01\right]$ on physical fatigue is only found at the last measurement, indicating a delayed effect for this factor.

\section{Impact of fatigue on the activity of the patient}

Table 6 presents the correlations between the subscales 'reduced activity' and 'general fatigue' and between 'reduced activity' and 'physical fatigue' at each measurement point. All correlations are significant at $P<0.01$. The lowest correlation is 0.57 and the highest 0.86 . Fatigue is accompanied by a strong reduction in activity.

\section{Discussion}

This longitudinal study is the first large-scale examination of the course of fatigue in 157 patients with breast cancer during as well as after receiving adjuvant chemotherapy. Patients were studied directly before, during or after infusions at the first, third and fifth cycle of chemotherapy, 4 and 12 weeks after completion of chemotherapy. 


\section{Prevalence of fatigue}

For three different classifications into a fatigue group and a non-fatigue group the prevalence of fatigue was compared across time. The hypothesis that fatigue is highly prevalent during, as well as after, chemotherapy treatment can be supported, but, of course, it also depends on the method of classification of patients into fatigue and non-fatigue groups. More interesting is the fact that the changes in prevalence over time, as found in our study, are comparable, regardless of how this classification was done. In the present study, as in the previous study by Jacobsen et al. [7], a significant increase in the prevalence rates of all groups is seen after the start of chemotherapy. After this increase, as in previous studies [6,7], a stability in the prevalence rate is found during chemotherapy treatment. After the treatment of chemotherapy the prevalence rates seem to decline.

\section{Course of fatigue}

The results for the subscales general and physical fatigue are to a large extent similar.

The type of operation turns out to influence fatigue. Women with a mastectomy operation were significantly more fatigued during the whole observation period than women who underwent a lumpectomy. Probably, the extent of the surgery influences the experience of fatigue, and the loss of a breast can have devastating psychological effects on women [23].

Supplementary to chemotherapy, $69 \%$ of the women in the present study received radiotherapy. Receiving radiotherapy led to an increase in fatigue. More specifically, the longer the duration of radiotherapy (number of days of receiving radiotherapy), the higher the fatigue, and the longer the time interval between the last radiotherapy session and the measurement point, the less fatigue was experienced at that measurement point. The findings with regard to radiotherapy are logically explicable. The accumulation of radiotherapy treatments increased the experience of fatigue. This may be explained by the trip to the treatment centre. Women had to go each weekday to the treatment centre during a period of about 5 weeks. This could be rather intensive. Besides, daily routine activities had to be adjusted to the treatments. Finally, it may be the effect of radiotherapy itself or a combination of the therapies that makes these patients more fatigued [24]. After radiotherapy treatment, women recover from this intensive period, which makes the normalisation after the last treatment comprehensible. The work of Irvine et al. [25] partially support this reasoning.

Only general fatigue was influenced by marital status: divorced women were more fatigued than women living with a partner or single women. An explanation for the significant differences between the groups might be the change in the 


\section{Chapter 3}

domestic atmosphere in the (recent) past and emotional distress caused by the divorce. The finding that women living with a partner reported less fatigue might also be dependent on whether there is tangible support reducing fatigue.

The course of fatigue during the study is different for the CMF group and the doxorubicin group. Although the measurement points did not cover each treatment cycle, the intensity of fatigue in the CMF group seems to be relatively stable throughout the treatment cycles. This finding supports the hypothesis that the intensity of fatigue stays stable throughout the treatment cycles. Sitzia and Huggins [6] and Berger [8] found similar results. A reason for the stability could be habituation to the experience of fatigue. The standard for determining the level of fatigue might be changing, a shift in the internal norm. This process of changing one's internal standard is called response shift [26].

In the doxorubicin group only a significant increase in fatigue was seen during the initial measurements. Berger and Walker [14] found similar results. They found that chemotherapy protocols that contain intravenous doxorubicin were directly associated with higher fatigue levels at the first treatment. Also Jacobsen et al. [7] reported that breast cancer patients receiving chemotherapy protocols that all contain intravenous doxorubicin experienced significantly more fatigue after the start of chemotherapy.

The CMF group shows a 'late effect' on fatigue, which was not seen in the doxorubicin group. The CMF group reported significantly more fatigue 4 weeks after the completion of chemotherapy than that in the fifth cycle of chemotherapy. An explanation for this finding might be that healthcare providers become a support system for patients. The end of chemotherapy marks the loss of this support system and a change in routine. The support system is suddenly closed at a time when their fears of recurrence are enhanced [10]. This may have a negative impact on fatigue. The contact the women in the CMF group have with healthcare providers is probably more intensive than in the doxorubicin group, because they had to visit the hospital more frequently. After the significant increase in the CMF group, a significant decrease in the level of fatigue is seen 12 weeks after chemotherapy, probably because the patients have become accustomed to their daily activities again. An alternative explanation may be that the metabolism of the orally administered drug in the CMF schedule is different resulting in this delayed effect.

The level of fatigue at the last measurement did not significantly differ from the pre-treatment measurement. The hypothesis that the intensity of fatigue declines after completion is therefore supported. A limitation of the present study is the absence of a healthy control group to compare fatigue levels. Everyone experiences fatigue on daily basis. It is not known whether the fatigue at the last measurement can be regarded as normal fatigue. Probably, it cannot 
be regarded as normal fatigue. First, previous studies show that the time span after completion of chemotherapy considered in our study is most probably too short [27-29]. Secondly, it should be noted that women might be fatigued before starting any treatment. Cimprich [30] found a prevalence of fatigue of $77 \%$ before primary surgery. This increased fatigue in patients before the start of chemotherapy may reflect lingering physical and psychological stress associated with having recently undergone breast cancer surgery [7]. It should be noted that the comparability of the results of this study to other studies may be limited because of different measurement points that are utilized during, as well as after, receiving adjuvant chemotherapy [16].

\section{Impact of fatigue on the activity of the patient}

Fatigue has a strong impact on daily functioning. This finding is supported by previous studies $[8,13,15]$.

One limitation of the present study may be the lack of homogeneity in the doxorubicin group, in which five different chemotherapy regimens are represented. This may have affected the power to detect more changes in fatigue over time for this particular group. From this study we may conclude that CMF is likely to result in a delayed increase in fatigue. However, note that no measurement took place at the last chemotherapy treatment. The possibility exists that fatigue levels at the last treatment were higher than the levels one cycle before the end of treatment. Further research, in which an assessment at the last chemotherapy treatment is included is needed to conclude whether there is really a late effect in the CMF group. In addition, ongoing studies should include a comparison group of healthy subjects; fatigue tends to decline after completion of chemotherapy, but whether the fatigue levels can be regarded as 'normal' is not yet clear.

Based on the results of this study, more specific information about fatigue can be given to breast cancer patients receiving adjuvant chemotherapy. In addition, ongoing research should include interventions addressing how to reduce or to cope with fatigue during, as well as after, receiving adjuvant chemotherapy.

\section{References}

1. Irvine, D.M., et al., A critical appraisal of the research literature investigating fatigue in the individual with cancer. Cancer Nurs, 1991. 14(4): p. 188-99. 


\section{Chapter 3}

2. Atkinson, A., et al., NCCN Practice Guidelines for Cancer-Related Fatigue. Oncology, 2000. 14(11A): p. 151-61.

3. Piper, B.F., A.M. Lindsey, and M.J. Dodd, Fatigue mechanisms in cancer patients: developing nursing theory. Oncol Nurs Forum, 1987. 14(6): p. 17-23.

4. Nail, L.M. and K.B. King, Symptom distress. Fatigue. Semin Oncol Nurs, 1987. 3(4): p. 257-62.

5. Greene, D., et al., A comparison of patient-reported side effects among three chemotherapy regimens for breast cancer. Cancer Pract, 1994. 2(1): p. 57-62.

6. Sitzia, J. and L. Huggins, Side effects of cyclophosphamide, methotrexate, and 5fluorouracil (CMF) chemotherapy for breast cancer. Cancer Practice, 1998. 6 (1): p. 13-21.

7. Jacobsen, P.B., et al., Fatigue in women receiving adjuvant chemotherapy for breast cancer: Characteristics, course, and correlates. Journal of Pain and Symptom Management, 1999. 18(4): p. 233-242.

8. Berger, A.M., Patterns of fatigue and activity and rest during adjuvant breast cancer chemotherapy. Oncol Nurs Forum, 1998. 25(1): p. 51-62.

9. Berglund, G., et al., Late effects of adjuvant chemotherapy and postoperative radiotherapy on quality of life among breast cancer patients. Eur J Cancer, 1991. 27(9): p. 1075-81.

10. Beisecker, A.E., et al., Side effects of adjuvant chemotherapy: Perceptions of nodenegative breast cancer patients. Psycho Oncology, 1997. 6 (2): p. 85-93.

11. Gaston Johansson, F., et al., Fatigue, pain, and depression in pre-autotransplant breast cancer patients. Cancer Practice, 1999. 7(5): p. 240-247.

12. Okuyama, T., et al., Factors correlated with fatigue in disease-free breast cancer patients: application of the Cancer Fatigue Scale. Supportive Care in Cancer, 2000. 8(3): p. 215-222.

13. Berger, A.M. and P. Higginbotham, Correlates of fatigue during and following adjuvant breast cancer chemotherapy: a pilot study. Oncol Nurs Forum, 2000. 27(9): p. 1443-8.

14. Berger, A. and S.N. Walker, An explanatory model of fatigue in women receiving adjuvant breast cancer chemotherapy. Nursing Research, 2001. 50(3): p. 164-164.

15. Berger, A.M. and L. Farr, The influence of daytime inactivity and nighttime restlessness on cancer-related fatigue. Oncol Nurs Forum, 1999. 26(10): p. 1663-71.

16. De Jong, N., et al., Fatigue in patients with breast cancer receiving adjuvant chemotherapy: a review of the literature. Cancer Nurs, 2002. 25(4): p. 283-97.

17. Smets, E.M.A., B. Garssen, and B. Bonke, Het meten van vermoeidheid met de Multidimensionele Vermoeidheids Index (MVI-20): Een handleiding. 1995, Amsterdam: Medische Psychologie, Academisch Medisch Centrum, The Netherlands.

18. De Haes, J.C.M., et al., Measuring the quality of life of cancer patients with The Rotterdam Symptom Checklist (RSCL): A manual. 1996, Groningen: Northern Centre for Health Care Research ( $\mathrm{NCH})$, University of Groningen, The Netherlands. 


\section{Prevalence and course of fatigue}

19. Smets, E.M.A., et al., The Multidimensional Fatigue Inventory (MFI) Psychometric Qualities of an Instrument to Assess Fatigue. Journal of Psychosomatic Research, 1995. 39(5): p. 315-325.

20. Beahrs, O.H., Manual for staging of cancer. 4th ed. 1992: Philadelphia: Lippincott.

21. Rasbash, J., et al., MLwiN. 2000, Multilevel Models Project Institute of Education: London.

22. Snijders, T.A.B. and R.J. Bosker, Multilevel analysis: An introduction to basic and advanced multilevel modelling. 1999, London: Sage Publications.

23. Spencer, K.W., Significance of the breast to the individual and society. Plast Surg Nurs, 1996. 16(3): p. 131-2.

24. Woo, B., et al., Differences in fatigue by treatment methods in women with breast cancer. Oncol Nurs Forum, 1998. 25(5): p. 915-20.

25. Irvine, D.M., et al., Fatigue in women with breast cancer receiving radiation therapy. Cancer Nursing, 1998. 21 (2): p. 127-135.

26. Breetvelt, I.S. and F.S. Van Dam, Underreporting by cancer patients: the case of response-shift. Soc Sci Med, 1991. 32(9): p. 981-7.

27. Broeckel, J.A., et al., Characteristics and correlates of fatigue after adjuvant chemotherapy for breast cancer. J Clin Oncol, 1998. 16(5): p. 1689-96.

28. Bower, J.E., et al., Fatigue in breast cancer survivors: Occurrence, correlates, and impact on quality of life. Journal of Clinical Oncology, 2000. 18(4): p. 743-753.

29. Leddy, S.K., Healthiness, fatigue, and symptom experience in women with and without breast cancer. Holist Nurs Pract, 1997. 12(1): p. 48-53.

30. Cimprich, B., Pretreatment symptom distress in women newly diagnosed with breast cancer. Cancer Nurs, 1999. 22(3): p. 185-94. 

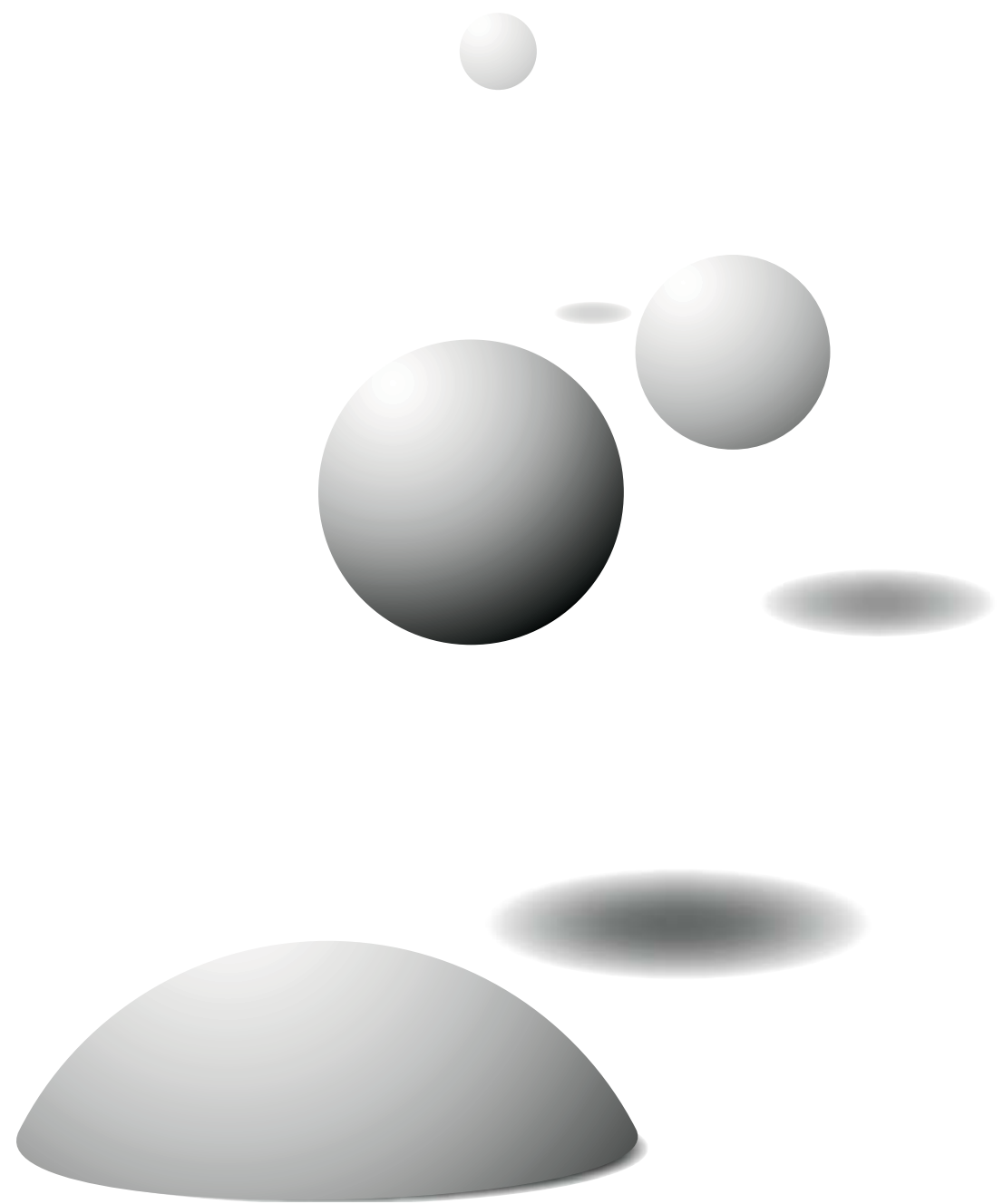


\section{Chapter 4}

\section{Course of mental fatigue and motivation in breast cancer patients receiving adjuvant chemotherapy}

Nynke de Jong, MSc, RN, Math J.J.M. Candel, PhD, Harry C. Schouten, MD, PhD, Huda Huijer Abu-Saad, FEANS, PhD, RN, \& Annemie M. Courtens, PhD, RN

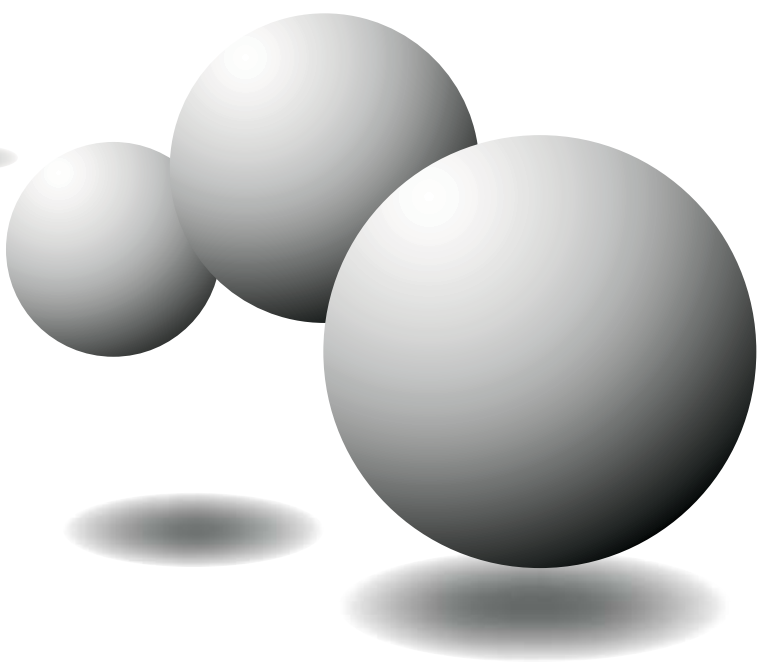

Published in: Annals of Oncology 2005; 16: 372-382.

(awarded the CAPHRI (Care And Public Health Research Institute) 2007 Philipsen Award for best publication 2005/2006) 


\section{AbStract}

Background: The purpose of this study is to determine the course of fatigue referring to cognitive symptoms (scale 'mental fatigue') as well as the motivation to start any activity (scale 'reduced motivation'), as a function of chemotherapy, in breast cancer patients undergoing adjuvant chemotherapy.

Patients and methods: In a prospective cohort study a sample of 157 patients with breast cancer was interviewed at the first, third and fifth cycle of adjuvant chemotherapy as well as 4 and 12 weeks after completion of adjuvant chemotherapy. Patients were treated with standard adjuvant chemotherapy, either a doxorubicin containing schedule or cyclophosphamide, methotrexate and 5-fluorouracil (CMF). The psychological dimensions of fatigue were measured by the Multidimensional Fatigue Inventory. A linear multilevel model was used for analysing the courses.

Results: The course of mental fatigue and motivation were not affected by the type of chemotherapy. The course of mental fatigue and motivation varied, but seemed to be stable during the treatment of chemotherapy. After the completion of chemotherapy, a weak improvement was seen. Relatively many patients experienced depressive symptoms during the study. These symptoms were correlated with both dimensions of fatigue.

At all measurements mental fatigue was influenced by type of operation where women with a mastectomy were significantly more mentally fatigued than women that had undergone a lumpectomy, but nevertheless they were significantly more motivated to start any activity. Age, marital status, number of treatments and the interval between the operation and the first treatment of chemotherapy seem to be also important determinants.

Conclusions: An unequivocal pattern of mental fatigue and reduced motivation during as well after adjuvant chemotherapy was not found. Depressive symptoms are definitely related to these variables. Type of operation had a significant impact on mental fatigue and motivation to start any activity.

Health care providers should be aware of the high rate of patients who experience depressive symptoms during and after the treatment of chemotherapy.

Further research should include the trajectory preceding adjuvant chemotherapy and a longer study period afterwards. Moreover, the exact influence of the variables 'age', 'marital status', 'number of treatments' and 'the interval between the operation and the first treatment of chemotherapy' on fatigue is unclear and needs further study.

Key words: adjuvant chemotherapy, breast cancer, mental fatigue, motivation 


\section{INTRODUCTION}

Fatigue has been identified as the most disabling symptom experienced by patients during treatment for cancer. The National Comprehensive Cancer Network (NCCN) found that $70-100 \%$ of the cancer patients were affected by fatigue [1]. Despite the high prevalence of fatigue and its profoundly negative effect on patients' quality of life, little is known about fatigue [2].

Breast cancer has been 0the most frequently occurring malignancy in women since the early 1990s in the Netherlands [3]. A large subset of these patients receives adjuvant chemotherapy as part of the standard treatment. The course of fatigue in these patients has also hardly been examined. In a recent literature review [2], high and fluctuating prevalence rates of fatigue in breast cancer patients have been found not only during but also after adjuvant chemotherapy. The intensity of fatigue seems to be stable throughout the treatment cycles. After the treatment of adjuvant chemotherapy, patients still experience fatigue, but it is unknown whether this fatigue can be regarded as normal fatigue. The influence of different factors on the course of fatigue is unclear and less well studied [2]. The impact of different chemotherapy regimens on the course of fatigue is not unequivocal, but seems to be an important factor. Berger and Walker found [4] recently that chemotherapy protocols that contain intravenous doxorubicin were directly associated with higher fatigue at the first treatment. They studied 60 women during the first three cycles of adjuvant breast chemotherapy [4]. De Jong et al. [5] reported that the course of general and physical fatigue during and after chemotherapy treatment was significantly different for the CMF group (cyclophosphamide, methotrexate and 5-fluorouracil), compared with a doxorubicin group. After the start of chemotherapy, a direct increase in fatigue in the doxorubicin group is seen, whereas the increase in the CMF group does not show until after the fifth cycle of chemotherapy.

Fatigue is associated with various symptoms [2]. There is evidence for a relationship between fatigue and the severity of psychological symptoms [2]. The loss of a breast can have devastating psychological effects on women [6]. Depressive symptoms are a common and disruptive problem for cancer patients [7]. That fatigue and depression are related is beyond doubt, but the interpretation of this relation is, however, complicated [8]. The symptoms of fatigue and depression overlap. In addition, fatigue is one of the key symptoms of depression and may be the result of depressed mood. On the other hand, a person who continuously perceives his or her energy as insufficient may become depressed. Cancer fatigue and depression may co-occur without having a causal relationship, because they can both originate from the same pathology [8]. 


\section{Chapter 4}

The course of fatigue in breast cancer patients receiving adjuvant chemotherapy with regard to psychological aspects, such as cognitive functioning, concentration ability, mental effort and mood-state, is less frequently studied. Cimprich [9] has reported a decline in the capacity for attention and concentration in women undergoing treatment for breast cancer in the initial phases of illness.

In a recent study by De Jong et al. [5] the course of general and physical fatigue, as a function of chemotherapy (CMF group versus doxorubicin group), was studied in 157 breast cancer patients undergoing adjuvant chemotherapy. These two dimensions of fatigue were measured by the Multidimensional Fatigue Inventory (MFI-20) [5]. This study is part of this large-scale examination and will describe, also using the MFI-20, the psychological dimensions of fatigue: mental fatigue and reduced motivation. Cognitive symptoms such as having difficulties concentrating are included in the scale 'mental fatigue' [10]. Lack of motivation to start any activity is covered by the scale 'reduced motivation' [10]. In this study, these two subscales were examined, because only these two subscales relate to psychological aspects of fatigue and both may be related in a unique way to quality of life as compared with the other subscales of the MFI-20. Depression was measured by the Center for Epidemiological Studies Depression Scale (CES-D) [11]. This scale measures depressive feelings which may result from experiencing a particular incident [12].

As a result of the absence of longitudinal studies on the course of dimensions of fatigue conducted thus far, the purpose of the present study was to examine the course of 'mental fatigue' and 'reduction in motivation' during (two or three measurement points) as well as after (two measurement points) adjuvant chemotherapy.

In this manuscript, we test two hypotheses. The first is mainly based on a literature review [2]: the intensity of mental fatigue and reduction in motivation remains stable during the treatment of chemotherapy and changes in a positive direction after completion. The impact of different chemotherapy regimens, like doxorubicin containing regimens, on the course of fatigue is unclear and will therefore be further investigated in the present study. The second hypothesis holds that, during as well as after adjuvant chemotherapy, fatigue and depressive symptoms are related.

\section{Patients AND MEthods}

\section{Patient selection}

Breast cancer patients treated in six hospitals, mainly in the south of the Netherlands, were enrolled in this study if they met the following criteria: (1) 
had no metastasis or other malignancy, (2) were not treated with cytostatics before, (3) had to be treated with outpatient adjuvant chemotherapy, (4) did not have a chronic disease (such as hypertension, kidney disease, heart problems, diabetes mellitus, etc.) or a poor psychological state (such as diagnosed with a depression), (5) did not use morphine or narcoleptics, (6) were not deaf, (7) had to be 18 years or older, and (8) could speak and understand Dutch. Patients were recruited in the period from March 1998 till October 2000.

Before the first cycle of adjuvant chemotherapy and after checking the inclusion criteria, the oncologist or the oncology nurse introduced the study to the patient with written information describing the purpose and procedure of the investigations. The oncologist or the oncology nurse contacted the principal investigator of this study after obtaining written informed consent. The principal investigator and a properly trained assistant interviewed the participants. All local medical ethical committees of the participating centres had approved the study.

\section{Data collection}

Data were collected, using the Multidimensional Fatigue Inventory (MFI-20) [13], five times except when receiving the CA (cyclophosphamide and doxorubicin) treatment, in which case participants were interviewed only four times. Patients had the first interview at the start of chemotherapy, the second at the third cycle and the third at the fifth cycle except for the CA regimen, where the third interview was omitted. The last two interviews were held 4 and 12 weeks after the last cycle. The first three interviews took place directly before, during or after infusion in the hospital. The interviews after the last cycle were done by phone. The medical data were retrieved from charts after the interviews.

\section{Operationalisation of variables}

The intensity of fatigue. Fatigue was assessed by a 20-item questionnaire, the Multidimensional Fatigue Inventory (MFI-20) [13]. This self-report instrument, especially designed for cancer patients, consists of five scales based on different dimensions: general fatigue, physical fatigue, reduced activity, reduced motivation and mental fatigue. Each scale consists of four statements. The score for each scale was calculated as the sum of the scores of the four statements, for which high scores indicate more subjective fatigue. Statements should be answered with respect to the last days. Data of all subscales were collected. This study will focus on the results of two scales 'mental fatigue' and 'reduced motivation'. Cognitive symptoms such as having difficulties concentrating are included in the scale 'mental fatigue' [10]. Lack of motivation to start any activity is covered by the scale 'reduced motivation' [10]. The items of these subscales are presented in Table 1.

The MFI-20 was previously tested and validated in studies with cancer 


\section{Chapter 4}

Table 1. Items of the subscales 'mental fatigue' and 'reduced motivation' of the MFI-20

\begin{tabular}{|c|c|}
\hline & Items \\
\hline \multicolumn{2}{|l|}{ Subscale } \\
\hline Mental fatigue & $\begin{array}{l}\text { 1. When I am doing something, I can keep my thoughts on it* } \\
\text { 2. I can concentrate well } \\
\text { 3. It takes a lot of effort to concentrate on things } \\
\text { 4. My thoughts easily wander }\end{array}$ \\
\hline Reduced motivation & $\begin{array}{l}\text { 1. I feel like doing all sorts of nice things } \\
\text { 2. I dread having to do things } \\
\text { 3. I have a lot of plans } \\
\text { 4. I don't feel like doing anything }\end{array}$ \\
\hline
\end{tabular}

patients receiving radiotherapy, patients with 'chronic fatigue syndrome', psychology students, medical students, army recruits and junior physicians. The internal consistency for the two scales 'mental fatigue' and 'reduced motivation' in these studies as measured by Cronbach's alpha averaged 0.86 (with a range of 0.77 to 0.93 ) and 0.72 (with a range of 0.57 to 0.82 ), respectively [14].

Patients in this study were asked to rate, in an interview, their fatigue as experienced during the previous 2 weeks. A period of 2 weeks was chosen to obtain a more stable a measure of the experienced fatigue between chemotherapy cycles. Instead of presenting the items in a self-report questionnaire, the items were administered in a face-to-face interview, since this took less time of the respondents. Another reason for administering the scales in a face-to-face interview was that there was a closer contact between the interviewer and patient. The personal attention of the interviewer was thought to be more motivating for respondents to continue participating in the study.

Depressive symptoms. The Center for Epidemiological Studies Depression Scale (CES-D) [11] was used to measure depressive symptoms. This self-report scale, administered as a structured interview in the present study, contains 20 items selected from the previously validated scale of depression. Patients indicated how often within the last 2 weeks they experienced the symptoms, responding 'rarely or none of the time' (0); 'some or little of the time' (1); 'occasionally or a moderate amount of time' (2); and 'most or all of the time' (3). The range of scores is 0 to 60 , with higher scores indicating more symptoms. The cut-off score for a depressive syndrome is 16 .

The CES-D has been tested in healthy subjects, cancer patients, myocardium infarct patients and students. The internal consistency was good and varied 
between 0.79 and 0.92 [12]. In another study the psychometric properties of CES-D were assessed for both women undergoing treatment for breast cancer and for women with no history of cancer. Here, also good internal consistencies were found, with alpha coefficients larger than 0.85 [7].

Treatment of adjuvant chemotherapy. Patients were receiving one of the following adjuvant treatments: CEF (cyclophosphamide, 4-epi-doxorubicin and 5-fluorouracil) every 21 days, CAF (cyclophosphamide, doxorubicin and 5fluorouracil) every 21 days, 4-epi-doxorubicin every 28 days (on days 1 and 8), 4-epi-doxorubicin/taxotere with the first three cycles every 28 days (on days 1 and 8 ) and the last three cycles every 21 days, CA (cyclophosphamide and doxorubicin) every 21 days and CMF [cyclophosphamide, methotrexate (oral administration from day 1 to day 14 or intravenous) and 5-fluorouracil] every 28 days (on days 1 and 8). Most regimens consisted of six cycles except the CA regimen which consisted of four cycles.

In this study, two groups were compared: the doxorubicin group (CEF, $\mathrm{CAF}$, 4-epi-doxorubicin, 4-epi-doxorubicin/taxotere and CA) and the CMF group. The participating hospitals based the choice for either schedule on their current practice. The involvement of different adjuvant chemotherapy regimens in the doxorubicin group made it possible to create a sizeable sample in a relatively short period of time.

Stage of breast cancer. The anatomic extent of breast cancer was described by using the TNM (tumour-node-metastasis) clinical classification [15].

Type of operation. In this study, patients underwent a mastectomy or a lumpectomy with or without lymph nodes excision. In the analyses two groups were compared because of small sizes of the other groups: (1) mastectomy with lymph nodes excision, and (2) lumpectomy with lymph nodes excision. During the study period no reconstructive surgery was done.

\section{Statistical Analyses}

It was statistically tested whether there were differences in patient characteristics between the CMF group and the doxorubicin group.

The reliability of the MFI-20 and the CES-D was examined by calculating Cronbach's $\alpha$. This coefficient of internal consistency was calculated for each measurement point.

The course of mental fatigue, as well as motivation and the dependency on the type of treatment of adjuvant chemotherapy, were analysed with a linear multilevel model using the MLwiN program (version 1.10.0006) [16]. The data consist of a series of repeated measurements nested within hospitals and individual subjects. The data, which have a hierarchical nature, may be 
characterised by dependencies between units at lower levels of the hierarchy. In this case, multilevel analysis is an appropriate technique [17]. Before the main analyses were executed, a PP-plot of the residuals at the individual level was made to check the normality assumption of multilevel analysis.

In the analyses concerning the effect of chemotherapy regimen on the course of fatigue, dummy variables were included to represent the several measurement points. When the first measurement is taken as a reference, changes relative to the baseline measurement are analysed. The effect of chemotherapy on the course of fatigue was represented by interaction terms between these dummy variables and a binary variable chemotherapy. To correct for possibly confounding factors in this analysis several covariates were added: 'age', 'marital status', 'having children', 'education', 'having a job', 'type of operation', 'stage of breast cancer', 'haemoglobin level (measured in $\mathrm{mmol} / \mathrm{l}$ ) before the first treatment of chemotherapy', 'the number of days between the operation and the first treatment of chemotherapy', 'the number of treatments at each measurement point' and 'radiotherapy'. For the covariate 'radiotherapy' three different variables were used: a variable indicating whether a patient had received radiotherapy at any point of measurement, the number of days of radiotherapy the patient had had at the time of measurement and the number of days between the last day of radiotherapy and the time of measurement. Also these covariates were included as interaction terms with the dummy variables representing the time points. In this way, possible differences in patient characteristics between the chemotherapy groups are corrected for.

A multi-collinearity analysis was done to determine whether independent variables were strongly associated with each other.

Stepwise deletion took place in which non-significant covariates were deleted. A significance level of 0.05 was used. The least significant covariate, with significance level above 0.05 was deleted first. A new analysis was done, without this particular covariate, after which the least significant covariate was again deleted, provided that its significance level was above 0.05. This process continued until all covariates with significance level above 0.05 were deleted. For this model, the effect of the variable 'treatment of adjuvant chemotherapy' was examined. For the final model fatigue scores, which are differences relative to baseline and are also adjusted for differences between the chemotherapy groups, can be calculated. These will be denoted as adjusted baseline differences.

Finally, correlations were also calculated between depressive symptoms and the subscale 'mental fatigue' as well as depressive symptoms and the subscale 'reduced motivation' to examine their relationship. 


\section{ResUlts}

\section{Response rate}

A sample of 175 breast cancer patients were eligible for the study. Eighteen patients $(10 \%)$ were excluded for different reasons: $13(7 \%)$ declined further participation, three $(2 \%)$ stopped the adjuvant chemotherapy prematurely because of physical problems and two $(1 \%)$ had a poor physical state. Depending on their adjuvant chemotherapy schedules the remaining 157 patients could be interviewed four $(n=20)$ or five $(n=137)$ times. The response rate for the first two interviews was $100 \%$. Two respondents were not interviewed at the third measurement (response rate 99\%). At the last two measurements, the response rate was $97 \%$. A change in the treatment schedule was the cause of the non-response except for two interviews. Most interviews (79\%) were conducted by the principal investigator.

\section{Sample Characteristics}

The characteristics of the patients who were excluded from the study $(n=18)$ were not available. Demographic and medical characteristics of the included patients are shown in Table 2. Forty-six patients (29\%) had received the CMF treatment, the remainder had received one of the chemotherapies covered by the doxorubicin group. There were two characteristics on which the groups differed: 'age' and 'having a job'. Patients in the doxorubicin group were significantly ( $t=-2.133 ; P=0.035$ ) older than patients in the CMF group. The mean age was 48.2 years $(\mathrm{SD}=9.0)$ in the doxorubicin group and 45.0 years $(\mathrm{SD}=7.9)$ in the CMF group. Significantly $\left(\chi^{2}(1)=4.768, P=0.034\right)$ fewer patients in the doxorubicin group had a job compared to the CMF group. Details on the total number of chemotherapy treatments are shown in Table 3.

\section{Internal consistency of the MFI-20 and the CES-D}

For all five measurement occasions, Cronbach's $\alpha$ for the subscale 'mental fatigue' was greater than 0.90 (Table 4). The mean Cronbach's $\alpha$ of this subscale averaged across all measurement occasions was 0.93. The mean Cronbach's $\alpha$ of the subscale 'reduced motivation' was lower, 0.82. At measurement occasion 1 and 2 the Cronbach's $\alpha$ values for this scale were below 0.80 , but above 0.75 .

The Cronbach's $\alpha$ values of the CES-D were 0.90 or higher, with a mean of 0.91 .

\section{Normality and multcollinearity}

A PP-plot of the residuals at the individual level was made to check the normality assumption. The PP-plot shows that residuals at this level are normally distributed. 


\section{Chapter 4}

\begin{tabular}{|c|c|c|c|c|c|c|}
\hline \multirow{4}{*}{$\begin{array}{l}\text { Age (years)* } \\
\text { Mean (SD) } \\
\text { Range }\end{array}$} & \multicolumn{2}{|c|}{$\begin{array}{l}\text { Doxorubicin group } \\
\quad(n=111)\end{array}$} & \multicolumn{2}{|c|}{$\begin{array}{l}\text { CMF group } \\
(n=46)\end{array}$} & \multicolumn{2}{|c|}{$\begin{array}{c}\text { Total } \\
(n=157)\end{array}$} \\
\hline & \multirow{3}{*}{\multicolumn{2}{|c|}{$\begin{array}{c}48.2(9.0) \\
27-70\end{array}$}} & \multirow{2}{*}{\multicolumn{2}{|c|}{$45.0(7.9)$}} & \multirow{2}{*}{\multicolumn{2}{|c|}{$47.3(8.8)$}} \\
\hline & & & & & & \\
\hline & & & & & & -70 \\
\hline & $n$ & $\%$ & $n$ & $\%$ & $n$ & $\%$ \\
\hline \multicolumn{7}{|l|}{ Marital status } \\
\hline Married/living together & 91 & 82 & 40 & 87 & 131 & 83 \\
\hline Single & 11 & 10 & 3 & 7 & 14 & 9 \\
\hline Divorced & 7 & 6 & 3 & 7 & 10 & 6 \\
\hline Widow & 2 & 2 & - & - & 2 & 1 \\
\hline \multicolumn{7}{|l|}{ Children } \\
\hline Yes & 87 & 78 & 37 & 80 & 124 & 79 \\
\hline No & 24 & 22 & 9 & 20 & 33 & 21 \\
\hline \multicolumn{7}{|l|}{ Educational levelt } \\
\hline Low & 43 & 39 & 13 & 28 & 56 & 36 \\
\hline Middle & 43 & 39 & 24 & 52 & 67 & 43 \\
\hline High & 25 & 23 & 9 & 20 & 34 & 22 \\
\hline \multicolumn{7}{|l|}{ Job* } \\
\hline Yes & 59 & 53 & 33 & 72 & 92 & 59 \\
\hline No & 52 & 47 & 13 & 28 & 65 & 41 \\
\hline \multicolumn{7}{|l|}{ Stage of breast cancer $\ddagger$} \\
\hline I & 9 & 8 & 3 & 7 & 12 & 8 \\
\hline II & 90 & 81 & 35 & 76 & 125 & 80 \\
\hline III & 4 & 4 & 2 & 4 & 6 & 4 \\
\hline I and III (two tumours) & - & - & 1 & 2 & 1 & 1 \\
\hline $\begin{array}{l}\text { Unknown (missing at the data } \\
\text { collection point) }\end{array}$ & 8 & 7 & 5 & 11 & 13 & 8 \\
\hline \multicolumn{7}{|l|}{ Type of operation§ $\S$} \\
\hline Mastectomy without lymph nodes excision & 3 & 3 & - & - & 3 & 2 \\
\hline Mastectomy with lymph nodes excision & 53 & 48 & 20 & 43 & 73 & 47 \\
\hline Lumpectomy without lymph nodes excision & 1 & 1 & - & - & 1 & 1 \\
\hline Lumpectomy with lymph nodes excision & 52 & 47 & 26 & 57 & 78 & 50 \\
\hline Unknown & 2 & 2 & - & - & 2 & 1 \\
\hline \multicolumn{7}{|l|}{$\begin{array}{l}\text { Treatment of adjuvant } \\
\text { chemotherapy }\end{array}$} \\
\hline CEF & 38 & 34 & - & - & 38 & 24 \\
\hline CAF & 27 & 24 & - & - & 27 & 17 \\
\hline 4 epi-doxorubicin & 21 & 19 & - & - & 21 & 13 \\
\hline 4 epi-doxorubicin / taxotere & 5 & 5 & - & - & 5 & 3 \\
\hline CA & 20 & 18 & - & - & 20 & 13 \\
\hline CMF (no oral administration) & - & - & 15 & 33 & 15 & 10 \\
\hline CMF (partially oral administration) & - & - & 31 & 67 & 31 & 20 \\
\hline \multicolumn{7}{|l|}{ Radiotherapy } \\
\hline Yes & 75 & 68 & 33 & 72 & 108 & 69 \\
\hline No & 36 & 32 & 13 & 28 & 49 & 31 \\
\hline \multicolumn{7}{|l|}{$\begin{array}{l}\text { Anaemia (haemoglobin level, } \\
\mathrm{mmol} / \mathrm{l}<7.3)^{¥}\end{array}$} \\
\hline Yes & 10 & 9 & 1 & 2 & 11 & 7 \\
\hline No & 99 & 89 & 43 & 94 & 142 & 90 \\
\hline Unknown & 2 & 2 & 2 & 4 & 4 & 3 \\
\hline
\end{tabular}


Table 2. Patient characteristics (continued)

\begin{tabular}{|c|c|c|c|}
\hline \multicolumn{4}{|l|}{$\begin{array}{l}\text { Length of radiotherapy treatment } \\
\text { (days) }\end{array}$} \\
\hline Mean (SD) & $42.9(5.7)$ & $43.4(5.5)$ & $43.1(5.6)$ \\
\hline Range & $26-51$ & $32-57$ & $26-57$ \\
\hline \multicolumn{4}{|l|}{ Number of radiotherapy treatments } \\
\hline Mean (SD) & $30.4(3.5)$ & $30.4(3.4)$ & $30.4(3.5)$ \\
\hline Range & $25-35$ & $25-33$ & $25-35$ \\
\hline \multicolumn{4}{|l|}{$\begin{array}{l}\text { Days between operation and } 1^{\text {st }} \\
\text { chemotherapy treatment }\end{array}$} \\
\hline Mean (SD) & $33.9(21.6)$ & $38.8(26.5)$ & $35.3(23.2)$ \\
\hline Range & $9-215$ & $15-125$ & $9-215$ \\
\hline \multicolumn{4}{|l|}{ Haemoglobin level, mmol// ${ }^{¥}$} \\
\hline Mean (SD) & $8.1(0.8)$ & $8.3(0.6)$ & $8.2(0.7)$ \\
\hline Range & $5.9-9.7$ & $7.0-9.9$ & $5.9-9.9$ \\
\hline \multirow{2}{*}{\multicolumn{4}{|c|}{$\begin{array}{l}\text { * Statistically significant difference }(P<0.05) \text { in characteristic between the doxorubicin group and CMF grour } \\
\text { † Low is primary school/lower vocational education; middle is lower general secondary education/intermediat } \\
\text { vocational education; and high is higher general secondary education/higher vocational education/universit } \\
\text { ¥ Three groups, stage of breast cancer I, II and III, were included in the comparison between the doxorubicin } \\
\text { group and CMF group. }\end{array}$}} \\
\hline & & & \\
\hline \multicolumn{4}{|c|}{$\begin{array}{l}\S \text { Two groups, mastectomy or lumpectomy with lymph nodes excision, were included in the comparison } \\
\text { between the doxorubicin group and CMF group. }\end{array}$} \\
\hline \multicolumn{4}{|c|}{$\begin{array}{l}¥ \text { The haemoglobin level was determined before the first treatment of chemotherapy; the conversion factor } \\
\text { from } \mathrm{mmol} / \mathrm{l} \text { to } \mathrm{g} / \mathrm{dl} \text { is } 1.6 \text {. }\end{array}$} \\
\hline
\end{tabular}

Table 3. Total number of treatments specified for the two chemotherapy groups $(n=157)$

\begin{tabular}{|l|c|c|c|c|c|}
\hline Total number of treatments $\rightarrow$ & $\mathbf{4}$ & $\mathbf{5}$ & $\mathbf{6}$ & $\mathbf{8}$ & Total $(\boldsymbol{n})$ \\
\hline $\begin{array}{l}\text { Treatment of adjuvant } \\
\text { chemotherapy }\end{array}$ & & & & \\
\hline $\begin{array}{l}\text { Doxorubicin group } \\
\text { CMF }\end{array}$ & 21 & 10 & 72 & 8 & 111 \\
\hline
\end{tabular}

Table 4. Internal consistencies (IC) of the MFI-20 and CES-D

\begin{tabular}{|c|c|c|c|c|c|c|c|c|c|c|}
\hline \multirow[t]{2}{*}{ Measurement point $\rightarrow$} & \multicolumn{2}{|c|}{$\begin{array}{c}\text { 1st cycle* } \\
n=157\end{array}$} & \multicolumn{2}{|c|}{$\begin{array}{c}3 \text { rd cycle } \\
n=157\end{array}$} & \multicolumn{2}{|c|}{$\begin{array}{c}\text { 5th cyclet } \\
\qquad n=135\end{array}$} & \multicolumn{2}{|c|}{$\begin{array}{c}4 \text { weeks after } \\
\text { the last cycle } \\
\quad n=152\end{array}$} & \multicolumn{2}{|c|}{$\begin{array}{c}12 \text { weeks after } \\
\text { the last cycle } \\
n=152\end{array}$} \\
\hline & $n$ & IC & $n$ & IC & $n$ & IC & $n$ & IC & $n$ & IC \\
\hline Mental fatigue & 157 & 0.92 & 157 & 0.93 & 135 & 0.94 & 152 & 0.91 & 152 & 0.93 \\
\hline Reduced motivation & 157 & 0.75 & 157 & 0.77 & 135 & 0.85 & 152 & 0.85 & 152 & 0.87 \\
\hline CES-D & 155 & 0.90 & 156 & 0.90 & 135 & 0.92 & 151 & 0.92 & 152 & 0.94 \\
\hline
\end{tabular}




\section{Chapter 4}

None of the independent variables was very strongly associated with another independent variable (correlations always lower than 0.2) indicating that multicollinearity was not problem for the analysis.

\section{Course of two psychological dimensions of fatigue}

The course of fatigue is studied by analysing separately the results of two scales of the MFI-20 corresponding to the different dimensions that can be distinguished: mental fatigue and reduced motivation. In Figure 1, raw mean scores of both subscales are presented to give a first impression of the course of the two dimensions of fatigue. Both courses seemed to be relatively stable during the study period. A specific description of both courses is given next.

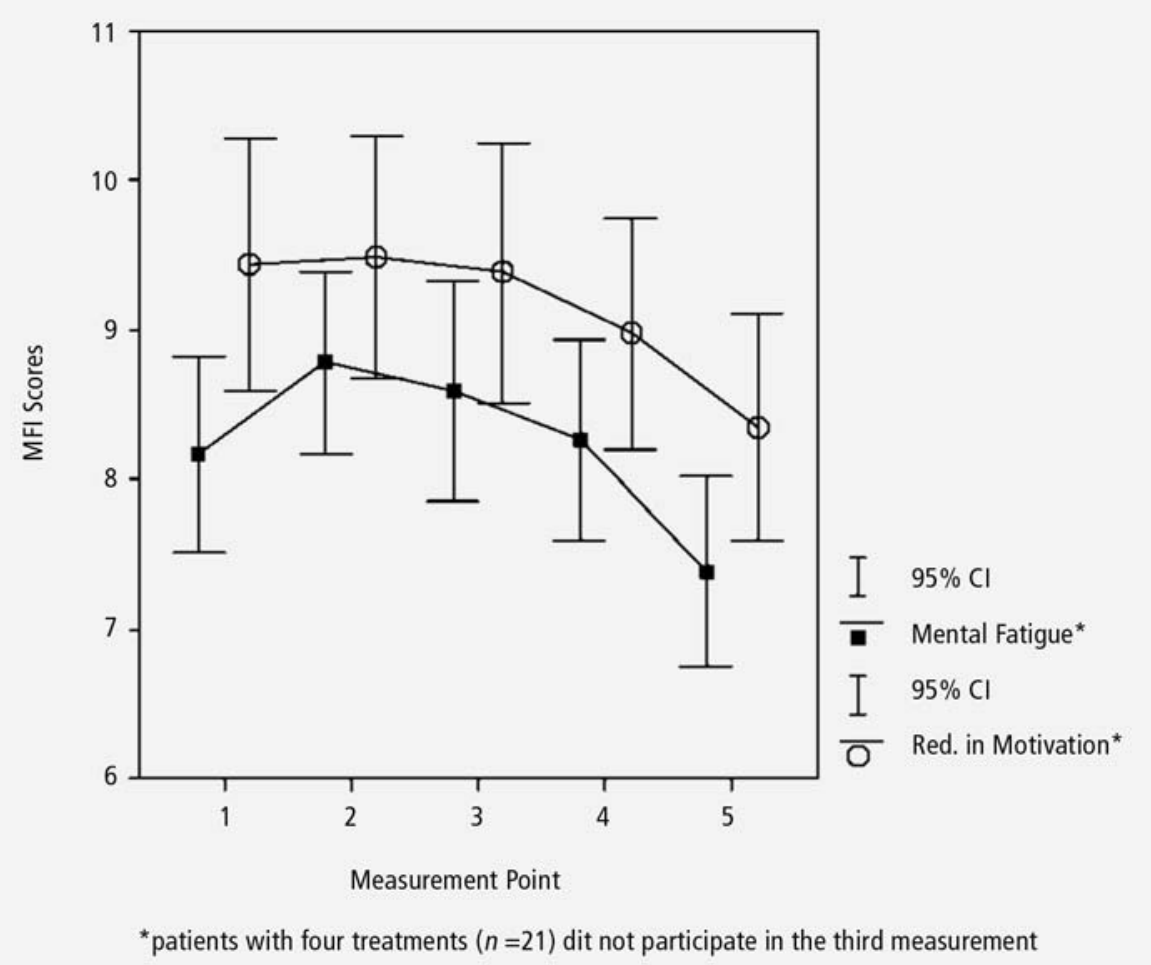

Figure 1. Raw mean scores of the MFI subscales 'mental fatigue' and 'reduction in motivation' (range 4-20, the higher the score the more mental fatigue or reduction in motivation is experienced) ( $n=157)$. 


\section{Course of mental fatigue}

Mental fatigue is not affected by the type of chemotherapy. The course of mental fatigue during the study is significantly different for groups depending on the variables 'interval between operation and first treatment of chemotherapy' $\left(\Delta \chi^{2}(4)=11.754, P<0.05\right)$, 'number of treatments' $\left(\Delta \chi^{2}(4)=14.362, P<0.01\right)$, and 'marital status' $\left(\Delta \chi^{2}(12)=21.868, P<0.05\right)$.

The variable 'interval between operation and first treatment of chemotherapy' was categorised into the groups: 1 to 25 days ( $n=46), 26$ days to 50 days $(n=97)$ and 51 days or more $(n=14)$. When combining all variables, the subgroups were too small to perform separate analyses for each resulting stratum. Consequently, stratification only took place for each variable separately that interacted with the variable 'measurement points'. By investigating the time effects in this way for each stratum, the averaged effects are examined, where the other two variables that interact with measurement points were averaged across.

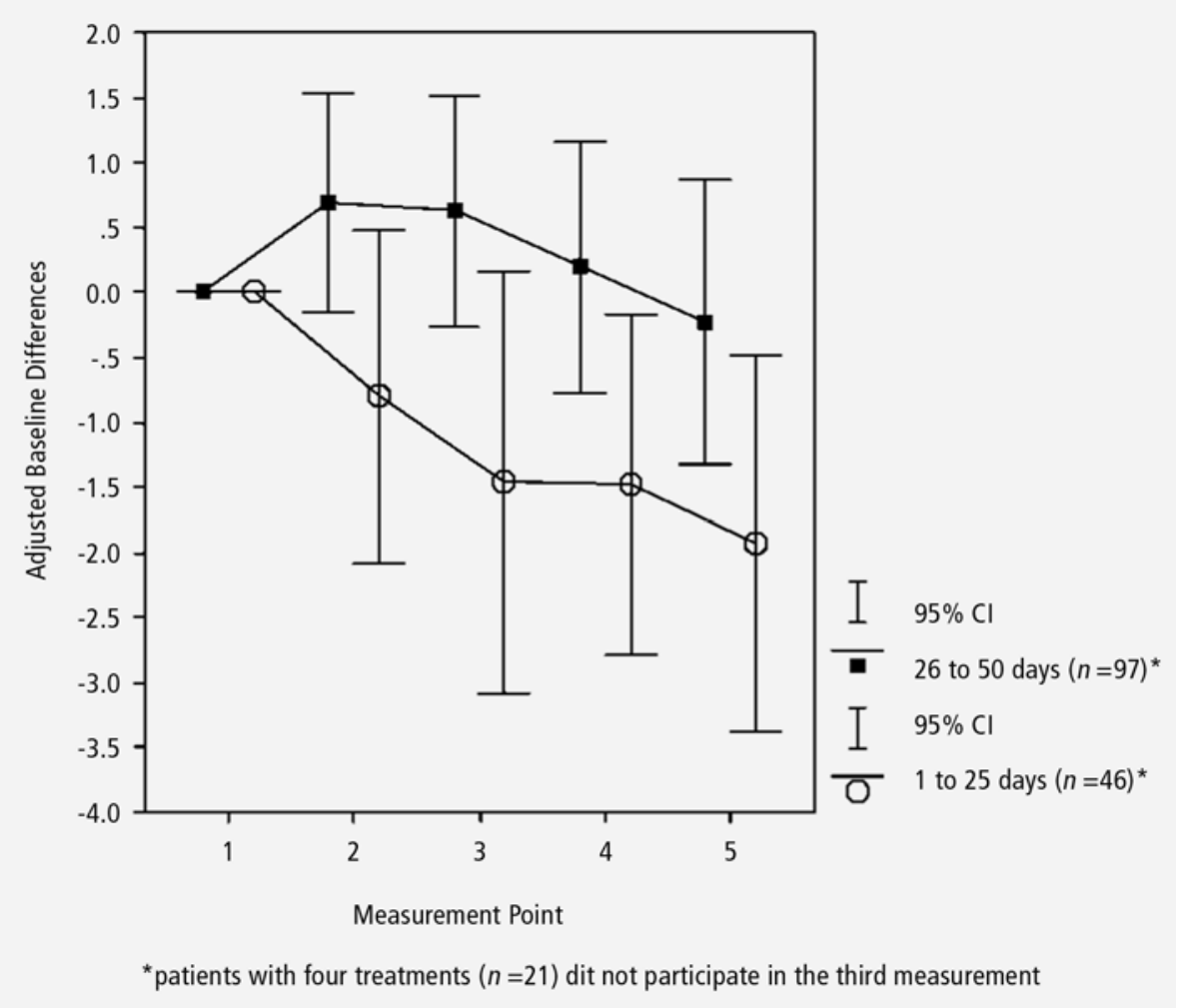

Figure 2. The course of mental fatigue as a function of the days between the operation and the start of chemotherapy. 


\section{Chapter 4}

The course of mental fatigue for the different groups that were distinguished with respect to the variable 'interval between operation and first treatment of chemotherapy', is displayed in Figure 2. The level of mental fatigue seems to be higher in those with a larger interval between operation and first treatment of chemotherapy. The subgroup whose interval is 51 days or more was too small to warrant a reliable analysis. For the group ' 1 to 25 days' there was a decrease in the mental fatigue from the first measurement occasion onwards. The difference in mental fatigue between consecutive measurement points turns out not to be significant. There is, however, a significant decrease between measurements 1 and $4\left(\Delta \chi^{2}(1)=4.678, P<0.05\right)$ and measurements 1 and 5 $\left(\Delta \chi^{2}(1)=6.349, P<0.05\right)$. After the last chemotherapy treatment patients experience significantly less mental fatigue than at the start.

For the group ' 26 to 50 days' an initial increase was followed by a decrease from measurement occasion 2 onwards. None of the pairwise

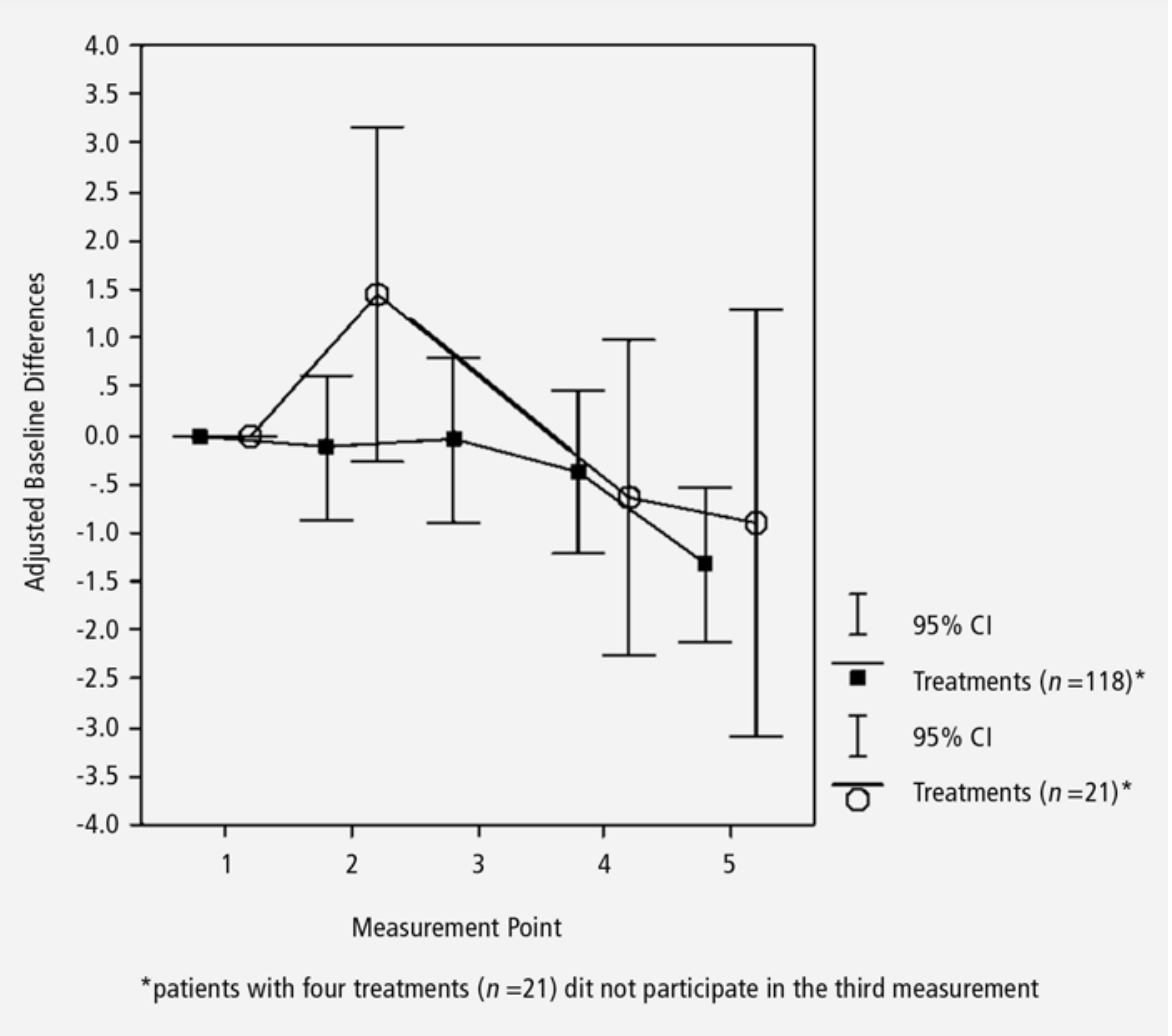

Figure 3. The course of mental fatigue as a function of the number of chemotherapy treatments. 
comparisons between measurement occasions, however, were significant.

For the variable 'number of treatments of chemotherapy', only the groups with four $(n=21)$ and six $(n=118)$ treatments were large enough for reliable analyses. Figure 3 shows the development of mental fatigue for both groups. Note that the group with four treatments did not have any observations at measurement point 3. For this group, none of the pairwise comparisons between measurements occasions are significant. There is mainly a decrease in mental fatigue for the group with six treatments. However, only the consecutive measurement occasion 4 and measurement occasion 5 differed significantly $\left(\Delta \chi^{2}(1)=5.661, P<0.05\right)$. Furthermore, it was noticeable that there was the significant decrease between measurements 1 and $5\left(\Delta \chi^{2}(1)=3.975, P<0.05\right)$. In this subgroup too, mental fatigue was also significantly diminished after the last chemotherapy treatment.

Concerning the variable marital status, only the group of married women $(n=131)$ was large enough to warrant a reliable analysis. Their scores on mental

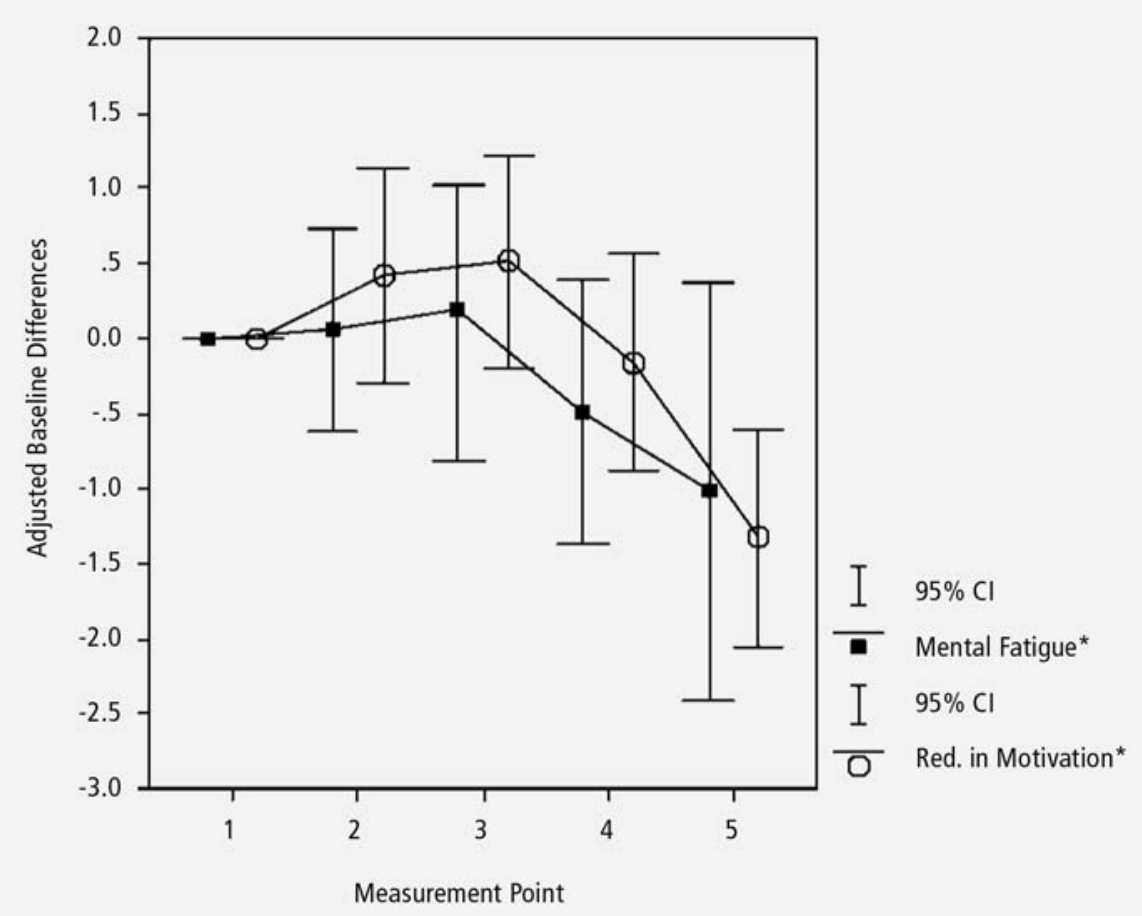

* patients with four treatments $(n=21)$ dit not participate in the third measurement

Figure 4. The course of mental fatigue and reduction in motivation for married women ( $n=131)$. 


\section{Chapter 4}

fatigue are displayed in Figure 4. In this subgroup mental fatigue also declined after the last treatment of chemotherapy, but nevertheless no pairwise comparison differed significantly.

Considering the other covariates, there were significant effects of type of operation $\left(\Delta \chi^{2}(1)=150.057, P<0.01\right)$ and age $\left(\Delta \chi^{2}(1)=9.397, P<0.01\right)$. The final model of mental fatigue indicated that patients who underwent a lumpectomy experience significantly less mental fatigue than patients who underwent a mastectomy. The effect of age on mental fatigue was negative, meaning that older patients reported significantly less mental fatigue than younger patients.

\section{Course of reduced motivation}

The course of reduction of motivation during the study was not significantly different for the CMF and the doxorubicin group, which means an equality in the changes of the motivation in both chemotherapy groups during the whole study.

The final model contains a significant interaction between the measurement occasions and marital status $\left(\Delta \chi^{2}(12)=24.236, P<0.05\right)$. This indicates that the course of reduced motivation during the study is different for married women, single women, divorced women and widows. It is impossible to examine all courses statistically because of the small sample sizes. Only the sample with married women was large enough to examine further. Figure 4 displays the course of reduced motivation for married women. This is conspicuously similar to the curve of mental fatigue for married women. As in the course of mental fatigue for married women, results show no significant differences between consecutive measurement points. Considering consecutive measurement points, the degree of motivation of the married women remains stable. Nevertheless, a significant difference was found between measurement occasion 3 and measurement occasion $5\left(\Delta \chi^{2}(1)=3.961, P<0.05\right)$. Married women were significantly more motivated at measurement 5 than at measurement 3 . The mental experienced fatigue, on the other hand, was not significantly different between these two measurements points.

Of the other covariates considered, there were significant effects of type of operation $\left(\Delta \chi^{2}(1)=136.640, P<0.01\right)$ and the number of treatments of chemotherapy $\left(\Delta \chi^{2}(2)=8.876, P<0.05\right)$. Patients who underwent a lumpectomy reported significantly more reduced motivation than those who underwent a mastectomy. Furthermore, the total number of chemotherapy treatments had a significantly negative effect on the reduced motivation $\left(\Delta \chi^{2}(1)=3.881, P<0.05\right)$. The motivation of women who received in total more treatments is significantly higher. 


\section{Results with respect to depressive symptoms}

Table 5 contains the results for the CES-D. At each measurement point, about 20\% of the sample has a score higher than the cut-off point 16 and was depressed.

Table 6 presents the correlations between depressive symptoms and subscale 'mental fatigue' and between depressive symptoms and subscale 'reduced motivation' at each measurement point. All correlations are significant at $P<0.01$. The lowest correlation is 0.52 and the highest 0.71 . Depressive symptoms were strongly associated with the psychological dimensions of fatigue.

Table 5. Depressive symptoms (CES-D scores)

\begin{tabular}{|c|c|c|c|c|c|c|c|c|c|c|}
\hline \multirow[t]{2}{*}{ Measurement point $\rightarrow$} & \multicolumn{2}{|c|}{$\begin{array}{l}\text { 1st cycle* } \\
n=157\end{array}$} & \multicolumn{2}{|c|}{$\begin{array}{c}\text { 3rd cycle } \\
n=157\end{array}$} & \multicolumn{2}{|c|}{$\begin{array}{c}\text { 5th cyclet } \\
\qquad n=135\end{array}$} & \multicolumn{2}{|c|}{$\begin{array}{l}4 \text { weeks after } \\
\text { the last cycle } \\
\quad n=152\end{array}$} & \multicolumn{2}{|c|}{$\begin{array}{c}12 \text { weeks after } \\
\text { the last cycle } \\
n=152\end{array}$} \\
\hline & $n$ & $\%$ & $n$ & $\%$ & $n$ & $\%$ & $n$ & $\%$ & $n$ & $\%$ \\
\hline $\begin{array}{l}\text { Total CES-D score } \\
\text { (range 0-60) }\end{array}$ & 155 & 100 & 156 & 100 & 135 & 100 & 151 & 100 & 152 & 100 \\
\hline Not depressed (score 0-15) & 123 & 79 & 125 & 80 & 105 & 78 & 119 & 79 & 115 & 76 \\
\hline Depressed (score 16-60) & 32 & 21 & 31 & 20 & 30 & 23 & 32 & 21 & 37 & 24 \\
\hline
\end{tabular}

Table 6. Correlations between 'depressive symptoms' and the subscale 'mental fatigue' and between 'depressive symptoms' and 'reduced motivation'*

\begin{tabular}{|c|c|c|c|c|c|c|c|c|c|c|}
\hline \multirow[t]{2}{*}{ Measurement point $\rightarrow$} & \multicolumn{2}{|r|}{ 1st cyclet } & \multicolumn{2}{|r|}{ 3rd cycle } & \multicolumn{2}{|c|}{ 5th cycle $\neq$} & \multicolumn{2}{|c|}{$\begin{array}{l}4 \text { weeks after } \\
\text { the last cycle }\end{array}$} & \multicolumn{2}{|c|}{$\begin{array}{l}12 \text { weeks after } \\
\text { the last cycle }\end{array}$} \\
\hline & $n$ & Correlation & $n$ & Correlation & $n$ & Correlation & $n$ & Correlation & $n$ & Correlation \\
\hline $\begin{array}{l}\text { Depression and } \\
\text { mental fatigue }\end{array}$ & 155 & 0.61 & 156 & 0.60 & 135 & 0.70 & 151 & 0.63 & 152 & 0.71 \\
\hline $\begin{array}{l}\text { Depression and } \\
\text { reduced motivation }\end{array}$ & 155 & 0.57 & 156 & 0.52 & 135 & 0.59 & 151 & 0.56 & 152 & 0.68 \\
\hline
\end{tabular}




\section{Discussion}

This longitudinal study represents the first large-scale examination of the course of two psychological dimensions of fatigue, 'mental fatigue' and 'reduced motivation', of the Multidimensional Fatigue Inventory (MFI-20), in 157 patients with breast cancer during (at the first, third and fifth treatment of chemotherapy) as well as after ( 4 and 12 weeks after the last treatment of chemotherapy) receiving adjuvant chemotherapy. The subscale 'mental fatigue' refers to cognitive symptoms, such as having difficulties concentrating, and lack of motivation to start any activity is covered by the subscale 'reduced motivation'.

In this study, the following two hypotheses are examined. (1) The intensity of mental fatigue and reduction in motivation remains stable during the treatment of chemotherapy and changes in a positive direction after completion. The impact of different chemotherapy regimens, like doxorubicin-containing regimens, on the course of fatigue is unclear and is investigated in the present study. (2) Fatigue and depressive symptoms during as well as after receiving adjuvant chemotherapy are related. Below, the conclusions with respect to the hypotheses are discussed.

\section{Course of the two psychological dimensions of fatigue}

Neither the course of mental fatigue nor the course of motivation was affected by type of chemotherapy. In other words, the extent of mental fatigue as well as the motivation in the CMF group and the doxorubicin group were the same. De Jong et al. [5] reported in another study that the course of general and physical fatigue was significantly different for these chemotherapy groups. Apparently, the difference in the chemical composition of the chemotherapies only has effect on the physical part of fatigue.

The course of mental fatigue, on the other hand, was affected by the interval between operation and first treatment of chemotherapy, number of treatments as well as marital status. The subgroups created for each of these variables were too small to carry out separate analyses for each resulting stratum. Analyses were done examining the course of fatigue by averaging across the strata defined by other interacting covariates. This, however, did not give insight into the exact courses of fatigue for each of the different groups that should be distinguished. In most of the analyses we see a stability of mental fatigue during the treatment of adjuvant chemotherapy, with a significant improvement in the last phase of the study. The hypothesis that the intensity of the dimensions is stable during the treatment of adjuvant chemotherapy and changes positively after completion is therefore supported. Although the course 
of motivation was affected by marital status and could only be described for married women, a similar tendency was seen. It should be noted that mental fatigue and reduction in motivation show a similar pattern across time which may be explained by both aspects reflecting the psychological side of fatigue. This finding additionally motivates presenting the results of these two dimensions of fatigue in one study.

An explanation for the stability during the treatment of chemotherapy could be that there is an increase in mental fatigue directly after hearing the diagnosis. Mental fatigue increases immediately, because of worries or anxiety about the recovery process or the treatment route and the motivation to start any activity might reduce. A recent study [18] in breast cancer patients partly supports this argument. The authors of this study found that cognitive fatigue was predicted by anxiety and pain [18]. In another study, a high prevalence of fatigue (77\%) was found before primary surgery [19]. Cimprich [9] has demonstrated a decline in the capacity for attention and concentration in women undergoing treatment for breast cancer in the initial phases of illness. Another reason for the increased fatigue in patients before the start of chemotherapy is the lingering physical and psychological stress associated with having recently undergone breast cancer surgery [20]. Patients with a short interval between the operation and the first treatment of chemotherapy could experience a heightened level of fatigue before the start of chemotherapy, which can actually only decrease. A final reason might be a shift in the internal norm of the experience of these dimensions of fatigue of the patient. This process of changing one's internal standard is called response shift [21]. Further research, in which the period preceding chemotherapy is also examined, must be done.

After the treatment of chemotherapy, mental fatigue diminished and motivation increased, but not all changes turn out to be significant. In fact, in some cases the extent of the two dimensions of fatigue at the last measurement was equal to the fatigue experienced during the treatment of chemotherapy.

The time after the last treatment might be too short to find a change in fatigue that is large enough to result in a significant effect in the statistical analysis. It might be that patients needed longer to recover from the treatments or had to cope with the treatment process they had undergone. Budin [22] reported that the course of psychosocial adjustment confronting the woman with breast cancer can be described as a series of phases associated with the clinical course of the treatment. A particularly stressful period for some breast cancer patients could be the period after completion of chemotherapy, when the woman continues recuperation from initial treatment and begins extensive reorganization and resumption of previous activities and roles. Beisecker et al. [23] reported that 
many patients experience ambivalence at the end of chemotherapy. They are pleased to be finished, but they are afraid they should keep doing something to prevent a recurrence. A limitation of the present study is the absence of a healthy control group with which to compare. In the study it is therefore unclear whether the findings at the last measurement can be regarded as normal or not.

\section{Determinants of the course of fatigue}

The course of mental fatigue is influenced by type of operation. Women undergoing a mastectomy were significantly more mentally fatigued than women that had undergone a lumpectomy. Cimprich [24] found a similar result. She concluded that older age and more extensive surgery increase the likelihood of loss of attention due, in part, to greater risk of attentional fatigue. Attentional fatigue manifests itself as a decreased capacity to concentrate or direct attention in daily life activities. The meaning of attentional fatigue is similar to both dimensions of fatigue investigated in the present study. Cimprich [24] studied 74 women newly diagnosed with stage I or II breast cancer. Data were obtained at about 12 days before and 15 days after breast-conserving surgery or mastectomy. The reason for an association here is probably not only the extent of the surgery, but also the psychological impact of it. The loss of a breast can have devastating psychological effects on women [6]. Research shows that women undergoing breast conservation or post-mastectomy procedures have better outcomes on selected psychosocial and quality-of-life measures than those who underwent a mastectomy [25]. Surgery of the breast is still seen as a negative aspect of the body image $[25,26]$. In this context, the influence of the type of operation on the course of motivation is therefore not expected and hard to explain. In this study women who underwent a mastectomy reported significantly less reduction in motivation than women undergoing a lumpectomy.

There is also an influence of age on the course of mental fatigue, meaning that older patients reported significantly less mental fatigue than younger patients. Results of other studies show that younger women with breast cancer have more severe emotional distress than older women. Loss of a breast or poor breast appearance would be more distressing to women whose youth gives them high expectations for physical beauty [27]. Another reason may be that younger women had the responsibility of caring for their families and young children [28]. Besides, older women had normally experienced more setbacks and therefore probably can cope better with it. Ongoing research, involving coping strategies, must be done. 
Furthermore, the total number of chemotherapy treatments has a significant effect on the course of motivation. The motivation of women who received in total more treatments is significantly less reduced. An explanation for this finding might be that these patients got an extra boost to go for it.

The following covariates did not influence the course of the psychological dimensions of fatigue: 'having children', 'education', 'having a job', 'stage of breast cancer', 'haemoglobin level before the first treatment of chemotherapy' and the variables with respect to radiotherapy. Bower et al. [29] found no relation between educational attainment and fatigue nor between employment status and fatigue. Other studies [20,30,31] support the absence of finding any relationship between stage of disease and fatigue. Okuyama et al. [31] reported that radiotherapy was not correlated with fatigue. None of these studies however examined the course of psychological aspects of fatigue, and the covariates used are defined differently.

\section{Depressive symptoms and fatigue}

It should be noted that the mean scores for the CES-D, given the range of possible scores, are rather low. However, at each measurement point, a relatively large group, that is about $20 \%$ of the sample, can be classified as suffering from a depressive syndrome.

A limitation of the CES-D is the validity of the cut-off point (depressed or not depressed) [12]. In a study involving 50 patients with depression and 150 healthy men and women, the cut-off score seems to be adequate for diagnosis of depression [32]. Results of another study showed that the standard cut-off score appears valid, but inefficient for depression screening in low-income women attending primary care clinics [33]. Best cut-off scores above 20 were found in studies with different populations [34, 35]. Apparently, different populations have different cut-off scores. In a study in cancer patients and in healthy individuals from the general population, findings support the use of a sumscore based on the 16 negatively formulated CES-D items as a more valid measure of depressive symptomatology [36]. The use of the cut-off score of 16 in cancer patients therefore seems to be legitimate. Further research, involving examination of the sensitivity and specificity, is needed to determine the most accurate cut-off score in breast cancer patients.

Fatigue and depressive symptoms are positively related during the whole study period, which supports the second hypothesis. In their studies, Visser and Smets [8] found a moderate relation. Other studies [29, 31, 37, 38] in breast cancer patients receiving chemotherapy showed also a positive relationship between depression and fatigue. 
The findings of the present study clarify the psychological dimensions of fatigue. A limitation of this study might be selection bias. The sample of patients who declined further participation is very small, but it is not known how many patients refused to participate in the study at the stage in which the oncologist or the oncology nurse introduced the study to the patients.

Note that patients were interviewed five times in relatively a short period of time. At each interview, they had to answer the same questions, which might cause a certain habituation. Moreover, different interview styles, i.e. face to face interviews and interviews by phone, were carried out. The internal consistency of both ways of administering the questionnaire are good. What is unknown is the way these methods may bias the results obtained on respondents' fatigue. A final remark concerning the period of study is the absence of a clear positive effect at the end of the study. The duration of the study might be too short to see any effect. The same can be said concerning the trajectory preceding adjuvant chemotherapy. Measurements somewhat longer before the start of chemotherapy may highlight increases in both mental fatigue and reduced motivation due to chemotherapy.

In summary, from this study we may conclude that no unequivocal pattern of mental fatigue and motivation is found, though there is a tendency of stability during the study with a potential decline in mental fatigue and an increase in motivation after completion of chemotherapy. In general, relatively many patients experienced depressive symptoms during the study. Health care providers should pay attention to the possibility of the patients experiencing depressive symptoms. Recognition and treatment of these symptoms can influence the course of the chemotherapy treatment, as well as the quality of life during and after the treatment of chemotherapy. Based on the results of this study, more specific information about the psychological part of fatigue can be given to breast cancer patients receiving adjuvant chemotherapy. Behaviour related to this psychological part, like having difficulties concentrating and lack of motivation to start any activity should be recognised by health care providers. Recognition and talking about these disturbances can be of value for the patient.

The depressive symptoms are definitively related to the psychological dimensions of fatigue. The psychological dimensions of fatigue are affected by type of operation. Age, marital status, number of treatments and the interval between the operation and the first treatment of chemotherapy also seem to be important determinants. Further research, involving these determinants must be carried out. 


\section{ReferenCes}

1. National Comprehensiv Cancer Network, Cancer-Related Fatigue. 2004.

2. De Jong, N., et al., Fatigue in patients with breast cancer receiving adjuvant chemotherapy: a review of the literature. Cancer Nurs, 2002. 25(4): p. 283-97.

3. Visser, O., et al., Incidence of cancer in the Netherlands 1997. 2001, Netherlands Cancer Registry (NCR): Utrecht.

4. Berger, A. and S.N. Walker, An explanatory model of fatigue in women receiving adjuvant breast cancer chemotherapy. Nursing Research, 2001. 50(3): p. 164-164.

5. De Jong, N., et al., Prevalence and course of fatigue in breast cancer patients receiving adjuvant chemotherapy. Annals of Oncology, 2004. 15: p. 896-905.

6. Spencer, K.W., Significance of the breast to the individual and society. Plast Surg Nurs, 1996. 16(3): p. 131-2.

7. Hann, D., K. Winter, and P. Jacobsen, Measurement of depressive symptoms in cancer patients: evaluation of the Center for Epidemiological Studies Depression Scale (CESD). J Psychosom Res, 1999. 46(5): p. 437-43.

8. Visser, M.R. and E.M. Smets, Fatigue, depression and quality of life in cancer patients: how are they related? Support Care Cancer, 1998. 6(2): p. 101-8.

9. Cimprich, B., Attentional fatigue following breast cancer surgery [see comments]. Res Nurs Health, 1992. 15(3): p. 199-207.

10. Smets, E.M., et al., Application of the multidimensional fatigue inventory (MFI-20) in cancer patients receiving radiotherapy. Br J Cancer, 1996. 73(2): p. 241-5.

11. Radloff, L.S., The CES-D Scale: A self-report depression scale for research in the general population. Applied Psychological Measurement, 1977. Vol 1(3): p. 385-401.

12. Bouma, J., et al., Het meten van symptomen van depressie met de CES-D: Een handleiding. 1995, Groningen: Noordelijk centrum voor Gezondheidsvraagstukken, Rijksuniversiteit Groningen.

13. Smets, E.M.A., B. Garssen, and B. Bonke, Het meten van vermoeidheid met de Multidimensionele Vermoeidheids Index (MVI-20): Een handleiding. 1995, Amsterdam: Medische Psychologie, Academisch Medisch Centrum, The Netherlands.

14. Smets, E.M.A., et al., The Multidimensional Fatigue Inventory (MFI) Psychometric Qualities of an Instrument to Assess Fatigue. Journal of Psychosomatic Research, 1995. 39(5): p. 315-325.

15. Beahrs, O.H., Manual for staging of cancer. 4th ed. 1992: Philadelphia: Lippincott.

16. Rasbash, J., et al., MLwiN. 2000, Multilevel Models Project Institute of Education: London.

17. Snijders, T.A.B. and R.J. Bosker, Multilevel analysis: An introduction to basic and advanced multilevel modelling. 1999, London: Sage Publications.

18. Haghighat, S., et al., Factors predicting fatigue in breast cancer patients. Supportive Care in Cancer, 2003. 11(8): p. 533-538. 


\section{Chapter 4}

19. Cimprich, B., Pretreatment symptom distress in women newly diagnosed with breast cancer. Cancer Nurs, 1999. 22(3): p. 185-94.

20. Jacobsen, P.B., et al., Fatigue in women receiving adjuvant chemotherapy for breast cancer: Characteristics, course, and correlates. Journal of Pain and Symptom Management, 1999. 18(4): p. 233-242.

21. Breetvelt, I.S. and F.S. Van Dam, Underreporting by cancer patients: the case of response-shift. Soc Sci Med, 1991. 32(9): p. 981-7.

22. Budin, W.C., Psychosocial adjustment to breast cancer in unmarried women. Res Nurs Health, 1998. 21(2): p. 155-66.

23. Beisecker, A.E., et al., Side effects of adjuvant chemotherapy: Perceptions of nodenegative breast cancer patients. Psycho Oncology, 1997. 6 (2): p. 85-93.

24. Cimprich, B., Age and extent of surgery affect attention in women treated for breast cancer. Research in Nursing and Health, 1998. 21 (3): p. 229-238.

25. Cohen, M.Z., D.L. Kahn, and R.H. Steeves, Beyond body image: the experience of breast cancer. Oncol Nurs Forum, 1998. 25(5): p. 835-41.

26. Mock, V., Body image in women treated for breast cancer. Nurs Res, 1993. 42(3): p. 153-7.

27. Schover, L.R., Sexuality and body image in younger women with breast cancer. J Natl Cancer Inst Monogr, 1994. 16: p. 177-82.

28. Woo, B., et al., Differences in fatigue by treatment methods in women with breast cancer. Oncol Nurs Forum, 1998. 25(5): p. 915-20.

29. Bower, J.E., et al., Fatigue in breast cancer survivors: Occurrence, correlates, and impact on quality of life. Journal of Clinical Oncology, 2000. 18(4): p. 743-753.

30. Mast, M.E., Correlates of fatigue in survivors of breast cancer. Cancer Nursing, 1998. 21(2): p. 136-142.

31. Okuyama, T., et al., Factors correlated with fatigue in disease-free breast cancer patients: application of the Cancer Fatigue Scale. Supportive Care in Cancer, 2000. 8(3): p. 215-222.

32. Dojka, E., M. Gorkiewicz, and A. Pajak, Wartosc pomiarowa skali CES-D do oceny depresji w populacji polskiej. Psychiatr Pol, 2003. 37(2): p. 281-92.

33. Thomas, J.L., et al., The utility of the CES-D as a depression screening measure among low-income women attending primary care clinics. The Center for Epidemiologic Studies-Depression. Int J Psychiatry Med, 2001. 31(1): p. 25-40.

34. Chabrol, H., et al., Etude de la CES-D dans un echantillon de 1953 adolescents scolarises. Encephale, 2002. 28(5 Pt 1): p. 429-32.

35. Haringsma, R., et al., The criterion validity of the Center for Epidemiological Studies Depression Scale (CES-D) in a sample of self-referred elders with depressive symptomatology. Int J Geriatr Psychiatry, 2004. 19(6): p. 558-63. 
36. Schroevers, M.J., et al., The evaluation of the Center for Epidemiologic Studies Depression (CES-D) scale: Depressed and Positive Affect in cancer patients and healthy reference subjects. Qual Life Res, 2000. 9(9): p. 1015-29.

37. Andrykowski, M.A., S.L. Curran, and R. Lightner, Off-treatment fatigue in breast cancer survivors: A controlled comparison. Journal of Behavioral Medicine, 1998. 21(1)): p. 1-18.

38. Gaston Johansson, F., et al., Fatigue, pain, and depression in pre-autotransplant breast cancer patients. Cancer Practice, 1999. 7(5): p. 240-247. 

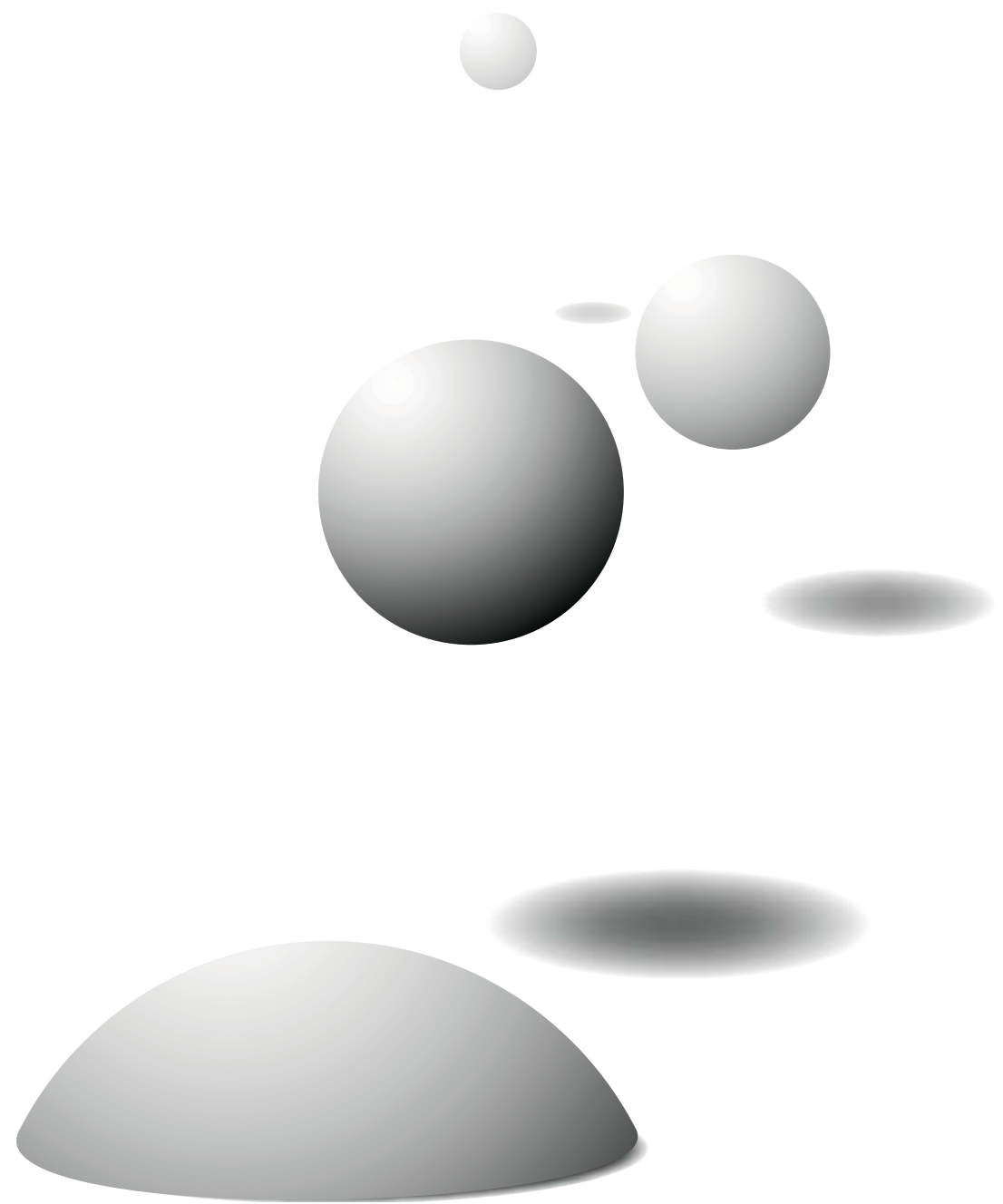


\section{Chapter 5}

\section{Course of the fatigue dimension}

'activity level' and the interference of fatigue with daily living activities for patients with breast cancer receiving adjuvant chemotherapy

Nynke de Jong, MSc, RN, Math J.J.M. Candel, PhD, Harry C. Schouten, MD, PhD, Huda Huijer Abu-Saad, FEANS, PhD, RN, \& Annemie M. Courtens, PhD, RN

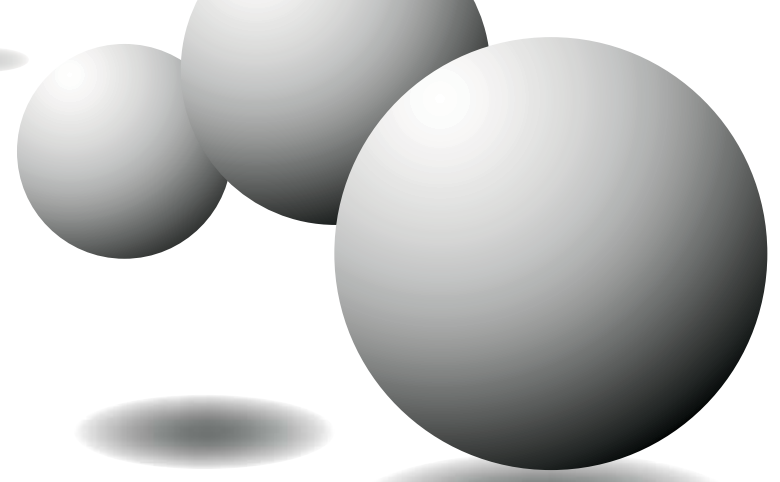

Published in: Cancer Nursing 2006; 29(5): E1-E13. 


\section{Chapter 5}

\section{Abstract}

The purpose of this study was to determine the course of the activity level, seen as a dimension of fatigue, as a function of chemotherapy within a breast cancer population receiving adjuvant chemotherapy. The second purpose of this study was to determine the course of the interference of fatigue, in general, with daily activities within a breast cancer population receiving adjuvant chemotherapy.

In a prospective cohort study, a sample of 157 patients with breast cancer was interviewed, at the first, third, and fifth cycle of adjuvant chemotherapy as well as 4 and 12 weeks after the last cycle of adjuvant chemotherapy. The chemotherapy was administered with either a doxorubicin-containing schedule or cyclophosphamide, methotrexate and 5-fluorouracil (CMF). These 2 groups were compared. The activity level was measured by the Multidimensional Fatigue Inventory. A linear multilevel model was used to analyse the course. The revised Piper Fatigue Scale was used to examine the behavioural changes in the interference of fatigue with activities of daily living. A logistic multilevel model was used to analyse the course of this interference over time.

The activity level seems to be rather stable during the treatment with chemotherapy. After completion of chemotherapy, an improvement is observed. The activity level reported at the first and the last measurement do not significantly differ. The course of the activity level is not affected by type of chemotherapy regimen. Age, having children, and the stage of breast cancer turn out to be important determinants of the course of activity level. At all measurement occasions, women with a mastectomy were significantly more hampered in their activity level than women that had undergone a lumpectomy. The longer the duration of radiotherapy, the less active, and the longer the time interval between the last radiotherapy session and the measurement point, the more active patients were at that measurement point. A phenomenon not easy to explain is that the activity level in women who had received, in total, more chemotherapy treatments was significantly less diminished than those who had received fewer treatments.

During the study period, in approximately $15 \%$ to $35 \%$ of the sample, fatigue interferes considerably with their daily living activities. Furthermore, the interference of fatigue with activities in daily life first increases after the start of chemotherapy and decreases after completion of chemotherapy.

Fatigue definitely affects the daily living activities of patients with breast cancer receiving adjuvant chemotherapy. With this knowledge health care providers can inform patients on what they can expect. Further research should include the trajectory preceding chemotherapy and a healthy control group.

Key words: activity level, adjuvant chemotherapy, breast cancer 


\section{INTRODUCTION}

Breast cancer has been the leading form of cancer in women since the early 1990s, not only in the Netherlands but also elsewhere. Optimal symptom management becomes increasingly important, as breast cancer treatment improves and survival rates increase [1].

Fatigue is a common symptom among patients with cancer. It has been recognized that fatigue is the most frequently reported symptom of cancer and cancer therapy [2], notably chemotherapy [3]. The National Comprehensive Cancer Network (NCCN) reported that $70 \%$ to $100 \%$ of the patients with cancer experience fatigue [4].

Fatigue is the most distressing side effect reported by patients receiving chemotherapy $[5,6]$. It is deleterious to the activities and quality of life of patients with cancer $[7,8]$. For healthy individuals, fatigue seems to maintain a healthy balance between rest and activity. It might be a protective, sometimes even pleasant, regulatory response to physical or psychological stress [9]. For patients with cancer, fatigue becomes a chronic and unpleasant sensation [10], which can be a major obstacle to maintaining normal daily activities and quality of life. The interference with daily functioning is highly important and has been recognized. A recent definition of cancer-related fatigue formulated by a panel of fatigue experts, who were convened by the NCCN, describes the interference explicitly as "a persistent, subjective sense of tiredness related to cancer or cancer treatment that interferes with usual functioning" [4](p. MS-2).

In this study the activity level is seen as a dimension of fatigue. It describes the patients' perception of her physical activities. Smets et al. [11] named this dimension 'reduced activity'. Despite associations reported between fatigue and activity levels, little is known about the course of activity level, seen as a dimension of fatigue, during and after receiving adjuvant chemotherapy treatment. The impact of different chemotherapy regimens on the course of this dimension of fatigue is not clear. Moreover, it is unclear which other factors are influencing the course of the activity level.

Early work [12-14] in patients with breast cancer had established that higher fatigue was associated with lower activity. It is not known to what degree the activities of daily living are disrupted as a result of fatigue. Greene et al. [15] reported moderate levels of disruption in activities of daily living in patients with breast cancer receiving chemotherapy. It is not clear if this disruption was only caused by fatigue. Berger [16] reported that the behavioural subscale scores of the revised Piper Fatigue Scale (PFS), relating to the severity, distress, and degree of disruption in activities of daily living, were significantly different 


\section{Chapter 5}

over time, with scores higher at chemotherapy treatments and lower at cycle midpoints. The interference of fatigue with daily activities within a breast cancer population has been rarely studied.

Many previous studies are characterised by methodological shortcomings, like a small sample size, the lack of a well-validated measure of reduced activity and the absence of a longitudinal design, which limits the conclusions that can be drawn [17]. The present study is part of a large-scale fatigue project in patients with breast cancer receiving adjuvant chemotherapy trying to circumvent the major weaknesses of previous studies. The purpose of this study was to determine the course of the activity level, seen as a dimension of fatigue, as a function of chemotherapy within a breast cancer population receiving adjuvant chemotherapy. The second purpose of this study was to determine the course of the interference of fatigue, in general, with daily activities within a breast cancer population receiving adjuvant chemotherapy.

The present article addresses the following research questions:

1. How does the activity level, seen as a dimension of fatigue, within a breast cancer population receiving adjuvant chemotherapy, change in the course of time?

2 Does the course of activity level depend on the regimen of chemotherapy (cyclophosphamide, methotrexate and 5-fluorouracil [CMF] or doxorubicin group) and what other determinants are influencing this course?

3. To what degree is fatigue interfering with daily living activities and does the degree of interference change over time?

\section{PATIENTS AND METHODS}

\section{Population Sample and Procedure}

Patients with breast cancer treated in 6 hospitals, mainly in the south of the Netherlands, were included in this study if they (1) had no metastasis or other malignancy, (2) were treated with cytostatics for the first time, (3) were treated with outpatient adjuvant chemotherapy (4) had no chronic disease (like hypertension, kidney disease, heart problems, diabetes mellitus etc.) or a poor psychological state (such as diagnosed with a depression), (5) did not use morphine or narcoleptics, (6) were not deaf, (7) were 18 years or older, and (8) could speak and understand Dutch.

The local medical ethical committees of all participating centers had approved the study. The oncologist or the oncology nurse verified eligibility before they introduced the study to the patients. When the patient was eligible, 
Table 1. Items of the subscale 'reduced activity' of the MFI-20 (range of scale score: 4-20)

\begin{tabular}{l|l}
\hline Subscale & Items* \\
\hline Reduced activity & 1. I feel very active \\
& 2. I think I do a lot in a day \\
3. I think I do very little in a day \\
4. I get little done
\end{tabular}

* For each item, there are 5 response categories ranging from 'yes, that's correct' (score 1) to 'no, that's incorrect' (score 5).

written information describing the purpose and procedure of the study was given. The patient had given written informed consent before the interview. The interviews were conducted by the principal investigator and a properly trained assistant.

Patients were interviewed, using the Multidimensional Fatigue Inventory (MFI-20) [11] and the revised Piper Fatigue Scale (revised PFS) [18], 5 times except when receiving the cyclophosphamide and doxorubicin (CA) treatment, in which case participants were interviewed only 4 times. The first 3 interviews took place in the hospital and were held directly before, during or after the first, the third, and the fifth cycle of chemotherapy, except for the CA regimen, where the third interview was omitted. An interview at each cycle of chemotherapy was expected to be too much for the patients and not feasible for the investigator. Therefore, an interval of 6 to 8 weeks between the interviews was chosen. For the same reason the last 2 interviews were held 4 and 12 weeks after the last cycle. These 2 interviews were done by phone because the patients were not present at the outpatients' department. Medical data were retrieved from charts and were gathered after the interviews.

\section{Operationalisation of variables}

Activity level. The Multidimensional Fatigue Inventory (MFI-20) [11] was used to assess the course of the activity level. This 20-item self-report questionnaire consists of 5 subscales based on different dimensions: general fatigue, physical fatigue, reduced activity, reduced motivation and mental fatigue. Each item of each subscale was answered on a 5-point Likert scale. The score of each subscale was obtained as the sum of the scores on 4 items. Higher scores indicate more subjective fatigue. In the present study, we will focus on the results of the subscale 'reduced activity'. High scores on this subscale indicate a low activity level. The items of this subscale are presented in Table 1 . The MFI-20 was previously tested and validated in the following patient groups: cancer patients receiving radiotherapy, patients with 'chronic fatigue syndrome', psychology students, 


\section{Chapter 5}

Table 2. Items of the subscale 'behavioural/severity' of the revised PFS (range of scale scores: 0 - 60)

Subscale Items*

Behavioural/severity 1. To what degree is the fatigue you are feeling now causing you distress? +

2. To what degree is the fatigue you are feeling now interfering with your ability to complete your work or school activities?

3. To what degree is the fatigue you are feeling now interfering with your ability to visit or socialize with your friends?

4. To what degree is the fatigue you are feeling now interfering with your ability to engage in sexual activity?

5. Overall how much is the fatigue, which you are experiencing now, interfering with your ability to engage in the kind of activities you enjoy doing?

6. How would you describe the degree of intensity or severity of the fatigue which you are experiencing now?

* Each answer could be given on a scale ranging from 0 to 10; higher scores indicate that fatigue is interfering more with activities of daily living.

${ }^{\dagger}$ This question was not included in the questionnaire.

medical students, army recruits and junior physicians. The mean internal consistency for the subscale 'reduced activity' in different patient groups was 0.76 with a range of 0.53 to 0.86 [19]. The mean of Cronbach's $\alpha$ 's across all measurement points in this study is 0.87 , with a range of 0.84 to 0.91 . For the practical reason that the patients were already being interviewed, patients were asked to rate their fatigue as experienced during the previous 2 weeks in a faceto-face interview. In addition, a self-report questionnaire was expected to be too time-consuming for the patient.

Interference of fatigue with activities in daily living. The revised Piper Fatigue Scale (revised PFS) is an instrument to measure subjective fatigue [18]. This 22 item questionnaire consists of 4 subscales. In the present study, 1 subscale was used: the behavioural/severity subscale. This subscale reflects the degree to which fatigue interferes with activities of daily living [18]. The subscale contains 6 items, and the score has to be calculated as the sum of the scores on these 6 items. The questions of this subscale are displayed in Table 2. In the present study, the subscale included 5 items instead of 6 because an older version of the PFS was used. The scores in the present study were calculated as the sum of the scores of the 5 items. High scores indicate that fatigue is interfering more with activities of daily living. The behavioural/ severity scale of the revised PFS was previously tested and validated in women with breast cancer [18]. The internal consistency of the subscale in this study was 0.92 [18]. A pilot study [12] in breast cancer patients receiving adjuvant chemotherapy showed internal consistencies for the total and all subscale scores ranging from 0.91 to 0.98 . For the behavioural/severity subscale, the 
mean of Cronbach's $\alpha$ 's across all measurement points in this study is 0.89 , with a range of 0.78 to 0.98 .

In the present study, a distinction was made between little or no interference with daily living activities (score $\leq 5$ ) and great interference with daily living activities (score $>5$ ). This distinction was made to examine the number of patients for whom fatigue strongly interferes with their daily living activities.

Treatment of adjuvant chemotherapy. Patients were receiving 1 of the following adjuvant chemotherapies: CEF (cyclophosphamide, 4-epi-doxorubicin and 5fluorouracil) every 21 days; CAF (cyclophosphamide, doxorubicin and 5fluorouracil) every 21 days; 4-epi-doxorubicin every 28 days (on days 1 and 8); 4-epi-doxorubicin/taxotere with the first three cycles every 28 days (on days 1 and 8 ) and the last three cycles every 21 days, CA (cyclophosphamide and doxorubicin) every 21 days; and CMF (cyclophosphamide, methotrexate [oral administration from day 1 to day 14 or intravenous] and 5-fluorouracil) every 28 days (on days 1 and 8). Most regimens consist of 6 cycles except the CA regimen which consists of 4 cycles. The choice of regimen was based on current practice in the participating hospitals. The involvement of different adjuvant chemotherapy regimens made it possible to create a sizeable sample in a relatively short period of time. In the present study, 2 groups were compared: the doxorubicin group (CEF, CAF, 4-epi-doxorubicin, 4-epi-doxorubicin/taxotere and CA) and the CMF group. Stage of breast cancer. The anatomic extent of breast cancer was reported by using the TNM clinical classification [20].

Type of surgery. In this study, patients underwent a mastectomy or a lumpectomy with or without lymph nodes excision. Two groups were compared because of small sizes of the other groups: (1) mastectomy with lymph nodes excision, and (2) lumpectomy with lymph nodes excision. During the study period, no reconstructive surgery was done.

\section{Statistical Analyses}

First, it was statistically tested whether there were differences in patient characteristics between the CMF group and the doxorubicin group.

Furthermore, an overview of raw mean scores of the subscale 'reduced activity' of the MFI-20 was described to obtain a general impression of the course of the activity level. The course of the activity level was analysed with a linear multilevel model using the MLwiN program (version 1.10.0006) [21]. The data consist of a series of repeated measurements nested within hospitals and individual subjects. The data, which have a hierarchical nature, may be characterised by dependencies between units at lower levels of the hierarchy. In this case multilevel analysis is an appropriate technique [22]. 


\section{Chapter 5}

In the analyses concerning the effect of chemotherapy regimen on the course of fatigue, dummy variables were included to represent the several measurement points. When the first measurement is taken as a reference, changes relative to the baseline measurement are analysed. The effect of chemotherapy on the course of fatigue was represented by interaction terms between these dummy variables and a binary variable chemotherapy. To correct for possibly confounding factors in this analysis, several covariates were added: 'age', 'marital status', 'having children', 'education', 'having a job', 'type of surgery', 'stage of breast cancer', 'haemoglobin level (measured in $\mathrm{mmol} / \mathrm{L}$ ) before the first treatment of chemotherapy', 'the number of days between the operation and the first treatment of chemotherapy', 'the number of treatments at each measurement point' and 'radiotherapy'. For the covariate 'radiotherapy' 3 different variables were used: a variable indicating whether a patient had received radiotherapy at any point of measurement, the number of days of radiotherapy the patient had had at the time of measurement and the number of days between the last day of radiotherapy and the time of measurement. Also these covariates were included as interaction terms with the dummy variables representing the time points. In this way, possible differences in patient characteristics between the chemotherapy groups are corrected for.

Stepwise deletion took place in which nonsignificant covariates were deleted. The effect of the variable 'treatment of adjuvant chemotherapy' was examined after the final model was determined in which only significant covariates were included. For the final model fatigue scores, which are baseline differences and are also adjusted for differences between the chemotherapy groups, can be calculated. These will be denoted as adjusted baseline differences.

For the subscale 'behavioural/severity' of the revised PFS an overview of the mean subscale score as well as the mean item scores was displayed. The interference with daily living activities at each measurement point was examined by choosing a cutoff for the scores on the subscale of the PFS. A 'little or no interference' and a 'strong interference' group was created. Differences in the incidence of strong interference across time were analysed through a logistic multilevel model using the MLwiN program (version 1.10.0006) [21]. In this model, only dummy variables were included to represent the several measurement occasions. 


\section{ResUlts}

\section{Response Rate}

A total of 175 breast cancer patients were recruited for the study. For different reasons, $18(10 \%)$ patients were excluded. To be precise: $13(7 \%)$ declined further participation, $3(2 \%)$ stopped the adjuvant chemotherapy prematurely, and $2(1 \%)$ had a poor physical state. The remaining 157 patients were interviewed four $(n=$ $20)$ or five $(n=137)$ times depending on their adjuvant chemotherapy schedule. The response rates are displayed in Table 3. The cause of the nonresponse was mainly a change in the treatment schedule. The principal investigator conducted $79 \%$ of the interviews; the other interviews were conducted by an assistant.

\section{Sample Characteristics}

Information on the demographic and medical characteristics is shown in Table 4. Seventy-one percent of the patients had received one of the chemotherapy regimens covered by the doxorubicin group; the remainder had received the CMF treatment. There were 2 characteristics on which the doxorubicin group and CMF group differed: 'age' and 'having a job'. The CMF group was significantly $(t=-2.133 ; P=0.035)$ younger than the doxorubicin group. The average age in the CMF group was 45.0 years $(\mathrm{SD}=7.9)$ compared with 48.2 years $(\mathrm{SD}=9.0)$ in the doxorubicin group. In the CMF group significantly $\left(\chi^{2}(1)\right.$ $=4.768, \mathrm{P}=0.034$ ) more patients had a job compared to the doxorubicin group. No other characteristics were significantly different between the 2 groups. Table 5 describes the total number of chemotherapy treatments for each of the chemotherapy regimens, and Table 6 describes the numbers of patients receiving radiotherapy at the different measurement points. Most patients received

Table 3. Response rates of patients with breast cancer specified for each measurement occasion Measurement Total (n) Participants in study

\begin{tabular}{|l|l|}
\hline 1 \\
\hline 2 \\
\hline $3 *$ \\
\hline 4 \\
5
\end{tabular}

\begin{tabular}{|c|c|}
\hline & $n$ \\
\hline 157 & 157 \\
\hline 157 & 15 \\
\hline 137 & 135 \\
\hline 157 & 15 \\
\hline 157 & 152 \\
\hline
\end{tabular}

\section{n} 157 157 135

152

152

$\%$
100 100 99 97 97

* Patients receiving only 4 chemotherapy treatments did not have this interview. 


\section{Chapter 5}

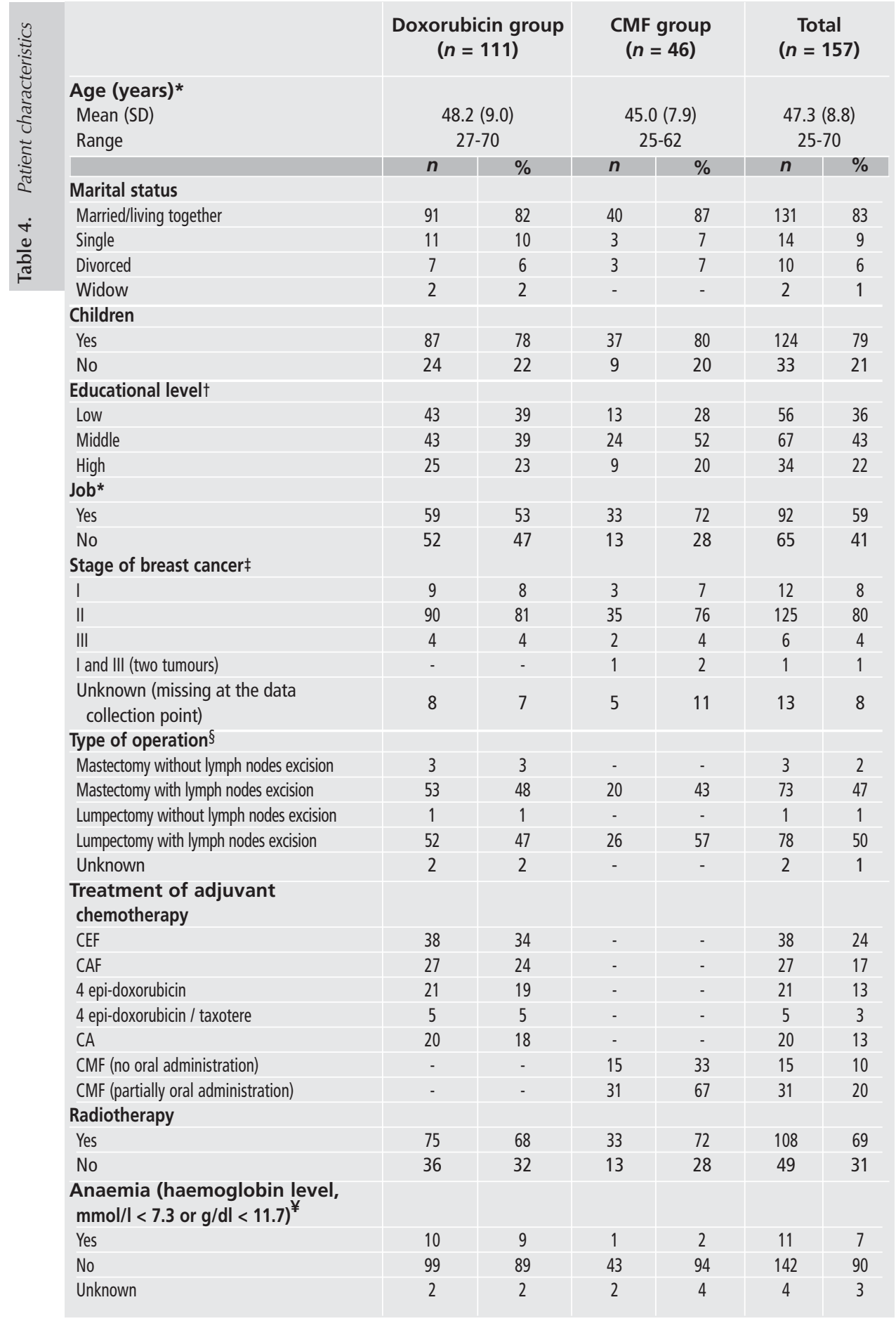




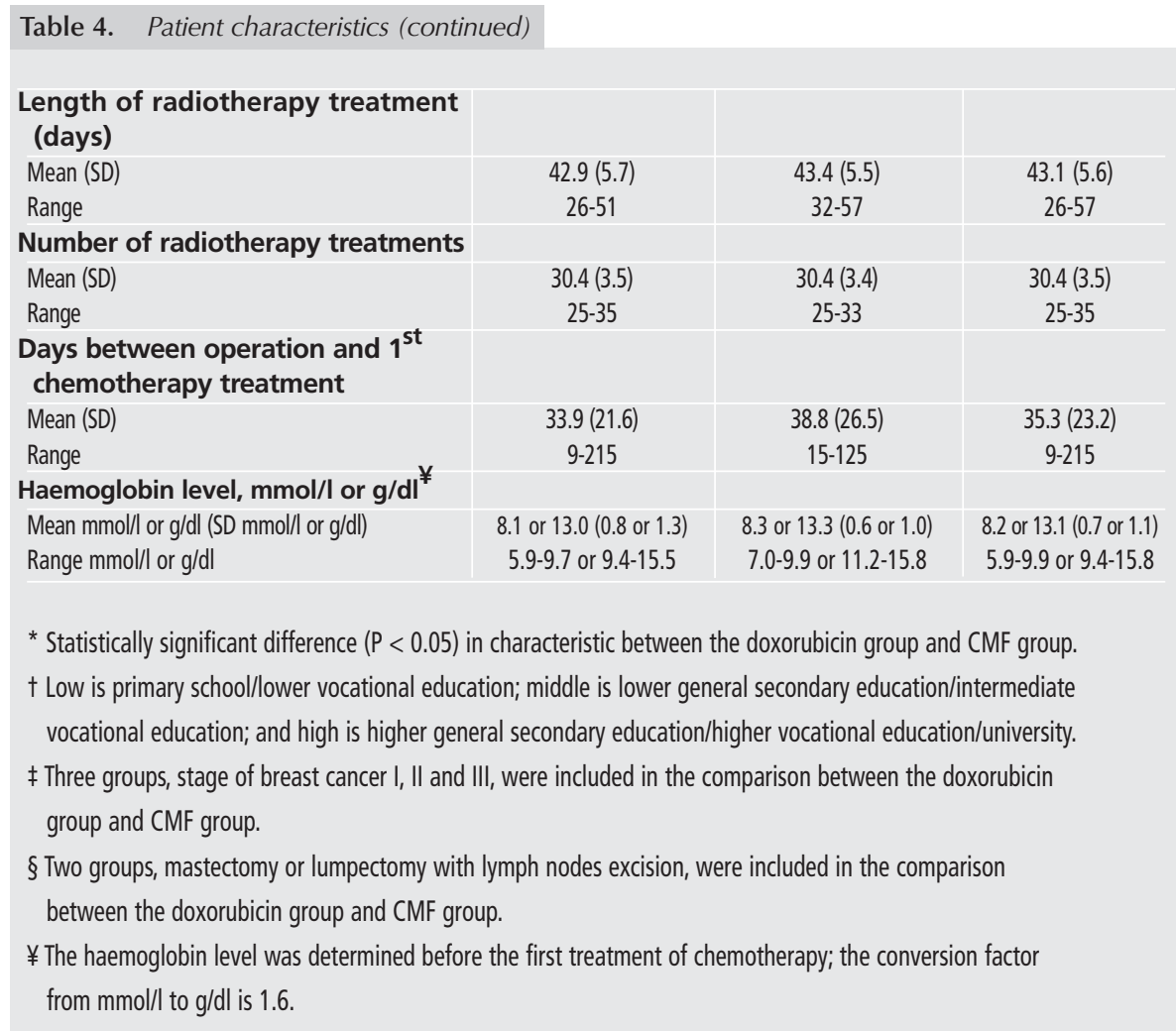

6 treatments of chemotherapy. Most patients who received radiotherapy were receiving radiotherapy at the second measurement (corresponding to the third treatment of chemotherapy).

\section{Activity level}

The course of the activity level was studied by analysing the results for the subscale 'reduced activity' of the MFI-20. The raw mean scores and accompanying confidence intervals of this subscale are displayed in Figure 1. It seems that the activity level is stable during the study period with an improvement at the end. However, notice the large confidence intervals of these mean scores indicating that there are large variances in the scale scores at each time point. In the next section, a more detailed description of the course of the activity level and its determinants is given.

\section{Course of the activity level and its determinants}

Type of chemotherapy does not affect the activity level of the patients, which 


\section{Chapter 5}

\begin{tabular}{|c|c|c|c|c|c|}
\hline Total number of treatments $\rightarrow$ & 4 & 5 & 6 & 8 & \\
\hline \multicolumn{6}{|l|}{$\begin{array}{l}\text { Treatment of adjuvant } \\
\text { chemotherapy }\end{array}$} \\
\hline Doxorubicin group & 21 & 10 & 72 & 8 & 111 \\
\hline CMF & - & - & 46 & - & 46 \\
\hline
\end{tabular}

\begin{tabular}{|c|c|c|c|c|c|c|c|}
\hline \multirow[t]{2}{*}{$\begin{array}{l}\text { Measurement } \\
\text { occasion }\end{array}$} & \multicolumn{2}{|c|}{$\begin{array}{c}\text { Receiving } \\
\text { radiotherapy } \\
\text { at measurement }\end{array}$} & \multicolumn{2}{|c|}{$\begin{array}{l}\text { Receiving or having } \\
\text { finished radiotherapy } \\
\text { at measurement }\end{array}$} & \multicolumn{2}{|c|}{$\begin{array}{l}\text { Not having } \\
\text { received } \\
\text { radiotherapy }\end{array}$} & \multirow{2}{*}{$\begin{array}{c}\text { Total } \\
n\end{array}$} \\
\hline & $n$ & $\%$ & $n$ & $\%$ & $n$ & $\%$ & \\
\hline 1 & 8 & 5 & 11 & 7 & 146 & 93 & 157 \\
\hline 2 & 58 & 37 & 89 & 57 & 68 & 43 & 157 \\
\hline $3^{*}$ & 3 & 2 & 94 & 70 & 41 & 30 & 135 \\
\hline 4 & 8 & 5 & 98 & 64 & 54 & 36 & 152 \\
\hline 5 & 2 & 1 & 103 & 68 & 49 & 32 & 152 \\
\hline
\end{tabular}

means that the course in the activity level in the 2 chemotherapy groups (CMF versus doxorubicin) was equal during the whole study period. However, the course of the activity level was significantly different for groups defined by the variables 'age' $\left(\Delta \chi^{2}(4)=10.606, P<0.05\right)$, 'having children' $\left(\Delta \chi^{2}(4)=10.303\right.$, $P<0.05)$ and 'stage of breast cancer' $\left(\Delta \chi^{2}(8)=16.020, P<0.05\right)$.

Subgroups were formed based on these variables. The variable 'age' was categorised into two groups: 25 to 45 years $(n=71)$ and 46 to 70 years $(n=86)$. Separate analyses for each stratum that could be defined based on these 3 interacting variables were not performed because these strata were too small. Therefore, for each variable separately, stratification was conducted. By investigating the time effects in this way for each stratum the averaged effects were examined, where the other 2 variables that interact with measurement points were averaged across.

Figure 2 shows the course of reduced activity for the different groups that were distinguished with respect to the variable 'age'. Adjusted baseline 


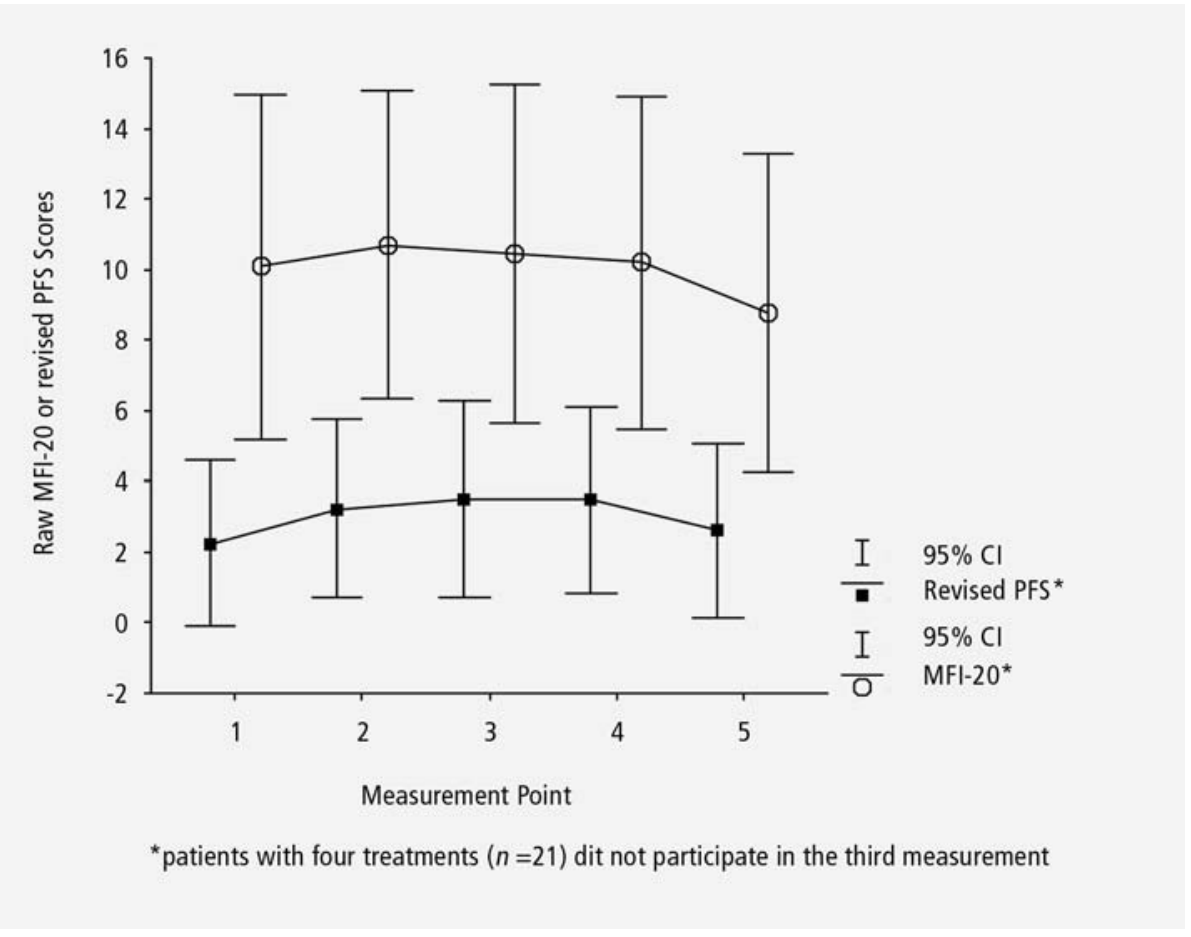

Figure 1. Raw mean scores of the subscale 'reduced activity' of the MFI-20 (range 4-20) and the subscale 'behavioural/severity' of the revised PFS (range 0-10) ( $n=157)$.

differences are displayed. The level of activity for the group '46-70 years old' is quite stable during the whole study period, except for the significant difference between measurements 4 and $5\left(\Delta \chi^{2}(1)=5.216, P<0.05\right)$. Patients were significantly more active at measurement 5 than at measurement 4 . The difference in activity level between measurements 3 and 5 is also significant $\left(\Delta \chi^{2}(1)=6.418\right.$, $P<0.05)$. For the group of 45 years and younger, none of the pairwise comparisons between measurement occasions were significant. Here, the activity level is constant during the whole study period. Examining Figure 2, one would expect a difference between measurement occasion 1 and 5 for this age group, but probably because of the large variance of the scores within this group, no significant difference was found.

An examination of the time points at which the changes in the activity level are different between the 2 'age' groups revealed significant differences for the changes between measurements 1 and 3 and between measurements 2 and 3 $\left(\Delta \chi^{2}(1)=9.246, P<0.01\right.$ and $\Delta \chi^{2}(1)=4.466, P<0.05$, respectively). The older 


\section{Chapter 5}

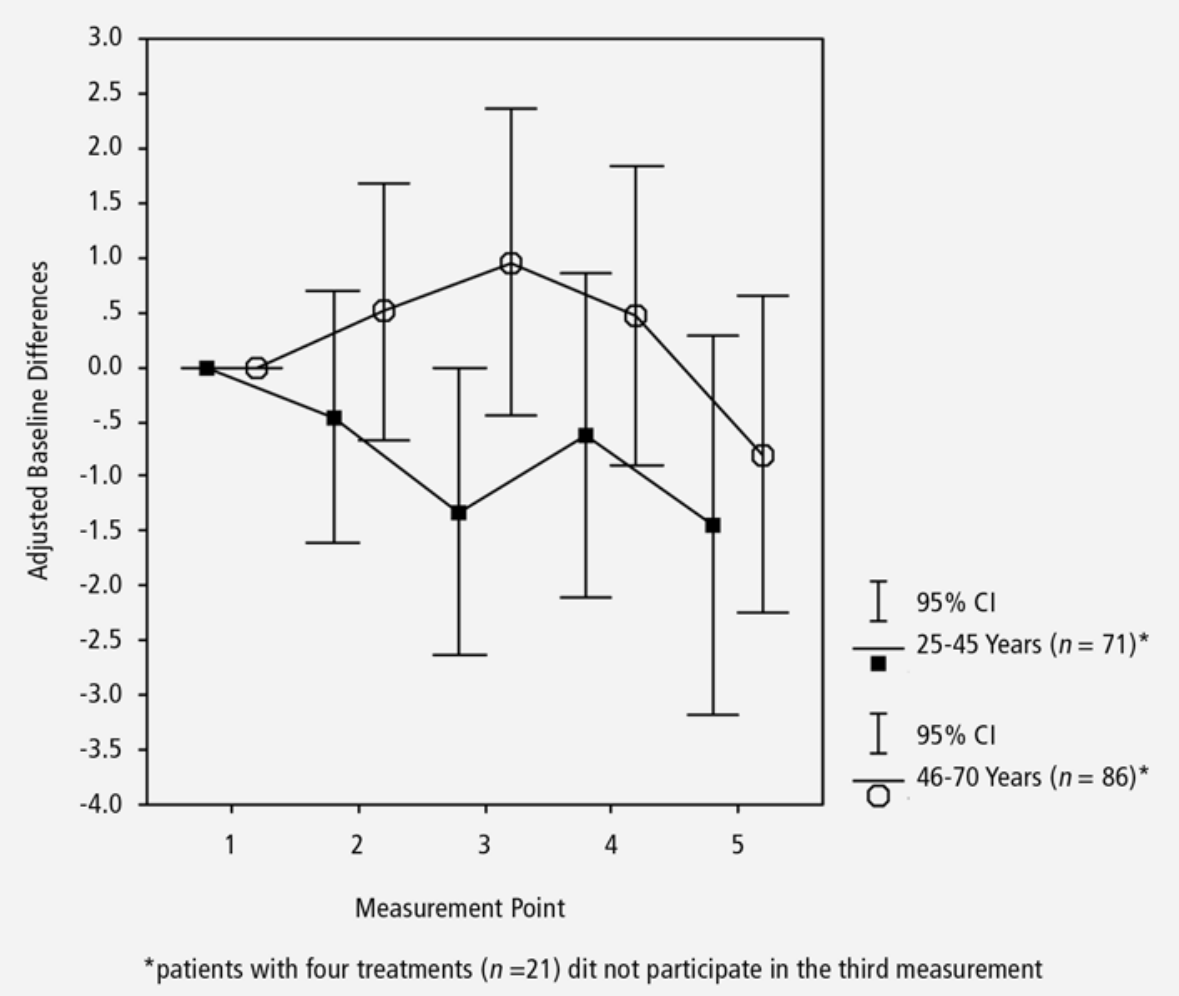

Figure 2. The course of the subscale 'reduced activity' as a function of age.

group was more restricted in activity than the younger group at these time points.

The course of the level of activity for the different groups of the variable 'having children' is presented in Figure 3. As can be seen, the 2 lines intersect at measurement 5 , which turns out to correspond with a significant difference in the course of the activity level between the groups with and without children, when comparing measurements 4 and $5\left(\Delta \chi^{2}(1)=6.799, P<0.01\right)$. The group 'having children' shows an increase in activity level, whereas the group "no children" shows a slight decrease. When other differences over time between the 2 groups are examined, a significant difference is only found between measurements 1 and $4\left(\Delta \chi^{2}(1)=4.705, P<0.05\right)$.

Furthermore, for the group 'having children' a significant difference is seen between measurements 4 and $5\left(\Delta \chi^{2}(1)=6.03, P<0.05\right)$. Patients with children are significantly more active at measurement 5 than at measurement 4 . 


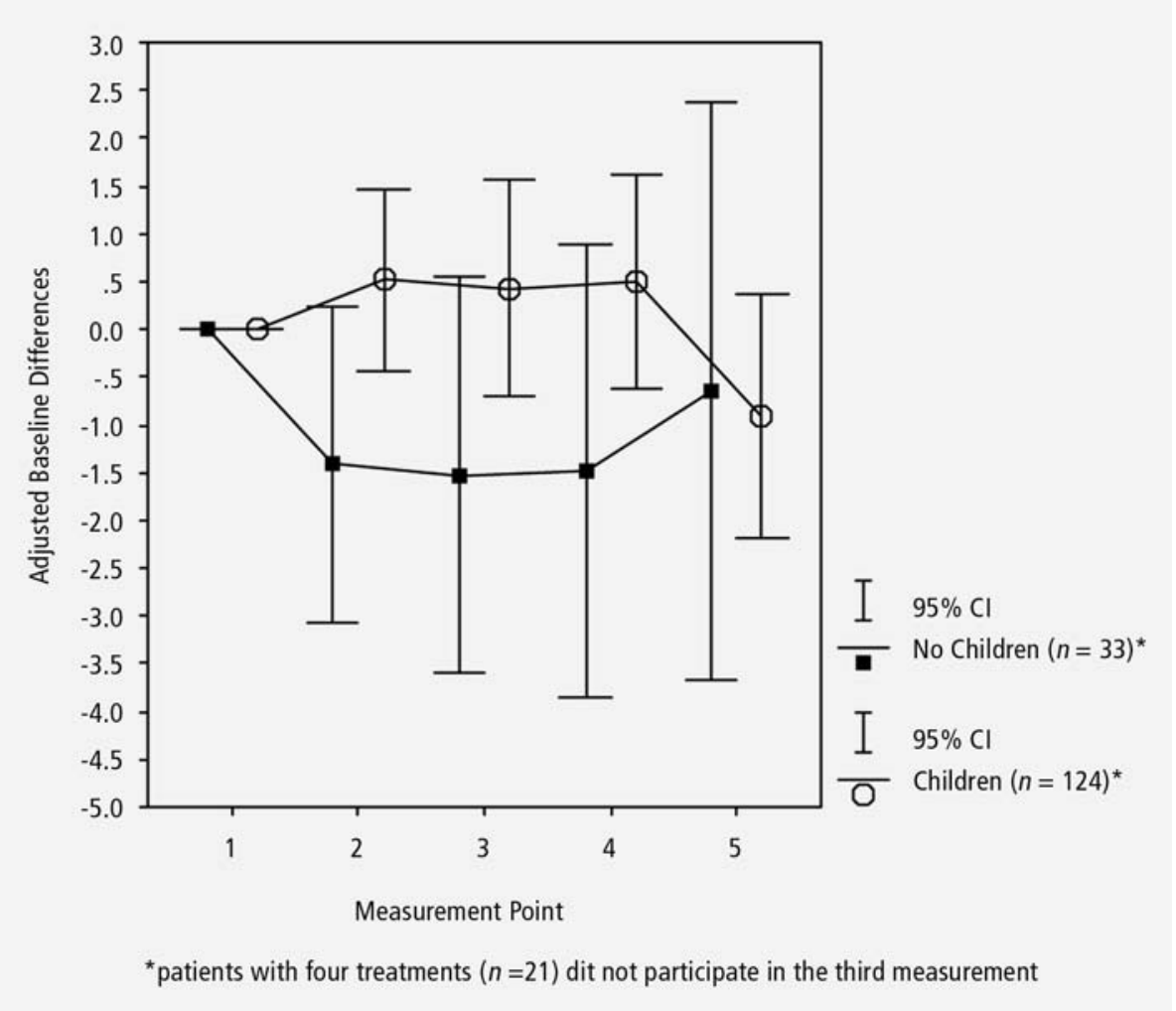

Figure 3. The course of the subscale 'reduced activity' as a function of having children.

The changes between measurements 2 and 5 as well as between measurements 3 and 5 are also significant $\left(\Delta \chi^{2}(1)=4.905, P<0.05\right.$ and $\Delta \chi^{2}(1)=4.387, P<$ 0.05 , respectively): patients are more active at measurement 5 when compared to measurement 2 and 3. The group 'no children' on the other hand, showed no significant changes in the activity level, probably because of large score variances within this group.

For the different groups of the variable 'stage of breast cancer', statistical testing was only possible for the group 'stage II'. The remaining groups (stages I and III) were considered too small to yield reliable results. Also the group 'stage II' showed stability in activity levels during the treatment of chemotherapy and 4 weeks after the last treatment of chemotherapy (see Figure 4). At the last measurement, compared to the measurements 2, 3 and 4, a significant $\left(\Delta \chi^{2}(1)\right.$ $=4.041, P<0.05, \Delta \chi^{2}(1)=4.178, P<0.05$ and $\Delta \chi^{2}(1)=4.884, P<0.05$, 


\section{Chapter 5}

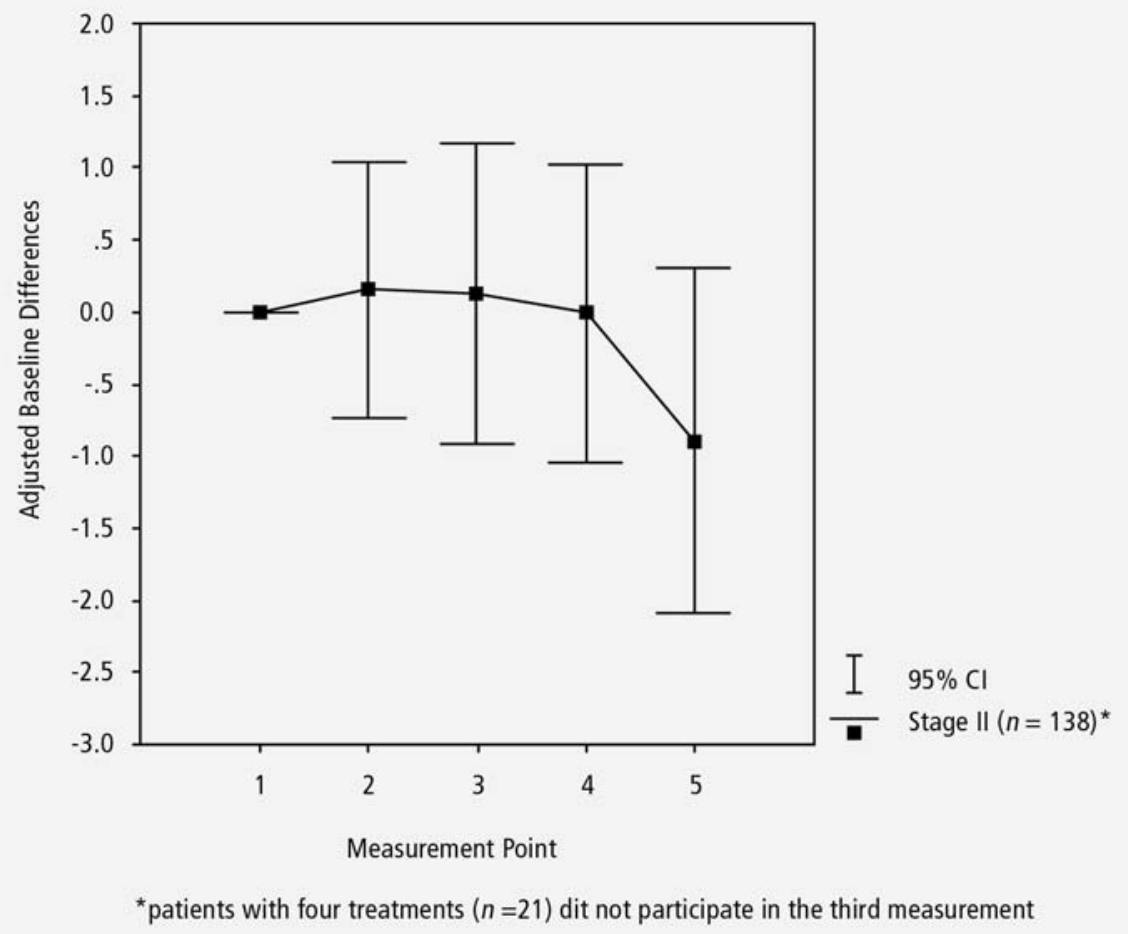

Figure 4. The course of the subscale 'reduced activity' for the patients in stage II of breast cancer.

respectively) increase in activity is seen in these patients. All significant comparisons for the group 'stage II' are such that the activity level at the last measurement is significantly higher than at the other measurements.

With respect to the other covariates, there were significant main effects for type of surgery $\left(\Delta \chi^{2}(1)=145.924, P<0.01\right)$, the duration of radiotherapy $\left(\Delta \chi^{2}(1)\right.$ $=7.429, P<0.01)$, the interval between measurement point and time of the last radiotherapy $\left(\Delta \chi^{2}(1)=11.296, P<0.01\right)$ and the number of treatments of chemotherapy $\left(\Delta \chi^{2}(2)=10.104, P<0.01\right)$. Patients who had undergone a lumpectomy had a higher level of activity than those who had had a mastectomy. The effects for radiotherapy were the following: the longer the duration of radiotherapy, the less active, and the longer the time interval between the last radiotherapy session and the measurement point, the more active patients were at that measurement point. Moreover, women who received in total more chemotherapy treatments were significantly more active than those who received fewer. In other words, the activity level was less restricted. 


\section{The impact of fatigue on daily living activities}

The subscale 'behavioural/severity' of the revised PFS reflects the impact of fatigue on activities of daily living. Figure 1 shows that the mean subscale scores are relatively low and are stable over time. Mean subscale scores as well as mean item scores are presented in Table 7. In general during the study period, the mean item scores were also relatively low, but the high standard deviations indicate a lot of individual differences between women. The sample sizes for item 1 are very small. This indicates that not many women were working or had school activities. It is noticeable that after completion of chemotherapy, more and more patients were getting back to work or to school activities. The sample sizes for this item were too small to identify a reliable pattern or to report meaningful results. Not all women answered item 3, the question about the interference with the ability to engage in sexual activity. The reason was that some women did not wish to comment or that the interviewer assessed it was not appropriate to ask this question given the patient's situation. For the items 'to visit or socialize with your friends' (item 2), 'to engage in sexual activity' (item 3) and 'to engage in the kind of activities you enjoy doing' (item 4), a slight mean increase is seen in the intensity of interference after the start of the first treatment of chemotherapy. The mean scores on item 5, which describes the degree of intensity or severity of fatigue, are at almost all measurement points the highest scores. For this item too, a slight mean increase can be seen after the first measurement. However, these observations are not statistically significant.

Examining the prevalences of strong interference as based on the total subscale score in Table 7, it can be noted that at each measurement these prevalences are between $15 \%$ and $35 \%$. Statistical testing shows that the prevalence of strong interference, first increases significantly after the start of chemotherapy $(t=2.597, P<0.01)$. The increase continues, in that between the third and the fifth cycle of chemotherapy also a significant increase was observed $(t=2.519, P<0.02)$. After completion of chemotherapy, however, the number of patients in the 'strong interference' group decreases. Between measurements 3 and 4 no significant difference $(t=-1.712, P>0.08)$ was observed in the prevalence, but between measurements 4 and 5 , a significant decline $(t=-2.271, p<0.03)$ was seen. Twelve weeks after completion of chemotherapy, the prevalence of strong interference was not larger when compared to the prevalence at the start of chemotherapy $(t=1.120, P>0.25)$. 


\section{Chapter 5}

Table 7. Raw mean scores of the subscale 'behavioural/severity' of the revised PFS (range 0-10)

\begin{tabular}{|c|c|c|c|c|}
\hline \multirow[t]{2}{*}{ Measurement point $\rightarrow$} & \multicolumn{2}{|c|}{ 1st cyclet } & \multicolumn{2}{|c|}{ 3rd cycle } \\
\hline & $n(\%)$ & mean(SD) & $n(\%)$ & mean(SD) \\
\hline $\begin{array}{l}\text { Total score subscale } \\
\text { Little or no interference* } \\
\text { Strong interference }\end{array}$ & $\begin{array}{c}157(100) \\
133(85) \\
24(15)\end{array}$ & $\begin{array}{l}2.2(2.3) \\
1.5(1.6) \\
6.4(1.1)\end{array}$ & $\begin{array}{c}157(100) \\
118(75) \\
39(25)\end{array}$ & $\begin{array}{l}3.2(2.5) \\
2.1(1.7) \\
6.7(1.1)\end{array}$ \\
\hline $\begin{array}{l}\text { Item } 1 \S \text { (total score) } \\
\text { Little or no interference* } \\
\text { Strong interference }\end{array}$ & $\begin{array}{l}11(100) \\
8(73) \\
3(27)\end{array}$ & $\begin{array}{l}3.4(2.8) \\
2.1(2.2) \\
6.7(0.6)\end{array}$ & $\begin{array}{c}13(100) \\
10(77) \\
3(23)\end{array}$ & $\begin{array}{l}3.1(3.0) \\
1.8(2.1) \\
7.3(0.6)\end{array}$ \\
\hline $\begin{array}{l}\text { Item } 2 \text { (total score) } \\
\text { Little or no interference* } \\
\text { Strong interference }\end{array}$ & $\begin{array}{c}157(100) \\
142(90) \\
15(10)\end{array}$ & $\begin{array}{l}1.5(2.4) \\
0.9(1.6) \\
7.2(1.1)\end{array}$ & $\begin{array}{c}156(100) \\
136(87) \\
20(13)\end{array}$ & $\begin{array}{l}2.2(2.5) \\
1.5(1.8) \\
6.9(1.0)\end{array}$ \\
\hline $\begin{array}{l}\text { Item } 3 \text { (total score) } \\
\text { Little or no interference* } \\
\text { Strong interference }\end{array}$ & $\begin{array}{c}132(100) \\
114(86) \\
18(14)\end{array}$ & $\begin{array}{l}1.9(3.1) \\
0.9(1.6) \\
8.6(1.5)\end{array}$ & $\begin{array}{c}122(100) \\
91(75) \\
31(25)\end{array}$ & $\begin{array}{l}3.3(3.3) \\
1.6(2.0) \\
8.0(1.5)\end{array}$ \\
\hline $\begin{array}{l}\text { Item } 4 \text { (total score) } \\
\text { Little or no interference* } \\
\text { Strong interference }\end{array}$ & $\begin{array}{c}157(100) \\
139(89) \\
18(11)\end{array}$ & $\begin{array}{l}2.0(2.8) \\
1.3(1.9) \\
7.8(1.3)\end{array}$ & $\begin{array}{c}156(100) \\
122(78) \\
34(22)\end{array}$ & $\begin{array}{l}2.9(3.1) \\
1.6(2.0) \\
7.5(1.3)\end{array}$ \\
\hline $\begin{array}{l}\text { Item } 5 \text { (total score) } \\
\text { Little or no interference* } \\
\text { Strong interference }\end{array}$ & $\begin{array}{c}157(100) \\
127(81) \\
30(19)\end{array}$ & $\begin{array}{l}3.2(2.9) \\
2.2(1.9) \\
7.8(1.4)\end{array}$ & $\begin{array}{c}157(100) \\
98(62) \\
59(38)\end{array}$ & $\begin{array}{l}4.5(3.0) \\
2.7(2.0) \\
7.6(1.3)\end{array}$ \\
\hline $\begin{array}{r}\text { * Little or no interference } \\
\text { § The items are as follows: } \\
\text { item 1: To what degree } \\
\text { school activities? } \\
\text { item 2: To what degree } \\
\text { your friends? } \\
\text { item 3: To what degree } \\
\text { item 4: Overall how muc } \\
\text { the kind of activ } \\
\text { item 5: How would you } \\
\text { † The first three interviews } \\
\text { ‡ Patients receiving only fo }\end{array}$ & $\begin{array}{l}\text { are feeling } \\
\text { are feeling } \\
\text { are feeling } \\
\text { which you ar } \\
\text { ing? } \\
\text { ee of intensi } \\
\text { ly before, du } \\
\text { treatments }\end{array}$ & $\begin{array}{l}\text { erence a score } \\
\text { erfering with y } \\
\text { erfering with y } \\
\text { erfering with y } \\
\text { iencing now, in } \\
\text { verity of the fa } \\
\text { after infusion. } \\
\text { have this inter }\end{array}$ & $\begin{array}{l}\text { lity to compl } \\
\text { lity to visit o } \\
\text { lity to engag } \\
\text { ng with your } \\
\text { vhich you are }\end{array}$ & $\begin{array}{l}\text { Ar work or } \\
\text { lize with } \\
\text { xual activity? } \\
\text { to engage in } \\
\text { iencing now? }\end{array}$ \\
\hline
\end{tabular}




\begin{tabular}{|c|c|c|c|c|c|}
\hline \multicolumn{2}{|c|}{ 5th cycle $\neq$} & \multicolumn{2}{|c|}{$\begin{array}{l}4 \text { weeks after } \\
\text { the last cycle }\end{array}$} & \multicolumn{2}{|c|}{$\begin{array}{l}12 \text { weeks after } \\
\text { the last cycle }\end{array}$} \\
\hline$n(\%)$ & mean(SD) & $n(\%)$ & mean(SD) & $n(\%)$ & mean(SD) \\
\hline $\begin{array}{c}135(100) \\
89(66) \\
46(34)\end{array}$ & $\begin{array}{l}3.5(2.8) \\
1.8(1.5) \\
6.9(1.1)\end{array}$ & $\begin{array}{c}152(100) \\
111(73) \\
41(27)\end{array}$ & $\begin{array}{l}3.5(2.6) \\
2.2(1.6) \\
6.9(1.3)\end{array}$ & $\begin{array}{c}152(100) \\
122(80) \\
30(20)\end{array}$ & $\begin{array}{l}2.6(2.5) \\
1.6(1.5) \\
6.7(1.2)\end{array}$ \\
\hline $\begin{array}{c}14(100) \\
11(79) \\
3(21)\end{array}$ & $\begin{array}{l}3.1(3.3) \\
1.7(2.0) \\
8.0(1.7)\end{array}$ & $\begin{array}{c}19(100) \\
15(79) \\
4(21)\end{array}$ & $\begin{array}{l}2.8(2.6) \\
1.8(1.7) \\
6.8(1.5)\end{array}$ & $\begin{array}{c}36(100) \\
31(86) \\
5(14)\end{array}$ & $\begin{array}{l}2.1(2.6) \\
1.3(1.6) \\
7.2(0.8)\end{array}$ \\
\hline $\begin{array}{c}135(100) \\
105(78) \\
30(23)\end{array}$ & $\begin{array}{l}2.6(2.9) \\
1.3(1.8) \\
7.0(1.1)\end{array}$ & $\begin{array}{c}152(100) \\
127(84) \\
25(16)\end{array}$ & $\begin{array}{l}2.4(2.8) \\
1.4(1.7) \\
7.5(1.0)\end{array}$ & $\begin{array}{c}152(100) \\
137(90) \\
15(10)\end{array}$ & $\begin{array}{l}1.8(2.5) \\
1.2(1.7) \\
7.4(1.1)\end{array}$ \\
\hline $\begin{array}{l}97(100) \\
62(64) \\
35(36)\end{array}$ & $\begin{array}{l}3.9(3.7) \\
1.5(2.0) \\
8.1(1.4)\end{array}$ & $\begin{array}{c}114(100) \\
84(74) \\
30(26)\end{array}$ & $\begin{array}{l}3.7(3.2) \\
2.1(1.9) \\
8.1(1.3)\end{array}$ & $\begin{array}{c}116(100) \\
95(82) \\
21(18)\end{array}$ & $\begin{array}{l}2.7(3.0) \\
1.5(1.8) \\
7.8(1.4)\end{array}$ \\
\hline $\begin{array}{c}134(100) \\
95(71) \\
39(29)\end{array}$ & $\begin{array}{l}3.1(3.3) \\
1.3(1.7) \\
7.7(1.3)\end{array}$ & $\begin{array}{c}152(100) \\
115(76) \\
37(24)\end{array}$ & $\begin{array}{l}3.2(3.1) \\
1.7(1.8) \\
7.8(1.1)\end{array}$ & $\begin{array}{c}152(100) \\
126(83) \\
26(17)\end{array}$ & $\begin{array}{l}2.3(2.8) \\
1.3(1.8) \\
7.4(1.2)\end{array}$ \\
\hline $\begin{array}{c}135(100) \\
81(60) \\
54(40)\end{array}$ & $\begin{array}{l}4.5(3.0) \\
2.4(1.7) \\
7.7(1.2)\end{array}$ & $\begin{array}{c}152(100) \\
96(63) \\
56(37)\end{array}$ & $\begin{array}{l}4.6(3.1) \\
2.7(1.9) \\
8.0(1.3)\end{array}$ & $\begin{array}{c}152(100) \\
109(72) \\
43(28)\end{array}$ & $\begin{array}{l}3.7(3.0) \\
2.1(1.6) \\
7.9(1.2)\end{array}$ \\
\hline
\end{tabular}




\section{Chapter 5}

\section{DisCUSSION}

This longitudinal study represents the first large-scale examination of the course of the activity level, seen as a dimension of fatigue, as well as the extent of interference of fatigue in general with daily activities within 157 patients with breast cancer during as well as after receiving adjuvant chemotherapy. Measurement occasions were before, during or after infusion at the first, third and fifth cycle of chemotherapy, as well as four and twelve weeks after completion of chemotherapy.

In this study the following research questions were addressed:

1. How does the activity level, seen as a dimension of fatigue, within a breast cancer population receiving adjuvant chemotherapy, change in the course of time?

2. Does the course of activity level depend on the regimen of chemotherapy (CMF or doxorubicin group) and what other determinants are influencing this course?

3. To what degree is fatigue interfering with daily living activities and does the degree of interference change over time?

\section{Course of the activity level and its determinants (questions 1 and 2)}

During the study, the course of the activity level, measured by a subscale of the MFI-20, was the same for the CMF group and for the doxorubicin group. It is remarkable that in another study of De Jong et al. [23], the courses of general fatigue and physical fatigue (2 other subscales of the MFI-20), were significantly different for the 2 chemotherapy groups. Comparing these courses to the course of the activity level, no similarity was seen in the pattern across time. We [23] also reported that the doxorubicin group showed a significant increase in general and physical fatigue during the first cycles of chemotherapy and the CMF group after the last cycle of chemotherapy. The activity level as examined in this study, on the other hand was stable until the fourth measurement occasion, 4 weeks after completion of chemotherapy, after which patients became more active. A socalled mirror-image pattern of fatigue as found by Berger [16], where an increase in fatigue is accompanied by a reduction in the activity level, was therefore not found in our study. Note that in Berger's study other measurement points and measurement instruments were used as compared in the present study.

The course of mental fatigue and motivation in the study of De Jong et al. [24], on the other hand, tended to be stable during the study, but with a decline in mental fatigue and an increase in motivation after the completion of chemotherapy. This would be in line with the course of the activity level found in the 
present study. A limitation of the present study is that, in the scale no distinction is made between physical and mental activities. This would enable a more precise analysis of the relations between activity level, on the one hand, and mental and physical fatigue on the other hand.

The course of the activity level was affected by age and having children as well as the stage of breast cancer. The subgroups created for these variables simultaneously were too small to perform separate analyses for each resulting subgroup. Overall, a significant improvement of the activity level is seen in the last phase of the study. Like the present study, Berger [16] found a kind of stability in the activity level during the treatment of chemotherapy. Berger and Higginbotham [12] found an improvement in the activity level after completion of chemotherapy.

In a literature review [17] on breast cancer patients receiving chemotherapy, the findings on stability in the intensity of fatigue throughout the treatment cycles were also reported. The stability can be explained by an enhanced need for social support before initiation of chemotherapy. The uncertainties and fears experienced by the cancer patients are likely to result in this need [25]. Activities of the patients can be taken over, not only because of psychological reasons but also because of the physical condition after surgery. Even before primary surgery, a high prevalence of fatigue is found [26]. The activity level can therefore be influenced at an early stage. Further research involving the period preceding chemotherapy is needed.

Another reason for the stability in activity during treatment might be a shift in the internal norm of the patient [27]. For example, the same degree of fatigue experienced can be later described as a no-fatigue experience. Moreover, there is a risk that patients, because of the relatively short period of time between the measurements, may recognize the questions, which can thus influence the way they respond.

Apparently, the measurement time selected in this study (12 weeks after chemo) after completion of chemotherapy is long enough to show any improvement in the activity level. It is notable that the activity level at 12 weeks post chemo is comparable to the activity level at the start of the study. In the present study, it is clear that patients are becoming more active after the chemotherapy treatment, but whether the activity level can be regarded as 'normal' is not yet clear. A limitation of the present study is the absence of a control group with which to compare the findings. Future research should involve a healthy control group.

Type of surgery was found to influence the level of activity over time. Women treated with a mastectomy were significantly more hampered in activity than women that had undergone a lumpectomy. Undergoing mastectomy was a 


\section{Chapter 5}

significant predictor of fatigue in a recent study [28]. Another study [29] shows that women undergoing breast conservation or postmastectomy procedures have better outcomes on selected psychosocial and quality-of-life measures than those who had only undergone a mastectomy. The extent of the surgery might influence the activity level, but so might the possible destructive psychological impact on a woman who lost a breast.

In the present study, supplementary to chemotherapy, $69 \%$ of the women received radiotherapy. The activity level was also influenced by radiotherapy variables. The longer the duration of radiotherapy, the less active patients were. In addition, the longer the time interval between the last radiotherapy session and the measurement point, the more active patients became. These findings can be explained by the fact that the trips to the treatment centre can be very exhausting [23]. Woo et al. [30] concluded in their study that the effect of radiotherapy itself or a combination of therapies makes the patients more fatigued. This finding might be explaining the result found in this study. The normalisation after the last treatment of radiotherapy is comprehensible knowing that women recover from the intensive period of receiving radiotherapy [23]. This reasoning is partially supported by Irvine et al. [31].

A phenomenon which is difficult to explain is the influence of the number of chemotherapy treatments on the level of activity. The activity level in women, who had received in total more treatments of chemotherapy, was significantly higher than those who completed fewer treatments. In another study of De Jong [24], related to our project, the motivation level of women who received, in total, more treatments was also significantly higher. This could be an explanation for this finding. That is, the treatments provide the patients with a kind of extra boost 'to go for it'.

None of the following variables influenced the activity level: 'marital status', 'education', 'having a job', 'haemoglobin level before the first treatment of chemotherapy', 'the number of days between the operation and the first treatment of chemotherapy' and 'type of chemotherapy'. Similar results were found in studies related to our project [23, 24]. Other existing studies did not examine the course of different dimensions of fatigue, which makes it almost impossible to compare results. Bower et al. [32] and Haghigat et al. [28] found no relation between educational attainment and fatigue. Employment status was also not associated with fatigue [32]. Okuyama et al. [33] reported that the number of days since operation was not correlated with fatigue.

\section{Impact on daily life activities (question 2)}

Although the mean score of the subscale of the PFS was low (indicating little or no interference) and seemed stable during the study period, at each measure- 
ment, a relatively large group, approximately $15 \%$ to $35 \%$ of the sample, reported that fatigue interfered to a strong extent with their daily living activities.

It is also clear that for significantly more patients fatigue interferes to a strong extent with their daily living activities after the first infusion of chemotherapy. During chemotherapy, this group grows significantly. After completion of chemotherapy this group shrinks. At the end of the study, the group with strong interference is similar in size to the group at the start of chemotherapy. The present results cannot be compared to previous work, because no comparable division was made.

The results presented must be considered within the limitations of this study. The present study used an earlier version of the revised PFS to examine changes in the interference of fatigue with activities of daily living. One item is missing compared to the new version of this scale, which may have influenced the results.

Another limitation is that it is not clear whether fatigue causes a reduction in activity or vice versa. A reduction in acitivity might refer to a consequence of fatigue, but an adjustment or a decline in physical activities can also be the start of fatigue. Studies [34-36] support this assumption.

Before the start of chemotherapy, the activity level might already have changed. The experienced activity level at the end of the study compared to the measurement at the start of the chemotherapy treatment was not different. In that case, the measurement time after completion was too short to show any improvement in the activity level. Further research, involving the trajectory preceding adjuvant chemotherapy and a longer study period afterwards, needs to be done.

Improved understanding of the activity level and the impact of fatigue on daily life activities of breast cancer patients receiving chemotherapy will better equip healthcare providers to understand and address the needs of these patients. Finally, future research should include interventions addressing how patients can maintain or improve the activity level during as well as after receiving adjuvant chemotherapy.

\section{REFERENCES}

1. Sadler, I.J. and P.B. Jacobsen, Progress in understanding fatigue associated with breast cancer treatment. Cancer Investigation, 2001. 19(7): p. 723-731.

2. Richardson, A. and E. Ream, The experience of fatigue and other symptoms in patients receiving chemotherapy. Eur J Cancer Care Engl, 1996. 5(2 Suppl): p. 24-30. 


\section{Chapter 5}

3. Ream, E., A. Richardson, and C. Alexander-Dann, Facilitating patients' coping with fatigue during chemotherapy-pilot outcomes. Cancer Nurs, 2002. 25(4): p. 300-8.

4. NCCN, National Comprehensive Cancer Network (NCCN) Cancer-Related Fatigue. http://www.nccn.org/professionals/physician g/s/PDF/fatigue.pdf. 2005.

5. Portenoy, R.K. and L.M. Itri, Cancer-related fatigue: guidelines for evaluation and management. Oncologist, 1999. 4(1): p. 1-10.

6. Richardson, A., Fatigue in Cancer Patients: a Review of the Literature. European Journal of Cancer Care, 1995. 4: p. 20-32.

7. Ferrell, B.R., et al., Bone tired: the experience of fatigue and its impact on quality of life. Oncol Nurs Forum, 1996. 10: p. 1539-1547.

8. Vogelzang, N.J., et al., Patient, caregiver, and oncologist perceptions of cancer-related fatigue: results of a tripart assessment survey. The Fatigue Coalition. Semin Hematol, 1997. 34(3 Suppl 2): p. 4-12.

9. Servaes, P., C. Verhagen, and G. Bleijenberg, Fatigue in cancer patients during and after treatment: prevalence, correlates and interventions. European Journal of Cancer, 2002. 38(1): p. 27-43.

10. Piper, B.F., A.M. Lindsey, and M.J. Dodd, Fatigue mechanisms in cancer patients: developing nursing theory. Oncol Nurs Forum, 1987. 14(6): p. 17-23.

11. Smets, E.M.A., B. Garssen, and B. Bonke, Het meten van vermoeidheid met de Multidimensionele Vermoeidheids Index (MVI-20): Een handleiding. 1995, Amsterdam: Medische Psychologie, Academisch Medisch Centrum, The Netherlands.

12. Berger, A.M. and P. Higginbotham, Correlates of fatigue during and following adjuvant breast cancer chemotherapy: a pilot study. Oncol Nurs Forum, 2000. 27(9): p. 1443-8.

13. Servaes, P., S. Verhagen, and G. Bleijenberg, Determinants of chronic fatigue in disease-free breast cancer patients: a cross-sectional study. Annals of Oncology, 2002. 13(4): p. 589-598.

14. Berger, A.M. and L. Farr, The influence of daytime inactivity and nighttime restlessness on cancer-related fatigue. Oncol Nurs Forum, 1999. 26(10): p. 1663-71.

15. Greene, D., et al., A comparison of patient-reported side effects among three chemotherapy regimens for breast cancer. Cancer Pract, 1994. 2(1): p. 57-62.

16. Berger, A.M., Patterns of fatigue and activity and rest during adjuvant breast cancer chemotherapy. Oncol Nurs Forum, 1998. 25(1): p. 51-62.

17. De Jong, N., et al., Fatigue in patients with breast cancer receiving adjuvant chemotherapy: a review of the literature. Cancer Nurs, 2002. 25(4): p. 283-97.

18. Piper, B.F., et al., The revised Piper Fatigue Scale: psychometric evaluation in women with breast cancer. Oncol Nurs Forum, 1998. 25(4): p. 677-84.

19. Smets, E.M.A., et al., The Multidimensional Fatigue Inventory (MFI) Psychometric Qualities of an Instrument to Assess Fatigue. Journal of Psychosomatic Research, 1995. 39(5): p. 315-325.

20. Beahrs, O.H., Manual for staging of cancer. 4th ed. 1992: Philadelphia: Lippincott. 
21. Rasbash, J., et al., MLwiN. 2000, Multilevel Models Project Institute of Education: London.

22. Snijders, T.A.B. and R.J. Bosker, Multilevel analysis: An introduction to basic and advanced multilevel modelling. 1999, London: Sage Publications.

23. De Jong, N., et al., Prevalence and course of fatigue in breast cancer patients receiving adjuvant chemotherapy. Annals of Oncology, 2004. 15: p. 896-905.

24. De Jong, N., et al., Course of mental fatigue and motivation in breast cancer patients receiving adjuvant chemotherapy. Annals of Oncology, 2005. 16: p. 372-382.

25. Wortman, C.B., Social support and the cancer patient. Conceptual and methodologic issues. Cancer, 1984. 53(10 Suppl): p. 2339-62.

26. Cimprich, B., Pretreatment symptom distress in women newly diagnosed with breast cancer. Cancer Nurs, 1999. 22(3): p. 185-94.

27. Breetvelt, I.S. and F.S. Van Dam, Underreporting by cancer patients: the case of response-shift. Soc Sci Med, 1991. 32(9): p. 981-7.

28. Haghighat, S., et al., Factors predicting fatigue in breast cancer patients. Supportive Care in Cancer, 2003. 11(8): p. 533-538.

29. Cohen, M.Z., D.L. Kahn, and R.H. Steeves, Beyond body image: the experience of breast cancer. Oncol Nurs Forum, 1998. 25(5): p. 835-41.

30. Woo, B., et al., Differences in fatigue by treatment methods in women with breast cancer. Oncol Nurs Forum, 1998. 25(5): p. 915-20.

31. Irvine, D.M., et al., Fatigue in women with breast cancer receiving radiation therapy. Cancer Nursing, 1998. 21 (2): p. 127-135.

32. Bower, J.E., et al., Fatigue in breast cancer survivors: Occurrence, correlates, and impact on quality of life. Journal of Clinical Oncology, 2000. 18(4): p. 743-753.

33. Okuyama, T., et al., Factors correlated with fatigue in disease-free breast cancer patients: application of the Cancer Fatigue Scale. Supportive Care in Cancer, 2000. 8(3): p. 215-222.

34. Schwartz, A.L., et al., Exercise reduces daily fatigue in women with breast cancer receiving chemotherapy. Med Sci Sports Exerc, 2001. 33(5): p. 718-23.

35. Sarna, L. and F. Conde, Physical activity and fatigue during radiation therapy: a pilot study using actigraph monitors. Oncol Nurs Forum, 2001. 28(6): p. 1043-6.

36. Dimeo, F., Radiotherapy-related fatigue and exercise for cancer patients: A review of the literature and suggestions for future research. Normal Tissue Reactions in Radiotherapy and Oncology, 2002. 37: p. 49-56 

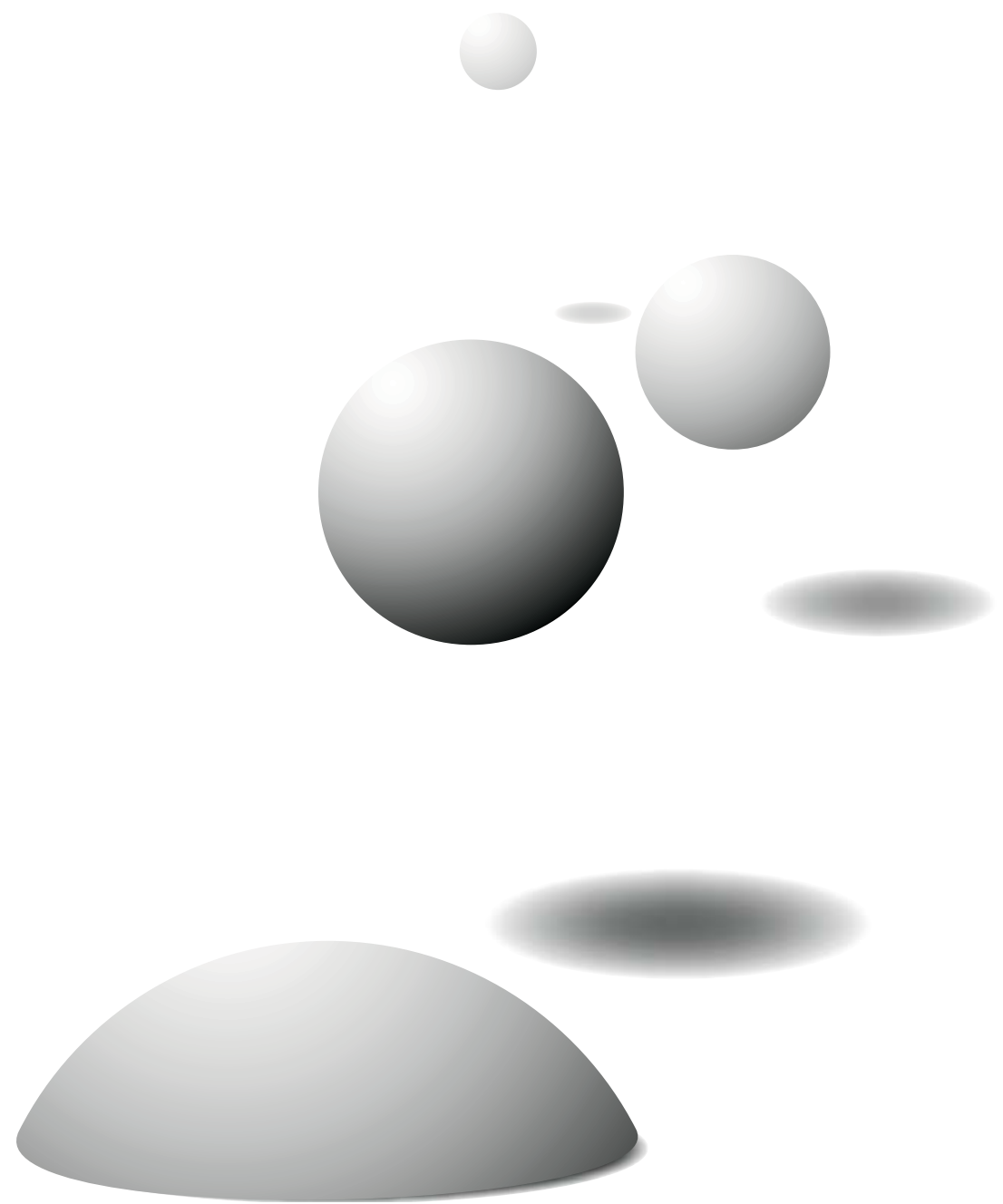


\section{Chapter 6}

\section{Course of fatigue between two cycles of adjuvant chemotherapy in breast cancer patients}

Nynke de Jong, MSc, RN, Arnold D.M. Kester, PhD, Harry C. Schouten, MD, PhD, Huda Huijer Abu-Saad, FEANS, PhD, RN, \& Annemie M. Courtens, PhD, RN

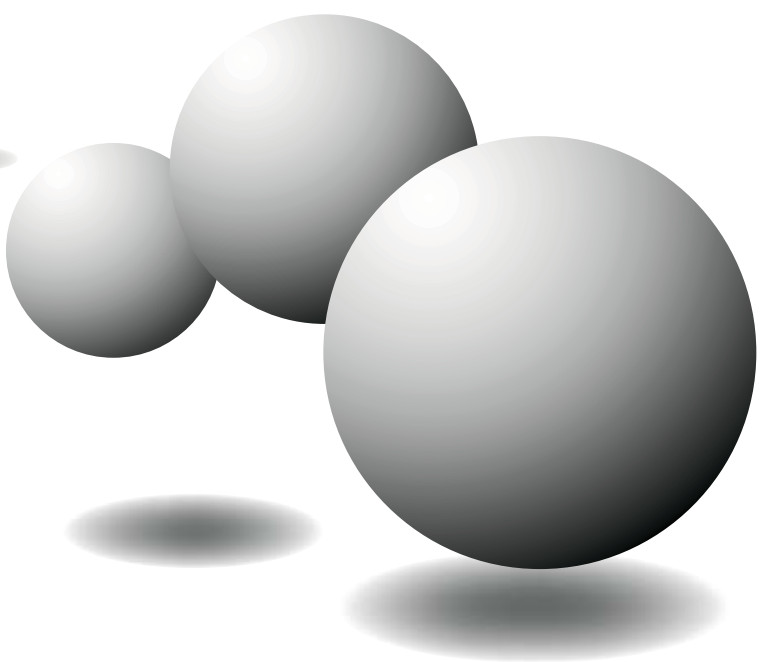

Published in: Cancer Nursing 2006; 29(6): 467-477. 


\section{Chapter 6}

\section{Abstract}

The purpose of this study was to determine the course of fatigue in patients with breast cancer between 2 cycles of adjuvant chemotherapy, from the day of administration until the day of the next infusion. In a prospective cohort study, a sample of 151 patients with breast cancer receiving adjuvant chemotherapy was recruited from 6 hospitals in mainly the south of the Netherlands. Patients reported their experience of fatigue in a diary, the Shortened Fatigue Questionnaire, on a daily basis between the third and fourth treatment with adjuvant chemotherapy. Patients were treated with either a doxorubicin containing schedule or with cyclophosphamide, methotrexate and 5-fluorouracil (CMF, 28 days). In the 28-day regimens, infusions were given on day 1 and day 8 . The days after completion of the third and the start of the fourth treatment with chemotherapy were statistically analyzed. We tested the hypothesis that the maximum fatigue score occurs in the first 4 days after treatment.

The mean age of the sample was 47.2 years $(S D=8.8)$. Most women $(84 \%)$ were married or lived together with a partner. The majority $(80 \%)$ of all patients had been diagnosed with stage II breast cancer. The division between mastectomies (47\%) and lumpectomies (52\%) was approximately equal. Sixty percent of the patients received radiotherapy before the third treatment with chemotherapy and/or in the period they kept the diary. A chaotic pattern of fatigue between the 2 cycles of chemotherapy emerged. Smooth (splines) curves showed an average highest level of fatigue on day 3 from the start. For the 28 day regimens another distinct peak was seen around day 11. A relatively larger number of patients experienced peak fatigue levels before day 5. The course of fatigue in the CMF group was significantly different compared to the doxorubicin regimens. The fatigue peak in the CMF group was lower. Women taking cyclophosphamide orally experienced the peak level of fatigue significantly later. Influences of other variables were not observed in any chemotherapy group.

Cancer-related fatigue has a chaotic nature. The first days after treatment with chemotherapy are the worst. The type of chemotherapy has a significant impact on the course of fatigue. Improved understanding of the nature and course of fatigue could equip health care providers better for informing patients about what they may expect. Future research should include interventions aimed at reducing or coping with fatigue.

Key words: adjuvant chemotherapy, breast cancer, fatigue 


\section{INTRODUCTION}

Fatigue is one of the most common complaints of patients undergoing cancer treatment [1]. The National Comprehensive Cancer Network (NCCN) has reported that $70 \%$ to $100 \%$ of the patients with cancer report fatigue [2]. Most patients report fatigue while undergoing cancer-related therapies. The exact cause of fatigue is unknown [1]. Factors associated with fatigue include the cancer itself, cancer treatment, depression or anxiety, some medications, pain, nausea, vomiting, diarrhoea, poor nutrition, anaemia, infections and insomnia [1]. Fatigue is a complex, multicausal and multidimensional subjective experience, and therefore, no single definition is widely accepted [3-5]. However, a panel of experts in the field of fatigue, convened by the NCCN, defined cancer-related fatigue as "a persistent, subjective sense of tiredness related to cancer or cancer treatment that interferes with usual functioning" [2] $]^{(\mathrm{p} . \mathrm{MS}-2)}$. In a study by Holley [6], cancer-related fatigue, when compared with 'typical' fatigue, was found to be more rapid in onset, more energy draining, more intense, longer lasting, more severe and more unrelenting. The unusual character of cancer-related fatigue described in Holly's study [6] is in line with the definition of the NCCN. Fatigue is the most frequently reported side effect in cancer patients who receive chemotherapy. Hilfinger Messias et al. [7] state results on how overwhelming and debilitating fatigue can be for patients undergoing chemotherapy.

The leading form of cancer in women since the early 1990s has been breast cancer, not only in the Netherlands but also elsewhere.

Schwartz [8] reported that breast cancer patients receiving adjuvant chemotherapy demonstrated a chaotic pattern with erratic and wide swings in their fatigue. De Jong et al. [9] reported in their literature review on breast cancer patients who received chemotherapy that the first 2 days after chemotherapy treatment seemed to be the worst period. Other symptoms in women undergoing chemotherapy for breast cancer show a similar pattern. The worst nausea and the worst vomiting occurred on the third day after having chemotherapy $[10,11]$.

According to recent breast cancer studies $[12,13]$, the type of surgery does influence the course of fatigue, whereas the influence of other characteristics, such as radiotherapy, marital status, and age, is unclear.

The intensity of fatigue in patients with breast cancer between 2 cycles of chemotherapy treatments has rarely been investigated. Previous studies, mentioned in a literature review [9], are marked by several limitations, including a small sample size. In addition, information about fatigue on each day between 2 cycles of chemotherapy treatments is often missing, which means that the 
understanding of the course of fatigue remains incomplete. Moreover, the influence of other characteristics on the course of fatigue is unknown.

The present study is part of a fatigue project in breast cancer patients receiving adjuvant chemotherapy. The purpose of the present study was to investigate the course of fatigue in patients with breast cancer between 2 cycles of chemotherapy treatment, from the day of administration until the day on which the next cycle starts. The research questions are: How does the experience of fatigue change in the course of time and are there any factors which are influencing the course of fatigue? More specific, in the present study, we tested one hypothesis. Previous studies support the hypothesis that the intensity of fatigue increases directly after administering chemotherapy. Therefore, the hypothesis that the maximum fatigue score occurs in the first 4 days after treatment with chemotherapy was tested. The impact of different chemotherapy regimens on the course of fatigue was unclear and was therefore further examined in this study. Finally, the influence of other characteristics on the course of fatigue was studied.

\section{Patients AND MEthods}

\section{Population sample and procedure}

Patients with breast cancer attending for adjuvant chemotherapy were accrued from 6 hospitals in mainly the south of the Netherlands.

After checking the inclusion criteria, the study was introduced by an oncologist or the oncology nurse before the first treatment with adjuvant chemotherapy. Written information was given in which the purpose and procedure of the investigation were explained. The principal investigator of the present study was contacted by the oncologist or the oncology nurse if the patient agreed to participate. All patients gave their informed consent in writing. The procedures were approved by all local medical ethical committees of the participating health centres.

To be eligible for participation, patients with breast cancer: (1) had to have no metastasis or other malignancy, (2) had to be treated with cytostatics for the first time, (3) had to be treated with outpatient adjuvant chemotherapy, (4) should not suffer from a chronic disease (including hypertension, kidney disease, heart problems, diabetes mellitus etc) or be in a poor psychological state, (5) should not use morphine or narcoleptics, (6) should not be deaf, (7) had to be 18 years or older, and (8) had to be able to speak and understand Dutch.

Patients were seen 3 times during chemotherapy for this fatigue project: at the beginning of the first, third, and fifth cycles of chemotherapy. After intake at 
the first visit, a diary, the Shortened Fatigue Questionnaire (SFQ) [14], was given at the time of the third treatment with chemotherapy and had to be filled in daily, starting on the day of the third chemotherapy treatment until the day of the fourth chemotherapy treatment. The interviewer explained the importance of filling in the diary and emphasised the need of completeness. The start of the third cycle was chosen because the patient should be more familiar with receiving a chemotherapy treatment than at the start of the first cycle of chemotherapy. Besides, the opportunity to bring the diary back existed, which might raise the response. Patients were asked to bring the diary at the third measurement point, the fifth treatment of chemotherapy. Medical data were collected from the charts afterwards.

\section{Operationalisation of variables}

Intensity of fatigue. The SFQ [14] is an instrument to determine the intensity of the patient's bodily fatigue. The SFQ, a 7-point scale, was developed based on 2 Dutch fatigue questionnaires: the Checklist Individual Strength (CIS)[15] and the Multidimensional Fatigue Inventory (MFI-20)[16]. The SFQ, in the present study used as a diary, was developed for daily medical practice and clinical scientific studies. The questionnaire is reliable, easy to use and can be completed quickly. Its internal consistency is good (Cronbach's alpha: 0.88) and it can discriminate between patient groups and healthy control groups [14]. The questionnaire consists of 4 questions: 'I feel tired', 'I tire easily', 'I feel fit' and 'I feel physically exhausted', each with a 7-point answer scale. The properly-signed sum score varies from a minimum of 4 to a maximum of 28 . High scores indicate more subjective fatigue.

Patients were asked to rate their fatigue as experienced during 1 day for a period of 21 or 28 days, depending on their chemotherapy regimen. The diary had to be filled in all days between the third and fourth treatment with adjuvant chemotherapy.

Treatment with adjuvant chemotherapy. The treatment regimens used were: CEF (cyclophosphamide, 4-epi-doxorubicin and 5-fluorouracil), CAF (cyclophosphamide, doxorubicin and 5-fluorouracil), 4-epi-doxorubicin, 4-epidoxorubicin/taxotere, CA (cyclophosphamide and doxorubicin) and CMF (cyclophosphamide, methotrexate (oral administration from day 1 to day 14 or intravenous) and 5-fluorouracil) (see Table 1). Most regimens consisted of 6 cycles except the CA regimen, which consisted of 4 cycles.

For some chemotherapy schedules, the third treatment existed of 2 infusions given on day 1 and day 8 (see Table 1). These patients filled in 28 days of the diary, whereas others filled in 21 days. 


\section{Chapter 6}

Table 1. Characteristics of the diary specified by chemotherapy treatment $(n=151)$

Treatment with adjuvant

Infusion 3rd treatment given on Total number of days of the diary

chemotherapy (n)

doxorubicin-group $(n=107)$

dox21 group $(n=82)$ :

CEF $(n=37)$

CAF $(n=25)$

$\mathrm{CA}(n=20)$

day 1

day 1

day 1

21

21

21

dox28 group $(n=25)$ :

4 epi-doxorubicin $(n=20)$

4 epi-doxorubicin / taxotere $(n=5)$

day 1 and day 8

28

day 1 and day 8

28

CMF group

CMF $(n=44)$

day 1 and day 8

28

Several groups were compared for the analysis: the '21 days-doxorubicin group' or 'dox 21' (CEF, CAF and CA), the '28 days-doxorubicin group' or 'dox28' (4-epi-doxorubicin and 4-epi-doxorubicin/taxotere) and the CMF group (28 days). The choice of schedule was based on current practice in the participating hospitals. The involvement of various adjuvant chemotherapy regimens made it possible to generate a sizeable sample in a relatively short period of time. The days that followed on completion of the full third treatment were compared. This means that only the last 3 weeks, 21 days, were compared. We chose for a time schedule in which no infusion took place because of its possible influence on the course of fatigue.

Stage of breast cancer. The TNM (T, tumor; N, regional lymph node; M, distant metastases) clinical classification for describing the anatomic extent of breast cancer was used [17]. Indications for adjuvant chemotherapy were standard.

Type of surgery. In the present study, 2 types of surgery were compared: (1) mastectomy with lymph nodes excision; and (2) lumpectomy with lymph nodes excision. The other types, mastectomy or lumpectomy without lymph nodes excision, were excluded because of their small sample size. No reconstructive surgery was done during the study period.

\section{Statistical analyses}

It was statistically tested whether there were differences in patient characteristics between the different chemotherapy groups. We used chi-square tests for categorical 
characteristics and $t$ tests for continuous data. The Mann-Whitney $U$ test was used to compare the level of education.

The reliability of the SFQ was examined by calculating Cronbach's $\alpha$. The Cronbach's $\alpha$ of the SFQ is the mean of the Cronbach's $\alpha$ of each day of the diary.

First, an overview of raw mean scores of the SFQ of the different chemotherapy groups was presented to give an impression of the course of fatigue between 2 cycles of adjuvant chemotherapy.

To obtain a clearer picture of the course of fatigue, we calculated cubic spline fits of the mean fatigue score per chemotherapy group. Cubic splines provide a smoothly curved estimate of the mean fatigue, calculated per group or for individual patients, using third-order polynomials between the so-called knots. The polynomials are restricted to ensure a smooth transition at the knots. For these splines, the knots were chosen at 5, 10 and 15 days based on the assumption that changes in fatigue would be larger in the first weeks after chemotherapy. We tested for overall differences between chemotherapy groups using a longitudinal model assuming a random intercept per patient and robust estimation of the error variance (Stata version 8) [18]. Likewise, the different groups of the following variables were tested separately for the different chemotherapy groups: 'age', 'marital status', 'having children', 'education', 'having a job', 'season in which the diary was kept (spring and/or summer vs. autumn and/or winter)', 'type of surgery', 'stage of breast cancer', 'having cyclophosphamide oral', 'haemoglobin level (measured in $\mathrm{mmol} / \mathrm{l}$ ) before the third cycle of chemotherapy', 'number of days between the operation and the first treatment with chemotherapy' and 'radiotherapy'. Two different variables were used for the covariate 'radiotherapy': the number of days of radiotherapy the patient had had at the time of measuring and the number of days between the last day of radiotherapy and the time of measuring.

Subsequent analysis of the mean fatigue score, the maximum fatigue score and the day of the maximum fatigue score was done on values from individually fitted spline curves (see above), with estimated imputation of missing values and truncation at values 4 and 28 to avoid excessive estimates. These curves were calculated only when the number of diary entries was at least 9 , again to avoid large spurious oscillations. To compare the 21-day doxorubicin-therapy to the two 28-days therapy groups, we chose to compare the last 3 weeks only. For these comparisons, Kruskal-Wallis and Mann-Whitney $U$ tests were used because of non-normality of the tested variables. Pairwise tests between three groups were corrected for multiple comparisons using Bonferroni correction.

For the main hypothesis, we applied binomial tests to establish whether the maximum was reached relatively more frequently in days 1 to 4 . 


\section{Chapter 6}

\section{ResUlts}

\section{Response rate}

A sample of 175 patients with breast cancer met the eligibility criteria for the present study. A sample of $18(10 \%)$ of the original participants were excluded for various reasons: 13 (7\%) declined further participation, 3 (2\%) stopped the adjuvant chemotherapy prematurely and $2(1 \%)$ were in a poor physical state.

Because of a start-up delay, the dairy was given to 155 instead of the remaining 157 patients. Of the 155 patients, 151 returned the diary. The nonresponse was caused by one refusal to fill-in the diary and three patients who did not return the diary for unclear reasons. In total, 151 diaries were part of the analyses and were kept for $21(n=82)$ or $28(n=69)$ days, depending on their chemotherapy regimen (see Table 1). Table 2 displays the number of days on which patients filled in the diary.

As to the analyses of the last 3 weeks, 4 of the 151 patients were excluded because they had filled in less than 9 days of the diary. These patients were excluded in the calculation of individually smoothed curves since fitting the

Table 2. Response rates of patients with breast cancer specified by the number of days they filled in the diary

\begin{tabular}{|c|c|c|c|c|c|c|}
\hline \multirow[b]{2}{*}{ Number of days } & \multicolumn{2}{|c|}{$\begin{array}{c}\text { Doxorubicin group } \\
21 \text { days } \\
(\mathrm{n}=82)\end{array}$} & \multicolumn{2}{|c|}{$\begin{array}{c}\text { Doxorubicin group } \\
28 \text { days } \\
(n=25)\end{array}$} & \multicolumn{2}{|c|}{$\begin{array}{c}\text { CMF } \\
(n=44)\end{array}$} \\
\hline & $n$ & $\%$ & $n$ & $\%$ & $n$ & $\%$ \\
\hline 28 days & - & - & 20 & 80 & 38 & 86 \\
\hline 27 days & - & - & 2 & 8 & 1 & 2 \\
\hline 26 days & - & - & - & - & 1 & 2 \\
\hline 25 days & - & - & - & - & 1 & 2 \\
\hline 22 days & - & - & - & - & 1 & 2 \\
\hline 21 days & 67 & 82 & - & - & - & - \\
\hline 20 days & 10 & 12 & - & - & - & - \\
\hline 19 days & 0 & 0 & 1 & 4 & - & - \\
\hline 18 days & 1 & 1 & - & - & - & - \\
\hline 17 days & 1 & 1 & - & - & - & - \\
\hline 16 days & 1 & 1 & - & - & - & - \\
\hline 14 days & 1 & 1 & 2 & 8 & 1 & 2 \\
\hline 10 days & 1 & 1 & - & - & - & - \\
\hline 9 days & - & - & - & - & 1 & 2 \\
\hline
\end{tabular}


curve on less than 9 data points would lead to large spurious variations. We compared the fatigue scores of these four patients with the mean of their therapy group and found that it was on average 4.8 points higher $(\mathrm{SD}=2.1)$. However, because of the relatively very small number of these patients their omission could hardly influence the results of the further analyses.

\section{Sample characteristics}

Table 3 presents information about the demographic and medical characteristics of the sample.

The ages of the 151 patients with breast cancer ranged from 25 to 70 years, with a mean age of 47.2 years ( $\mathrm{SD}=8.8$ ). As Table 3 shows, twenty-nine percent of the patients received CMF treatment; the remainder received one of the chemotherapies covered by the doxorubicin group. The doxorubicin 28 days group was significantly older than the other two chemotherapy groups. The majority $(80 \%)$ had been diagnosed with stage II breast cancer. The division between mastectomies ( $47 \%$ ) and lumpectomies $(52 \%)$ was approximately equal. In addition to chemotherapy, $60 \%$ of the patients received radiotherapy before the third treatment with chemotherapy and/or in the period they kept the diary.

\section{Internal consistency}

The Cronbach's $\alpha$ of the SFQ is the mean of the Cronbach's $\alpha$ of all 28 days and is 0.92 . Only 2 of the 28 Cronbach's $\alpha$ 's were below 0.90 . The lowest Cronbach's $\alpha$ was 0.89 and the highest was 0.94 .

\section{Course of fatigue between two cycles of adjuvant chemotherapy}

The course of fatigue was studied by analysing the results of the SFQ. In Figure 1 , the mean scores of the SFQ for the different chemotherapy groups are displayed, which indicate a chaotic pattern of fatigue of patients. The line of the mean scores in each figure indicates an increase of fatigue after the first day of the diary. The chemotherapy groups with 28 days between the 2 cycles also show an increase after day 8 , the time of administering the second part of the third cycle of chemotherapy. The fatigue experienced by the CMF group on the first days is lower than the fatigue experienced by the other groups.

Smoothed (spline) curves, displayed in Figure 2, show a similar pattern as described for the mean scores. The highest average level of fatigue was experienced on day 3 after the start of the cycle. For the regimens with 28 days between two cycles of chemotherapy, a direct increase can be observed after day 8 , with another peak around day 11 .

The three curves were significantly different with $F_{14,150}=4.57, P<0.0001$. 


\section{Chapter 6}

Table 3. Patient characteristics

\begin{tabular}{|c|c|c|c|c|}
\hline \multirow{2}{*}{ Age (years) 1,3} & \multicolumn{2}{|c|}{$\begin{array}{l}\text { Doxorubicin group } 21 \text { days } \\
\qquad(n=82)\end{array}$} & \multicolumn{2}{|c|}{$\begin{array}{l}\text { Doxorubicin group } 28 \text { days } \\
\qquad(n=25)\end{array}$} \\
\hline & \multirow{4}{*}{\multicolumn{2}{|c|}{$\begin{array}{c}44.5 \\
27-70 \\
6.2\end{array}$}} & \\
\hline Mean & & & \multirow{3}{*}{\multicolumn{2}{|c|}{$\begin{array}{c}60.0 \\
50-69 \\
5.3\end{array}$}} \\
\hline Range & & & & \\
\hline \multirow[t]{2}{*}{ SD } & & & & \\
\hline & $n$ & $\%$ & $n$ & $\%$ \\
\hline \multicolumn{5}{|l|}{ Marital status ${ }^{4}$} \\
\hline living together & 70 & 85 & 18 & 72 \\
\hline Living alone & 12 & 14 & 7 & 28 \\
\hline \multicolumn{5}{|l|}{ Children } \\
\hline Yes & 65 & 79 & 20 & 80 \\
\hline No & 17 & 21 & 5 & 20 \\
\hline \multicolumn{5}{|l|}{ Level of education ${ }^{1,3}$} \\
\hline Low & 27 & 33 & 15 & 60 \\
\hline Middle & 33 & 40 & 7 & 28 \\
\hline High & 22 & 27 & 3 & 12 \\
\hline \multicolumn{5}{|l|}{ Job1,3 } \\
\hline Yes & 54 & 66 & 2 & 8 \\
\hline No & 28 & 34 & 23 & 92 \\
\hline \multicolumn{5}{|l|}{ Stage of breast cancer* } \\
\hline 1 & 9 & 11 & - & - \\
\hline$\|$ & 64 & 78 & 23 & 92 \\
\hline III & 4 & 5 & - & - \\
\hline Unknown (missing at the data collection point) & 5 & 6 & 2 & 8 \\
\hline \multicolumn{5}{|l|}{ Type of operation ${ }^{\dagger}$} \\
\hline Mastectomy without lymph nodes excision & 3 & 4 & - & - \\
\hline Mastectomy with lymph nodes excision & 41 & 50 & 9 & 36 \\
\hline Lumpectomy without lymph nodes excision & 1 & 1 & - & - \\
\hline Lumpectomy with lymph nodes excision & 35 & 43 & 16 & 64 \\
\hline Unknown & 2 & 2 & - & - \\
\hline \multicolumn{5}{|l|}{ Radiotherapy1, } \\
\hline Yes & 41 & 50 & 20 & 80 \\
\hline No & 41 & 50 & 5 & 20 \\
\hline \multicolumn{5}{|l|}{ Cyclophosphamide (oral) } \\
\hline Yes & - & - & - & - \\
\hline No & 82 & 100 & 25 & 100 \\
\hline \multicolumn{5}{|l|}{$\begin{array}{l}\text { Anaemia (haemoglobin level, } \\
\mathrm{mmol} / \mathrm{l}<7.3 \text { or } \mathrm{g} / \mathrm{dl}<11.7 \text { ) } 2,3, \S\end{array}$} \\
\hline Yes & 14 & 17 & 6 & 24 \\
\hline No & 63 & 77 & 18 & 72 \\
\hline Unknown & 5 & 6 & 1 & 4 \\
\hline \multicolumn{5}{|l|}{ Moment of filling in the diary } \\
\hline Spring and/or summer & 40 & 49 & 16 & 36 \\
\hline Autumn and/or winter & 42 & 51 & 9 & 64 \\
\hline
\end{tabular}


Course of fatigue between two cycles

\begin{tabular}{|c|c|c|c|c|c|}
\hline \multicolumn{2}{|c|}{$\begin{array}{l}\text { Doxorubicin group total } \\
\qquad(n=107)\end{array}$} & \multicolumn{2}{|c|}{$\begin{array}{l}\text { CMF group } \\
(n=44)\end{array}$} & \multicolumn{2}{|c|}{$\begin{array}{c}\text { Total } \\
(n=151)\end{array}$} \\
\hline & & \multicolumn{2}{|c|}{$\begin{array}{c}25-62 \\
8.1\end{array}$} & & $\begin{array}{c}25-70 \\
8.8\end{array}$ \\
\hline$n$ & $\%$ & $n$ & $\%$ & $n$ & $\%$ \\
\hline 88 & 82 & 39 & 89 & 127 & 84 \\
\hline 19 & 18 & 5 & 12 & 24 & 16 \\
\hline 85 & 79 & 35 & 80 & 120 & 80 \\
\hline 22 & 21 & 9 & 21 & 31 & 21 \\
\hline 42 & 39 & 12 & 27 & 54 & 36 \\
\hline 40 & 37 & 23 & 52 & 63 & 42 \\
\hline 25 & 23 & 9 & 21 & 34 & 23 \\
\hline 56 & 52 & 32 & 73 & 88 & 58 \\
\hline 51 & 48 & 12 & 27 & 63 & 42 \\
\hline 9 & 8 & 3 & 7 & 12 & 8 \\
\hline 87 & 81 & 34 & 77 & 121 & 80 \\
\hline 4 & 4 & 2 & 5 & 6 & 4 \\
\hline 7 & 7 & 5 & 11 & 12 & 8 \\
\hline 3 & 3 & - & - & 3 & 2 \\
\hline 50 & 47 & 18 & 41 & 68 & 45 \\
\hline 1 & 1 & - & - & 1 & 1 \\
\hline 51 & 48 & 26 & 59 & 77 & 51 \\
\hline 2 & 2 & - & - & 2 & 1 \\
\hline 61 & 57 & 30 & 68 & 91 & 60 \\
\hline 46 & 43 & 14 & 32 & 60 & 40 \\
\hline - & - & 31 & 71 & 31 & 21 \\
\hline 107 & 100 & 13 & 30 & 120 & 80 \\
\hline 20 & 19 & 5 & 11 & 25 & 17 \\
\hline 81 & 76 & 38 & 86 & 119 & 79 \\
\hline 6 & 6 & 1 & 2 & 7 & 5 \\
\hline 56 & 52 & 21 & 48 & 77 & 51 \\
\hline 51 & 48 & 23 & 52 & 74 & 49 \\
\hline
\end{tabular}




\section{Chapter 6}

Table 3. Patient characteristics

Days between operation and

1st chemotherapy treatment ${ }^{1,2}$

Mean (SD)

Range

Haemoglobin level, $\mathrm{mmol} / \mathrm{I}^{\S}$

Mean $\mathrm{mmol} / / \mathrm{l}$ or $\mathrm{g} / \mathrm{dl}(\mathrm{sd} \mathrm{mmol} / / \mathrm{lor} \mathrm{g} / \mathrm{dl})$

Range $\mathrm{mmol} / \mathrm{l}$ or $\mathrm{g} / \mathrm{dl}$

Doxorubicin group 21 days

$(n=82)$

$31.8(13.6)$

9-77

7.8 or $12.5(0.7$ or 1.1$)$

$6.0-9.4$ or $9.6-15.0$
Doxorubicin group 28 days

$(n=25)$

$42.0(37.6)$

14-215

7.6 or $12.2(0.4$ or 0.6$)$

6.5-8.3 or 10.4-13.3

${ }^{1}$ Statistically significant difference $(P<0.05)$ in characteristics between the doxorubicin group 21 days and the doxorubicin group 28 days.

2 Statistically significant difference $(P<0.05)$ in characteristics between the doxorubicin group 21 days and the CMF group.

${ }^{3}$ Statistically significant difference $(P<0.05)$ in characteristics between the doxorubicin group 28 days and the CMF group.

${ }_{*}^{4}$ Two groups, living together or living alone, were compared between the different groups.

* Three groups, stage of breast cancer I, II and III, were included in the comparison.

${ }^{\dagger}$ Two groups, mastectomy or lumpectomy with lymph nodes excision, were included in the comparison.

‡ If the answer is 'yes' patients were receiving radiotherapy and/or had finished radiotherapy during or before the study period.

$\S$ The haemoglobin level was determined before the third treatment with chemotherapy; the conversion factor from mmol/l to $\mathrm{g} / \mathrm{dl}$ is 1.6 .

It should be noted that the last three weeks were compared (see Figure 3). Pairwise comparison of the curves showed a difference between the CMF and each of the doxorubicin regimens (CMF group vs. dox28 group, $P=0.0018$; CMF group vs. dox21 group, $P<0.0001$, but not between the two doxorubicin regimens, $P=0.14$ (Bonferroni correction). This means that the pattern of fatigue between 2 cycles of chemotherapies of the CMF group is different from each of the doxorubicin regimens. The pattern of the 2 doxorubicin regimens, on the other hand, is similar.

\section{MEAN FIT, MAXIMUM FIT AND DAY OF MAXIMUM FIT BETWEEN CHEMOTHERAPY GROUPS}

For a more specific comparison of the chemotherapy groups, we also calculated the mean fit, the maximum fit, and the day of maximum fit from the individually fitted curves over the last 3 week (Table 4).

The mean fit this yielded significant differences between the treatment groups, but pairwise tests did not yield significant results.

Considering the maximum fit, only 1 significant effect is found between the dox21 group and the CMF group. The top of the fatigue level is significantly higher in the dox21 group than in the CMF group.

There were no significant differences between the different chemotherapy groups as to the day of maximum fit. In short, the top of the fatigue level between two cycles of chemotherapy fell around day 3 for all regimens (median $=3$, mean $=5.9$ ). 


\begin{tabular}{c|cc|}
$\begin{array}{c}\text { Doxorubicin group total } \\
(\boldsymbol{n}=107)\end{array}$ & $\begin{array}{c}\text { CMF group } \\
(\boldsymbol{n}=44)\end{array}$ & $\begin{array}{c}\text { Total } \\
(\boldsymbol{n}=151\end{array}$ \\
& & \\
\hline $34.2(21.9)$ & $39.2(27.1)$ & $35.6(23.6)$ \\
$9-215$ & $15-125$ & $9-215$ \\
\hline & & \\
7.7 or $12.3(0.6$ or 1.0$)$ & 8.2 or $13.1(0.7$ or 1.1$)$ & 7.9 or $12.6(0.7$ or 1.1$)$ \\
$6.0-9.4$ or $9.6-15.0$ & $6.6-9.4$ or $10.6-15.0$ & $6.6-9.4$ or $10.6-15.0$
\end{tabular}

\section{TEST OF THE MAIN HYPOTHESIS}

For this test, 8 of the 147 patients were excluded because the day of the highest fatigue level experienced by them in the last 3 weeks of the study period could not be calculated: 5 patients did not report any fatigue at all, 1 patient scored the maximum score (28) and 2 patients scored ' 16 ' each day. Of the remaining

Table 4. Mean fit, maximum fit and day of maximum fit between chemotherapy groups

\begin{tabular}{|c|c|c|c|c|c|c|}
\hline & \multicolumn{2}{|c|}{$\begin{array}{l}\text { Doxorubicin } \\
\text { group } 21 \text { days }\end{array}$} & \multicolumn{2}{|c|}{$\begin{array}{l}\text { Doxorubicin } \\
\text { group } 28 \text { days }\end{array}$} & \multicolumn{2}{|c|}{ CMF group } \\
\hline & $n$ & $\begin{array}{c}\text { Median } \\
\text { (quartiles) }\end{array}$ & $n$ & $\begin{array}{c}\text { Median } \\
\text { (quartiles) }\end{array}$ & $n$ & $\begin{array}{l}\text { Median } \\
\text { (quartiles) }\end{array}$ \\
\hline Mean fit & 82 & $\begin{array}{c}15.50 \\
(10.14 ; 19.95)\end{array}$ & 23 & $\begin{array}{c}16.38 \\
(11.43 ; 19.81)\end{array}$ & 42 & $\begin{array}{c}12.11 \\
(8.11 ; 16.48)\end{array}$ \\
\hline Maximum fit ${ }^{1}$ & 82 & $\begin{array}{c}23.99 \\
(19.60 ; 27.95)\end{array}$ & 23 & $\begin{array}{c}22.94 \\
(17.54 ; 27.18)\end{array}$ & 42 & $\begin{array}{c}19.67 \\
(13.03 ; 22.89)\end{array}$ \\
\hline Day of maximum fit & 80 & $\begin{array}{c}3 \\
(2 ; 6.25)\end{array}$ & 21 & $\begin{array}{c}5 \\
(1 ; 13.25)\end{array}$ & 38 & $\begin{array}{c}3 \\
(1 ; 6)\end{array}$ \\
\hline
\end{tabular}




\section{Chapter 6}
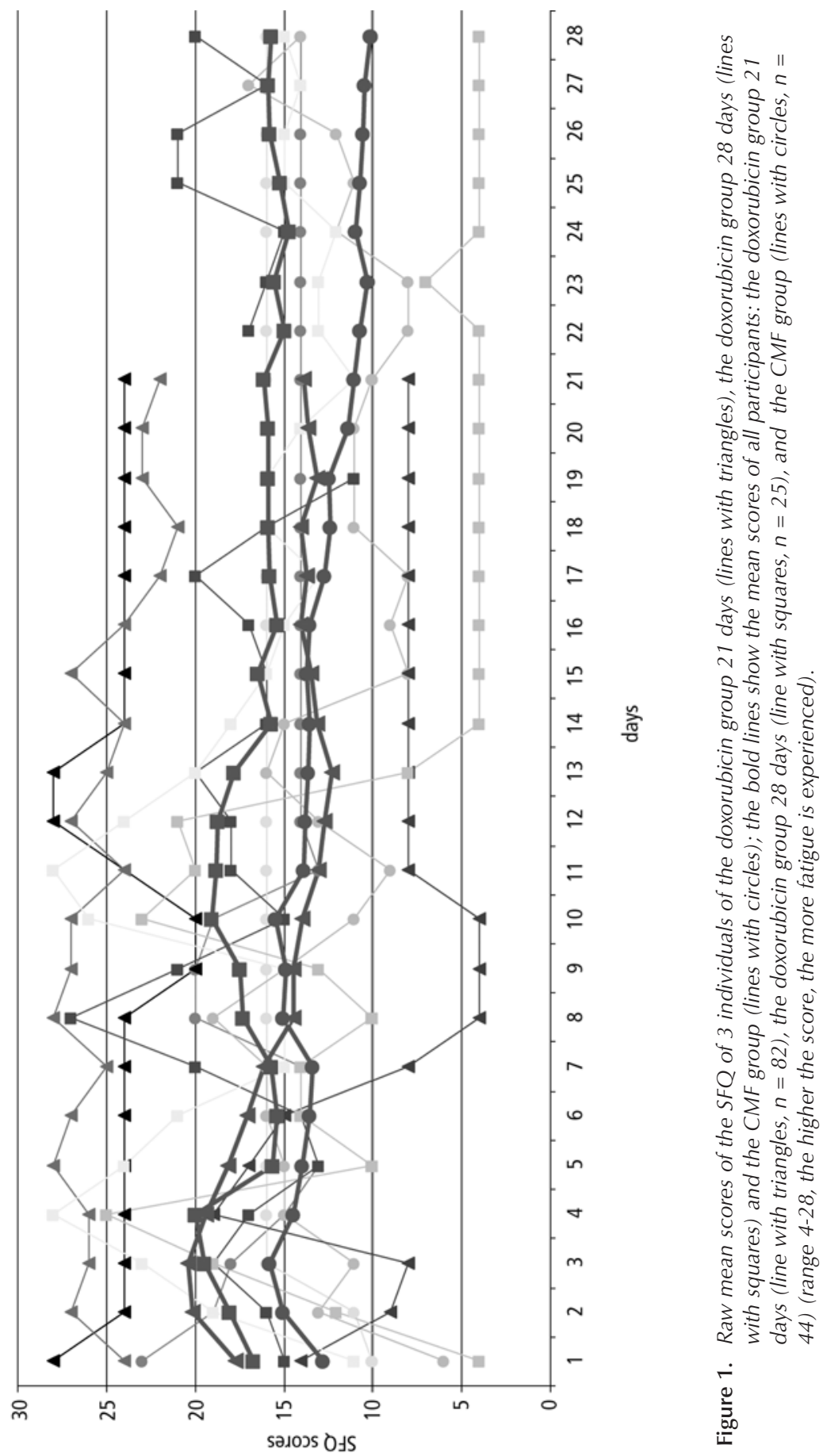


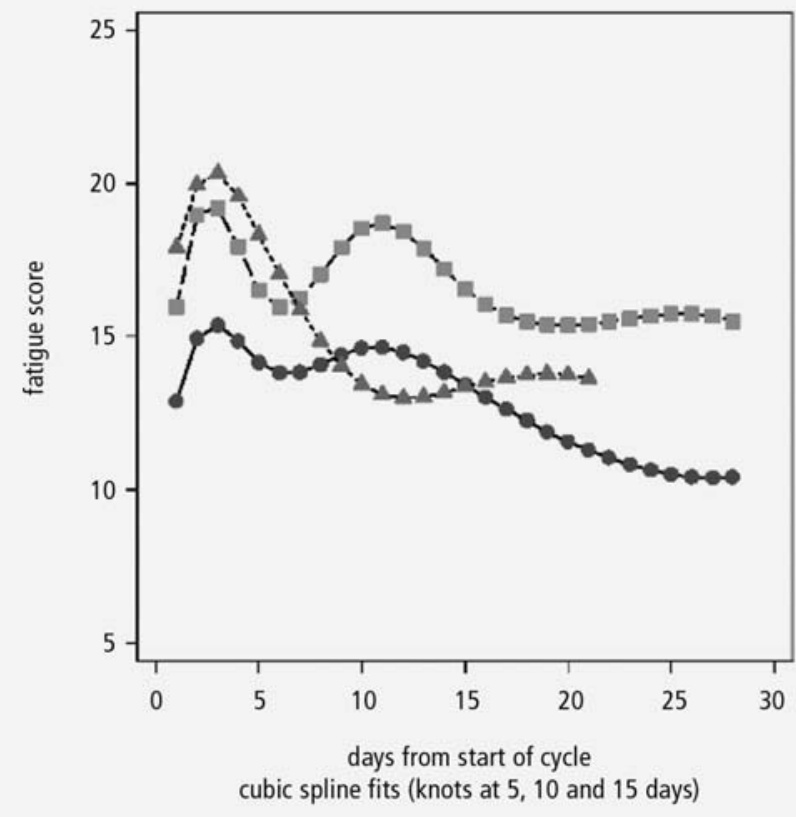

TREATMENT GROUP

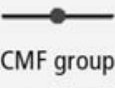

- - 타- -

dox. group 28 days

dox. group 21 days

Figure 2. Smoothed (spline) curves of the different chemotherapy groups (range 4-28).

139 patients for whom the day of maximum fit (the day of the top fatigue level) could be determined, 84 had the maximum fit before day 5 . When the maximum occurs randomly, the expected number is 26.5 , the $p$-value for the binomial test was $<0.0001$. This test was also highly significant within each chemotherapy therapy group. This means that in each regimen a significant majority of patients experienced their maximum fatigue level before day 5 .

\section{Influence of factors on the course of fatigue for the different chemotherapy groups}

The influence of several separate factors (demographic, disease, treatment and other, see section Statistical Analyses) for the various chemotherapy groups was analyzed. We report on the significant associations only.

Marital status (living together, yes or no). In the dox21 group the curves were significantly different $(P=0.0005)$. The test for the day of maximum fit was significant at $P=0.040$. Women with a partner have the day of maximum fatigue later.

Education. Only for the group dox 21 was a significant difference in the 3 curves 


\section{Chapter 6}

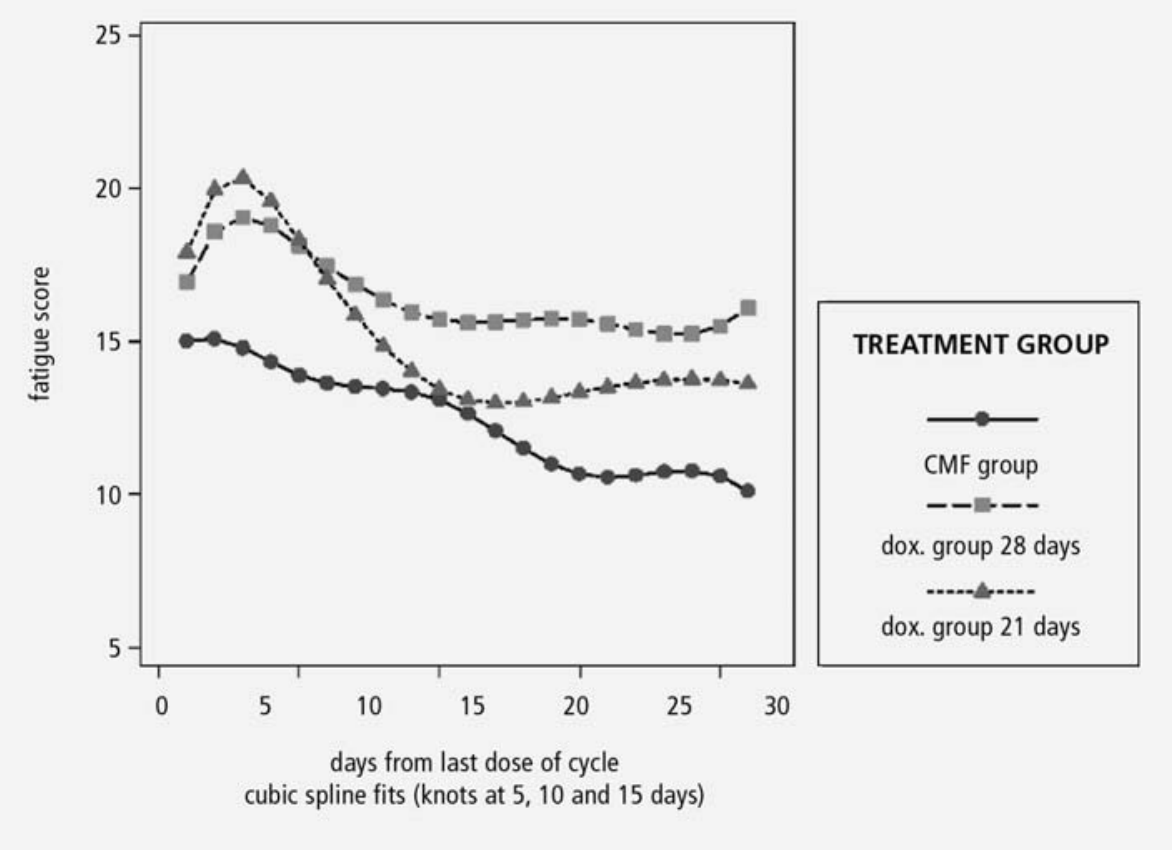

Figure 3. Smoothed (spline) curves of the last three weeks of the different chemotherapy groups (range 4-8).

was found $(P=0.038)$. Pairwise tests were not significant, however.

Type of surgery. In the dox28 group, the curves (mastectomy and lumpectomy) were significantly different $(P=0.028)$. Subsequent tests showed that the mean fit was significantly higher in the group of women who had undergone a mastectomy $(P=0.007)$. These patients experienced significantly more fatigue than women who had undergone a lumpectomy.

Cyclophosphamide (oral). Cyclophosphamide was given to CMF patients only. The curves appeared different $(P=0.0002)$, which was confirmed by a difference in day of maximum fit $(P=0.0001)$; if cyclophosphamide (oral) was used, the maximum was reached later. In addition, fatigue gradually declined in the cyclophosphamide group.

\section{DisCUSSION}

This longitudinal study is the first large-scale examination of the course of fatigue between 2 cycles of adjuvant chemotherapy. A sample of 151 patients with breast 
cancer reported daily, between the third treatment and the fourth treatment with adjuvant chemotherapy, their experience of fatigue in a diary, the SFQ.

In the present study 1 hypothesis was examined, namely, that the maximum fatigue score occurs in the first 4 days after treatment with chemotherapy.

\section{Course of fatigue between two cycles of adjuvant chemotherapy}

In general, the pattern of fatigue in different women with breast cancer who receive adjuvant chemotherapy, irrespective of which regimen, appeared chaotic, a crisscross of lines. Fatigue fluctuated. Schwartz [8] supports this finding. She found that breast cancer patients receiving adjuvant chemotherapy demonstrated a chaotic pattern with erratic and wide swings in their fatigue. The authors of a phenomenological study [19] confirm this result by mentioning that cancerrelated fatigue has an unpredictable nature. The fatigue experienced by patients in connection with the disease of cancer appeared totally different from the fatigue experienced as healthy individuals [5]. Everyone experiences fatigue on a daily basis and this is generally relieved by a good night's sleep. For patients with cancer it often becomes a chronic and unpleasant sensation [20]. In sum, cancerrelated fatigue is of an unusual and chaotic nature, much like the movements of an uncontrolled large marble. This knowledge must be included in the education for oncology nurses, which can contribute to a better transfer of information with respect to the nature of fatigue from oncology nurses to patients. Patients, who know what can be expected, will be less overwhelmed. Understanding from family members and others can ease the experience of fatigue.

However, the experience of fatigue is subjective: in the present study overall patterns of fatigue between 2 cycles of adjuvant chemotherapy were reported for the 3 chemotherapy groups. Women were treated with either a doxorubicin containing schedule (dox21 or dox 28 group) or with CMF. Considering all days (21 or 28 days) directly after the start of the third treatment until the fourth treatment with adjuvant chemotherapy, the average highest level of fatigue was experienced on day 3. Molassiotis and Chan [21] found in a heterogeneous cancer population a peak level of fatigue on day 3 post chemotherapy as well, which was more evident in the evenings. In the present study, fatigue experienced during different times in the day was not examined, which might result in an incomplete view on the reality. The variability of fatigue should be noted. Several other studies [2123] of a heterogeneous cancer population support the present study's result as well. Days 2 to 5 post-chemotherapy seem to be the most troublesome days. However, the pattern is not always the same [21]. De Jong et al. [9] reported in their literature review of breast cancer patients receiving chemotherapy that the first two days after chemotherapy treatment seem to be the worst period. A similar finding was noted by Berger and Higginbotham [24], who observed that 


\section{Chapter 6}

breast cancer patients receiving CA regimen $(n=14)$ experienced the highest levels of fatigue and symptom distress during the first four days after treatment 3. In this pilot study, measurements were divided into four phases during cycle 3: 2 days prior to treatment, days 1-4, days 5-10 and days 11-21. Note, that not only the symptom fatigue in breast cancer patients is the worst occurred directly after having chemotherapy, but also nausea and vomiting In the present study, the regimens (dox28 and CMF) with 28 days between the two cycles also showed a direct increase after day 8, with another top fatigue level around day 11, 3 days after the second infusion, the last part of the third treatment. As in the study of Richardson et al. [22], the pattern of fatigue appeared to reflect the drug administration. In that study, breast cancer patients receiving CMF protocol also experienced a superimposed increase of fatigue shortly after day $8[10,11]$. Information delivery to patients of a probable peak of fatigue in the first days after an infusion with chemotherapy must be standard performed by oncology nurses. With this knowledge patients can prepare themselves, for example they can take their activities of daily life into consideration.

In the present study, the course of fatigue immediately after completion of the full third treatment with adjuvant chemotherapy until the fourth treatment with adjuvant chemotherapy was compared between the chemotherapy groups. It should be noted that this means that 3 weeks were compared. The pattern of fatigue of the CMF group was significantly different from both doxorubicin groups. On the other hand, the pattern of fatigue of both doxorubicin groups was similar. Although pairwise comparisons between the chemotherapy groups showed no significant differences in the mean fit of fatigue, the average fatigue level experienced by the CMF group was the lowest during the study period. Recent research [12] into patients with breast cancer established a difference in the experience of fatigue between the 2 groups as well. A difference in the chemical composition of the chemotherapies affected only the physical part of fatigue $[12,13]$. Further research in fatigue regarding different chemotherapy groups should be done to be able to inform patients more specifically.

Fatigue is a multidimensional concept [9]. The use of a unidimensional measurement therefore consitutes a limitation of the present study. For that reason, the description of the course of fatigue remains incomplete. The advantage of the unidimensional measurement used is the form and the length, which makes keeping the diary a quick and easy process. A similar concept should be developed for a multidimensional measurement.

With regard to the maximum fit, the top of the fatigue level appeared significant higher in the dox21 group than in the CMF group. Although Greene et al. [25] reported no significant differences in intensity of fatigue related to whether doxorubicin was included, Berger and Walker [26] found that 
chemotherapy protocols that contain intravenous doxorubicin were directly associated with higher fatigue, which supports the finding of the present study. Jacobsen et al. [27] had similar findings after the start of chemotherapy. It should be noted that in the present study the CMF group had already received the first part of the third infusion one week before, which may smooth the increase. This might be also the reason why no significant difference was found in the maximum fit between the dox28 group and CMF group. Both chemotherapy groups had the same drug administration.

Considering all chemotherapy groups, the mean day of maximum fit was around day 6 . No significant differences were found in the day of maximum fit between the different chemotherapy groups. Nevertheless, in each regimen a significantly larger number of patients had their maximum fit before day 5 . The hypothesis that the maximum fatigue score occurs in the first four days after treatment with chemotherapy was therefore supported. Previous studies have shown that the highest mean score of fatigue in cancer patients receiving chemotherapy is found directly after an infusion of chemotherapy. However, there was no indication that these patients had their top fatigue level during that time. In the present study it appeared that most patients reached their top fatigue level on day 3. In general, as research by Cowley et al. [28] has shown, it can be said that the first week after chemotherapy is the worst. Cowley et al. [28] reported that patients still felt tired and exhausted in the second week, but were able to perform daily tasks then, albeit with difficulty. They were approaching normality by week 3 and just as they were beginning to feel normal again they had to repeat the cycle. Cowley et al. [28] found this in 12 women with breast cancer, which consitutes a relatively small sample. The rapid alterations in physical and mental state during chemotherapy resulted in a 'roller coaster' experience [28]. This pattern of a roller coaster had already been mentioned in a previous breast cancer study conducted by Berger [29] on 72 patients. In this study fatigue was found to be significantly lower at the midpoint of chemotherapy than 48 hours after chemotherapy. In the present study, this roller coaster pattern was also found. In week 2 and 3 after the infusion of chemotherapy patients reported less fatigue. However, it is not clear how patients experienced these weeks. It is, for instance, unknown whether the fatigue experienced in week 3 may be regarded as normal fatigue. It will therefore be necessary to conduct further research not only into these experiences, but also into the course of fatigue between different cycles of chemotherapy.

Summing up, it is helpful for oncology nurses to know what is happening regarding fatigue between 2 cycles of adjuvant chemotherapy in breast cancer patients. The existed information about fatigue for patients can be adjusted and specified. 


\section{Influence of factors on the course of fatigue for the different chemotherapy groups}

The influence of various factors on the course of fatigue for the different chemotherapy groups was examined separately. No single factor significantly influenced the course of fatigue of all 3 chemotherapy groups.

Previous studies $[12,13,30]$ into breast cancer patients during and after adjuvant chemotherapy, part of our project, type of surgery influenced all dimensions of fatigue. Women who had had a mastectomy were significantly more fatigued, less motivated and more hampered in their daily activities than women that had undergone a lumpectomy. The extent of the surgery and the psychological impact might be the cause [30]. An unexpected outcome of the present study was that the course of fatigue was only significantly different for this factor in the dox 28 group. It is probable that the difference in findings is caused by the use of a unidimensional measurement instrument as well as different measurement points.

The course of fatigue of the dox21 group was only influenced by the variable 'marital status'. Patients with a partner, the majority (85\%) of the sample, experienced their maximum fatigue 1 day later. This finding can not be explained.

It is clear that the variable 'taking cyclophosphamide orally' influenced the course of fatigue in the CMF group. Patients who took cyclophosphamide orally experienced their peak level of fatigue significantly later. As in the study of Richardson et al. [22], fatigue in patients with different types of cancer who are administered a combination of bolus and continuous chemotherapy declines gradually before the next cycle of treatment. Richardson et al. reported that this combination type of administration causes fatigue that is both more intense and unrelenting than fatigue induced by other modes of administration.

No significant differences (pairwise tests) in the course of fatigue for the different chemotherapy groups were found for the following variables: 'age', 'having children', 'education', 'having a job', 'season in which the diary is kept', 'haemoglobin level (measured in $\mathrm{mmol} / \mathrm{l}$ ) before the third cycle of chemotherapy', 'the number of days between the operation and the first treatment with chemotherapy' and 'radiotherapy'. Although the measurement points were totally different, previous studies $[12,13,30]$ into breast cancer patients receiving adjuvant chemotherapy also found no significant associations between fatigue and the variables mentioned.

It is difficult to conclude to what extent the findings of the present study are in line with findings of other studies. The results of the present study are quite unique. An explanation for not finding more significant results might be found in the relatively small sample of the (sub)groups. Not all intended tests were feasible. Further research should be done in this way to make firm conclusions. 
The results presented must be considered within the limitations of this study. A comparison with other studies is difficult, as different measurements were used. In addition, fatigue was studied as a onedimensional concept. To enhance the understanding of fatigue, a complex and subjective phenomenon, further research should include dimensions of fatigue. Moreover, filling in a questionnaire each day can cause a certain routine and stress, which might influence the results. Another limitation of the present study is that it compares the days of the different chemotherapy groups after completion of the full third treatment with chemotherapy. The 7 days before the second part of the third treatment with women who were included in the dox 28 or CMF group were not fully analysed, which may distort the results. Further research that includes this part of the course of treatment is needed to obtain a complete overview.

In the present study only the course between the third and fourth treatment with chemotherapy was studied. Ongoing research should include measurement points between more cycles to investigate possible differences.

The influence of single factors on the course of fatigue was examined separately and is therefore limited. A combination of factors could also influence the course. In addition, the fact that the compared samples were relatively small makes it difficult to generalise results to a larger population.

\section{Further research}

The pattern of fatigue is unusual and chaotic. It might be interesting to deepen the fatigue research by studying the days more in detail, for example different times during a day. One could combine that study with qualitative research to try to clarify the chaotic pattern.

Apparently, aside from the peak of fatigue, other symptoms such as nausea and vomiting occurred during the first days after having an infusion of chemotherapy. A research on a combination of symptoms and/or different single symptoms next to each other would be needed to complete the understanding.

Knowledge about fatigue should be developed more specifically, for example including cultural aspects, so that interventions for reducing or coping with fatigue can be built up and be detailed in measure work.

\section{References}

1. Tavio, M., I. Milan, and U. Tirelli, Cancer-related fatigue (Review). International Journal of Oncology, 2002. 21(5): p. 1093-1099. 


\section{Chapter 6}

2. NCCN, National Comprehensive Cancer Network (NCCN) Cancer-Related Fatigue. http://www.nccn.org/professionals/physician g/s/PDF/fatigue.pdf. 2005.

3. Tiesinga, L.J., T.W. Dassen, and R.J. Halfens, Fatigue: a summary of the definitions, dimensions, and indicators. Nurs Diagn, 1996. 7(2): p. 51-62.

4. Piper, B.F., Pathophysiological phenomena in nursing: human responses to illness. 1993, Philadelphia: W.B. Saunders Company. 279-302.

5. Magnusson, K., et al., A qualitative study to explore the experience of fatigue in cancer patients. European Journal of Cancer Care, 1999. 8(4): p. 224-232.

6. Holley, S., Cancer-related fatigue - Suffering a different fatigue. Cancer Practice, 2000. 8(2): p. 87-95.

7. Hilfinger Messias, D.A.K., et al., Patient's Perspectives of Fatigue While Undergoing Chemotherapy. Oncology Nursing Forum, 1997. 24(1): p. 43-48.

8. Schwartz, A.L., Daily fatigue patterns and effect of exercise in women with breast cancer. Cancer Practice, 2000. 8(1): p. 16-24.

9. De Jong, N., et al., Fatigue in patients with breast cancer receiving adjuvant chemotherapy: a review of the literature. Cancer Nurs, 2002. 25(4): p. 283-97.

10. Dibble, S.L., et al., Delayed chemotherapy-induced nausea in women treated for breast cancer. Oncol Nurs Forum, 2003. 30(2): p. E40-7.

11. Dibble, S.L., et al., Chemotherapy-induced vomiting in women treated for breast cancer. Oncol Nurs Forum, 2004. 31(1): p. E1-8.

12. De Jong, N., et al., Prevalence and course of fatigue in breast cancer patients receiving adjuvant chemotherapy. Annals of Oncology, 2004. 15: p. 896-905.

13. De Jong, N., et al., Course of mental fatigue and motivation in breast cancer patients receiving adjuvant chemotherapy. Annals of Oncology, 2005. 16: p. 372-382.

14. Alberts, M., et al., Verkorte vermoeidheidsvragenlijst: een praktisch hulpmiddel bij het scoren van vermoeidheid. Nederlands Tijdschrift Geneeskunde, 1997. 2: p. 1526-1530.

15. Vercoulen, J.H., et al., Dimensional assessment of chronic fatigue syndrome. J Psychosom Res, 1994. 38(5): p. 383-92.

16. Smets, E.M.A., B. Garssen, and B. Bonke, Het meten van vermoeidheid met de Multidimensionele Vermoeidheids Index (MVI-20): Een handleiding. 1995, Amsterdam: Medische Psychologie, Academisch Medisch Centrum, The Netherlands.

17. Beahrs, O.H., Manual for staging of cancer. 4th ed. 1992: Philadelphia: Lippincott.

18. StataCorp, Stata Statistical Software: Release 8.0. 2003, College Station, TX: Stata Corporation.

19. Pearce, S. and A. Richardson, Fatigue in cancer: a phenomenological perspective. Eur J Cancer Care, 1996. 5(2): p. 111-5.

20. Piper, B.F., A.M. Lindsey, and M.J. Dodd, Fatigue mechanisms in cancer patients: developing nursing theory. Oncol Nurs Forum, 1987. 14(6): p. 17-23.

21. Molassiotis, A. and C.W.H. Chan, Fatigue patterns in Chinese patients receiving chemotherapy. Eur J Oncol Nurs, 2001. 5(1): p. 60-7. 
22. Richardson, A., E. Ream, and J. Wilson-Barnett, Fatigue in patients receiving chemotherapy: Patterns of change. Cancer Nursing, 1998. 21: p. 17-30.

23. Schwartz, A.L., et al., Fatigue patterns observed in patients receiving chemotherapy and radiotherapy. Cancer Invest, 2000. 18(1): p. 11-9.

24. Berger, A.M. and P. Higginbotham, Correlates of fatigue during and following adjuvant breast cancer chemotherapy: a pilot study. Oncol Nurs Forum, 2000. 27(9): p. 1443-8.

25. Greene, D., et al., A comparison of patient-reported side effects among three chemotherapy regimens for breast cancer. Cancer Pract, 1994. 2(1): p. 57-62.

26. Berger, A. and S.N. Walker, An explanatory model of fatigue in women receiving adjuvant breast cancer chemotherapy. Nursing Research, 2001. 50(3): p. 164-164.

27. Jacobsen, P.B., et al., Fatigue in women receiving adjuvant chemotherapy for breast cancer: Characteristics, course, and correlates. Journal of Pain and Symptom Management, 1999. 18(4): p. 233-242.

28. Cowley, L., et al., How women receiving adjuvant chemotherapy for breast cancer cope with their treatment: a risk management perspective. Journal of Advanced Nursing, 2000. 31(2): p. 314-321.

29. Berger, A.M., Patterns of fatigue and activity and rest during adjuvant breast cancer chemotherapy. Oncol Nurs Forum, 1998. 25(1): p. 51-62.

30. De Jong, N., et al., Course of the fatigue dimension 'activity level' and the interference of fatigue with daily living activities for patients with breast cancer receiving adjuvant chemotherapy. Cancer Nursing, 2006. 29(5): p. E1-E13. 

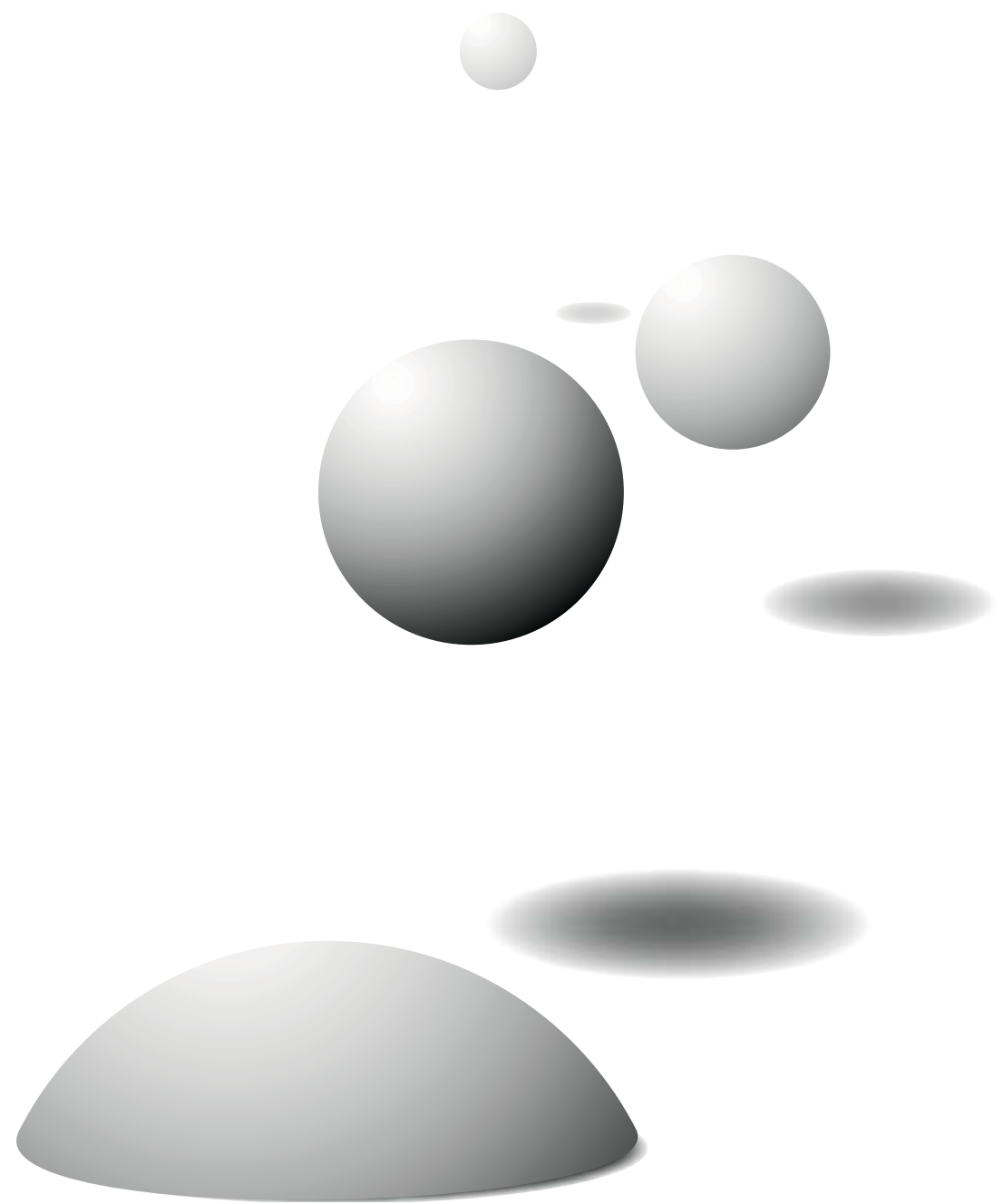


\section{Chapter 7}

\section{Influencing factors of fatigue in women with breast cancer receiving adjuvant chemotherapy: the development of a model}

Nynke de Jong, MSc, RN, Frits G.J. Meijerink, PhD, Harry C. Schouten, MD, PhD, Huda Huijer Abu-Saad, FEANS, PhD, RN, \& Annemie M. Courtens, PhD, RN

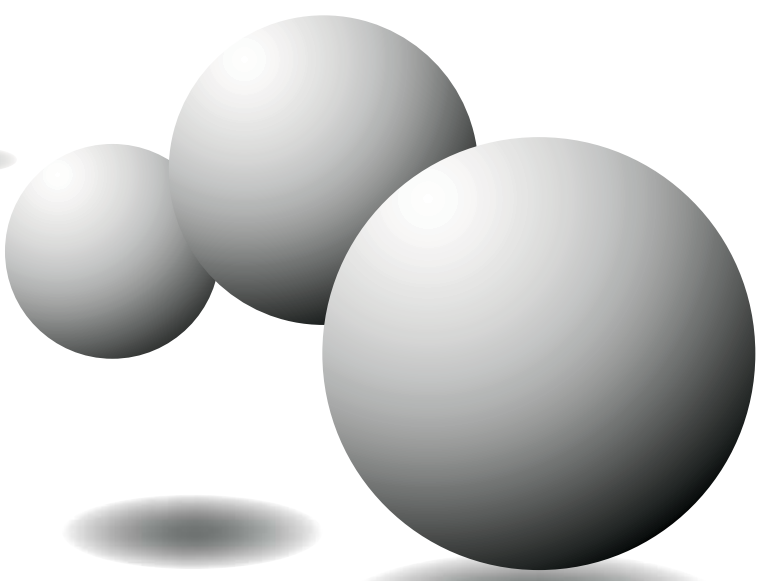

Submitted for publication 


\section{AbStRACT}

Background: The purpose of this prospective cohort study was to test a model of variables that influence fatigue and vice versa in breast cancer patients both during and after adjuvant chemotherapy.

Patients and methods: A model of variables that influence fatigue in breast cancer patients was developed based on a literature review and previous work of the authors. In a prospective cohort study the model was tested in a sample of 157 breast cancer patients. One model (for general fatigue) for all five time points was developed using EQS, a computer program for linear structural equation modeling. Results: A reasonable fit between model and data exist. In the identifiable and testable model two latent variables, (1) physical distress (measured by two observed indicators: general fatigue and physical symptom distress), and (2) psychological distress (measured by two observed indicators: depression and psychological symptom distress), were included. Physical distress is predicted by the variables: everyday social support, an active coping strategy, age, marital status, job, stage of breast cancer, chemotherapy regimen, $\mathrm{Hb}$ level and number of chemotherapy treatments. Psychological distress is predicted by age and everyday social support. A significant difference between patients with or without a job is seen during the treatment of chemotherapy with patients with a job being less fatigued. After completion of chemotherapy, patients living alone endure significantly more general fatigue than patients living not alone, higher social support leads to significantly less general fatigue and high scores on an active coping strategy leads to significantly more general fatigue. The analysis of the reciprocal effects between the two latent variables, physical and psychological distress, shows that during the first four measurements the effect of physical on psychological distress is stronger, whereas at the last measurement, the opposite holds. Now, three months after completion of chemotherapy the effect of the psychological distress on the physical distress has become larger.

Conclusions: Physical and psychological distress are important predictors of general fatigue. The social aspect seems to play a valuable role too. This is expressed by the influence of several variables of a demographic or social nature on general fatigue.

Improved understanding of the relation between different variables and fatigue in breast cancer patients receiving adjuvant chemotherapy as well as after completion of chemotherapy could better equip health care providers to understand and address the needs of these patients.

Key words: adjuvant chemotherapy, breast cancer, fatigue, model 


\section{INTRODUCTION}

Fatigue is a common symptom in cancer patients [1]. The National Comprehensive Cancer Network (NCCN) reported that fatigue affects $70 \%$ to $100 \%$ of cancer patients [2]. Little is known about fatigue, despite the high prevalence and its profoundly negative effect on patients' quality of life. According to the literature, fatigue is a multicausal, multidimensional and complex concept, which is difficult to define or describe [3]. Cancer-related fatigue is different from typical fatigue of everyday life. It is more rapid in onset, more energy draining, more intense, more severe, more unrelenting and it lasts longer [4]. The NCCN convened a panel of experts in the field of fatigue, which defined cancer-related fatigue as 'a distressing, persistent, subjective sense of tiredness or exhaustion related to cancer or cancer treatment that is not proportional to recent activity and interferes with usual functioning' $[2]^{\left({ }^{(p . ~ M S-2)}\right.}$. Now, it is recognised that cancer patients frequently become fatigued when undergoing treatment, notably chemotherapy [5].

Since the early 1990s breast cancer has been the most frequently occurring malignancy in women in the Netherlands [6]. Adjuvant chemotherapy is part of the standard treatment in a large subset of these patients. However, the influence of different variables on fatigue in breast cancer patients both during and after chemotherapy is unclear and less well studied than the prevalence [3].

The purpose of this prospective cohort study was to test a model of variables that influence fatigue and vice versa in breast cancer patients both during and after adjuvant chemotherapy. Figure 1 presents a model of variables and their expected effect on fatigue, based on literature and previous work of the authors.

\section{Demographic factors}

The influences of age, marital status and income on fatigue are not consistent and therefore unclear [1, 7-13]. Several studies [1, 7-9] found no association between educational attainment and fatigue. 'Having children' seems to have no impact on fatigue [1]. No influence of ethnicity [7, 9] and employment status [1, 7] on fatigue was found in the literature.

\section{Disease / physical factors}

No interference is seen in recent studies [1, 3, 8, 9, 13] between fatigue and stage of breast cancer, but irrespective of the type of cancer treatment, concurrent illness was found to have a strongly positive relation with fatigue [3].

In the literature anaemia has been characterized as a major contributor to fatigue $[14,15]$. Studies $[16,17]$ in breast cancer patients show that low haemoglobin 


\section{Chapter 7}

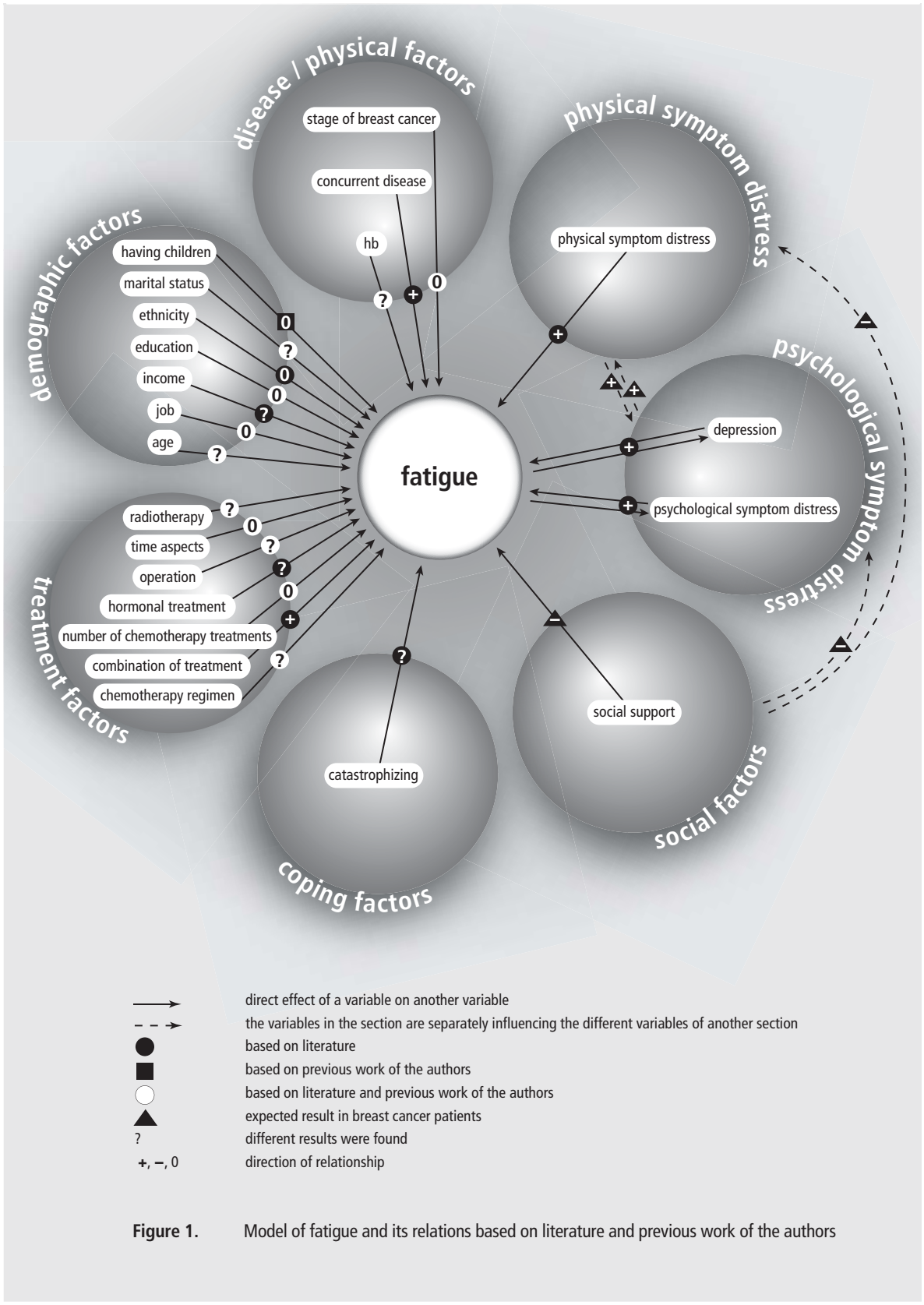


levels are associated with greater fatigue. Other studies [1, 18-20] report that haemoglobin was not significantly related to fatigue.

\section{Physical symptom distress}

The literature $[3,8,16-18,21,22]$ about the relationship between physical distress and fatigue in women with breast cancer is unequivocally positive. The influence of factors such as pain and impaired quality of sleep are highly consistent across several studies [3].

\section{Psychological symptom distress}

The relationship between fatigue and psychological symptoms, like anxiety, is evident [3]. Recent studies [8, 18, 21, 23, 24] found similar results. Other authors [25] reported in a study in breast cancer patients that the emphasis on recording fatigue during and following treatments for cancer needs to be accompanied by concurrent measurement of psychological symptoms. The loss of a breast and the surgery can have distressing psychological effects on women [26]. Depressive symptoms are a common problem in cancer patients and they are definitely related to fatigue $[27,28]$. It is often not clear, however, whether it is the symptoms that cause the fatigue or vice versa. Evidently, here the relation to fatigue can be displayed in two arrows, with either fatigue as starting point or depression/psychological symptom distress (see Figure 1). Researchers [3] have surmised that it is not unlikely that various variables, physical and psychological, are interrelated (see Figure 1).

\section{Social factors}

Nowadays, the importance of social relationships and social support for an individual's well-being is generally accepted [29]. In a non-cancer study, authors [30] reported that involvement in more social networks seems to protect against morbidity. Many authors have underlined the relationship between social support and physical and psychological well-being [29]. Social support is expected to have buffer effects, which means that social support protects people from the deleterious effects of stress [29].

\section{Coping factors}

Coping behaviours and thought can influence fatigue [31]. The relation between coping style 'catastrophising', which is characterised by negative self-statements and negative thoughts and ideas about the future, and health has revealed ambiguous results $[9,24,32,33]$. It is difficult to compare studies, because the coping concept has been operationalised in different ways [30]. 


\section{Treatment factors}

In recent studies $[1,8]$ differences have been observed in the experience of fatigue between types of operation (mastectomy versus lumpectomy), where women who underwent a mastectomy were more fatigued. On the other hand, other authors $[9,10,13]$ concluded that fatigue was not influenced by type of surgery (mastectomy or lumpectomy).

The relationship between chemotherapy regimen and fatigue is not clear. Several authors [10, 16, 17] found no association and some [1, 10, 22] did. A literature review in breast cancer patients shows that a combination of treatments resulted in more fatigue [3].

It is not clear how radiotherapy and fatigue are related. Some authors [1] found an association, others $[8,16,34]$ did not. The same result, no consistency, is seen for the influence of hormonal treatment on fatigue $[3,8,16]$.

Recent studies $[1,16,17]$ did not find a relation between the number of chemotherapy treatments and fatigue. Time aspects seems to have no effect on fatigue either $[1,3,16,17]$.

In this longitudinal study the data of 157 breast cancer patients, measured both during and after adjuvant chemotherapy, were used. The next section provides details regarding the sample. Moreover, the model of variables that influence fatigue and vice versa, presented in Figure 1, was adapted to a model that was tested in this study. More details can be found in the following sections.

\section{Patients AND methods}

\section{Patient selection}

Breast cancer patients with an indication for adjuvant chemotherapy treated in six hospitals, mainly in the south of the Netherlands, were included in this study if they met the following criteria: (1) had no metastasis or other malignancy, (2) had not been treated with cytostatics before, (3) had to be treated with outpatient adjuvant chemotherapy, (4) did not have a chronic disease (like hypertension, kidney disease, heart problems, Diabetes Mellitus, etc.) or a poor psychological state (such as diagnosed with a depression), (5) did not use morphine or narcoleptics, (6) were not deaf, (7) were 18 years or older, and (8) could speak and understand Dutch. In the period from March 1998 to October 2000175 patients were recruited. In total, $18(10 \%)$ patients were excluded for different reasons: $13(7 \%)$ declined further participation, $3(2 \%)$ stopped the adjuvant chemotherapy prematurely because of physical problems and $2(1 \%)$ 
Table 1. Measurement instruments which were used in the present study and what they measure

Measurement instruments

Multidimensional Fatigue Inventory (MFI-20)

Rotterdam Symptom Checklist (RSCL)

Utrecht Coping List (UCL)*

Social Support List (SSL12-I)

The Center for Epidemiological Studies

Depression Scale (CES-D)

* The UCL was only inserted in the first interview.

\section{What does the instrument measure?}

Intensity of fatigue: general fatigue

Psychological and physical symptom distress

Coping styles: 'active', 'social support seeking', 'avoiding' and

palliative'

Everyday social support, social support in problem situations and esteem support

Depressive symptoms

had a poor physical state. The remaining 157 patients, depending on their adjuvant chemotherapy schedules, were interviewed four $(n=20)$ or five $(n=137)$ times. The response rate for the first two interviews was $100 \%$, the third interview $99 \%$ and the last two interviews $97 \%$. A change in the treatment schedule was the main cause of the non-response. The majority of the interviews $(79 \%)$ were conducted by the principal investigator; a properly trained assistant conducted the other interviews.

Before the first cycle of adjuvant chemotherapy the patient had given written informed consent. All interviews were conducted by either the principal investigator or a properly trained assistant. All local medical ethical committees of the participating health centres had approved the study.

\section{Data collection}

Patients were interviewed five times except for those receiving the CA (cyclophosphamide and doxorubicin) treatment, who were interviewed only four times. Table 1 presents the measurement instruments that were used in the present study. The first three interviews took place in the hospital. These interviews were held directly before, during or after the first, the third and the fifth cycle of chemotherapy, except for the CA regimen, where the third interview was omitted. The last two interviews were held at 4 and 12 weeks, respectively, after the last cycle and were done by phone. Medical data were collected from charts and were gathered after the interviews.

\section{Sample Characteristics}

The details of 18 patients were not available and were excluded from the study. Demographic and medical characteristics of the included patients are listed in Tables 2 and 3 . The mean age was 47.3 years $(S D=8.8)$. The majority of the patients $(83 \%)$ lived together with a partner, had children $(79 \%)$ and had been 


\section{Chapter 7}

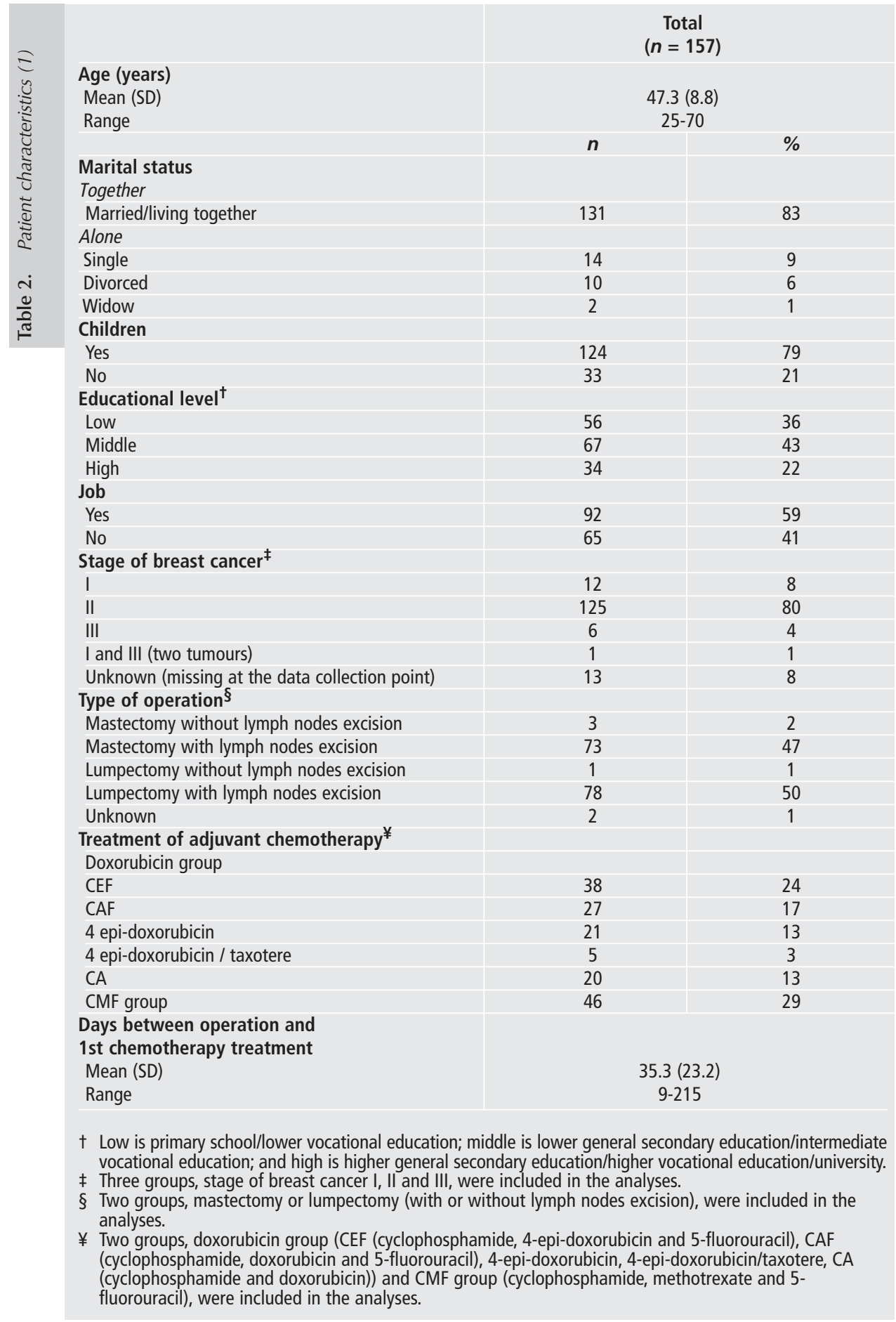


diagnosed with stage II breast cancer (80\%). A minority was highly educated (higher general secondary education/higher vocational education/university) (22\%). More than half of the population (59\%) had a job. The division of mastectomies and lumpectomies was approximately equal. Twenty-nine percent of the patients $(n=46)$ had received the CMF (cyclophosphamide, methotrexate and 5 -fluorouracil) treatment, the remainder had received one of the chemotherapies covered by the doxorubicin group. Information about the division of chemotherapy regimens can be found in paragraph 'operationalisation of variables'. The mean day between operation and $1^{\text {st }}$ chemotherapy treatment was 35.3 days $(\mathrm{SD}=$ 23.2). At the fifth cycle of chemotherapy 60 percent of the patients did not have anaemia (haemoglobin level is lower than $7.3 \mathrm{mmol} / \mathrm{l}$ ) (see Table 3). Most patients received six treatments of chemotherapy (77\%). Table 3 displays details of the numbers of patients receiving radiotherapy at the different measurement points. Most of the patients (56\%) who received radiotherapy were receiving radiotherapy at the second measurement (corresponding to the third treatment of chemotherapy).

\section{Model with its variables which is tested}

The final model, which is tested, is presented in Figure 2. The following variables were deleted from the model in Figure 1: income, ethnicity, concurrent disease, combination of treatment and hormonal treatment. The variable 'income' was not included because of the expectation that the variable would not add important information on top of the other demographic factors. Ethnicity did not play any role in this study, because all participants were white Dutch females. One of the exclusion criteria for participation in the study was that patients did not have any chronic disease. The variable 'concurrent disease' was therefore removed. In this study all patients received adjuvant chemotherapy, some of them received radiotherapy as well. The influence of radiotherapy was also tested. Hence, the variable 'combination of treatment' was eliminated from the model. The influence of hormonal treatment on fatigue was not possible to measure because most patients started hormone treatment after completion of adjuvant chemotherapy.

In this study the variable 'days between operation and chemotherapy' was the specific variable of time aspects.

Below, a description of the variables is given which were used in this study. For the variables regarding 'coping' ('avoiding', 'active', 'social support' and 'palliative' instead of the variable 'catastrophising') and 'social factors' ('esteem support', 'everyday social support' and 'social support in problem situations' instead of the variable 'social support'), Dutch validated instruments were used. No suitable other instruments were available at the moment of 


\section{Chapter 7}

Table 3. Patient characteristics (2)

\begin{tabular}{|c|c|c|c|c|c|c|c|c|c|c|}
\hline \multirow{2}{*}{$\begin{array}{l}\text { Measurement point } \rightarrow \\
\text { Haemoglobin level, } \\
\mathrm{mmol} / \mathrm{I}^{*}\end{array}$} & \multicolumn{2}{|c|}{ 1st cycle } & \multicolumn{2}{|c|}{ 3rd cycle } & \multicolumn{2}{|c|}{ 5th cycle $¥$} & \multicolumn{2}{|c|}{$\begin{array}{l}4 \text { weeks after } \\
\text { the last cycle } \\
\quad(n=152)\end{array}$} & \multicolumn{2}{|c|}{$\begin{array}{l}12 \text { weeks after } \\
\text { the last cycle } \\
(n=152)\end{array}$} \\
\hline & & & & & & & & & & \\
\hline Mean (SD) & \multirow{2}{*}{\multicolumn{2}{|c|}{$\begin{array}{l}8.2(08) \\
5.9-9.9\end{array}$}} & \multirow{2}{*}{\multicolumn{2}{|c|}{$\begin{array}{l}7.9(0.7) \\
6.0-9.4\end{array}$}} & \multirow{2}{*}{\multicolumn{2}{|c|}{$\begin{array}{l}7.5(0.7) \\
5.6-9.2\end{array}$}} & \multirow{2}{*}{\multicolumn{2}{|c|}{ - }} & \multirow{2}{*}{\multicolumn{2}{|c|}{ - }} \\
\hline Range & & & & & & & & & & \\
\hline Manye & $n$ & $\%$ & $n$ & $\%$ & $n$ & $\%$ & $n$ & $\%$ & $n$ & $\%$ \\
\hline \multicolumn{11}{|l|}{ Anaemia ${ }^{\S}$} \\
\hline Yes & 11 & 7 & 26 & 17 & 47 & 35 & - & - & - & - \\
\hline No & 142 & 91 & 124 & 79 & 81 & 60 & - & - & - & - \\
\hline Unknown & 4 & 3 & 7 & 5 & 7 & 5 & - & - & - & - \\
\hline \multicolumn{11}{|l|}{$\begin{array}{l}\text { Number of } \\
\text { treatmentst }\end{array}$} \\
\hline 4 & - & - & - & - & - & - & 20 & 13 & 20 & 13 \\
\hline 5 & - & - & - & - & - & - & 7 & 5 & 7 & 5 \\
\hline 6 & - & - & - & - & - & - & 117 & 77 & 117 & 77 \\
\hline 8 & - & - & - & - & - & - & 8 & 5 & 8 & 5 \\
\hline \multicolumn{11}{|l|}{$\begin{array}{l}\text { Treatment of } \\
\text { radiotherapy }\end{array}$} \\
\hline No radiotherapy & 146 & 93 & 68 & 43 & 41 & 30 & 54 & 36 & 49 & 32 \\
\hline $\begin{array}{l}\text { Radiotherapy at } \\
\text { measurement }\end{array}$ & 8 & 5 & 58 & 37 & 3 & 2 & 8 & 5 & 3 & 2 \\
\hline $\begin{array}{l}\text { Have had } \\
\text { radiotherapy } \\
\text { at measurement }\end{array}$ & 3 & 2 & 31 & 20 & 91 & 67 & 90 & 59 & 100 & 66 \\
\hline $\begin{array}{l}\text { * The haemoglobin level } \\
\text { mmol/l to g/dl is } 1.6 \text {. } \\
\S \text { Anaemia haemoglobin } \\
\dagger \text { Number of treatments } \\
\text { ₹ The first three interview } \\
¥ \text { Patients receiving only } f\end{array}$ & $\begin{array}{l}\text { vel, mi } \\
\text { adjuv } \\
\text { were } h \\
\text { ir hen }\end{array}$ & $\begin{array}{l}\mid<7 \\
\text { chem } \\
\text { direc }\end{array}$ & rapy. & & hem & & & fact & & \\
\hline
\end{tabular}

starting. For that reason these variables were included in the model. A short analysis of the expected direction for these variables is given in the next section.

\section{Operationalisation of variables}

Fatigue

The Multidimensional Fatigue Inventory (MFI-20) was used to assess the intensity of fatigue [35]. This 20-item self-report questionnaire, especially designed for cancer patients, consists of five scales based on different dimensions: general fatigue, physical fatigue, reduced activity, reduced motivation and mental fatigue. 


\section{The development of a model}

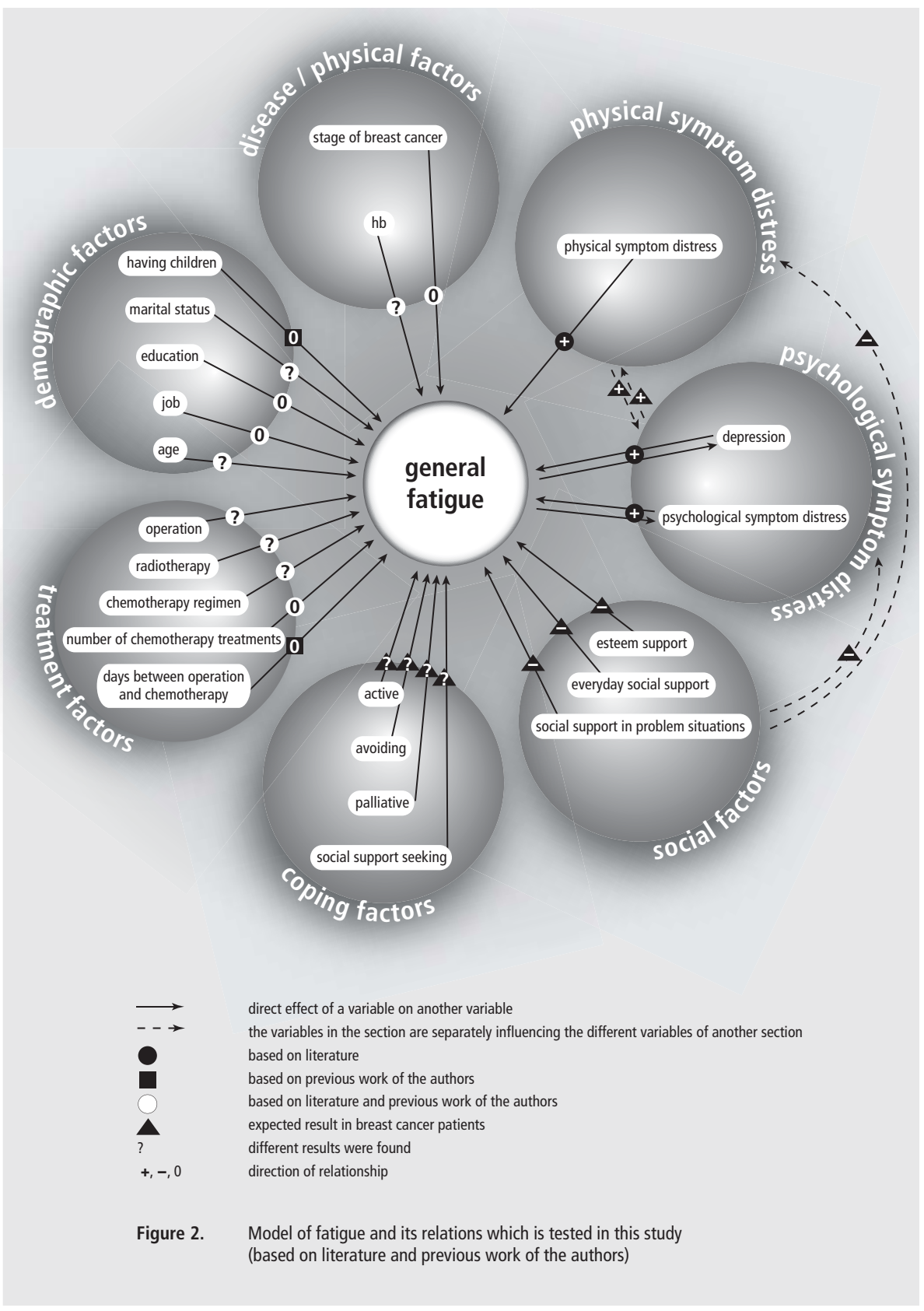




\section{Chapter 7}

Each subscale consists of four items. The score for each subscale was calculated as the sum of the scores of the four items, for which high scores indicate more subjective fatigue. This study focuses on the results of one subscale 'general fatigue'. This subscale consists of the following four items: 'I feel fit', 'I feel tired', 'I am rested' and 'I tire easily'. The MFI-20 has previously been tested and validated in different groups: cancer patients receiving radiotherapy, patients with 'chronic fatigue syndrome', psychology students, medical students, army recruits and junior physicians. The internal consistency for the subscale 'general fatigue' in these studies as measured by Cronbach's alpha averaged 0.85 (with a range of 0.83 to 0.90 ) [36].

Patients in this study were asked to rate their fatigue as experienced during the previous two weeks.

Responses were collected in a face-to face interview

\section{Demographic factors}

Age was measured in years. The following demographic factors were binary: marital status (together vs. alone), children (yes vs. no) and job (yes vs. no). The variable education consists of three levels: low (primary school/lower vocational education), middle (lower general secondary education/intermediate vocational education) and high (higher general secondary education/higher vocational education/university).

\section{Disease / physical factors}

Stage of breast cancer. The TNM (tumour-node-metastasis) clinical classification is used to report the anatomic extent of breast cancer [37].

Haemoglobin level ( $\mathrm{Hb}$ level). $\mathrm{Hb}$ level was measured in $\mathrm{mmol} / \mathrm{l}$. The level of $\mathrm{Hb}$ was only obtained for the first three measurement occasions. The variable is binary: (1) $\mathrm{mmol} / \mathrm{l}<7.3$ or $(2) \mathrm{mmol} / \mathrm{l} \geq 7.3$.

\section{Physical and psychological symptom distress}

Physical and psychological symptom distress. The Rotterdam Symptom Checklist (RSCL) is an instrument to determine the quality of life of cancer patients [38]. In the present study, two subscales were used: physical and psychological symptom distress. Patients were asked to indicate the degree to which they had been bothered by physical ( 23 items) and psychological ( 7 items) symptoms during the last two weeks, on a four-point Likert-scale (categories: not at all, a little, quite a bit, and very much). The RSCL has previously been shown to be reliable and a valid instrument in the evaluation of patients treated with chemotherapy [39, 40].

Depressive symptoms. Depressive symptoms were assessed by using the Center 
for Epidemiological Studies Depression Scale (CES-D) [41]. This self-report scale, containing, 20 items from the previously validated scale of depression, was administered as a structured interview in the present study. Patients indicated their experience of the symptoms within the last two weeks, responding "rarely or none of the time" (0); "some or little of the time" (1); "occasionally or a moderate amount of time" (2); and "most or all of the time" (3). High scores indicate more symptoms. The range of scores is 0 to 60 , with a cut-off of 16 for a depressive syndrome. The CES-D has been tested in different groups: healthy subjects, cancer patients, myocardium infarct patients and students. The internal consistency was good, varying between 0.79 and 0.92 [42].

\section{Social factors}

Social support was assessed with a shortened version of the Social Support ListInteractions (SSL-I), the SSL12-I [43]. The SSL12-I consists of three subscales with each four items: 'everyday social support', 'social support in problem situations' and 'esteem support' (higher score indicates a higher level of support) [44]. Cronbach's alphas in a study in the elderly (older than 60 years) were $0.72,0.71$ and 0.66 respectively [44]. The construct validity of the SSL12-I is satisfactory [44]. The instrument is meant to be used with elderly people. The expectation is that the instrument can also be used in younger respondents [43]. In a study with a younger population (mean age of 25.3 years) the internal consistency reliability of the three subscales ranges from 0.72 to 0.89 [45].

The three variables were expected to have a negative influence on fatigue as hypothesised in the introduction.

\section{Coping}

The short coping list (15 items) with a 4-point Likert scale ranging from 'seldom/never' to 'very often', based on the original 47-item 'Utrecht Coping List' (UCL), was used to assess coping [46, 47]. Four coping styles can be distinguished from the short coping list: 'active coping' (5 items), 'social support seeking' (5 items), 'avoiding' (3 items), and 'palliative coping' (2 items) [29]. The internal consistencies were $0.84,0.82,0.64$ and 0.44 respectively in a study with subjects with or without (multi) new morbidity [30]. The relationships between the coping strategies and fatigue are not clear.

\section{Treatment factors}

Treatment of adjuvant chemotherapy. Patients were treated with one of the following adjuvant treatments: CEF (cyclophosphamide, 4-epi-doxorubicin and 5-fluorouracil) every 21 days, CAF (cyclophosphamide, doxorubicin and 5fluorouracil) every 21 days, 4-epi-doxorubicin every 28 days (on days 1 and 8), 


\section{Chapter 7}

4-epi-doxorubicin/taxotere with the first three cycles every 28 days (on days 1 and 8 ) and the last three cycles every 21 days, CA (cyclophosphamide and doxorubicin) every 21 days and CMF (cyclophosphamide, methotrexate (oral administration from day 1 to day 14 or intravenous) and 5-fluorouracil) every 28 days (on days 1 and 8). Most of these regimens consist of six cycles except the CA regimen, which consists of four cycles. The choice for either schedule was based on current practices in the health centres. In the analysis chemotherapy is a binary variable: the doxorubicin group (CEF, CAF, 4-epi-doxorubicin, 4-epidoxorubicin/taxotere and CA) and the CMF group. The involvement of different adjuvant chemotherapy regimens in the doxorubicin group made it possible to form a sizeable sample in a relatively short period of time.

Note that the first measurement moment coincided with patients starting their chemotherapy treatment.

Type of operation. In the present study, patients underwent a mastectomy or a lumpectomy with or without lymph nodes excision. In the analyses two groups were compared because of small sizes of the other groups: (1) mastectomy, and (2) lumpectomy. None of the patients underwent a reconstructive surgery during the study period.

Radiotherapy. In this study the variable radiotherapy was assessed at each measurement: (1) no radiotherapy, (2) receiving radiotherapy at measurement or (3) having finished radiotherapy at measurement.

Number of chemotherapy treatments. At the first three measurement moments the number of treatments is equal. Therefore, this variable is only measured after completion of the treatment of chemotherapy.

Days between operation and chemotherapy. The days between the operation and the first treatment of chemotherapy were counted.

The model presented in Figure 2 is extensive and therefore not testable. In the next sections an explanation is given of how and to what extent the model is tested, based on theoretical and statistical foundations.

\section{Statistical Analyses}

The reliability of the MFI-20, RSCL, UCL, SSL12-I and CES-D was examined by calculating Cronbach's $\alpha$. The coefficient of internal consistency was calculated for each measurement point, except for the measurement UCL. The internal consistency for the UCL subscales was only measured at the first measurement occasion.

A model for general fatigue is developed. Only observed variables that correlate significantly with general fatigue are included in the model. Most of the variables are either measured at an interval measurement level or, in the case of 
binary variables, can be considered to have been measured at an interval level. Therefore the associations between these variables are measured using Pearson correlation coefficients. The correlations between the included observed variables are analysed using EQS [48], a computer program for linear structural equation modeling [49].

In EQS a distinction is made between measured variables and latent variables, such as physical distress or psychological distress. These latent variables are measured using one or more of the observed variables also called indicators. Reciprocal relations between physical distress and psychological distress are investigated. Total effect (sum of direct and indirect effect) of one variable (measured or latent) on general fatigue can be calculated using the estimated regression coefficients. Using these effects an ordering can be obtained of the importance of the variables included in the model on general fatigue.

Despite the fact that not all variables were measured at all measurement points, one model for all five time points was developed. An index of the fit of the model was obtained by means of its chi-squared value and the BenterBonnet normed fit index (BB-NFI). Model parameters are estimated by means of the maximum likelihood method.

Table 4. Internal consistencies (IC) of the MFI-20, RSCL, UCL, SSL12-I and CES-D

\begin{tabular}{|c|c|c|c|c|c|c|c|c|c|c|}
\hline \multirow[t]{2}{*}{ Measurement point $\rightarrow$} & \multicolumn{2}{|c|}{$\begin{array}{l}\text { 1st cycle* } \\
n=157\end{array}$} & \multicolumn{2}{|c|}{$\begin{array}{c}\text { 3rd cycle } \\
n=157\end{array}$} & \multicolumn{2}{|c|}{$\begin{array}{l}\text { 5th cycle? } \\
\qquad n=137\end{array}$} & \multicolumn{2}{|c|}{$\begin{array}{c}4 \text { weeks after } \\
\text { the last cycle } \\
n=152\end{array}$} & \multicolumn{2}{|c|}{$\begin{array}{c}12 \text { weeks after } \\
\text { the last cycle } \\
n=152\end{array}$} \\
\hline & $n$ & IC & $n$ & IC & $n$ & IC & $n$ & IC & $n$ & IC \\
\hline MFI-20 (general fatigue) & 157 & 0.89 & 157 & 0.89 & 135 & 0.93 & 152 & 0.93 & 152 & 0.93 \\
\hline \multicolumn{11}{|l|}{ RSCL } \\
\hline $\begin{array}{l}\text { Psychological symptom } \\
\text { distress }\end{array}$ & 157 & 0.90 & 157 & 0.89 & 135 & 0.91 & 152 & 0.87 & 152 & 0.91 \\
\hline $\begin{array}{l}\text { Physical symptom distress } \\
\text { UCL }\end{array}$ & 157 & 0.80 & 157 & 0.81 & 135 & 0.86 & 152 & 0.86 & 152 & 0.87 \\
\hline Active & 138 & 0.83 & - & - & - & - & - & - & - & - \\
\hline Social support seeking & 156 & 0.80 & - & - & - & - & - & - & - & - \\
\hline Avoiding & 140 & 0.17 & - & - & - & - & - & - & - & - \\
\hline Palliative & 156 & 0.33 & - & - & - & - & - & - & - & - \\
\hline \multicolumn{11}{|l|}{ SSL12-I } \\
\hline Everyday social support & 157 & 0.66 & 157 & 0.66 & 135 & 0.67 & 152 & 0.77 & 152 & 0.74 \\
\hline $\begin{array}{l}\text { Social support in problem } \\
\text { situation }\end{array}$ & 156 & 0.82 & 152 & 0.80 & 130 & 0.82 & 142 & 0.83 & 138 & 0.84 \\
\hline Esteem support & 157 & 0.68 & 157 & 0.69 & 134 & 0.64 & 151 & 0.78 & 152 & 0.76 \\
\hline CES-D & 155 & 0.90 & 156 & 0.90 & 135 & 0.92 & 151 & 0.92 & 152 & 0.94 \\
\hline
\end{tabular}


Internal consistency of the MFI-20, RSCL, UCL, SSL12-I and CES-D

For all five measurements occasions, the Cronbach's $\alpha$ for the subscale 'general fatigue' of the MFI-20 was 0.89 or higher (see Table 4). Good internal consistency rates can also be reported for the subscales of the RSCL ( 0.87 and higher for the psychological symptom distress scale; and 0.80 and higher for the physical symptom distress scale).

The internal consistency of the different UCL subscales was only measured at the first measurement occasion. The subscale 'active coping' and 'social support seeking' showed high internal consistencies, 0.83 and 0.80 respectively. The internal consistency of the subscale 'avoiding' and 'palliative coping' were very low, 0.17 and 0.33 respectively. These subscales will no longer be used in the analysis. In this study, the internal consistencies of the SSL12-I subscales were not below the 0.64 and the rates of the CES-D were not below the 0.90 .

\section{RESULTS}

\section{Reduction of variables of the model}

Table 5 gives an overview of the correlations of the observed variables from Figure 2 with general fatigue. The table shows that a number of correlations are significantly different from zero $(p<0.10)$. These variables will be entered into the model.

\section{Development of an identifiable and testable model}

The model of Figure 2 is convenient from the point of view of summarising the literature, but is too complicated for testing. The model that is empirically tested is represented in Figure 3a (inside cover, left side) (Maastricht Fatigue Model (MF Model)). In Figure 2 there are seven clusters of factors that have some relation with fatigue. In Figure 3a there are two latent variables: physical distress (F1) and psychological distress (F2). Concerning the relations with fatigue, three variables deserve particular attention: psychological and physical symptom distress and depression. According to Figure 2, four out of the six possible relations between these four variables are modelled either through a reciprocal relation or a unidirectional effect. In Figure 3a this part of the model is reformulated using two latent variables, physical distress (F1) and psychological distress (F2) that are hypothesised to have a reciprocal relation. Each latent variable is measured using two of the four indicators described above: physical distress (F1) by general fatigue and physical symptom distress and psychological distress (F2) by depression 
Table 5. Correlations between the observed variables and fatigue

\begin{tabular}{|c|c|c|c|c|c|}
\hline Measurement point $\rightarrow$ & $\begin{array}{l}\text { 1st cyclet } \\
\text { (n=157) }\end{array}$ & $\begin{array}{l}\text { 3rd cycle } \\
(n=157)\end{array}$ & $\begin{array}{l}\text { 5th cyclef } \\
(n=135)\end{array}$ & $\begin{array}{l}4 \text { weeks after } \\
\text { the last cycle } \\
\quad(n=152)\end{array}$ & $\begin{array}{l}12 \text { weeks after } \\
\text { the last cycle } \\
(n=152)\end{array}$ \\
\hline \multicolumn{6}{|l|}{ Disease / physical factors } \\
\hline Physical symptom distress & $0.68^{* * *}$ & $0.64^{* * *}$ & $0.74^{* * *}$ & $0.62^{* * *}$ & $0.70^{* * *}$ \\
\hline Stage of breast cancer & 0.11 & 0.04 & $0.15^{*}$ & 0.01 & 0.05 \\
\hline Haemoglobin level ${ }^{\mp}$ & -0.06 & -0.06 & $-0.27^{* * *}$ & - & - \\
\hline \multicolumn{6}{|l|}{ Mental factors } \\
\hline $\begin{array}{l}\text { Psychological symptom } \\
\text { distress }\end{array}$ & $0.31^{* * *}$ & $0.28^{* * *}$ & $0.41^{* * *}$ & $0.40^{* * *}$ & $0.57^{* * *}$ \\
\hline Depression ${ }^{¥}$ & $0.25^{* * *}$ & $0.42^{* * *}$ & $0.43^{* * *}$ & $0.47^{* * *}$ & $0.56^{* * *}$ \\
\hline \multicolumn{6}{|l|}{ Social factors } \\
\hline \multirow{2}{*}{$\begin{array}{l}\text { Everyday social support } \\
\text { Social support in problem }\end{array}$} & 0.03 & 0.00 & $-0.14^{*}$ & $-0.20^{\star * *}$ & $-0.15^{*}$ \\
\hline & & & & & \\
\hline situations & $\begin{array}{l}0.06 \\
0.06\end{array}$ & $\begin{array}{r}-0.01 \\
0.07\end{array}$ & $\begin{array}{r}0.05 \\
-0.05\end{array}$ & $\begin{array}{r}0.08 \\
-0.01\end{array}$ & $\begin{array}{r}0.07 \\
-0.07\end{array}$ \\
\hline \multicolumn{6}{|l|}{ Coping } \\
\hline Active & $0.14^{*}$ & 0.10 & $0.19^{* *}$ & $0.16^{*}$ & $0.16^{*}$ \\
\hline Social support seeking & 0.03 & 0.05 & 0.02 & 0.02 & -0.05 \\
\hline Avoiding & 0.11 & 0.05 & -0.01 & 0.05 & 0.07 \\
\hline Palliative & -0.08 & -0.05 & -0.13 & -0.01 & 0.02 \\
\hline \multicolumn{6}{|l|}{ Treatment factors } \\
\hline Type of chemotherapy ${ }^{¥}$ & - & $0.13^{*}$ & $0.17^{* *}$ & -0.04 & 0.08 \\
\hline Operation ${ }^{¥}$ & -0.03 & 0.00 & 0.01 & -0.01 & -0.08 \\
\hline Radiotherapy $(1)^{¥}$ & -0.03 & 0.06 & -0.06 & 0.03 & 0.12 \\
\hline Radiotherapy (2) & 0.05 & -0.03 & 0.03 & -0.07 & -0.12 \\
\hline Number of treatments & - & - & - & -0.07 & $-0.17^{\star *}$ \\
\hline $\begin{array}{l}\text { Days between operation } \\
\text { and chemotherapy }\end{array}$ & 0.09 & 0.09 & 0.10 & -0.04 & -0.02 \\
\hline \multicolumn{6}{|l|}{ Demographic factors } \\
\hline Age & -0.09 & -0.05 & -0.04 & $-0.14^{*}$ & -0.10 \\
\hline Marital status ${ }^{¥}$ & -0.06 & $-0.13^{*}$ & -0.10 & -0.13 & $-0.27^{* * *}$ \\
\hline Children ${ }^{¥}$ & -0.01 & 0.02 & 0.01 & 0.01 & -0.02 \\
\hline $\mathrm{Job}^{*}$ & $-0.14^{*}$ & $-0.19^{* *}$ & -0.13 & -0.04 & -0.03 \\
\hline Education $^{¥}$ & 0.02 & -0.02 & 0.04 & 0.11 & -0.01 \\
\hline \multicolumn{6}{|c|}{$\begin{array}{l}+ \text { The first three interviews were held directly before, during or after infusion. } \\
¥ \quad \text { Patients receiving only four chemotherapy treatments did not have this interview. } \\
¥ \text { Haemoglobin level: code } 0=\text { mmol/l ? 7.3, code } 1=\text { mmol/l< }<\text {.3; depression: code } 0=\text { no depression, } \\
\text { code } 1=\text { depression; type of chemotherapy: code } 0=C M F \text { group, code } 1=\text { doxorubicin group; operation: code } 0 \\
=\text { mastectomy, code } 1=\text { lumpectomy; radiotherapy }(1) \text { : code } 0=\text { no radiotherapy, code } 1=\text { receiving radiotherapy } \\
\text { at measurement; radiotherapy (2): code } 0=\text { no radiotherapy, code } 1=\text { having finished radiotherapy at } \\
\text { measurement; marital status: code } 0=\text { alone, code } 1=\text { together; children: code } 0=\text { no, code } 1=\text { yes; job: code } 0= \\
\text { no, code } 1=\text { yes; education: code } 1=\text { low, code } 2=\text { middle, code } 3=\text { high. }\end{array}$} \\
\hline
\end{tabular}




\section{Chapter 7}

and psychological symptom distress. Fatigue is now part of or an indicator of the physical distress. Findings in the study of Hwang et al. [50] supported a symptomoriented approach to the assessment of cancer-related fatigue. In this study wellbeing of a patient consists of a physical and a psychological part. The two arrows between F1 and F2 make it possible to estimate at each of the five measurement points which of the two influences is stronger: psychological on physical (of which fatigue is an indicator) or vice versa.

The other two variables of the cluster 'disease/physical factors' ( $\mathrm{Hb}$ level and stage of breast cancer) in Figure 2 are used as predictors of F1. These two variables are taken together with two variables from the cluster 'treatment factors': number of treatments and chemotherapy regimen. The double-headed arrow to the left of these four variables signifies that the correlations between them are left unmodelled.

The remaining five variables of the three clusters 'social factors', 'coping' and 'demographic factors' (every day social support, active, age, marital status and job) have also been taken together and again here the double-headed arrow to the left of them means that correlations between these five variables have been left unmodelled. Correlations between the two clusters of predictors are assumed zero. Finally, Figure 3a shows that F1 is predicted by all variables and F2 by age and every day social support.

\section{Estimating the effects on general fatigue}

Results are summarised in Table 6 . The variables given in the first column of this table present all those (observed or latent) included in the analysis. In the corresponding entries of columns two to six, the estimates of the total effects of the variables on general fatigue are shown for each measurement point. The first entry of the second column, for instance, shows that there is a very significant total effect of the latent variable physical distress on general fatigue (0.903). This total effect is composed of a direct and an indirect effect. The direct effect of physical distress is calculated as the estimated standardised regression coefficient (0.790). Because there exists a reciprocal relation between physical and psychological distress (if a person feels physically not well, this will cause him to feel mentally not well and vice versa), there is an also an indirect effect of physical distress (via psychological distress) on general fatigue. This effect is estimated to be 0.113 . The second entry shows that the total effect of psychological distress on general fatigue is 0.303 . In this case this total effect is composed only of the indirect effect; there is no direct arrow from psychological distress to general fatigue. The last two rows in the table give the $p$-value of the chi-square statistics and the BB-NFI. These two fit-indices show that the model of 
Table 6. The total effect (sum of indirect effects) of the variables on general fatigue, $p$-value of the chi-square statistic and the BB-NFI at each measurement point

\begin{tabular}{|c|c|c|c|c|c|}
\hline \multirow[t]{2}{*}{ Measurement point $\rightarrow$} & 1 st cycle ${ }^{\dagger}$ & 3rd cycle & 5th cycle ${ }^{\ddagger}$ & $\begin{array}{l}4 \text { weeks after } \\
\text { the last cycle }\end{array}$ & $\begin{array}{l}12 \text { weeks after } \\
\text { the last cycle }\end{array}$ \\
\hline & $\begin{array}{l}(n=15 /) \\
0.903^{* * *}\end{array}$ & $\begin{array}{l}(n=15 /) \\
0.944^{* * *}\end{array}$ & $\begin{array}{l}(n=135) \\
1.027^{* * *}\end{array}$ & $\begin{array}{l}(n=152) \\
1.030 * * *\end{array}$ & $\begin{array}{l}(n=152) \\
1.197^{* * *}\end{array}$ \\
\hline Psychological (F2) & $0.303^{* * *}$ & $0.382^{* * *}$ & $0.412^{* * *}$ & $0.516^{* * *}$ & $0.688^{* * *}$ \\
\hline Everyday social support & -0.005 & -0.038 & -0.122 & $-0.227^{* * *}$ & $-0.162^{* *}$ \\
\hline Active & 0.117 & $0.117^{*}$ & $0.144^{*}$ & $0.198^{* * *}$ & $0.167^{* *}$ \\
\hline Age & $-0.152^{*}$ & $-0.156^{*}$ & -0.132 & -0.107 & -0.059 \\
\hline Marital status & -0.089 & -0.094 & -0.096 & $-0.153^{* *}$ & $-0.183^{* *}$ \\
\hline Job & $-0.222^{* * *}$ & $-0.265^{* * *}$ & $-0.155^{*}$ & -0.102 & -0.060 \\
\hline Stage of breast cancer & 0.030 & -0.058 & 0.073 & 0.012 & 0.067 \\
\hline Chemotherapy regimen & - & 0.107 & $0.142^{*}$ & -0.021 & 0.058 \\
\hline Haemoglobin level & -0.051 & -0.037 & -0.078 & - & - \\
\hline Number of treatments & - & - & - & 0.002 & -0.087 \\
\hline P-value & 0.098 & 0.013 & 0.444 & 0.207 & 0.925 \\
\hline BB-NFI & 0.902 & 0.872 & 0.925 & 0.920 & 0.966 \\
\hline $\begin{array}{ll}+ & \text { The first three intervi } \\
\neq & \text { Patients receiving onl } \\
* & P<0.10 \\
* * & P<0.05 \\
* * * & P<0.01\end{array}$ & $\begin{array}{l}\text { vere held } \\
r \text { chemoth }\end{array}$ & $\begin{array}{l}\text { before, } d \mathrm{c} \\
\text { eatments }\end{array}$ & $\begin{array}{l}\text { fter infusior } \\
\text { lave this in }\end{array}$ & & \\
\hline
\end{tabular}

two, where the p-value is only 0.013 , indicating a low fit. Now that there seems to be a reasonable fit between model and data, we can interpret the parameter estimates, i.e. the total effect of the independent variables on general fatigue.

\section{Non-significant $(p \geq 0.05)$ variables on general fatigue (Figure $3 b$ (inside cover, right side))}

A number of variables do not seem to have any influence at all. First, stage of breast cancer does not seem to have any effect on general fatigue at any of the five measurement points. Only during the third measurement point does it reach the level of 0.073 . The same holds for haemoglobin level. Although this variable is measured only at the first three measurement points, and although there seems to be a trend during these three periods of increasing strength, its effect at the third measurement period is still not significant. Thirdly, number of treatments, measured only at the last two measurement periods, does not reach significance. Fourthly, there seems to be a negative effect of age on general fatigue, meaning that older people are less fatigued than younger people, although the effect seems to disappear over time. During the first two measurements the 
effect is significant $(0.05<p<0.10)$. At the third and later measurements the effect disappears. Finally, chemotherapy regimen did not turn out to be a significant factor.

\section{Significant $(p<0.05)$ variables on general fatigue (Figure $3 b$ (inside cover,} right side))

The effect of psychological and physical distress

In each measurement, psychological and physical distress has a highly significant positive effect on general fatigue. The authors were wondering whether the strength of the correlation between physical distress and fatigue might be artificial because of the fact that two items of the RSCL refer to fatigue ('tiredness' and 'lack of energy'). However, without these items the correlations in each measurement were as strong as the correlations with the whole list.

Over the five measurement points, the ratio of the total effects on general fatigue of physical distress to psychological distress yields the following sequence: 3.0, 2.5, 2.5, 2.0 and 1.7. Hence, the effect of the physical distress on general fatigue is monotonically decreasing, or in other words the effect of the psychological distress is increasing.

\section{The effect of social support}

The effect of social support on general fatigue seems to be getting stronger during the four periods. During the first measurement the relation is virtually non-existent $(-0.005)$. At the fourth measurement there is a reasonably strong significant effect $(-0.227)$, meaning that higher social support leads to less fatigue. During the last measurement the effect is still significant but it is declining (-0.162).

\section{The effect of coping strategy 'active'}

The pattern of the effect of coping strategy 'active' on fatigue seems to be highly comparable with the pattern of social support, although the sign of the effect is positive, meaning that high scores on this coping strategy lead to more general fatigue.

\section{The effect of marital status}

During the first three measurements there is a small non-significant difference between respondents living alone being more fatigued than respondents not living alone. During the fourth and fifth measurements, when respondents have completed the chemotherapy treatment, the differences become much larger and also highly significant in favour of living together. 
The effect of having a job

The effect of having a job on general fatigue gradually fades away over the measurements. During the first two measurements there is a strong significant difference between patients having a job and those who do not have a job: patients who do have a job are less fatigued. At the third measurement point the effect is only slightly significant and at the last two measurement points the effect has disappeared: at these measurements there is no difference any more.

\section{Direct effect of variables on psychological and physical distress}

The direct effect of the variables on psychological and physical distress is similar to the effect of these variables on general fatigue. No significant effect is found of the following variables on physical distress: stage of breast cancer, chemotherapy regimen, haemoglobin level and number of treatments. After completion of the treatment of chemotherapy, patients living alone experienced significantly more physical distress than patients not living alone. Patients with a job experienced significantly less physical distress than those without a job during the first two measurements. The coping strategy 'active' does not have any effect on physical distress. Directly after the last treatment of chemotherapy (fourth measurement) a significant negative effect is observed of 'everyday social support' on physical distress, meaning that higher social support leads to less physical distress. On the other hand, no significant effect is found for this variable on psychological distress. The only significant effect on psychological distress is of the variable 'age' in the first measurement, meaning that older patients experienced less physical distress than younger patients.

\section{Reciprocal effects between psychological distress (f1) and physical distress (f2)}

In each measurement, psychological distress has a significant positive effect on physical distress and vice versa (see Figure 3a).

For each of the five measurements Table 7 shows the estimates of the parameters of the reciprocal effects between physical distress and psychological distress. The entries in the third column give the estimates of the effect of psychological distress on physical distress and the fourth column those of physical on psychological distress. A comparison of the two columns shows that during the first four measurements the effect of physical distress on psychological distress is larger than the reciprocal effect. However, for the last measurement, taken three months after completion of the chemotherapy treatment, the opposite holds: the effect of the psychological distress on physical distress has become larger than the effect vice versa. 


\section{Chapter 7}

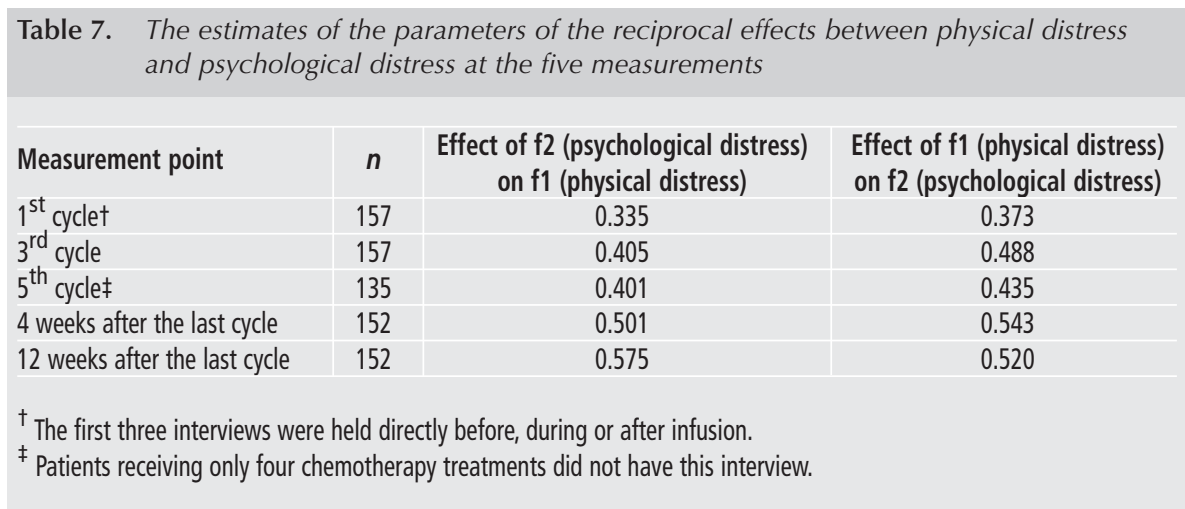

\section{Discussion}

This study focuses on the results of general fatigue. The main finding is that physical and psychological distresses are important predictors of general fatigue. Other significant predictors of general fatigue are: job, marital status, everyday social support and an active coping strategy. The direction of the influence of these variables on psychological and/or physical distress as well as the period of time that the influence is significant is similar to the effects of these variables on general fatigue.

The analysis of the reciprocal effects between physical and psychological distress shows that during the first four measurements (during adjuvant chemotherapy as well as four weeks after completion of adjuvant chemotherapy) the effect of physical on psychological distress is stronger, whereas at the last measurement (twelve weeks after completion of adjuvant chemotherapy) the opposite holds.

\section{Factors relating to general fatigue}

\section{Demographic factors}

The variables 'education' and 'having children' were not included in the model. No relationship between the separate variables and general fatigue was found, which confirms the findings of the model based on the literature and previous work of the authors [1]. Age, on the other hand, was adopted in the final model but did not have any effect on general fatigue.

After completion of adjuvant chemotherapy, general fatigue was influenced by marital status: women living alone were more fatigued than women not living alone. The fact that women with a partner reported less fatigue might be dependent 
on whether there is tangible support [1]. It is possible that women living alone received more support from others during adjuvant chemotherapy than afterwards. After completion of the treatment with chemotherapy, the support could be diminished because no treatment was received and therefore help with transport to the outpatients department as well as support during the visit and afterwards were not needed anymore. Moreover, patients are normally feeling and looking better after completion of adjuvant chemotherapy, which could suggest to the social environment that women living alone need little or no support and therefore they do not get support. Courtens et al. [51] reported similar findings in a study with different types of cancer. Here, the expectation towards the patient and/or limited knowledge about chemotherapy among informal carers could play an important role.

During the first two measurements patients who did have a job were significantly less fatigued than those without a job. It is possible that patients who did have a job were psychologically and physically stronger at the start of the study, which made the difference in the first measurements.

\section{Disease/physical factors}

Anaemia, multifactorial in origin, is a common occurrence in patients with cancer, particularly those receiving cytotoxic chemotherapy, that may result in a decreased functional capacity and quality of life [52-54]. Although, the relationship between haemoglobin and fatigue is not clear, at the clinical level, its relationship is universally accepted [55]. In this study no significant effect of the haemoglobin level on general fatigue is observed. It should be noted that there seems to be a trend during the first three measurements of increasing strength. Similar findings were reported in the study of Holzner et al. [56] in cancer patients undergoing chemotherapy. In this study, correlation between $\mathrm{Hb}$ values and fatigue was moderate with a tendency to increase during chemotherapy. A limitation of the study is that no haemoglobin levels were measured after completion of chemotherapy.

The influence of stage of breast cancer on general fatigue confirms previous findings: no effect. Note that the results of this study could be caused by the distribution of the subjects. The majority $(80 \%)$ had stage II.

\section{Psychological and physical distress}

Both factors separately, psychological and physical distress, do influence general fatigue in a significant positive way. The influence of these factors was expected and therefore confirms previous findings [3]. It is still not clear whether these symptoms cause the fatigue or vice versa. Qualitative research should give more information.

During the study, the effect of the physical distress on general fatigue is 


\section{Chapter 7}

decreasing or, put differently, the effect of the psychological distress is increasing. With this knowledge, health care providers can better tailor their aftercare to these patients.

It should be noted that depression is an indicator of psychological distress. The indicators (physical symptom distress, psychological symptom distress and depression) acquire a prominent role in the experience of fatigue, which is not unlikely in the basis of other studies [3,50].

\section{Social factors}

The effect of everyday social support on general fatigue seems to be getting stronger during the study. After completion of chemotherapy there is a strong significant effect, meaning that higher everyday social support leads to less fatigue. Similar effects were found by other authors. The author of an early study [57] had reported that the uncertainties and fears experienced by a person diagnosed with cancer are likely to result in an enhanced need for social support. Results of another study [58] among 117 patients with suspected breast cancer, awaiting diagnosis, showed that patients reported elevated levels of anxiety and high levels of social support. It is not clear why the effect of everyday social support is significant only after completion of chemotherapy. According to Van den Akker et al. [30, 31] the social network is increasingly recognised as a factor in health maintenance and survival. It represents the web of social relationships that every person maintains, including both intimate relations with family and close friends and more formal relationships with other individuals and groups [30]. Following a qualitative study [59], the social network provides an opportunity to delegate roles, and thus conserves energy.

Note that esteem support and social support in problem situations, two other subscales of social support, do not correlate significantly with general fatigue. Probably this support, a kind of psychological support, does not have any impact on the experience of fatigue.

\section{Coping factors}

McHaffie [60] reported that how well a person copes is central in determining his or her well-being, no matter how ill he or she is. The daily lives of almost every individual are filled with stressful experiences, which require some form of coping. The impact of each varies, because people switch between their many roles and because these roles are changing [60]. Individuals with cancer must deal with the treatment process and its side-effects, the uncertainty of the disease course and adapt to the changes in physical functioning and other negative life changes that are inevitably imposed by the disease [61]. In this study a significant difference is found between an active coping strategy and general fatigue in the 
last two measurements. Patients who are inclined to take an active stance in problem situations experience more fatigue than those who did not. Van den Akker et al. [30] found a similar result in their study in primary care subjects, using the same measurement instrument reporting an association between an active coping style and the occurrence of multimorbidity. According to the authors, this is likely to be a result rather than a cause of multimorbidity, subjects with multiple pathology being more apt to deal actively with problems because their (health) problems are less easy to avoid [30].

The coping strategy 'seeking for social support' did not have a significant influence on general fatigue. According to Manne et al. [61] seeking social support can be described as efforts to seek either informational, tangible, or emotional support. The question is whether patients need to seek social support. It might be that patients are supported naturally in the phase of receiving chemotherapy and directly afterwards. Moreover, the attention patients received in the stages of their treatment(s) by professionals (during the study period) may obviate the need to seek social support. The time after completion of chemotherapy could be too short for the variable to become significant.

The internal consistency of the subscales 'avoiding' and 'palliative coping' were so low that these were not included in the analysis, which limited the findings in this study. No complete overview of coping can therefore be given.

\section{Treatment factors}

As expected, the number of chemotherapy treatments did not have any effect on general fatigue. It should be mentioned that $77 \%$ of all patients received six treatments of chemotherapy. This might be a reason for not finding an effect. In this study too, chemotherapy regimen is a non-significant variable on general fatigue. In another study with the same data [1] a significant influence of chemotherapy regimen on the course of general fatigue during the study was found. In the doxorubicin group a significant increase in fatigue was seen during the initial measurements. The CMF group shows a 'late effect' on fatigue. The reason for not finding very significant effects in this study might be due to the way the data was analysed, which was separately performed for each of the five measurements. In addition, the lack of homogeneity in the doxorubicin group, in which five different chemotherapy regimens are presented, may be a limitation of this study.

The variables 'days between operation and chemotherapy', 'radiotherapy' and 'operation' were not entered into the model because these variables were not significantly correlated with general fatigue. For the first-mentioned variable 
no influence was expected. It should be noted, however, that the expectation is only based on one study [1]. A similar circumstance arises for the variable 'radiotherapy': in several studies $[8,16,34]$ no relationship is found between radiotherapy and fatigue, whereas De Jong et al. [1] reported that receiving radiotherapy led to an increase in general fatigue. The course of general fatigue was studied, which might cause the difference in the findings between the studies. The result in this study are derived from the same database [1], though the measurement points are studied independently. Probably, radiotherapy does not influence fatigue of itself, but receiving radiotherapy (in course of time) does increase the general fatigue level. Type of operation has also an impact on the course of general fatigue, but was a non-significant variable in this study. According to the literature, surgery of the breast has a negative impact on body image [62,63], which could have an indirect effect on the experience of general fatigue. The difference in the extent of surgery does not have an impact on general fatigue either. Results in previous studies [1, 8-10, 13] vary. It is not exactly clear why these results are incongruous.

\section{Factors relating to physical and/or psychological distress}

The influence of factors on general fatigue is quite similar to the effect on physical and psychological distress. Only deviant influences are described in this section.

For variable 'age' no influence on general fatigue was observed, but this variable has a significant effect on psychological distress at the first measurement point. The effect is negative, meaning that older women experienced less psychological distress. Findings in other studies show that younger women with breast cancer have more severe emotional distress than older women. Schover [64] reported that the loss of a breast or poor breast appearance would be more distressing to women whose youth gives them high expectation for physical beauty. Or probably, younger women had the responsibility of caring for their families and young children [12]. It is unclear why the influence of age does not turn out significant in other measurement points.

The variable 'everyday social support' is only significant for its effect on physical distress in the fourth measurement. This variable showed significant effects on general fatigue in all measurements after completion of the treatment of chemotherapy. An explanation cannot be given.

Note that not all direct effects on physical and psychological are mentioned; only variables which influence general fatigue significantly are entered into the model. 


\section{Reciprocal effects between psychological distress and physical distress}

In the model developed here physical and psychological distress is reciprocally connected. Each measurement shows a significant relationship. As in the study of De Jong et al. [3] it is not unthinkable that several symptoms are interrelated in a network of symptoms. A limitation of this study is that no separate symptoms are involved.

During the first four measurements the effect of physical distress on psychological distress is larger than the effect vice versa. This is not unlikely, knowing that chemotherapy affects cells, including healthy cells, in the body. Patients are busy having treatments, rather than coming to terms with sorrow at that period of time. For the last measurement, which is taken three months after completion of the chemotherapy treatment, the opposite holds: the effect of the psychological distress on physical distress has become larger than the effect vice versa. The result sounds very plausible, as the body physically rehabilitates after completion of the treatment of chemotherapy. Besides, patients might have more time to reflect then. According to the literature, surgery of the breast has a negative impact on body image $[62,63]$. Moreover, the loss of a breast can have important psychological effects on women [26]. The feelings could be suppressed during the chemotherapy treatment. It is also possible that patients then realize what they were going through. Another approach is that many patients experience ambivalence at the end of chemotherapy. Patients are pleased to be finished, but they are afraid they should keep doing something to prevent a recurrence [65]. Okamura et al. [66] reported that it is important for all oncology staff to pay careful attention to the psychological health of patients who have been informed of their cancer recurrence. Johnson [67] reported in her pilot study that the majority of women diagnosed with breast cancer expressed moderate fears about recurrence. She also reported that many women spoke about life circumstances that were more salient than the possibility of recurrence. Finally the pressure of the society can also have an influence. After completion of chemotherapy patients are expected to be healthy again. In an environment that sees things relatively in black and white terms, complaining about defects is not tolerated anymore.

The results reported must be considered within the limitations of this study. It should be noted that the comparability of the results to other studies might be limited because no study has previously been conducted like the present one. A model comprising data of breast cancer patients during as well as after receiving adjuvant chemotherapy is quite unique. An advantage is that the final model is based on a huge amount of data. On the other hand, patients had to answer the same question at each interview; this might cause a degree of habituation. Besides, response shift can affects results. In this study response 


\section{Chapter 7}

shift refers to a change in the meaning of fatigue over time. This change can be (a) a change in the respondent's internal standards of measurement (recalibration), (b) a change in the respondent's values; or (c) a redefinition of the target construct (reconceptualization) [68]. Additionally, different interview styles (face-to-face and by phone) were carried out. Moreover, the unpredictable nature and the unusual character of cancer-related fatigue have been underexposed. De Jong et al. [69] found a chaotic pattern of fatigue in different women with breast cancer who receive adjuvant chemotherapy, irrespective of which regimen. They compared the pattern with a movement of an uncontrolled large marble [69]. Other studies [59, 70] confirm this finding. Another limitation might be that fatigue is a multidimensional concept [3] and therefore the description of the model in this study may remain incomplete. The model includes just one of the five dimensions of fatigue of the measurement instrument used in this study. To enhance the understanding of fatigue, a complex and subjective phenomenon, further research should include the different dimensions of fatigue.

\section{Future research}

Improved understanding of the relation between different variables and fatigue in breast cancer patients receiving adjuvant chemotherapy as well as after completion of chemotherapy could better equip health care providers to understand and address the needs of these patients. Future research should include interventions, based on the model presented in this study, addressing how patients can maintain or improve their quality of life during as well as after adjuvant chemotherapy.

\section{REFERENCES}

1. De Jong, N., et al., Prevalence and course of fatigue in breast cancer patients receiving adjuvant chemotherapy. Annals of Oncology, 2004. 15: p. 896-905.

2. NCCN, National Comprehensive Cancer Network (NCCN) Cancer-Related Fatigue. http://www.nccn.org/professionals/physician g/s/PDF/fatigue.pdf. 2006.

3. De Jong, N., et al., Fatigue in patients with breast cancer receiving adjuvant chemotherapy: a review of the literature. Cancer Nurs, 2002. 25(4): p. 283-97.

4. Holley, S., Cancer-related fatigue - Suffering a different fatigue. Cancer Practice, 2000. 8(2): p. 87-95.

5. Ream, E., A. Richardson, and C. Alexander-Dann, Facilitating patients' coping with fatigue during chemotherapy-pilot outcomes. Cancer Nurs, 2002. 25(4): p. 300-8.

6. KWF Kankerbestrijding, Kanker in Nederland. Trends, prognoses en implicaties voor zorgvraag. 2004, Oisterwijk: Drukkerij van den Boogaard. 
7. Bower, J.E., et al., Fatigue in breast cancer survivors: Occurrence, correlates, and impact on quality of life. Journal of Clinical Oncology, 2000. 18(4): p. 743-753.

8. Haghighat, S., et al., Factors predicting fatigue in breast cancer patients. Supportive Care in Cancer, 2003. 11(8): p. 533-538.

9. Jacobsen, P.B., M.A. Andrykowski, and C.L. Thors, Relationship of catastrophizing to fatigue among women receiving treatment for breast cancer. J Consult Clin Psychol, 2004. 72(2): p. 355-61.

10. Jacobsen, P.B., et al., Fatigue in women receiving adjuvant chemotherapy for breast cancer: Characteristics, course, and correlates. Journal of Pain and Symptom Management, 1999. 18(4): p. 233-242.

11. Mast, M.E., Correlates of fatigue in survivors of breast cancer. Cancer Nursing, 1998. 21(2): p. 136-142.

12. Woo, B., et al., Differences in fatigue by treatment methods in women with breast cancer. Oncol Nurs Forum, 1998. 25(5): p. 915-20.

13. Donovan, K.A., et al., Course of fatigue in women receiving chemotherapy and/or radiotherapy for early stage breast cancer. J Pain Symptom Manage, 2004. 28(4): p. 373-80.

14. Sabbatini, P., Contribution of anemia to fatigue in the cancer patient. Oncology New York, 2000. 14(11A Suppl. 10): p. 69-71.

15. Portenoy, R.K. and L.M. Itri, Cancer-related fatigue: guidelines for evaluation and management. Oncologist, 1999. 4(1): p. 1-10.

16. Mar Fan, H.G., et al., Fatigue, menopausal symptoms, and cognitive function in women after adjuvant chemotherapy for breast cancer: 1- and 2-year follow-up of a prospective controlled study. J Clin Oncol, 2005. 23(31): p. 8025-32.

17. Tchen, N., et al., Cognitive function, fatigue, and menopausal symptoms in women receiving adjuvant chemotherapy for breast cancer. J Clin Oncol, 2003. 21(22): p. 4175-83.

18. Nieboer, P., et al., Fatigue and relating factors in high-risk breast cancer patients treated with adjuvant standard or high-dose chemotherapy: a longitudinal study. J Clin Oncol, 2005. 23(33): p. 8296-304.

19. Blesch, K.S., et al., Correlates of fatigue in people with breast or lung cancer. Oncol Nurs Forum, 1991. 18(1): p. 81-7.

20. Geinitz, H., et al., Fatigue, serum cytokine levels, and blood cell counts during radiotherapy of patients with breast cancer. Int J Radiat Oncol Biol Phys, 2001. 51(3): p. 691-8.

21. Curran, S.L., A.O. Beacham, and M.A. Andrykowski, Ecological momentary assessment of fatigue following breast cancer treatment. J Behav Med, 2004. 27(5): p. 425-44.

22. Berger, A. and S.N. Walker, An explanatory model of fatigue in women receiving adjuvant breast cancer chemotherapy. Nursing Research, 2001. 50(3): p. 164-164.

23. Bower, J.E., et al., Fatigue in long-term breast carcinoma survivors: a longitudinal investigation. Cancer, 2006. 106(4): p. 751-8. 


\section{Chapter 7}

24. Andrykowski, M.A., et al., Use of a case definition approach to identify cancer-related fatigue in women undergoing adjuvant therapy for breast cancer. J Clin Oncol, 2005. 23(27): p. 6613-22.

25. Bennett, B., et al., Fatigue and psychological distress-exploring the relationship in women treated for breast cancer. Eur J Cancer, 2004. 40(11): p. 1689-95.

26. Spencer, K.W., Significance of the breast to the individual and society. Plast Surg Nurs, 1996. 16(3): p. 131-2.

27. Hann, D., K. Winter, and P. Jacobsen, Measurement of depressive symptoms in cancer patients: evaluation of the Center for Epidemiological Studies Depression Scale (CESD). J Psychosom Res, 1999. 46(5): p. 437-43.

28. Visser, M.R. and E.M. Smets, Fatigue, depression and quality of life in cancer patients: how are they related? Support Care Cancer, 1998. 6(2): p. 101-8.

29. Komproe, I.H., et al., Available support and received support: Different effects under stressful circumstances. Journal of Social and Personal Relationships, 1997. Vol 14(1): p. 59-77.

30. Van den Akker, M., et al., Marginal impact of psychosocial factors on multimorbidity: results of an explorative nested case-control study. Soc Sci Med, 2000. 50(11): p. 1679-93.

31. Shapiro, D.E., et al., Stage I/ breast cancer: differences between four coping patterns in side effects during adjuvant chemotherapy. J Psychosom Res, 1997. 43(2): p. 143-57.

32. Broeckel, J.A., et al., Characteristics and correlates of fatigue after adjuvant chemotherapy for breast cancer. J Clin Oncol, 1998. 16(5): p. 1689-96.

33. Jacobsen, P.B., L.M. Azzarello, and D.M. Hann, Relation of catastrophizing to fatigue severity in women with breast cancer. Cancer Research Therapy and Control, 1999. 8: p. 155-164.

34. Okuyama, T., et al., Factors correlated with fatigue in disease-free breast cancer patients: application of the Cancer Fatigue Scale. Supportive Care in Cancer, 2000. 8(3): p. 215-222.

35. Smets, E.M.A., B. Garssen, and B. Bonke, Het meten van vermoeidheid met de Multidimensionele Vermoeidheids Index (MVI-20): Een handleiding. 1995, Amsterdam: Medische Psychologie, Academisch Medisch Centrum, The Netherlands.

36. Smets, E.M.A., et al., The Multidimensional Fatigue Inventory (MFI) Psychometric Qualities of an Instrument to Assess Fatigue. Journal of Psychosomatic Research, 1995. 39(5): p. 315-325.

37. Beahrs, O.H., Manual for staging of cancer. 4th ed. 1992: Philadelphia: Lippincott.

38. Haes de, J.C.M., et al., Measuring the quality of life of cancer patients with The Rotterdam Symptom Checklist (RSCL): A manual. 1996, Groningen: Northern Centre for Health Care Research (NCH), University of Groningen, The Netherlands. 
39. De Haes, J.C.J.M. and M. Olschewski, Quality of life assessment in a cross-cultural context: Use of the Rotterdam Symptom Checklist in a multinational randomised trial comparing CMF and Zoladex (Goserlin) treatment in early breast cancer. Annals of Oncology, 1998. 9(7): p. 745-750.

40. Paci, E., Assessment of validity and clinical application of an Italian version of the Rotterdam Symptom Checklist. Qual Life Res, 1992. 1(2): p. 129-34.

41. Radloff, L.S., The CES-D Scale: A self-report depression scale for research in the general population. Applied Psychological Measurement, 1977. Vol 1(3): p. 385-401.

42. Bouma, J., et al., Het meten van symptomen van depressie met de CES-D: Een handleiding. 1995, Groningen: Noordelijk centrum voor Gezondheidsvraagstukken, Rijksuniversiteit Groningen.

43. Van Sonderen, E., Het meten van sociale steun met de Sociale Steun Lijst (SSL-I) en Sociale Steun Lijst-Discrepanties (SSL-D). Een handleiding. 1993, Groningen: Noordelijk Centrum voor Gezondheidsvraagstukken, Rijksuniversiteit Groningen.

44. Van Eijk, L.M., G.I.J.M. Kempen, and F.L.P. Van Sonderen, Een korte schaal voor het meten van sociale steun bij ouderen: de SSL12-I (A short scale for measuring social support in the elderly: The SSL12-I). Tijdschrift voor Gerontologie en Geriatrie, 1994. Vol 25(5): p. 192-196.

45. Veenstra, K.M., et al., Quality of life in survivors with a Van Ness-Borggreve rotationplasty after bone tumour resection. J Surg Oncol, 2000. 73(4): p. 192-7.

46. Schaufeli, W. and D. Van Dierendonck, De betrouwbaarheid en validiteit van de Utrechtse Coping Lijst. Een longitudinaal onderzoek bij schoolverlaters (The reliability and validity of the Utrecht Coping List: A longitudinal study among school-leavers). Gedrag Gezond, 1992. Vol 20(1): p. 38-45.

47. Sanderman, O. Robbert, and Johan, De Utrechtse Coping Lijst (UCL): validiteit en betrouwbaarheid (The Utrecht Coping List (UCL): Validity and reliability). Gedrag Gezond, 1992. 20(1): p. 32-37.

48. Bollen, K.A., Structural Equations with Latent Variables. 1989, New York: John Wiley.

49. Bentler, P.M., EQS Structural Equations Program Manual. 1995, Encino, Calif. Multivariate Software (version 6.1).

50. Hwang, S.S., et al., Multidimensional independent predictors of cancer-related fatigue. Journal of Pain and Symptom Management, 2003. 26(1): p. 604-614.

51. Courtens, A.M., et al., Longitudinal study on quality of life and social support in cancer patients. Cancer Nurs, 1996. 19(3): p. 162-9.

52. Groopman, J.E. and L.M. Itri, Chemotherapy-induced anemia in adults: Incidence and treatment. Journal of the National Cancer Institute, 1999. 91(19): p. 1616-1634.

53. Itri, L.M., Optimal hemoglobin levels for cancer patients. Semin Oncol, 2000. 27(2 Suppl 4): p. 12-5. 


\section{Chapter 7}

54. Littlewood, T.J., The impact of hemoglobin levels on treatment outcomes in patients with cancer. Semin Oncol, 2001. 28(2 Suppl 8): p. 49-53.

55. Sobrero, A., et al., Fatigue: a main component of anemia symptomatology. Semin Oncol, 2001. 28(2 Suppl 8): p. 15-8.

56. Holzner, B., et al., The impact of hemoglobin levels on fatigue and quality of life in cancer patients. Annals of Oncology, 2002. 13(6): p. 965-973.

57. Wortman, C.B., Social support and the cancer patient. Conceptual and methodologic issues. Cancer, 1984. 53(10 Suppl): p. 2339-62.

58. Drageset, S. and T.C. Lindstrom, The mental health of women with suspected breast cancer: the relationship between social support, anxiety, coping and defence in maintaining mental health. J Psychiatr Ment Health Nurs, 2003. 10(4): p. 401-9.

59. Pearce, S. and A. Richardson, Fatigue in cancer: a phenomenological perspective. Eur J Cancer Care, 1996. 5(2): p. 111-5.

60. McHaffie, H.E., Coping: an essential element of nursing. J Adv Nurs, 1992. 17(8): p. 933-40.

61. Manne, S.L., et al., Coping with chemotherapy for breast cancer. J Behav Med, 1994. 17(1): p. 41-55.

62. Cohen, M.Z., D.L. Kahn, and R.H. Steeves, Beyond body image: the experience of breast cancer. Oncol Nurs Forum, 1998. 25(5): p. 835-41.

63. Mock, V., Body image in women treated for breast cancer. Nurs Res, 1993. 42(3): p. 153-7.

64. Schover, L.R., Sexuality and body image in younger women with breast cancer. J Natl Cancer Inst Monogr, 1994. 16: p. 177-82.

65. Beisecker, A.E., et al., Side effects of adjuvant chemotherapy: Perceptions of nodenegative breast cancer patients. Psycho Oncology, 1997. 6 (2): p. 85-93.

66. Okamura, H., et al., Psychological distress following first recurrence of disease in patients with breast cancer: prevalence and risk factors. Breast Cancer Res Treat, 2000. 61(2): p. 131-7.

67. Johnson-Vickberg, S.M., Fears about breast cancer recurrence. Cancer Pract, 2001. 9(5): p. 237-43.

68. Sprangers, M.A. and C.E. Schwartz, Integrating response shift into health-related quality of life research: a theoretical model. Soc Sci Med, 1999. 48(11): p. 1507-15.

69. De Jong, N., et al., Course of fatigue between two cylces of adjuvant chemotherapy in breast cancer patients. Cancer Nursing, 2006. 29(6): p. 467-477.

70. Schwartz, A.L., Daily fatigue patterns and effect of exercise in women with breast cancer. Cancer Practice, 2000. 8(1): p. 16-24. 
The development of a model 

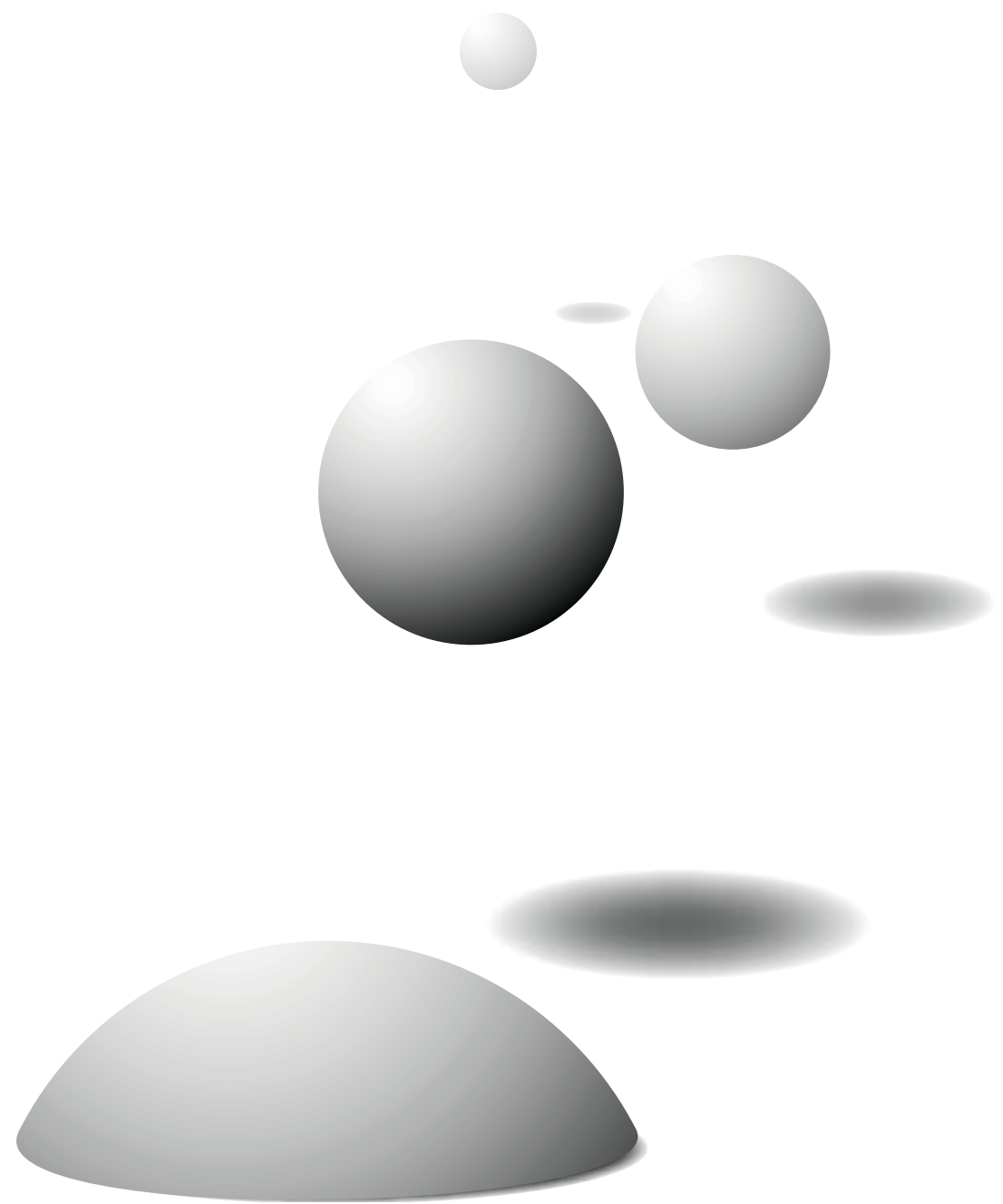
Chapter 8

General discussion 
Chapter 8 


\section{INTRODUCTION}

Fatigue is a major concern in patients with cancer [1]. This dissertation has investigated the extent of fatigue in breast cancer patients experienced during and after adjuvant chemotherapy. The studies on the course of fatigue are important contributions to the understanding of fatigue in cancer patients. Moreover, the influence of variables on fatigue has been examined as well.

This chapter briefly summarises the main findings and outlines some methodological reflections. Finally, the chapter presents implications for practice and recommendations for future research.

\section{Prevalence of fatigue}

Fatigue is highly prevalent both during and after the treatment of chemotherapy (see Table 1). In the literature, prevalence rates of fatigue between 58 and $94 \%$ were found during treatment of chemotherapy and 56-95\% afterwards [2]. Note that the rates reported depend on the method of classification of patients into fatigue and non-fatigue groups. It is therefore difficult to compare prevalence rates of different studies. What is more interesting is that the changes in prevalence over time, as found in our study, are comparable, regardless of how the classification was done. As in a previous study by Jacobsen et al. [3], a significant increase in the prevalence rates of all groups is seen after the start with chemotherapy. After this increase, as in previous studies [3, 4], a stability in the prevalence rate is found during chemotherapy treatment. After the treatment of chemotherapy the prevalence rates seem to decline.

Table 1. Prevalence of fatigue

\begin{tabular}{|c|c|c|c|c|c|c|c|c|c|c|}
\hline \multirow[t]{2}{*}{ Measurement point $\rightarrow$} & \multicolumn{2}{|c|}{$\begin{array}{c}1 \text { st } \text { cyclea }^{\mathrm{a}} \\
n=157\end{array}$} & \multicolumn{2}{|c|}{$\begin{array}{c}3^{\text {rd }} \text { cycle } \\
n=157\end{array}$} & \multicolumn{2}{|c|}{$\begin{array}{c}5^{\text {th }} \text { cycleb } \\
n=135\end{array}$} & \multicolumn{2}{|c|}{$\begin{array}{c}4 \text { weeksc } \\
n=152\end{array}$} & \multicolumn{2}{|c|}{$\begin{array}{c}12 \text { weeksc } \\
n=152\end{array}$} \\
\hline & $n$ & $\%$ & $n$ & $\%$ & $n$ & $\%$ & $n$ & $\%$ & $n$ & $\%$ \\
\hline \multicolumn{11}{|l|}{ Original data RSCL: } \\
\hline Not at all (1) & 56 & 36 & 30 & 19 & 25 & 19 & 27 & 18 & 36 & 24 \\
\hline A little (2) & 61 & 39 & 59 & 38 & 50 & 37 & 62 & 41 & 69 & 45 \\
\hline Quite a bit (3) & 33 & 21 & 49 & 31 & 39 & 29 & 39 & 26 & 31 & 20 \\
\hline Very much (4) & 7 & 5 & 19 & 12 & 21 & 16 & 24 & 16 & 16 & 11 \\
\hline
\end{tabular}




\section{Chapter 8}

\section{Course of fatigue during and after adjuvant chemotherapy}

During adjuvant chemotherapy and after completion of adjuvant chemotherapy The course of fatigue was studied using five dimensions of fatigue [5]: general fatigue, physical fatigue, reduced activity, mental fatigue and reduced motivation. Importantly, the course of general and physical fatigue is different for the doxorubicin group and CMF group. In the doxorubicin group a direct increase in fatigue was found. Other studies $[3,6]$ found similar results. In the CMF group a moderate direct increase occurred, followed by a delayed, after the last cycle of chemotherapy, strong increase. The contact with healthcare providers the women in the CMF group have is probably more intensive than in the doxorubicin group, because they had to visit the hospital more frequently. The end of chemotherapy marks the loss of this support system and a change in routine that might cause this increase of fatigue. The chemical composition of the CMF regimen could also cause the late effect in the experienced fatigue. However, no specific data are available.

Furthermore, we may conclude that no unequivocal pattern of activity level, mental fatigue and motivation has been observed, though there is a tendency of stability during the study with a significant improvement of the activity level, a potential decline in mental fatigue and an increase in motivation after completion of chemotherapy. Different studies [7-9] show that the trajectory preceding chemotherapy could influence the experience of fatigue in advance, which could cause the stability. Anxiety, pain and surgery are mentioned as predictors. Another reason for the stability could be habituation to the experience of fatigue. Besides, response shift can affects results. In this study response shift refers to a change in the meaning of fatigue over time. This change can be (a) a change in the respondent's internal standards of measurement (recalibration), (b) a change in the respondent's values; or (c) a redefinition of the target construct (reconceptualization) [10].

In general, the level of each dimension at twelve weeks after completion of adjuvant chemotherapy did not significantly differ from the pre-chemotherapy treatment measurement. The time after the last treatment might be too short to find a change in fatigue that is large enough to result in a significant effect in the statistical analysis. It might be that patients needed longer to recover from the treatments or had to cope with the treatment process they had undergone. It is unknown whether the fatigue at the last measurement can be regarded as normal fatigue. Probably not, high prevalence rates of fatigue, long after completion of chemotherapy are evident [11].

What is noticeable is that all courses of the dimensions of fatigue are influenced by type of surgery. Women with a mastectomy operation were at a disadvantage compared to women who underwent a lumpectomy. The extent of 
the surgery influences physically the experience of fatigue and the loss of a breast can have important psychological effects on women [12].

Supplementary to chemotherapy, $69 \%$ of the women received radiotherapy. Receiving radiotherapy led physically to an increase in fatigue. More specifically, the longer the duration of radiotherapy (number of days of receiving radiotherapy), the higher the fatigue, and the longer the time interval between the last radiotherapy session and the measurement point, the less fatigue was experienced at that measurement point. The accumulation of radiotherapy treatments increased the experience of fatigue. This may be partly explained by the trip to the treatment centre. Women had to go each weekday to the treatment centre during a period of about five weeks. This could be rather intensive. Besides, daily routine activities had to be adjusted to the treatments. Finally, it may be the effect of radiotherapy itself or a combination of the therapies that makes these patients more fatigued [13]. After the treatment with radiotherapy women recover from this intensive period, which may explain the normalisation of the extent of fatigue after the last treatment. Irvine et al. [14] partially support this reasoning.

\section{Between two cycles of adjuvant chemotherapy}

The pattern of fatigue in women with breast cancer receiving adjuvant chemotherapy, irrespective of which regimen, appears chaotic, a criss-cross of lines. Fatigue fluctuates like an uncontrolled large marble. Other studies [15, 16] support this finding.

Results in this dissertation showed an average highest level of fatigue on day 3 from the start. For the 28 day regimens another distinct peak was seen around day 11. As in the study of Richardson et al. [17], the pattern of fatigue appeared to reflect the drug administration. A relatively larger number of patients experienced peak fatigue levels before day 5 . The first days after treatment with chemotherapy are the worst [11, 17-20]. The type of chemotherapy has a significant impact on the course of fatigue. The course of fatigue in the CMF group was significantly different compared to the doxorubicin regimens. The fatigue peak in the CMF group was lower. Women taking cyclophosphamide orally experienced the peak level of fatigue significantly later.

\section{Impact on daily living activities}

In this dissertation a relatively large group, about $15 \%$ to $35 \%$ of the sample, reported that fatigue interfered to a large extent with their daily living activities. Fatigue has a strong impact on daily functioning. This finding is supported by previous studies $[18,21,22]$. For healthy individuals, fatigue seems to maintain a healthy balance between rest and activity. It might be a protective, sometimes even pleasant, regulatory response to physical or psychological stress [23]. For 


\section{Chapter 8}

patients with cancer, fatigue becomes a chronic and unpleasant sensation [24], which can be a major obstacle to maintaining normal daily activities and quality of life. The interference with daily functioning is highly important and has been recognised, also in this dissertation. It is clear that, in our study, for significantly more patients fatigue interferes to a large extent with their daily living activities after the first infusion of chemotherapy. During chemotherapy this group grows significantly. After completion of chemotherapy this group shrinks. At the end of the study, the group with strong interference is similar in size to the group at the start of chemotherapy.

\section{Depressive symptoms and fatigue}

This dissertation reports that about $20 \%$ of the sample can be classified as suffering from a depressive syndrome during as well as after adjuvant chemotherapy treatment. Fatigue and depressive symptoms have a positive relationship during the whole study period. Visser and Smets [25] found in their study a moderate relation. Other studies [26-29] in breast cancer patients receiving chemotherapy showed also a positive relationship between depression and fatigue. That fatigue and depression are related is beyond doubt, but the interpretation of this relation is, however, complicated [25]. The symptoms of fatigue and depression overlap. In addition, fatigue is one of the key symptoms of depression and may be the result of depressed mood. On the other hand, a person who continuously perceives his or her energy as insufficient may become depressed. Cancer fatigue and depression may co-occur without having a causal relationship, because they can both originate from the same pathology [25].

\section{Physical and psychological distress}

During the first four measurements the effect of physical distress on psychological distress is larger than the effect vice versa. This does not come as a surprise, knowing that chemotherapy affects cells, including healthy cells, in the body. Patients are busy having treatments, rather than come to terms with sorrow at that same period of time. For the last measurement, which was taken three months after completion of the chemotherapy treatment, the opposite holds: the effect of the psychological distress on physical distress has become larger than the effect vice versa. The result sounds very reasonable, as the body physically rehabilitates after completion of the treatment of chemotherapy. Besides, patients might have more time to reflect then. According to the literature, surgery of the breast has a negative impact on body image [30, 31]. Moreover, the loss of a breast can have important psychological effects on women [12]. The feelings could be suppressed during the chemotherapy treatment. It is 
also possible that patients then realise what they were going through. Another approach is that many patients experience ambivalence at the end of chemotherapy. Patients are happy to be finished, but they are afraid they should keep doing something to prevent a recurrence [32].

\section{Factors relating to general fatigue}

A model of variables that influence fatigue in breast cancer patients was developed based on literature review and previous work of the authors.

Both physical and psychological distress are important predictors of general fatigue. The influence of these factors was expected and thus confirms previous findings [11]. It is still not clear whether the symptoms, such as depression and anxiety, cause the fatigue or vice versa. Qualitative research should give more information.

Treatment factors do not influence general fatigue at all, whereas the social aspect seems to be of great value. This is observed in the influence of several variables of demographic or social nature on general fatigue. For example, after completion of adjuvant chemotherapy general fatigue was influenced by marital status: women living alone were more fatigued than women living with their spouse. The fact that women with a partner reported less fatigue might be dependent on whether there is tangible support [2]. It is possible that women living alone received more support from others during adjuvant chemotherapy than afterwards. After completion of the treatment of chemotherapy, the support could be diminished because no treatment was received and therefore transport to the outpatients department as well as support during the visit and afterwards were not needed anymore. Moreover, patients feel normal and look better after completion of adjuvant chemotherapy which could suggest to the social environment that women living alone need little or no support and therefore they do not get support. Courtens et al. [33] reported similar findings in a study with different types of cancer. Here, the expectation of others with respect to the patient and/or limited knowledge they have about chemotherapy could play an important role. The effect of everyday social support on general fatigue seems to be getting stronger during the study. After completion of chemotherapy there is a strong significant effect, meaning that higher everyday social support leads to less fatigue. Similar effects were found by other authors. The author of an early study [34] had reported that the uncertainties and fears experienced by a person diagnosed with cancer are likely to result in an enhanced need for social support.

In our study a significant influence, in the last two measurements, between an active coping strategy and general fatigue was found. Patients who are inclined to take an active stance in problem situations experience more fatigue 


\section{Chapter 8}

than those who did not. Van den Akker et al. [35] found a similar result in their study in primary care subjects, using the same measurement instrument reporting an association between an active coping style and the occurrence of multimorbidity. According to the authors, this is likely to be a result rather than a cause of multimorbidity, subjects with multiple pathology being more apt to deal actively with problems because their (health) problems are less easy to avoid [35].

\section{Theoretical reflections regarding the model}

In chapter 1, the introduction chapter, an expected simplified model of fatigue and its related factors was presented. This model was based on a limited number of studies, including less well specified studies. Chapter 2 described a model of fatigue and its related factors based on the literature. Only studies on breast cancer receiving adjuvant chemotherapy were included. In both chapters, 1 and 2, fatigue was presented in the centre of the model. Note that no different dimensions were taken into account. An addition in the model of chapter 2 compared to the model in chapter 1 is the expected mutual relationship between physical symptom distress and psychological symptom distress. Noticeably, the model in chapter 2 shows that in general the separate relationships between fatigue and the following factors, demographic factors, disease/physical factors, social factors, coping factors and treatment factors, are unclear or nil. On the other hand, the relationship between fatigue and physical or psychological symptom distress seems to be unequivocal. The model based on literature and previous work of authors, presented in chapter 7, shows similar characteristics. Note that fatigue in the model which is tested, called general fatigue, is one of the five dimensions of fatigue of the MFI-20 [5]. The model is therefore restricted and incomplete. In the final model, Maastricht Fatigue Model (MFM), (general) fatigue is seen as a part of the physical symptom distress and for that reason is not a central variable anymore. The well-being of a patient consists of a physical and a psychological part. In the literature the outcomes of studies indicate that several symptoms are interrelated in a network of symptoms [11], which is also seen and expected in the model in chapter 2. By removing (general) fatigue from the centre, the authors emphasise the relationships between fatigue and physical distress as well as psychological distress.

\section{Methodological reflections}

\section{Course of fatigue (longitudinal studies)}

The literature review (chapter 2) examined different studies with cross-sectional designs or longitudinal designs on fatigue in breast cancer patients receiving adjuvant chemotherapy. One of the conclusions is that there is a lack of studies 
on fatigue both during and after receiving adjuvant chemotherapy and between two cycles of adjuvant chemotherapy. This dissertation determines the course of fatigue in breast cancer patients during (at the first, third and fifth cycle) as well as after (4 and 12 weeks after completion) receiving adjuvant chemotherapy and between two cycles of adjuvant chemotherapy. The longitudinal designs address the development of fatigue over time. Patients were used as their own gold standard, which made it possible to show how the fatigue level develops. A limitation is that it is still unknown whether the fatigue assessed at the time points can be regarded as normal fatigue. Everyone experiences fatigue on daily basis. No healthy control group was involved to compare fatigue levels.

A relatively large sample, 157 patients, was studied for over a half year. The response rate at the end of the study, 12 weeks after completion of adjuvant chemotherapy, was very good $(97 \%)$. Previous studies show that the time span after completion of chemotherapy considered in our study is most likely too short $[27,36,37]$. It might be that patients needed longer to recover from the treatments or had to cope with the treatment process they had undergone. It should also be noted that women might be fatigued before starting any treatment. Cimprich [7] found a prevalence of fatigue of $77 \%$ before primary surgery. The increased fatigue in patients before the start of chemotherapy may reflect lingering physical and psychological stress associated with having recently undergone breast cancer surgery [3]. The Multidimensional Fatigue Inventory (MFI-20) was used to assess the course of fatigue [5]. This 20-item questionnaire, especially designed for cancer patients, consists of five dimensions. The results of the different dimensions give detailed information regarding fatigue. The fatigue scores, the MFI-20 scores, could not be compared with other groups (like psychology students, soldiers) published in the measurement instrument or with other studies, because no raw fatigue scores were published. Future research should include this information in their publication.

The response rate of the study between two cycles of adjuvant chemotherapy in a relatively large sample $(n=155)$ is also very high. About $95 \%$ of the diaries returned $(97 \%)$ were used in the analyses. Patients had to report their experience of fatigue in a diary, the Shortened Fatigue Questionnaire, on a daily basis between the third and fourth treatment with adjuvant chemotherapy. Future research should include measurement points between more cycles to investigate possible differences. This study on the development of fatigue between two cycles is one of the first large scale examinations. Fatigue was studied as a unidimensional concept. To enhance the understanding of fatigue, a complex and subjective phenomenon, further research should include dimensions of fatigue. 


\section{Chapter 8}

The development of a model (based on data of 5 cross-sectional studies)

A model of variables that influence fatigue in breast cancer patients was developed based on literature review and previous work of the authors. In a prospective cohort study the model was tested. The final model, presented in chapter 7, based on data of 157 breast cancer patients during as well as after receiving adjuvant chemotherapy, is quite unique. An advantage is that the final model is based on a huge quantity of data. The data consist of five cross-sectional studies (the five measurements separately). Moreover, the final model incorporates information elicited both during and after receiving adjuvant chemotherapy, giving a broad scope to the model.

The Utrecht Coping List (UCL) [38, 39], which was used, was not satisfactory. The internal consistency of the subscales 'avoiding' and 'palliative coping' were so low that these were not included in the analysis, which limited the findings in this study. No complete overview of the effects of coping styles can therefore be given. Future studies should consider using a different instrument.

Results of the studies can be generalised, though the lack of homogeneity of the doxorubicin group, in which five different chemotherapy regimens are represented, must be mentioned. This may have affected the power to detect more changes across time in fatigue for this particular group. Additionally, it should be noted that in our studies many different analyses were executed, which might enhance the chance of significant results.

Note that patients were interviewed five times in relatively a short period of time. They were not interviewed at each treatment of chemotherapy, which limited the overview of the fatigue pattern during chemotherapy. At each interview, they had to answer the same questions, which might have led to a certain habituation. Moreover, different interview styles, face-to-face interviews and interviews by phone, were executed. The internal consistency of both ways of administering the questionnaire is good. It is unknown how these methods may bias the results obtained regarding respondents' fatigue.

\section{Implications for practice and future research}

Improved understanding of the courses of fatigue in breast cancer patients receiving chemotherapy will better equip health care providers to understand and address the needs of these patients. The existing information about fatigue for patients can be adjusted and specified. Health care providers should pay attention to the possibility of the patients experiencing depressive symptoms. Recognition and treatment of these symptoms can influence the course of the chemotherapy treatment as well as the quality of life during and after the treatment of chemotherapy positively.

The pattern of fatigue is unusual and chaotic. This knowledge must be included in the education for healthcare providers, like oncologists and oncology 
nurses, which can contribute to a better transfer of information with respect to the nature of fatigue to patients. Patients who know what they can expect will be less overwhelmed. Understanding from family members and others can ease the experience of fatigue. Future research must be combined with qualitative research to try to clarify the chaotic pattern. Oncology nurses must routinely give information to patients about a probable peak of fatigue in the first days after an infusion with chemotherapy. With this knowledge patients can prepare themselves; for example, they can adjust their activities of daily life.

Understanding of the relation between different variables and fatigue in breast cancer patients receiving adjuvant chemotherapy as well as after completion of chemotherapy could help health care providers to recognise the needs of these patients. Future research should include interventions, based on the model presented in this study, addressing how patients can maintain or improve their quality of life during as well as after adjuvant chemotherapy. Health care providers should detect psychological distress in an early stage. For example, health care providers could incorporate a short depression list as a standard part of their anamnesis to give a quick indication if a patient suffers from depressive symptoms. Moreover, an intervention for diminishing psychological distress should be developed.

The model presented in chapter 7 should be tested in patients with other types of cancer. Note that the model can also be tested in men or in mixed groups. Finally, the model can be tested in other patients groups such as rheumatic patients and patients with chronic fatigue syndrome.

Further research, in which an assessment at the last treatment of chemotherapy is included, needs to conclude whether there is really a late effect in the CMF group. In addition, future studies should include a comparison group of healthy women. Fatigue tends to decline after completion of chemotherapy, but whether the fatigue levels can be regarded as 'normal' is not yet clear. Moreover, research involving the trajectory preceding adjuvant chemotherapy and a longer study period afterwards needs to be executed.

\section{References}

1. Irvine, D.M., et al., A critical appraisal of the research literature investigating fatigue in the individual with cancer. Cancer Nurs, 1991. 14(4): p. 188-99.

2. De Jong, N., et al., Prevalence and course of fatigue in breast cancer patients receiving adjuvant chemotherapy. Annals of Oncology, 2004. 15: p. 896-905.

3. Jacobsen, P.B., et al., Fatigue in women receiving adjuvant chemotherapy for breast cancer: Characteristics, course, and correlates. Journal of Pain and Symptom Management, 1999. 18(4): p. 233-242. 


\section{Chapter 8}

4. Sitzia, J. and L. Huggins, Side effects of cyclophosphamide, methotrexate, and 5-fluorouracil (CMF) chemotherapy for breast cancer. Cancer Practice, 1998. 6 (1): p. 13-21.

5. Smets, E.M.A., B. Garssen, and B. Bonke, Het meten van vermoeidheid met de Multidimensionele Vermoeidheids Index (MVI-20): Een handleiding. 1995, Amsterdam: Medische Psychologie, Academisch Medisch Centrum, The Netherlands.

6. Berger, A. and S.N. Walker, An explanatory model of fatigue in women receiving adjuvant breast cancer chemotherapy. Nursing Research, 2001. 50(3): p. 164-164.

7. Cimprich, B., Pretreatment symptom distress in women newly diagnosed with breast cancer. Cancer Nurs, 1999. 22(3): p. 185-94.

8. Cimprich, B., Attentional fatigue following breast cancer surgery [see comments]. Res Nurs Health, 1992. 15(3): p. 199-207.

9. Haghighat, S., et al., Factors predicting fatigue in breast cancer patients. Supportive Care in Cancer, 2003. 11(8): p. 533-538.

10. Sprangers, M.A. and C.E. Schwartz, Integrating response shift into health-related quality of life research: a theoretical model. Soc Sci Med, 1999. 48(11): p. 1507-15.

11. De Jong, N., et al., Fatigue in patients with breast cancer receiving adjuvant chemotherapy: a review of the literature. Cancer Nurs, 2002. 25(4): p. 283-97.

12. Spencer, K.W., Significance of the breast to the individual and society. Plast Surg Nurs, 1996. 16(3): p. 131-2.

13. Woo, B., et al., Differences in fatigue by treatment methods in women with breast cancer. Oncol Nurs Forum, 1998. 25(5): p. 915-20.

14. Irvine, D.M., et al., Fatigue in women with breast cancer receiving radiation therapy. Cancer Nursing, 1998. 21 (2): p. 127-135.

15. Schwartz, A.L., Daily fatigue patterns and effect of exercise in women with breast cancer. Cancer Practice, 2000. 8(1): p. 16-24.

16. Pearce, S. and A. Richardson, Fatigue in cancer: a phenomenological perspective. Eur J Cancer Care, 1996. 5(2): p. 111-5.

17. Richardson, A., E. Ream, and J. Wilson-Barnett, Fatigue in patients receiving chemotherapy: Patterns of change. Cancer Nursing, 1998. 21: p. 17-30.

18. Berger, A.M. and P. Higginbotham, Correlates of fatigue during and following adjuvant breast cancer chemotherapy: a pilot study. Oncol Nurs Forum, 2000. 27(9): p. 1443-8.

19. Molassiotis, A. and C.W.H. Chan, Fatigue patterns in Chinese patients receiving chemotherapy. Eur J Oncol Nurs, 2001. 5(1): p. 60-7.

20. Schwartz, A.L., et al., Fatigue patterns observed in patients receiving chemotherapy and radiotherapy. Cancer Invest, 2000. 18(1): p. 11-9.

21. Berger, A.M., Patterns of fatigue and activity and rest during adjuvant breast cancer chemotherapy. Oncol Nurs Forum, 1998. 25(1): p. 51-62.

22. Berger, A.M. and L. Farr, The influence of daytime inactivity and nighttime restlessness on cancer-related fatigue. Oncol Nurs Forum, 1999. 26(10): p. 1663-71. 
23. Servaes, P., C. Verhagen, and G. Bleijenberg, Fatigue in cancer patients during and after treatment: prevalence, correlates and interventions. European Journal of Cancer, 2002. 38(1): p. 27-43.

24. Piper, B.F., A.M. Lindsey, and M.J. Dodd, Fatigue mechanisms in cancer patients: developing nursing theory. Oncol Nurs Forum, 1987. 14(6): p. 17-23.

25. Visser, M.R. and E.M. Smets, Fatigue, depression and quality of life in cancer patients: how are they related? Support Care Cancer, 1998. 6(2): p. 101-8.

26. Andrykowski, M.A., S.L. Curran, and R. Lightner, Off-treatment fatigue in breast cancer survivors: A controlled comparison. Journal of Behavioral Medicine, 1998. 21(1)): p. 118.

27. Bower, J.E., et al., Fatigue in breast cancer survivors: Occurrence, correlates, and impact on quality of life. Journal of Clinical Oncology, 2000. 18(4): p. 743-753.

28. Gaston Johansson, F., et al., Fatigue, pain, and depression in pre-autotransplant breast cancer patients. Cancer Practice, 1999. 7(5): p. 240-247.

29. Okuyama, T., et al., Factors correlated with fatigue in disease-free breast cancer patients: application of the Cancer Fatigue Scale. Supportive Care in Cancer, 2000. 8(3): p. 215222.

30. Cohen, M.Z., D.L. Kahn, and R.H. Steeves, Beyond body image: the experience of breast cancer. Oncol Nurs Forum, 1998. 25(5): p. 835-41.

31. Mock, V., Body image in women treated for breast cancer. Nurs Res, 1993. 42(3): p. 153-7.

32. Beisecker, A.E., et al., Side effects of adjuvant chemotherapy: Perceptions of nodenegative breast cancer patients. Psycho Oncology, 1997. 6 (2): p. 85-93.

33. Courtens, A.M., et al., Longitudinal study on quality of life and social support in cancer patients. Cancer Nurs, 1996. 19(3): p. 162-9.

34. Wortman, C.B., Social support and the cancer patient. Conceptual and methodologic issues. Cancer, 1984. 53(10 Suppl): p. 2339-62.

35. Van den Akker, M., et al., Marginal impact of psychosocial factors on multimorbidity: results of an explorative nested case-control study. Soc Sci Med, 2000. 50(11): p. 1679-93.

36. Broeckel, J.A., et al., Characteristics and correlates of fatigue after adjuvant chemotherapy for breast cancer. J Clin Oncol, 1998. 16(5): p. 1689-96.

37. Leddy, S.K., Healthiness, fatigue, and symptom experience in women with and without breast cancer. Holist Nurs Pract, 1997. 12(1): p. 48-53.

38. Sanderman, O. Robbert, and Johan, De Utrechtse Coping Lijst (UCL): validiteit en betrouwbaarheid (The Utrecht Coping List (UCL): Validity and reliability). Gedrag Gezond, 1992. 20(1): p. 32-37.

39. Schaufeli, W. and D. Van Dierendonck, De betrouwbaarheid en validiteit van de Utrechtse Coping Lijst. Een longitudinaal onderzoek bij schoolverlaters (The reliability and validity of the Utrecht Coping List: A longitudinal study among school-leavers). Gedrag Gezond, 1992. Vol 20(1): p. 38-45. 

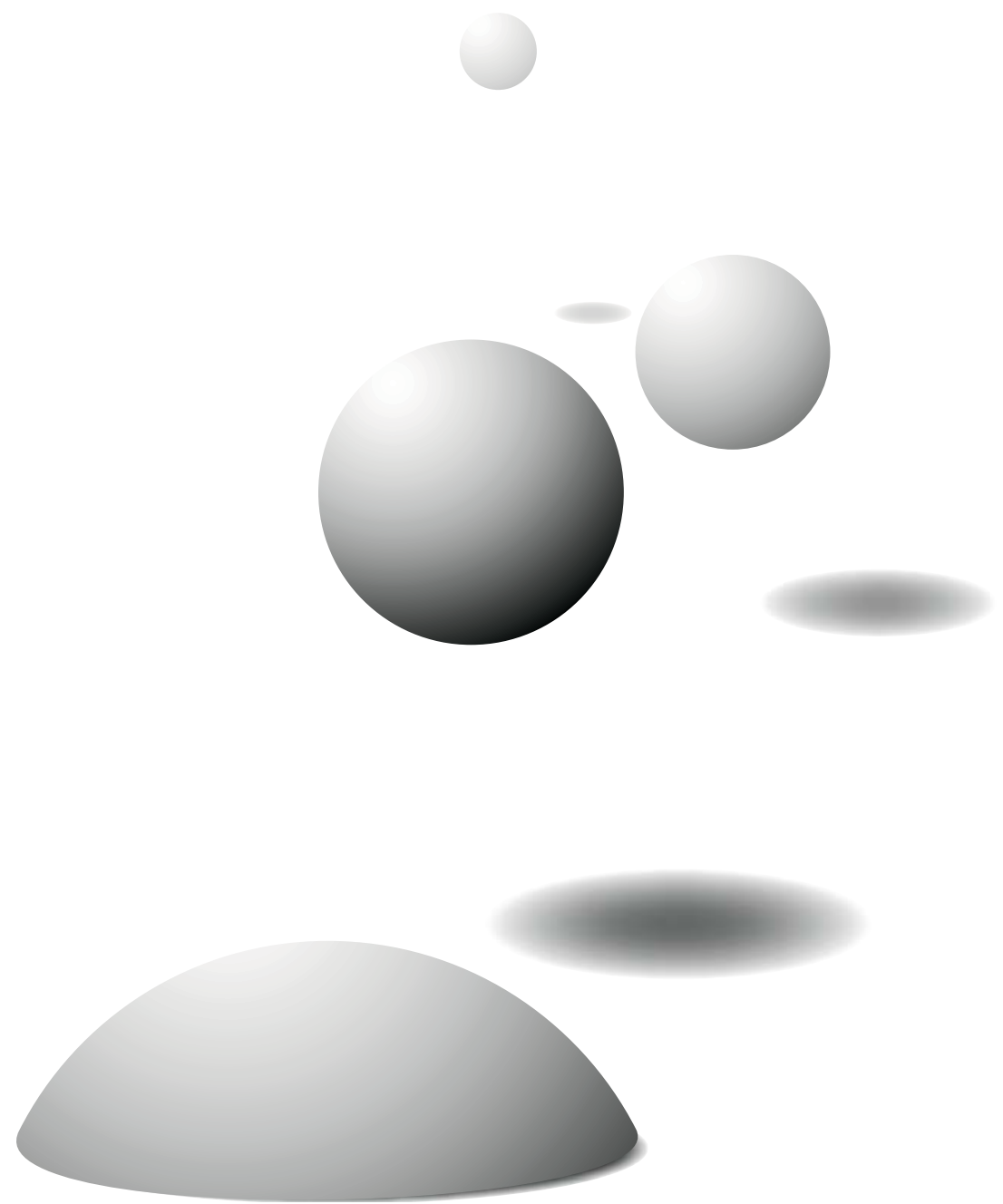
Summary

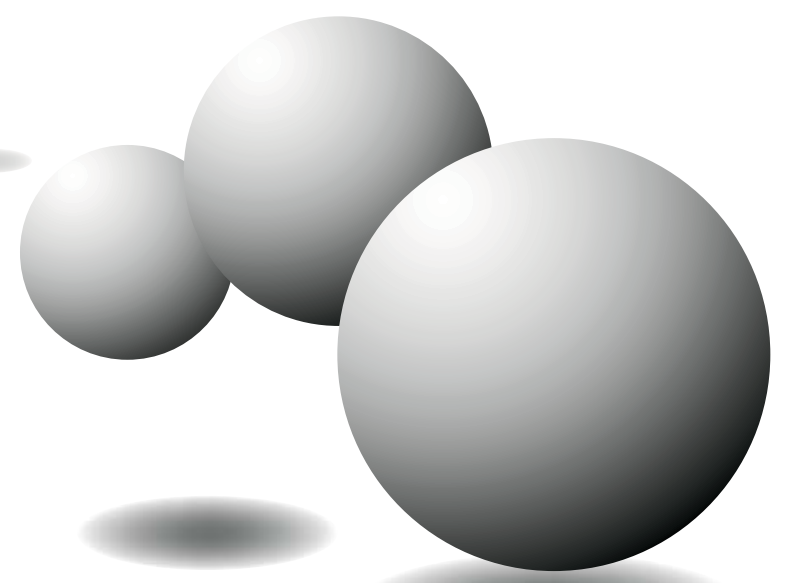


Fatigue is a major concern in patients with cancer. Little is known about fatigue in cancer, despite the high prevalence and its profound effects on patients' quality of life. It is recognised that cancer patients frequently become fatigued when undergoing treatment, notably chemotherapy. Because breast cancer is the most frequently occurring malignancy in women in the Netherlands and adjuvant chemotherapy is part of the standard treatment in a large subset of these patients, we analysed fatigue in relation to chemotherapy in breast cancer patients.

Chapter 2 introduces the concept of fatigue, and presents a literature review on prevalence and course of fatigue in breast cancer patients receiving chemotherapy. Fatigue is one of the most common side-effects of chemotherapy. In the literature high and fluctuating prevalence rates of fatigue have been described not only during but also after adjuvant chemotherapy. The intensity of fatigue seems to be stable throughout the treatment cycles, despite the general perception that more chemotherapy treatment leads to greater fatigue. The first two days after a chemotherapy treatment seem to be the worst period. In addition, factors relating to fatigue are described. Symptom distress, whether it is physical or psychological, plays a crucial role in experiencing fatigue. The outcomes of the studies indicate that several symptoms are interrelated in a network of symptoms. Stage of disease seemingly does not have significant impact on fatigue. The influence of type of surgery is debatably. Factors such as changes in weight, menopausal symptoms, coping, social support, and biochemical changes have been mentioned in the literature as potentially contributing to fatigue. Results are conflicting and need further study.

There is a lack of studies that investigate fatigue in breast cancer patients during as well as after receiving adjuvant chemotherapy. It is obvious that breast cancer patients experience fatigue, but the course of fatigue during and after adjuvant chemotherapy is unclear. Besides, it is uncertain which determinants influence fatigue during this course. Moreover, the nature of 'chemotherapyrelated fatigue' is less well studied.

Chapters 3, 4 and 5 focus on the course of fatigue in 157 breast cancer patients during the first, third and fifth cycles of adjuvant chemotherapy and four and twelve weeks after the last cycle. The chemotherapy the patients received was either a doxorubicin-containing schedule, or cyclophosphamide, methotrexate and 5-fluorouracil (CMF). The Multidimensional Fatigue Inventory (MFI-20) was used to assess the course of fatigue. This questionnaire consists of five subscales based on different dimensions: general fatigue, physical fatigue, reduced activity, reduced motivation and mental fatigue. In each of the chapters 3, 4 and 5, one or two dimension(s) are described, each assessed in separate studies. 
Chapter 3 determines the prevalence of fatigue and the courses of general and physical fatigue as a function of chemotherapy. The prevalence of fatigue increases significantly after the start of chemotherapy, whereas after the end of treatment with chemotherapy it seems to decline. The courses of general and physical fatigue are to a large extent similar. A different impact of the chemotherapy regimen on the course of fatigue is found. In the doxorubicin group a direct increase in fatigue is found. In the CMF group a moderate direct increase occurs, followed by a delayed strong increase. An increase in fatigue is associated with a decrease in daily functioning. At all measurements fatigue is affected by type of operation, such that women with a mastectomy are more fatigued than women who had undergone a lumpectomy. Receiving radiotherapy also leads to an increase in fatigue.

Chapter 4 elaborates on the course of fatigue with respect to cognitive symptoms (scale 'mental fatigue') as well as the motivation to start any activity (scale 'reduced motivation'), as a function of chemotherapy. The course of mental fatigue and motivation is not affected by the type of chemotherapy. The course of mental fatigue and motivation varies, but seems to be stable during the treatment of chemotherapy. After the completion of chemotherapy a weak improvement is seen.

The Center for Epidemiological Studies Depression Scale (CES-D) was used to measure depressive symptoms. Many patients experienced depressive symptoms during the study. These symptoms correlate with both dimensions of fatigue. Health care providers should be aware of the high numbers of patients experiencing depressive symptoms during and after the treatment of chemotherapy.

At all assessment points mental fatigue was influenced by type of operation where women with a mastectomy are significantly more mentally fatigued than women that have undergone a lumpectomy, but nevertheless they are significantly more motivated to start any activity.

Further research should include the trajectory preceding adjuvant chemotherapy and a longer study period afterwards. Moreover, the exact influence of the variables 'age', 'marital status', 'number of treatments' and 'the interval between the operation and the first treatment of chemotherapy' on fatigue is unclear and needs further study.

Chapter 5 reports the course of the activity level, perceived as a dimension of fatigue, as a function of chemotherapy within the breast cancer population receiving adjuvant chemotherapy. In addition, the course of the interference of fatigue with daily activities in this population is determined. The activity level seems to be rather stable during the treatment with chemotherapy. After completion 
of chemotherapy an improvement is observed. The activity level reported at the first and the last measurement does not differ significantly. The course of the activity level is not affected by type of chemotherapy regimen. Age, having children and the stage of breast cancer seem to be important determinants of the course of the activity level. At all measurement points women with a mastectomy are significantly more hampered in their activity level than women that had undergone a lumpectomy. The longer the duration of radiotherapy, the less active, and the longer the time interval between the last radiotherapy session and the assessment point, the more active patients are at that assessment point. A phenomenon not easy to explain is that the activity level in women who had received in total more chemotherapy treatments was significantly less diminished than those who had received fewer treatments.

The revised Piper Fatigue Scale is used to examine the behavioural changes in the interference of fatigue with activities of daily living. During the study period, in about $15 \%$ to $35 \%$ of the patients in the sample, fatigue interferes considerably with their daily living activities. Furthermore, the interference of fatigue with activities in daily life first increases after the start of chemotherapy and decreases after completion of chemotherapy.

With this knowledge health care providers can inform patients about what they can expect. Further research should include the trajectory preceding chemotherapy as well as a healthy control group.

Chapter 6 describes the course of fatigue in patients with breast cancer between two cycles of adjuvant chemotherapy, from the day of administration until the day of the next infusion. One hundred and fifty-one patients reported their experience of fatigue in a diary, the Shortened Fatigue Questionnaire, on a daily basis between the third and fourth treatment with adjuvant chemotherapy. Patients were treated with either a doxorubicin containing schedule or with CMF. Depending on the chemotherapy regimen, patients filled in 21 or 28 days of the diary. In the 28-day regimens, infusions were given on day 1 and day 8 . The days after completion of the third and the start of the fourth treatment with chemotherapy were analysed statistically. The hypothesis that the maximum fatigue score occurs in the first four days after treatment was tested.

A chaotic pattern of fatigue between the two cycles of chemotherapy emerges. Smooth curves (splines) show the average highest level of fatigue on day 3 from the start. For the 28-day regimens another distinct peak is seen around day 11 .

A relatively larger number of patients experience peak fatigue levels before day 5 . Most of these patients report day 3 as the worst day. The course of fatigue 
in the CMF group is significantly different compared to the doxorubicin regimens. The fatigue peak in the CMF group is lower. Women taking cyclophosphamide orally experience the peak level of fatigue significantly later. Influences of other variables were not observed in any chemotherapy group.

Improved understanding of the nature and course of fatigue can enable health care providers to better inform patients about what they may expect. Future research should include interventions aimed at reducing or coping with fatigue.

Chapter 7 outlines a model of variables that influence fatigue in breast cancer patients based on literature review and the previous chapters. In this chapter the model is tested in a sample of 157 breast cancer patients. One model (for general fatigue) for all five time points is developed using EQS, a computer program for linear structural equation modelling. In the identifiable and testable model two latent variables, (1) physical distress (measured by two observed indicators: general fatigue and physical symptom distress), and (2) psychological distress (measured by two observed indicators: depression and psychological symptom distress), are included. Physical distress is predicted by the variables: every day social support, active as coping strategy, age, marital status, job, stage of breast cancer, chemotherapy regimen, $\mathrm{Hb}$ level and number of chemotherapy treatments. Psychological distress is predicted by age and everyday social support.

Physical and psychological distresses are important predictors of general fatigue. General fatigue imbedded in a network of symptoms is not unlikely anymore. The social aspect seems to be of great importance as well. This is observed through the influence of several demographic or social variables on general fatigue.

The knowledge that chemotherapy affects cells, including healthy cells, in the body could explain that the physical distress compared to psychological distress is larger during the first four assessment points. Time to reflect and cope with the whole situation occurred after completion of chemotherapy, which could account for the larger effect of psychological distress at the last measurement point.

Improved understanding of the relation between different variables and fatigue in breast cancer patients receiving adjuvant chemotherapy as well as after completion of chemotherapy can better equip health care providers to understand and address the needs of these patients. Future research should include interventions, based on the model presented in this study, addressing how patients can maintain or improve their quality of life both during and after adjuvant chemotherapy. 
Chapter 8 discusses the main findings of the various studies and presents some methodological reflections. The main findings focus on the prevalence of fatigue, course of fatigue and the influence of variables on fatigue during and after adjuvant chemotherapy. Methodological criticism may include the absence of a healthy control group, time span of the study, the assessment points and the different chemotherapy regimens in the doxorubicin group. The chapter ends by discussing implications of our findings for practice and providing topics for future research. 

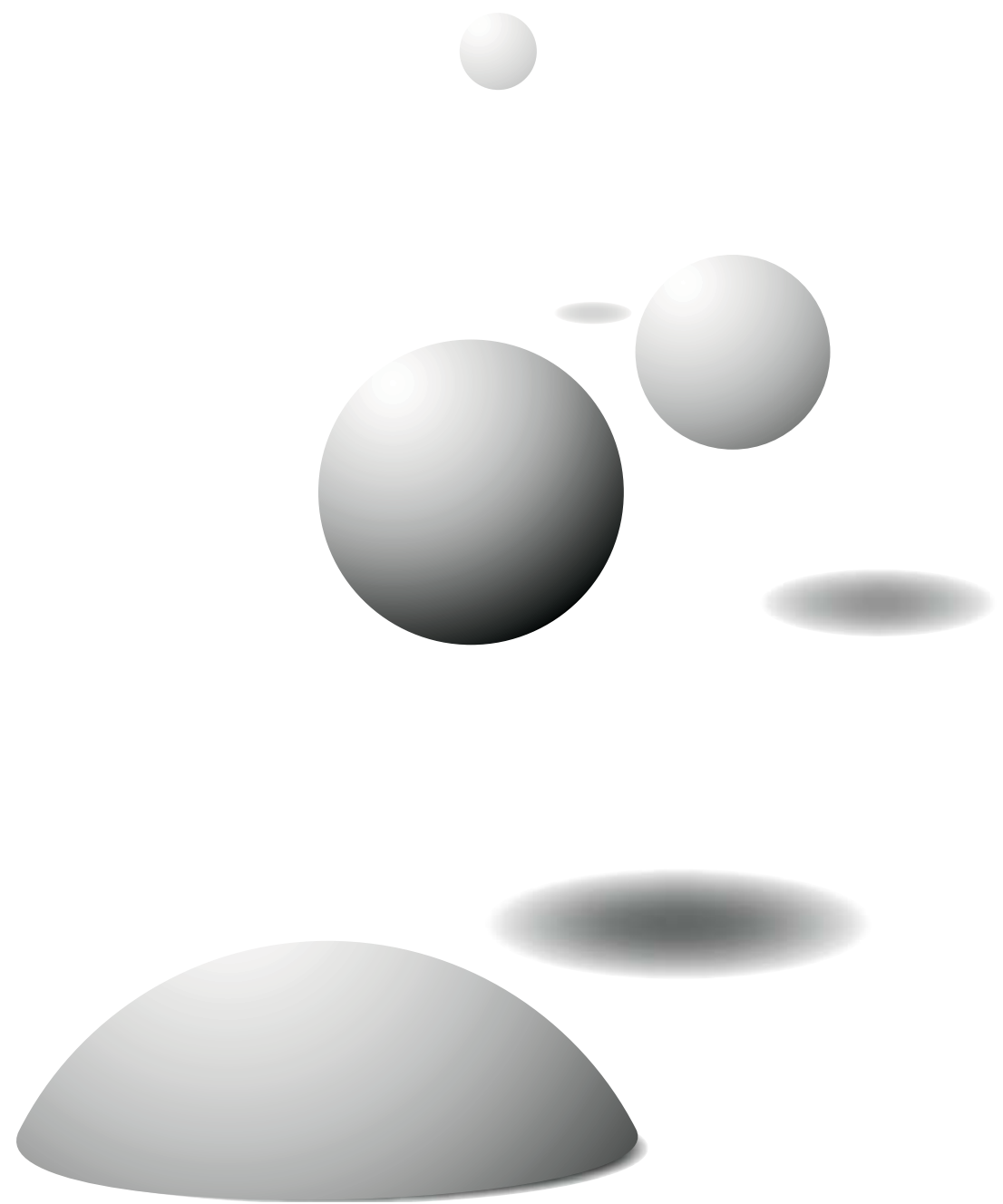
Samenvatting

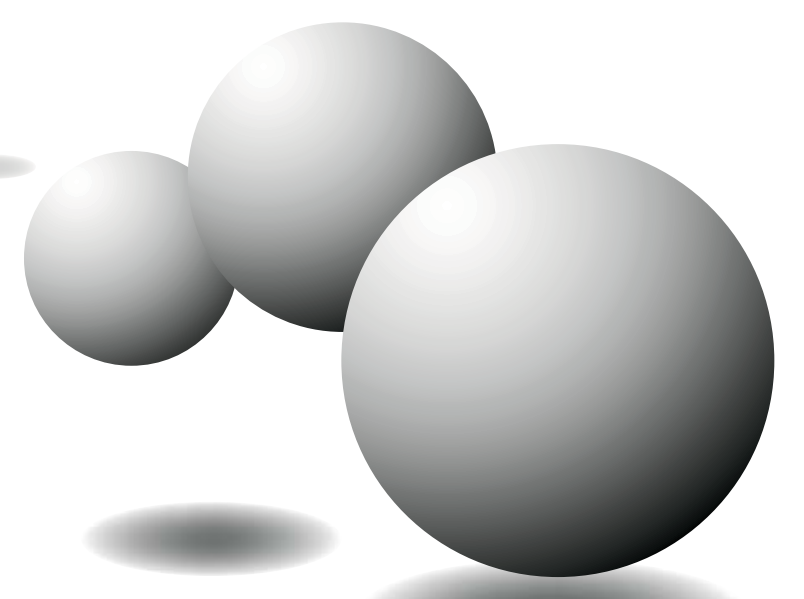


Vermoeidheid is een grote zorg voor kankerpatiënten. Weinig is bekend over vermoeidheid bij kanker ondanks de hoge prevalentie en haar diepgaande effecten op de kwaliteit van leven van patiënten. Het wordt erkend dat kankerpatiënten frequent vermoeid worden wanneer zij een behandeling ondergaan. Dit geldt voornamelijk voor chemotherapie. Nu in Nederland borstkanker één van de meest voorkomende kwaadaardige tumoren bij vrouwen is en adjuvante chemotherapie voor het grootste gedeelte deel uitmaakt van de standaardbehandeling, hebben we vermoeidheid bij borstkankerpatiënten in relatie tot chemotherapie onderzocht.

Hoofdstuk 2 introduceert het concept 'vermoeidheid'. In dit hoofdstuk wordt bovendien een literatuurstudie naar de prevalentie en het verloop van vermoeidheid bij borstkankerpatiënten die chemotherapie ondergaan, weergegeven. Vermoeidheid is één van de meest voorkomende bijwerkingen van chemotherapie. In de literatuur worden niet alleen tijdens adjuvante chemotherapie hoge en variërende vermoeidheidsprevalentie cijfers gevonden, maar ook na afloop van de adjuvante chemotherapiebehandeling. De intensiteit van vermoeidheid lijkt stabiel tijdens de chemokuren, hoewel men in het algemeen ervan uitgaat dat meer chemokuren leiden tot meer vermoeidheid. De eerste twee dagen na de chemokuur lijkt de slechtste periode te zijn. Bovendien worden factoren gerelateerd aan vermoeidheid beschreven. Klachten, of deze nu fysiek of psychisch van aard zijn, spelen een belangrijke rol in het ervaren van vermoeidheid. De resultaten van studies wijzen er op dat verscheidene symptomen met elkaar in verband staan, in een netwerk van symptomen. Het stadium van de ziekte lijkt geen significante invloed te hebben op vermoeidheid. De invloed van de type operatie wordt bediscussieerd. Factoren, zoals gewichtsveranderingen, menopausale symptomen, coping, sociale steun en biochemische veranderingen worden in de literatuur als mogelijke bijdragen aan de vermoeidheid gezien. De resultaten zijn tegenstrijdig en moeten verder worden onderzocht.

Aan studies over borstkankerpatiënten tijdens en na afloop van adjuvante chemotherapiebehandeling bestaat een tekort. Het is duidelijk dat borstkankerpatiënten vermoeidheid ervaren, maar hoe het verloop van vermoeidheid is tijdens en na afloop van een adjuvante chemotherapie-behandeling is onduidelijk. Bijvoorbeeld: welke determinanten beïnvloeden het verloop van vermoeidheid? De aard van chemotherapie gerelateerde vermoeidheid is bovendien onvoldoende onderzocht.

De hoofdstukken 3, 4 en 5 richten zich op het verloop van vermoeidheid bij 157 borstkankerpatiënten tijdens (bij de eerste, derde en vijfde chemokuur) en 
na afloop (4 en 12 weken na de laatste chemokuur) van een adjuvante chemotherapiebehandeling (doxorubicinegroep of CMF (cyclofosfamide, methotrexate en 5-fluorouracil) groep). De Multidimensionele Vermoeidheids Index (MVI-20) wordt gebruikt om het verloop van vermoeidheid vast te stellen. Deze vragenlijst bestaat uit vijf subschalen en is gebaseerd op verschillende dimensies: algemene vermoeidheid, lichamelijke vermoeidheid, reductie in activiteit, reductie in motivatie en mentale vermoeidheid. In elk hoofdstuk (3, 4 en 5) worden één of twee dimensies, die elk in afzonderlijke studies zijn onderzocht, beschreven.

Hoofdstuk 3 beschrijft de prevalentie van vermoeidheid en het verloop van algemene en lichamelijke vermoeidheid als functie van chemotherapie. De prevalentie van vermoeidheid neemt na de start van de chemotherapiebehandeling significant toe. Na afloop van de chemotherapiebehandeling lijkt de prevalentie te dalen. Het verloop van algemene en lichamelijke vermoeidheid is voor een groot deel hetzelfde. Een verschillende invloed van de chemokuren op het verloop van vermoeidheid wordt aangetroffen. In de doxorubicine groep is een directe toename van vermoeidheid gevonden. In de CMF groep werd na de start een gemiddelde toename gevonden, die gevolgd werd door een vertraagd sterke toename. Een toename van vermoeidheid wordt geassocieerd met een afname in het dagelijks functioneren. In elke meting wordt vermoeidheid beïnvloed door het type operatie: vrouwen die een mastectomie hebben ondergaan zijn meer vermoeid dan vrouwen die een lumpectomie hebben ondergaan. Behandeld zijn met radiotherapie leidt ook tot een toename van vermoeidheid.

Hoofdstuk 4 gaat over het verloop van vermoeidheid dat refereert aan zowel cognitieve symptomen (subschaal 'mentale vermoeidheid') als de motivatie om een activiteit te beginnen (subschaal 'reductie in motivatie') als functie van chemotherapie. Het verloop van mentale vermoeidheid en motivatie wordt niet beïnvloed door het type chemokuur. Het verloop van mentale vermoeidheid en motivatie varieert, maar lijkt stabiel te zijn tijdens de chemotherapiebehandeling. $\mathrm{Na}$ afloop van de chemotherapiebehandeling is een lichte verbetering te zien. De 'Center for Epidemiological Studies Depression Scale' (CES-D) wordt gebruikt om depressieve symptomen te meten. Veel patiënten ervaren depressieve symptomen tijdens de studie. Deze symptomen zijn gecorreleerd met beide dimensies van vermoeidheid. Gezondheidswerkers moeten zich bewust zijn van het hoge aantal patiënten dat depressieve symptomen tijdens en na afloop van de chemotherapiebehandeling ervaart. In elke meting wordt mentale vermoeidheid beïnvloed 
door het type operatie: vrouwen die een mastectomie ondergaan zijn significant meer mentaal vermoeid dan vrouwen die een lumpectomie hebben ondergaan, maar niettemin zijn zij significant meer gemotiveerd om een activiteit te starten.

Vervolgonderzoek zou het traject vóór adjuvante chemotherapie-behandeling moeten omvatten en een langere periode na afloop. Bovendien is de invloed van leeftijd, burgerlijke staat, aantal kuren en het interval tussen de operatie en de eerste chemokuur op vermoeidheid onduidelijk en moet dit verder onderzocht worden.

Hoofdstuk 5 rapporteert het verloop van het activiteitsniveau, dat als een dimensie van vermoeidheid wordt gezien, als een functie van chemotherapie binnen de borstkankerpopulatie die chemotherapiebehandeling ondergaat. Daarnaast wordt het verloop van de belemmering van vermoeidheid op dagelijkse activiteiten in deze populatie vastgesteld. Het activiteitenniveau blijkt stabiel tijdens de chemotherapiebehandeling. Na afloop van de chemotherapiebehandeling wordt een verbetering geconstateerd. Het activiteitenniveau van de eerste en laatste meting verschilt niet significant. Het verloop van het activiteitenniveau wordt niet beïnvloed door het type chemokuur. Leeftijd, het hebben van kinderen en het stadium van borstkanker blijken belangrijke determinanten van het verloop van het activiteitenniveau. In elke meting worden vrouwen die een mastectomie hebben ondergaan significant meer gehinderd in hun activiteitenniveau dan vrouwen die een lumpectomie hebben ondergaan. Hoe langer men radiotherapie krijgt, hoe minder actief men is en hoe langer de tijd tussen de laatste radiotherapie sessie en de meting, hoe actiever patiënten zijn. Een fenomeen dat niet gemakkelijk te verklaren is dat het activiteitenniveau van vrouwen die in totaal meer chemokuren hebben gekregen significant minder afnam dan zij die minder chemokuren kregen.

De gereviseerde 'Piper Fatigue Scale' wordt gebruikt om gedragsveranderingen door de belemmeringen van vermoeidheid op dagelijkse activiteiten te onderzoeken. Tijdens de onderzoeksperiode is ongeveer 15 tot 35 procent van de steekproef aanzienlijk door vermoeidheid belemmerd in haar dagelijks leven activiteiten. Bovendien neemt de belemmering van vermoeidheid op dagelijks leven activiteiten eerst toe na de start van de chemotherapiebehandeling en neemt deze af na afloop van de chemotherapie-behandeling. Met deze kennis kunnen gezondheidszorgmedewerkers patiënten informeren over wat ze kunnen verwachten. Vervolgonderzoek zou het traject vóór de chemotherapiebehandeling en een gezonde controle groep moeten omvatten. 


\section{Samenvatting}

Hoofdstuk 6 beschrijft het verloop van vermoeidheid van borstkankerpatiënten tussen twee adjuvante chemotherapie cycli, van de dag van de toediening tot de dag van het volgende infuus. Een steekproef van 151 patiënten rapporteerde dagelijks hun ervaring van vermoeidheid tussen de derde en vierde adjuvante chemokuur in een dagboekje, de 'Shortened Fatigue Questionnaire'. Patiënten werden behandeld met een doxorubicine bevattende kuur of met CMF. Afhankelijk van de chemotherapiebehandeling vulden patiënten 21 of 28 dagen van het dagboekje in. De infusen van de kuren van 28 dagen werden op dag 1 en op dag 8 gegeven. De dagen na afloop van de derde chemokuur tot aan de start van de vierde kuur werden statistisch geanalyseerd. De hypothese dat de maximum vermoeidheidsscore in de eerste vier dagen na de chemokuur plaats vindt werd getest.

Er doet zich een chaotisch vermoeidheidspatroon tussen de twee chemokuren voor. Gladde (splines) curves laten een gemiddeld hoogste niveau van vermoeidheid zien op dag 3 vanaf de start. Voor de kuren met 28 dagen wordt een andere top rond dag 11 gevonden. Een relatief groot aantal patiënten ervaart de vermoeidheidspiek vóór dag 5. De meeste patiënten rapporteren dag 3 als de slechtste dag. Het verloop van vermoeidheid in de CMF groep is significant verschillend vergeleken met de doxorubicine kuren. De vermoeidheidspiek in de CMF groep is lager. Vrouwen die cyclofosfamide oraal nemen, ervaren de vermoeidheidspiek significant later. Invloeden van andere variabelen zijn niet geobserveerd in geen van de chemotherapiegroepen. Verbeterd begrip van de aard en verloop van vermoeidheid kan gezondheidsmedewerkers beter uitrusten om patiënten te informeren over wat ze zouden kunnen verwachten. Vervolgonderzoek zou interventies moeten bevatten met als doel vermoeidheid te verminderen of er mee om te kunnen gaan.

Hoofdstuk 7 schetst een model met variabelen die vermoeidheid bij borstkankerpatiënten beïnvloeden en dat gebaseerd is op een literatuurstudie en voorafgaand werk van de auteurs. In dit hoofdstuk wordt het model getest in een steekproef met 157 borstkankerpatiënten. Eén model (voor algemene vermoeidheid) voor alle vijf de metingen is ontwikkeld waarbij EQS werd gebruikt, een computerprogramma voor het schatten van lineaire structurele vergelijkingen met latente variabelen. In het model waarvan de parameters identificeerbaar en schatbaar zijn, worden twee latente variabelen verondersteld: (1) fysieke klachten (gemeten door twee geobserveerde indicatoren: algemene vermoeidheid en lichamelijke klachten), en (2) psychische klachten (gemeten door twee geobserveerde indicatoren: depressie en psychische klachten). Fysieke klachten worden voorspeld uit de variabelen: elke dag sociale steun, actief zijn als coping strategie, leeftijd, 
burgerlijke staat, werk, stadium van borstkanker, type chemokuur, haemoglobine niveau en het aantal chemokuren. Psychische klachten worden voorspeld uit leeftijd en dagelijkse sociale steun. Fysieke en psychische klachten zijn belangrijke voorspellers van algemene vermoeidheid. Het is niet meer onwaarschijnlijk dat algemene vermoeidheid deel uitmaakt van een network van symptomen. Het sociale aspect is ook van grote waarde. Dit wordt uitgedrukt door de invloed van verscheidene demografische variabelen of sociale aard op algemene vermoeidheid. De fysieke klachten vergeleken met psychische klachten zijn groter tijdens de eerste vier metingen. Dit zou kunnen worden verklaard door de wetenschap dat chemotherapie cellen in het lichaam aanvalt, ook gezonde cellen. Tijd om te reflecteren en om te gaan met de hele situatie krijgen patiënten na afloop van de chemotherapiebehandeling. Dit zou het grotere effect van psychische in de laatste meting kunnen verklaren. Door een verbeterd begrip van de relatie tussen verschillende variabelen en vermoeidheid van borstkankerpatiënten die adjuvante chemotherapie ondergaan, alsook na afloop van de chemotherapiebehandeling, kunnen gezondheidszorgmedewerkers zich beter uitrusten deze patiënten te begrijpen en zich te richten naar hun behoeftes. Vervolgonderzoek zou interventies moeten omvatten die op het model van deze studie zijn gebaseerd en aangeven hoe patiënten hun kwaliteit van leven kunnen handhaven of verbeteren tijdens en na afloop van adjuvante chemotherapiebehandeling.

In hoofdstuk 8 worden de belangrijkste resultaten van de verschillende studies besproken en worden methodologische kanttekeningen gemaakt. De belangrijkste resultaten richten zich op de prevalentie van vermoeidheid, verloop van vermoeidheid en de invloed van variabelen op vermoeidheid tijdens en na afloop van adjuvante chemotherapiebehandeling. Methodologische kanttekeningen betreffen de afwezigheid van een gezonde controle groep, de tijdspanne van de studie, de meetpunten en de verschillende chemokuren in de doxorubicine groep. Het hoofdstuk eindigt met een discussie over aanbevelingen voor de praktijk. Verder worden onderwerpen voor vervolgonderzoek gegeven. 

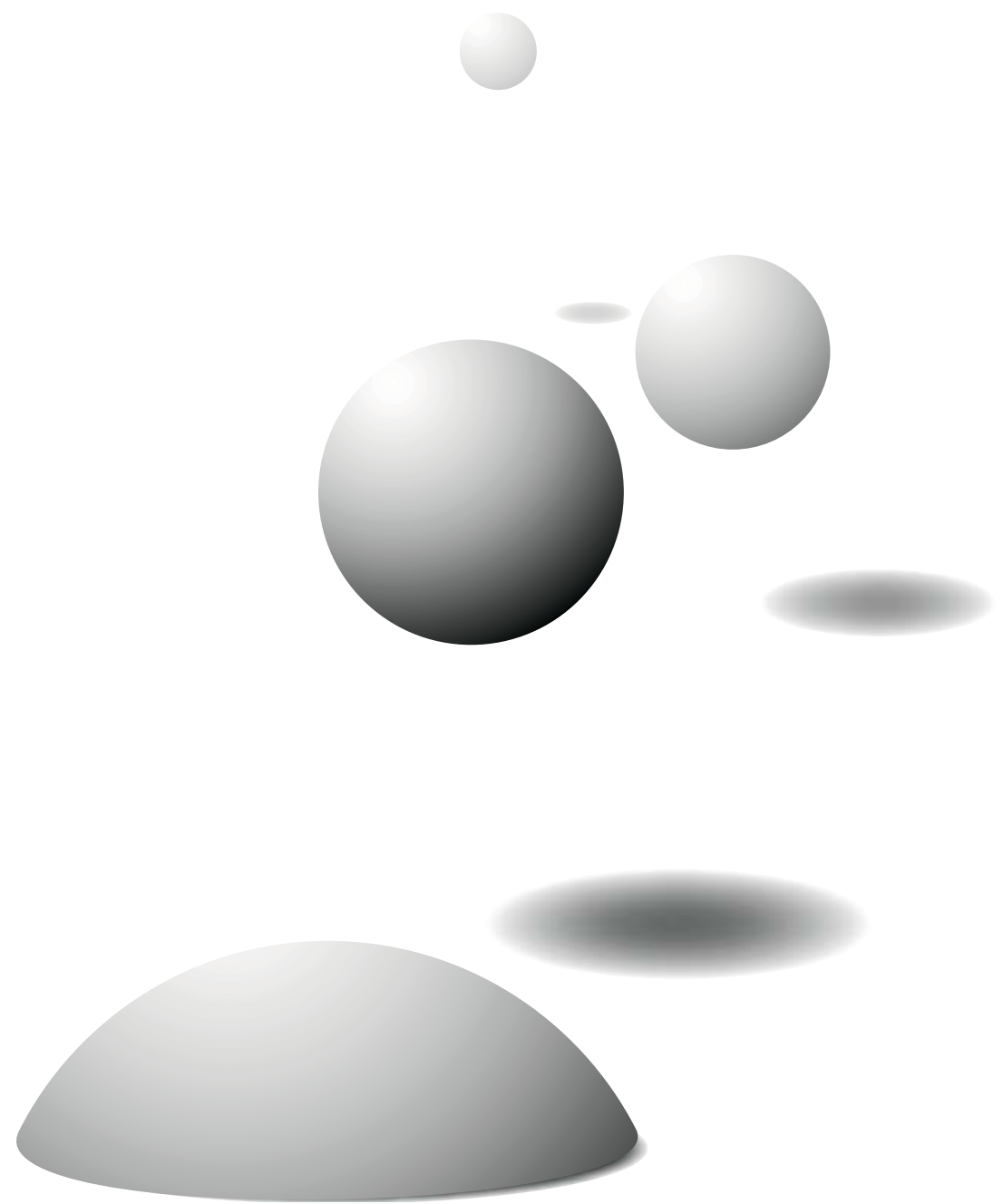


$$
\underline{v}
$$


Dankwoord 
Allereerst wil ik de patiënten hartelijk danken voor hun deelname aan het onderzoek, de oncologen en het personeel van de dagbehandeling van de volgende ziekenhuizen voor hun medewerking: academisch ziekenhuis Maastricht (azM), Maaslandziekenhuis (Sittard), Atrium Medisch Centrum (Heerlen en Brunssum), St. Jans Gasthuis (Weert) en Jeroen Bosch Ziekenhuis ('s-Hertogenbosch).

Het KWF Kankerbestrijding subsidieerde de start van het onderzoek, waarvoor ik zeer erkentelijk ben. De (financiële) ondersteuning van het onderzoek door het cluster Zorgwetenschappen (Universiteit Maastricht, Faculteit der Gezondheidswetenschappen) en in het bijzonder sectie Verplegingswetenschap heb ik erg op prijs gesteld.

Een speciaal woord van dank voor de begeleiding van mijn promotie gaat uit naar mijn copromotor dr. A.M. Courtens (Universiteit Maastricht) en promotor prof. dr. H.C. Schouten (academisch ziekenhuis Maastricht). Het advies (op afstand) van promotor prof. dr. H. Huijer Abu-Saad (American University of Beirut, Lebanon) heb ik zeer gewaardeerd.

Statistische analyses waren in dit proefschrift belangrijk. De statistici $d r$. M.J.J.M. Candel, dr. A.D.M. Kester (beiden Universiteit Maastricht) en dr. F.G.J. Meijerink (Universiteit Leiden) waren een grote steun voor het tot stand komen van het proefschrift. 

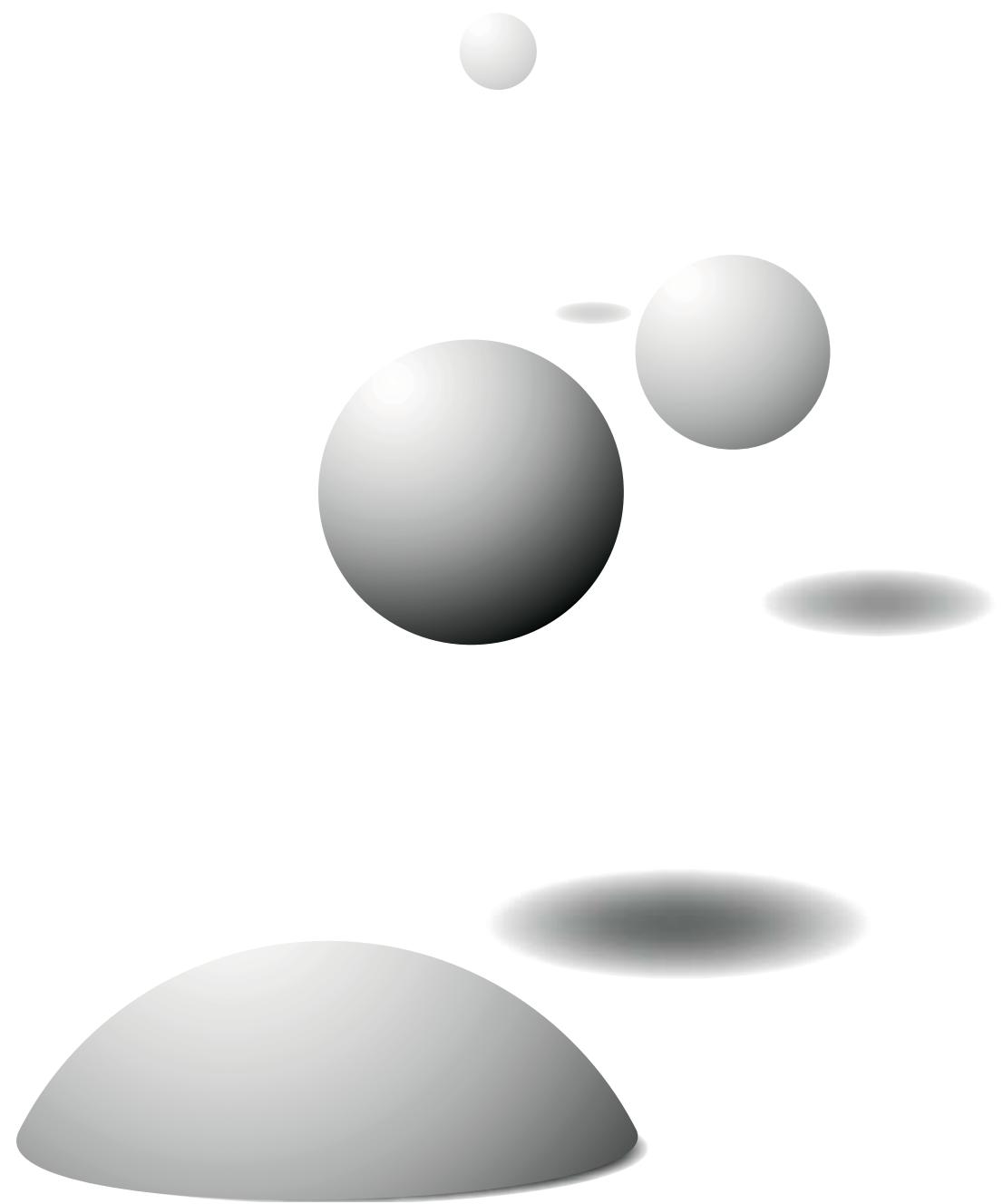


$$
\underline{\underline{w}}
$$


Nynke de Jong was born in November, 1971 Amsterdam, the Netherlands. After completing grammar school (Gymnasium B), she began her studies in nursing at the Hogeschool van Amsterdam. In 1995 she received her bachelor's degree. Subsequently, she studied Health Sciences at Maastricht University, where she graduated with a master's degree in 1998. Upon her graduation she started as a research assistant at the department of Health Care Studies (Nursing Science section) on the project 'Fatigue in breast cancer patients receiving adjuvant chemotherapy' and in 1999 she became the principal investigator of this project. Since 2000 she has worked as a researcher and university teacher while working on her dissertation. In 2005 her article 'Prevalence and course of fatigue in breast cancer patients receiving adjuvant chemotherapy' (Annals of Oncology 15: 896-905, 2004) was nominated for the Anna Reynvaan Science Prize for the best published article in nursing science in the Netherlands and Belgium. The article 'Course of mental fatigue and motivation in breast cancer patients receiving adjuvant chemotherapy' (Annals of Oncology 16: 372-382, 2005) was awarded the CAPHRI (Care And Public Health Research Institute) 2007 Philipsen Award for best publication 2005/2006.

Since the start of the project (1998) she has continued to work as a parttime community nurse. 

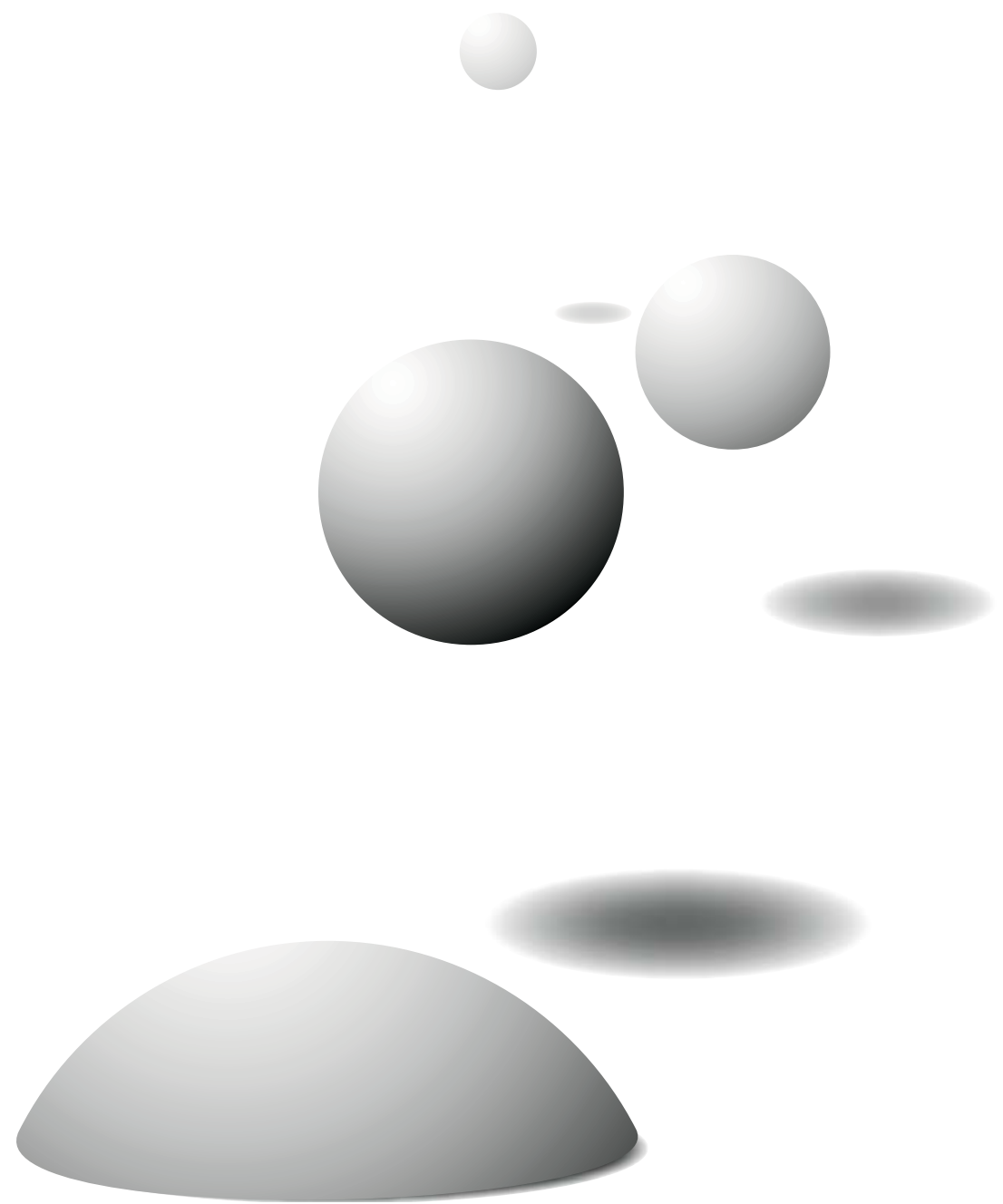


\section{List of publications regarding the fatigue studies (only articles)}

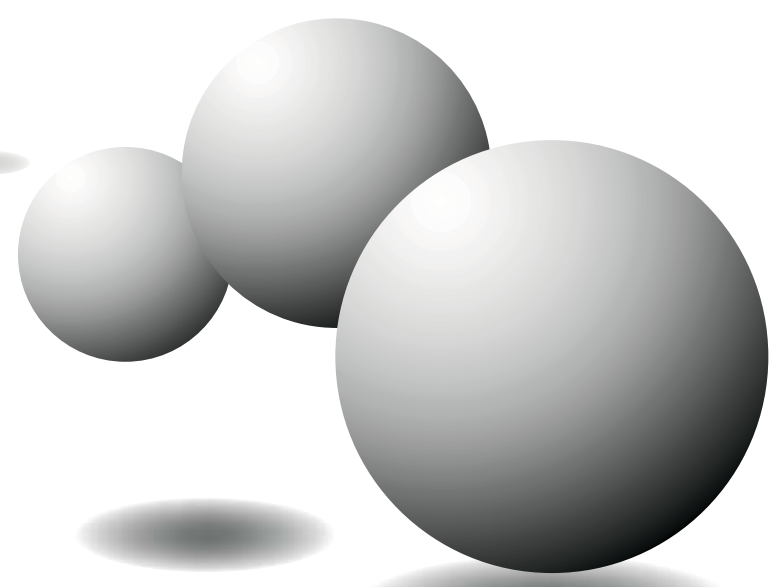


List of publications 
De Jong, N., et al., Chemotherapie maakt borstkankerpatiënten moe. Tijdschrift voor verpleegkundigen, 2001. 4: p. 123-125.

De Jong, N., et al., Fatigue in patients with breast cancer receiving adjuvant chemotherapy: a review of the literature. Cancer Nursing, 2002. 25(4): p. 283-97.

De Jong, N., et al., Am schlimmsten ist der zweite Tage. Pflegezeitschrift, 2003. 1: p. 32-34.

De Jong, N., et al., Prevalence and course of fatigue in breast cancer patients receiving adjuvant chemotherapy. Annals of Oncology, 2004. 15: p. 896-905. (nominated for the Anna Reynvaan Science Prize for the best published article in nursing science in the Netherlands and Belgium)

De Jong, N., et al., Course of mental fatigue and motivation in breast cancer patients receiving adjuvant chemotherapy. Annals of Oncology, 2005. 16: p. 372-382.

(awarded the CAPHRI (Care And Public Health Research Institute) 2007 Philipsen Award for best publication 2005/2006)

De Jong, N., et al., Prevalentie en verloop van vermoeidheid bij borstkankerpatiënten. Oncologica, 2005. 21(4): p. 236-242.

De Jong, N., et al., Die Art der Chemotherapie spielt eine Rolle. Pflegezeitschrift, 2005. 2: p. 100-103.

De Jong, N., et al., Course of the fatigue dimension 'activity level' as well as the interference of fatigue with daily living activities for breast cancer patients receiving adjuvant chemotherapy. Cancer Nursing, 2006. 5: p. E1-E13.

De Jong, N., et al., Course of fatigue between two cycles of adjuvant chemotherapy in breast cancer patients. Cancer Nursing, 2006. 29(6): p. 467-477.

De Jong, N., et al., Uitkomsten van een onderzoek naar vermoeidheid bij borstkankerpatiënten die adjuvante chemotherapiebehandeling ondergaan: Vermoeidheid in eerste vier dagen na kuur het hoogst. Oncologica, 2007 (accepted). 
De Jong, N., et al., Der Verlauf von Fatigue unter adjuvanter Chemotherapie bei Patientinnen mit Brustkrebs. Pflegezeitschrift, 2007 (accepted).

De Jong, N., et al., Influencing factors of fatigue in women with breast cancer receiving adjuvant chemotherapy: the development of a model (submitted for publication). 


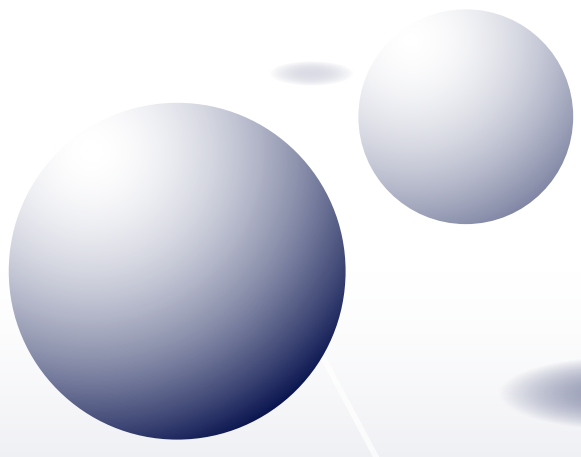

ISBN: 9789085900207 